\title{
Development of Drilling Control Technology to Reduce Drilling Noise during Roof Bolting Operations
}

\author{
Mingming Li
}

Follow this and additional works at: https://researchrepository.wvu.edu/etd

\section{Recommended Citation}

Li, Mingming, "Development of Drilling Control Technology to Reduce Drilling Noise during Roof Bolting Operations" (2015). Graduate Theses, Dissertations, and Problem Reports. 6073.

https://researchrepository.wvu.edu/etd/6073

This Dissertation is protected by copyright and/or related rights. It has been brought to you by the The Research Repository @ WVU with permission from the rights-holder(s). You are free to use this Dissertation in any way that is permitted by the copyright and related rights legislation that applies to your use. For other uses you must obtain permission from the rights-holder(s) directly, unless additional rights are indicated by a Creative Commons license in the record and/ or on the work itself. This Dissertation has been accepted for inclusion in WVU Graduate Theses, Dissertations, and Problem Reports collection by an authorized administrator of The Research Repository @ WVU.

For more information, please contact researchrepository@mail.wvu.edu. 


\title{
Development of Drilling Control Technology to Reduce Drilling Noise during Roof Bolting Operations
}

\section{Mingming Li}

\author{
Dissertation submitted \\ to the Benjamin M. Statler College of Engineering and Mineral Resources \\ at West Virginia University \\ in partial fulfillment of the requirements for the degree of \\ Doctor of Philosophy in \\ Mining Engineering
}

Yi Luo, Ph.D., Chair

Keith A. Heasley, Ph.D.

Rudy J. Matetic, Ph.D.

Victor H. Mucino, Ph.D.

Syd S. Peng, Ph.D.

Department of Mining Engineering

Morgantown, West Virginia

2015

Keywords: Roof bolting, Drilling noise, Noise dosage,

Drilling control technology, Specific energy

Copyright 2015 Mingming Li 


\section{ABSTRACT \\ Development of Drilling Control Technology to Reduce Drilling Noise during Roof Bolting Operations}

\section{Mingming Li}

Noise induced hearing loss is a serious health issue among coal mine workers. The roof bolting operation is one of the noisiest underground mining operations. It is second among all equipment in underground coal mines whose operators exceed $100 \%$ noise dosage according to MSHA data. In roof bolting, the noise generated in the roof drilling normally contributes a major proportion to the noise exposure to this particular group of miners. This study is to develop a drilling control technology to reduce noise generated during roof bolting drilling.

Previous research shows that the specific energy consumed in drilling bolt holes is inversely proportional to the bite depth (i.e., penetration per drill revolution). Less specific energy at a reasonably high bite depth means less energy is wasted in the drilling process for producing heat, bit wear, and noise. Properly controlled drilling will not only maintain good drilling productivity, but also significantly reduce the sound power level, noise dosage, and the required drilling energy. Rational drilling control is implemented through properly chosen penetration and rotational rates according to the specific rock strength, drill bit, and steel.

Several efforts are investigated in this research. The first one is to explore the feasibility of the drilling control technology for reducing drilling noise. Drilling experiments have been conducted in the laboratory. Different drilling parameters (penetration rate and rotational rate) and different drill bits and steels were utilized through drilling medium hard rock. The results show that significant reduction in noise dose can be achieved at a reasonably high bite depth when drilling medium hard rock. This research indicates that through proper control of the drilling parameters with regarded to rock type, the noise exposure to the roof bolter operators can be significantly reduced. At the same time, drilling productivity is not affected or even improved. Then an algorithm has been developed for finding the rational drilling control parameters that can minimize the noise dose of the bolter operators in roof bolting drilling. Also, a mathematical model for simulating roof bolt drilling has been improved to include the noise generation. This model can be used to estimate the rock strength as well as required drilling thrust and torque, specific energy, energy efficiency, and noise dose for a given rock strength. The safety check of drilling operation is also included in this model. As an additional effect of this drill control technology, the dust size distributions of drilling at different parameters were analyzed. This noise control algorithm can be incorporated into the existing drill control unit for potential drilling automation. 


\section{ACKNOWLEDGEMENT}

I would like to thank those who have contributed to the preparation and completion of this dissertation. First I would like to thank Dr. Yi. Luo for all of his support and guidance. Without his abundant help and invaluable assistance, this dissertation would not have been possible.

Special appreciation is given to the members of my advisory and examination committee: Dr. Keith A. Heasley, Dr. Rudy J. Matetic, Dr. Victor H. Mucino, and Dr. Syd S. Peng for their time and their expertise contributed to the enhancement of this research. Memory is given to Dr. Christopher J. Bise who was one of the committee members.

Special thanks are given to J. H. Fletcher \& Co. for their assistance of laboratory tests during this research. Special thanks are also given to mining engineering faculty Aaron Noble and Felicia Peng and graduate students, Biao Qiu, Ming Fan, Hua Jiang, Wan Wang, Yuting Xue and Seyed Hassan Amini for their help in laboratory tests. The author also expresses sincere appreciation to staff of the Mining Engineering Department for their selfless help.

Finally, sincere gratitude goes to my family members, my father, Yupin Li, mother, Wenqiong Luo, and my elder sister, Lili Li. Special thanks are given to my beloved boyfriend, Chaogang Hu. Without their endless love, constant support, patience, and understanding, I would never have reached this point. 


\section{TABLE OF CONTENTS}

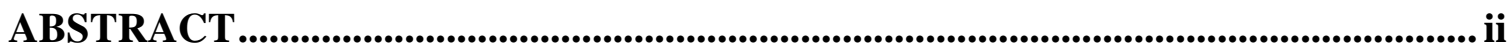

ACKNOWLEDGEMENT ....................................................................................ii

LIST OF TABLES .................................................................................................. vii

LIST OF FIGURES ......................................................................................................... vii

LIST OF ABBREVIATIONS AND SYMBOLS .................................................... xiii

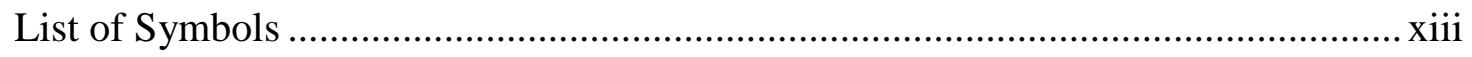

List of Abbreviations........................................................................................ $\mathrm{xvi}$

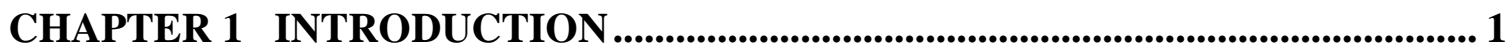

1.1 Background .............................................................................................. 1

1.2 Research objectives and scope ……………………………………………... 5

CHAPTER 2 LITERATURE REVIEW ............................................................. 7

2.1 Introduction of sound and noise ...................................................................... 7

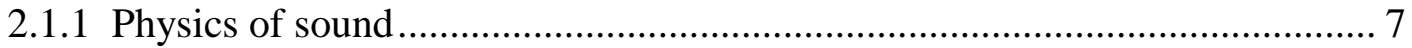

2.1.2 Noise induced hearing loss..................................................................... 10

2.1.3 Current noise standards ...................................................................... 10

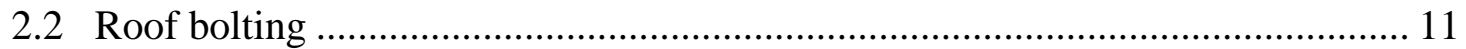

2.3 Study of a roof bolting machine noise ……………....................................... 12

2.4 Engineering noise control method on roof bolting machine ............................... 14

2.5 Rock drilling energy ........................................................................................ 19

2.6 Drilling parameters utilized to estimate rock strength ........................................ 21

2.7 Sound level used to determine rock properties ................................................... 22

2.8 Other related issues in roof bolting ................................................................ 23

2.8.1 Dust in roof bolting .............................................................................. 23

2.8.2 Bit wear in roof bolting ........................................................................... 24

CHAPTER 3 SCIENTIFIC BASES ............................................................................. 26

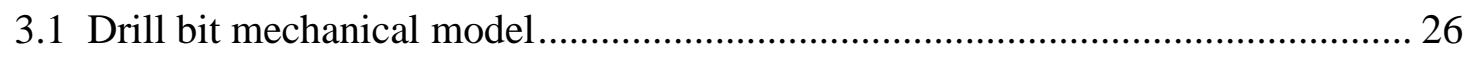

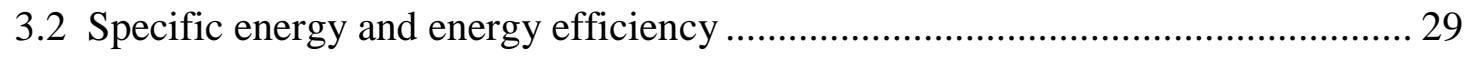

3.3 Proposed approach in this research ........................................................... 31 


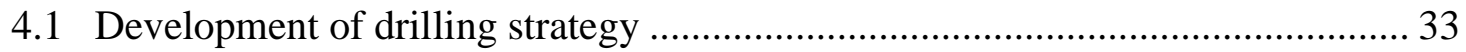

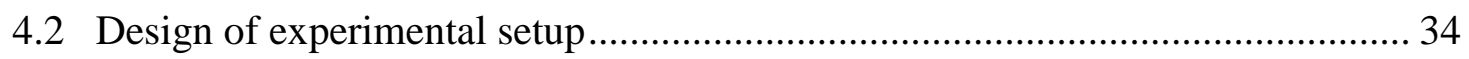

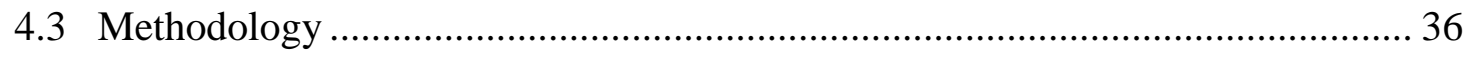

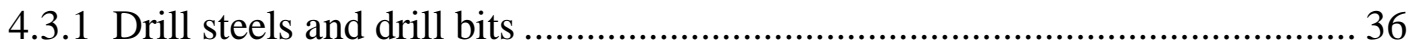

4.3.2 Drilling control parameters .................................................................... 38

4.3.3 Noise measurement ................................................................................. 41

4.3.4 Temperature measurement ……………………….................................. 43

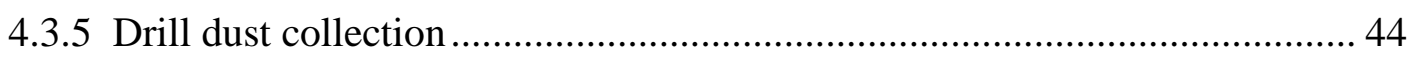

CHAPTER 5 EXPERIMENT RESULTS AND ANALYSIS..................................... 45

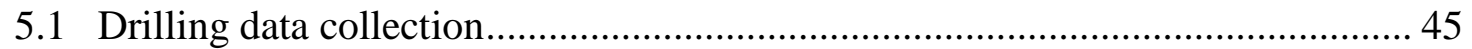

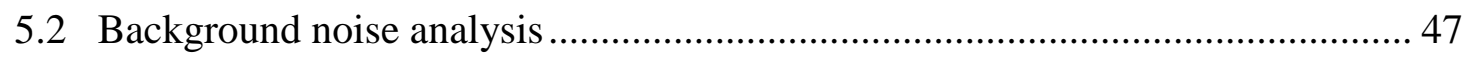

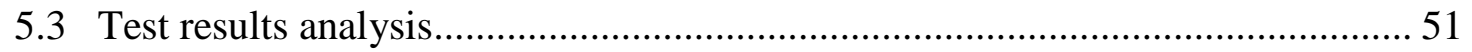

5.3.1 Feasibility to achieve preset controls ......................................................... 51

5.3.2 Average specific energy …………............................................................. 53

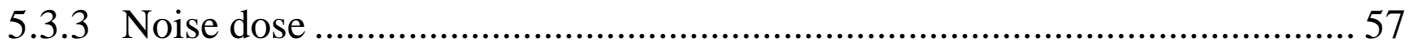

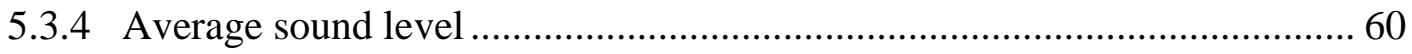

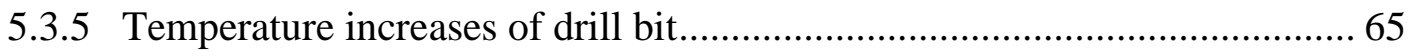

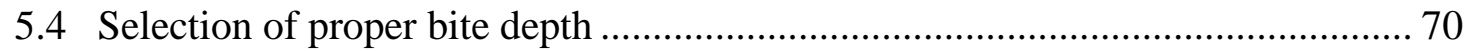

5.5 Proposed drilling control strategy ……………............................................... 75

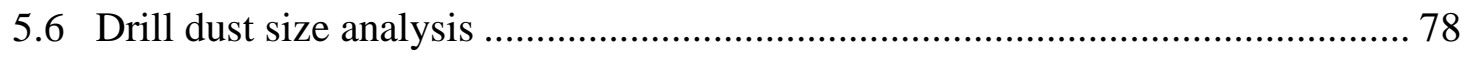

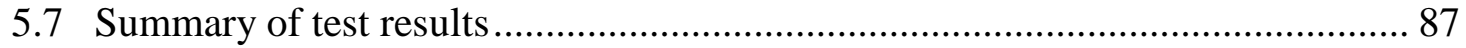

\section{CHAPTER 6 DEVELOPMENT OF DRILLING CONTROL TECHNOLOGY .. 88}

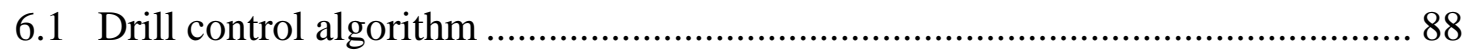

6.2 Minimum specific energy of drilling …………….......................................... 90

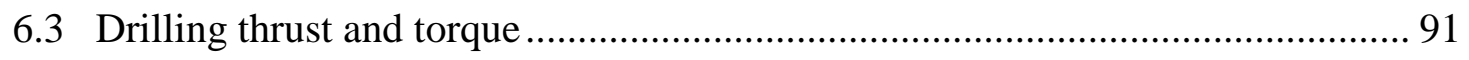

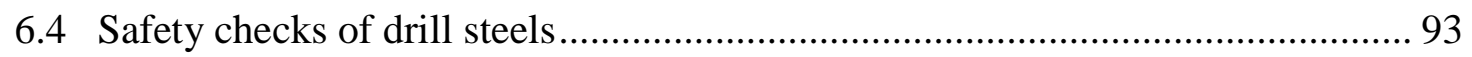

6.4.1 Maximum drilling thrust ……….............................................................. 94

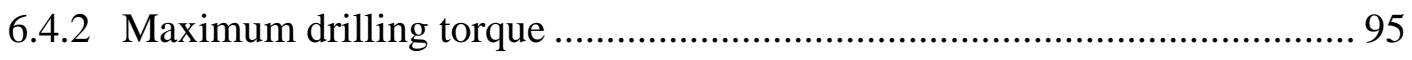

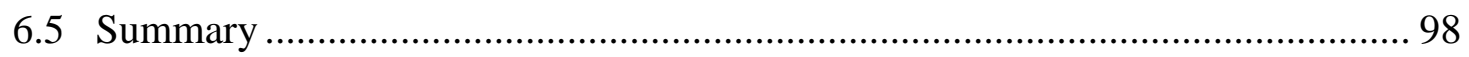

CHAPTER 7 CONCLUSIONS AND RECOMMENDATIONS ................................ 99 


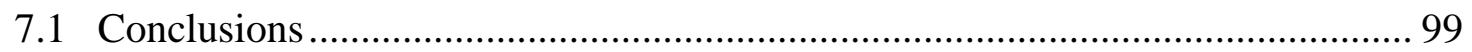

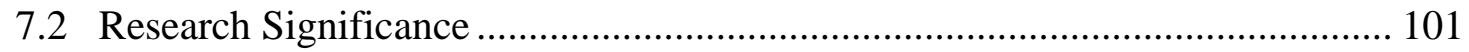

7.3 Recommendations for future research ...................................................... 101

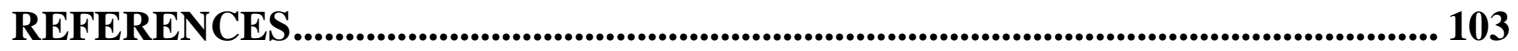

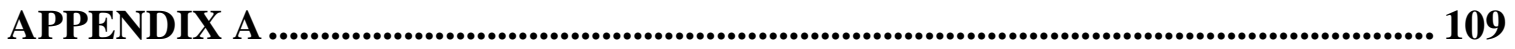

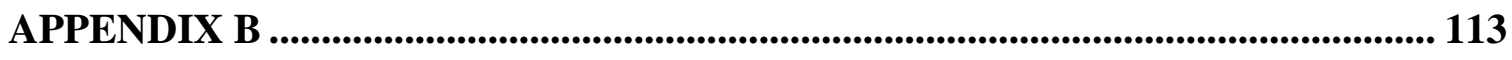

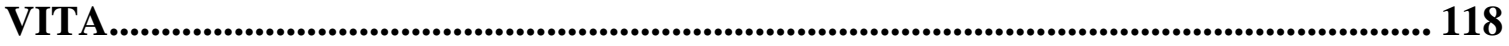

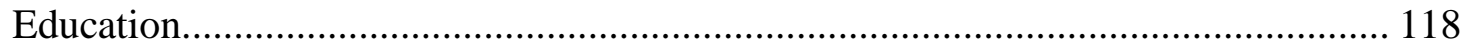

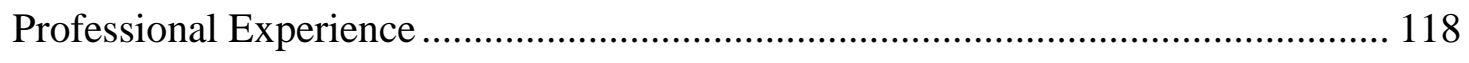

Author's Publication List during Ph.D. Study: ................................................ 118

Author's Technical Report List during Ph.D. Study:........................................ 119 


\section{LIST OF TABLES}

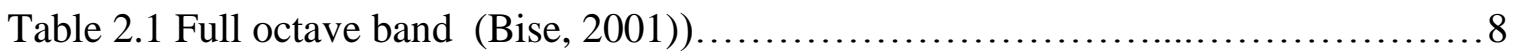

Table 2.2 Comparison of drilling noise control methods (Lowe et al., 2010)........17

Table 4.1 Preset drilling parameters.........................................40

Table 5.1 Raw data collected from the roof bolter control system......................45

Table 5.2 Measured and calculated drilling parameters based on raw data...............46

Table 5.3 A typical sample of noise dose .......................................... 50

Table 5.4 Dust sample collection in the fourth set of drilling tests..................... 79

Table 5.5 Average particle size for drilling tests at different bite depth..................82 


\section{LIST OF FIGURES}

Figure 1.1 Percent with hearing impairment among coal, metal/nonmetal miners and

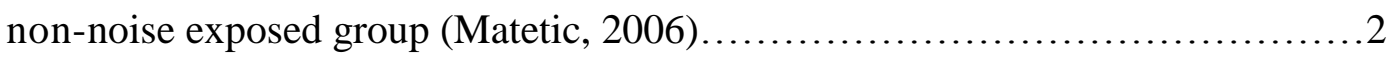

Figure 1.2 Percentage of equipment whose operators exceeded $100 \%$ dose $\ldots . . . . .3$

Figure 1.3 Percentage of operators who exceeded $100 \%$ noise dose....................

Figure 2.1 Roof bolting noise control methods (Bit isolator ( Coal News, 2013) and

Chuck isolator (Peterson et al., 2009)) .............................. 16

Figure 2.2 Roof bolting noise control methods (CDSE) (Matetic et al., 2008) and

redesigned CDSE (Azman et al., 2014)............................... 17

Figure 2.3 Standard and damped hexagonal drill steel and $4.1 \mathrm{~cm}[1.625-\mathrm{in}] \mathrm{bit}$

(Peterson \& Camargo, 2010)....................................... 18

Figure 3.1 Schematic of drilling roof bolt hole (Luo et al., 2014)............... 27

Figure 3.2 Bit-rock interaction model in rotary drilling (Luo et al., 2002)..........28

Figure 3.3 Specific energy versus bite depth from drilling data on a concrete

block.................................................................. 31

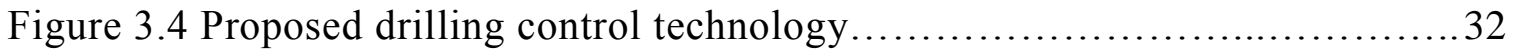

Figure 4.1Experimental setup of the drilling noise study....................... 35

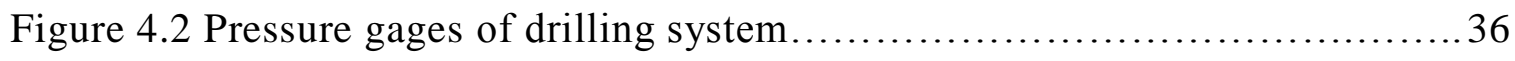

Figure 4.3 Drill steel and drill bit used in the test........................... 37

Figure 4.4 Drill bits used in the test (left: $1-3 / 8$-in, right: $7 / 8$-in) $\ldots \ldots \ldots \ldots \ldots \ldots \ldots . \ldots . \ldots$. 
Figure 4.5 Drilling parameter display panel.

Figure 4.6 Sound Level Meter, Noise Dosimeter, and PC Sound Recording System used in noise measurements (left to right)....

Figure 4.7 Reading from Sound Level Meter.

Figure 4.8 Thermal imaging camera used in noise measurement

Figure 5.1 Typical measured sound pressure level.......................... 48

Figure 5.2 Preset versus achieved bite depth in the 1 st and 2 nd sets of drilling tests

Figure 5.3 Preset versus achieved bite depth in the 3rd and 4th sets of drilling tests

Figure 5.4 Average specific energy from the first set of drilling tests

Figure 5.5 Average specific energy from the second set of drilling tests 55

Figure 5.6 Average specific energy from the third set of drilling tests .56

Figure 5.7 Average specific energy from the fourth set of drilling tests 56

Figure 5.8 Noise dose from the first set of drilling tests 58

Figure 5.9 Noise dose from the second set of drilling tests. .58

Figure 5.10 Noise dose from the third set of drilling tests 59

Figure 5.11 Noise dose from the fourth set of drilling tests 59

Figure 5.12 Average sound level from the first set of drilling tests .60

Figure 5.13 Average sound level from the second set of drilling tests 61 
Figure 5.14 Average sound level from the third set of drilling tests

Figure 5.15 Average sound level from the fourth set of drilling tests 62

Figure 5.16 Octave band sound level of drilling tests at varying rotational rate.... 63

Figure 5.17 Octave band sound level of drilling tests at varying penetration rate... 64

Figure 5.18 Octave band sound level of drilling tests using varying drill steels.... 65

Figure 5.19 Temperature increases of drill bit from the first set of drilling tests... 66

Figure 5.20 Temperature increases of drill bit from the second set of drilling tests 66

Figure 5.21 Temperature increases of drill bit from the third set of drilling tests

Figure 5.22 Temperature increases of drill bit from the fourth set of drilling tests 67

Figure 5.23 Temperature increase rate of drill bit from the 1st set of drilling tests. .68

Figure 5.24 Temperature increase rate of drill bit from the 2 nd set of drilling tests. .68

Figure 5.25 Temperature increase rate of drill bit from the 3rd set of drilling tests .69

Figure 5.26 Temperature increase rate of drill bit from the 4th set of drilling tests 
Figure 5.27 Average specific energy vs. bite depth for drilling tests using different bit-steel combinations in the first test................................. 71

Figure 5.28 Noise dose vs. bite depth for drilling tests using different bit-steel combinations in the first test.....

Figure 5.29 Specific energy vs. noise dose for the first sets of drilling tests .74

Figure 5.30 Distributions of average specific energy (A), noise dose (B), bit temperature increase (C), and equivalent sound level (D) for the drill operating range of $7 / 8$-in round drill steel................................ 75

Figure 5.31 Distributions of average specific energy (A), noise dose (B), bit temperature increase (C), and equivalent sound level (D) for the drill operating range of $7 / 8$-in hexagon drill steel............................. 77

Figure 5.32 Distributions of average specific energy (A), noise dose (B), bit temperature increase (C), and equivalent sound level (D) for the drill operating range of 1-1/8-in hexagon drill steel..........................78

Figure 5.33 Rock dust sample separated at varying particle sizes................ 80

Figure 5.34 Particle size distribution of dust in drilling tests using 7/8-in round drill steel..................................................................... 82

Figure 5.35 Particle size distribution of dust in drilling tests using 7/8-in hexagon drill steel. 83

Figure 5.36 Particle size distribution of dust in drilling tests using 1-1/8-in hexagon drill steel 83 
Figure 5.37 Cumulative volume percent of dust smaller than $74 \mu \mathrm{m}$ for $7 / 8$ hex drill steel

Figure 5.38 Size distribution of dust smaller than $25 \mu \mathrm{m}$ for $7 / 8$ hex drill steel......... 86

Figure 5.39 Size distribution of dust smaller than $5 \mu \mathrm{m}$ for $7 / 8$ hex drill steel.......... 86

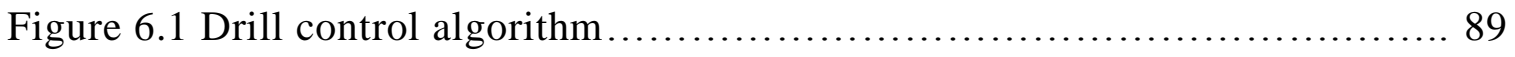

Figure 6.2 Required specific energy for various unconfined compressive strength (Luo et al., 2002)..........................................................91

Figure 6.3 Correlations between thrust and bite depth in the drilling tests..............92

Figure 6.4 Correlations between torque and scaled drilling parameters in the drilling tests............................................................ 93

Figure 6.5 Maximum allowable thrusts of the three types of drill steel in the beginning and middle drilling stages................................ 97

Figure 6.6 Maximum allowable torque of the three types of drill steels............97 


\section{LIST OF ABBREVIATIONS AND SYMBOLS}

\section{List of Symbols}

$A=$ area of the hole or excavation

b = bite depth

$B, C=$ constant factors

D = noise dose for drilling a bolt hole, $\%$

$D_{I} \quad=$ inner diameter of drill steel

$D_{O} \quad=$ outer diameter of drill steel

$e \quad=$ specific energy

$e_{F} \quad=$ energy consumed by thrust

$e_{T} \quad=$ energy consumed by torque

$E \quad=$ Young's modulus of the drill steel material

$F \quad=$ thrust

$F_{\max }=$ maximum or critical thrust

$H_{1} \quad=$ height of bit wear

$h_{2} \quad=$ height of bit inside the rock

$I=$ area moment of inertia

$I_{R d} \quad=$ area moment of inertia of round drill steel

$I_{\text {Hex }}=$ area moment of inertia of hexagon drill steel 


\begin{tabular}{|c|c|}
\hline$J$ & $=$ polar second moment of area \\
\hline $\mathbf{J}_{\mathrm{Rd}}$ & $=$ polar second moment of area of round drill steel \\
\hline $\mathrm{J}_{\mathrm{Hex}}$ & $=$ polar second moment of area of hexagon drill steel \\
\hline$k$ & $=$ constant factors \\
\hline$K$ & $=$ column effective length factor \\
\hline$L$ & $=$ unsupported length of the drill steel \\
\hline$L_{p}$ & $=$ sound pressure level, $\mathrm{dB}(\mathrm{A})$ \\
\hline$L_{p 1}$ & $=$ sound pressure level at location $1, \mathrm{~dB}(\mathrm{~A})$ \\
\hline$L_{p 2}$ & $=$ sound pressure level at location $2, \mathrm{~dB}(\mathrm{~A})$ \\
\hline$L(t)$ & $=$ sound pressure level at time $\mathrm{t}, \mathrm{dB}(\mathrm{A})$ \\
\hline$L_{w}$ & $=$ sound power level \\
\hline$L_{w}{ }^{\prime}$ & $=$ the corrected sound power level, $\mathrm{dB}(\mathrm{A})$ \\
\hline$P$ & $=$ measured root-mean-square $(\mathrm{rms})$ sound pressure \\
\hline$P_{0}$ & $=$ reference sound pressure, $20 \mu \mathrm{Pa}$ \\
\hline$W$ & $=$ measured sound power at a given time \\
\hline$W^{\prime}$ & $=$ corrected sound power at a given time \\
\hline$W_{B G}$ & $=$ average sound power of a noisy background \\
\hline$W_{B 0}$ & $=$ average background sound power during the lunch hour \\
\hline$W_{0}$ & $=$ reference sound power, the internationally accepted value is $10^{-12}$ watt. \\
\hline
\end{tabular}




$$
\begin{array}{ll}
r_{1} & =\text { distance from the source at location } 1 \\
r_{2} & =\text { distance from the source at location } 2 \\
S_{u t} & =\text { ultimate tensile strength } \\
t & =\text { time, second } \\
t_{t o l} & =\text { total duration time, second } \\
T_{1} & =\text { torque } \\
T_{1} & =\text { torque to overcome the shear strength } \\
T_{2} & =\text { torque to overcome the frictional resistance } \\
\tau_{\text {all }} & =\text { maximum allowable distortion stress } \\
T_{m a x} & =\text { maximum allowable torque } \\
v & =\text { penetration rate, in/sec } \\
w_{1} & =\text { width of bit wear } \\
w_{2} & =\text { normal contact width } \\
&
\end{array}
$$




\title{
List of Abbreviations
}

\author{
$\mathrm{HCP}=$ hearing conservation program \\ Hex = hexagon \\ IEC $=$ International Electrotechnical Commission \\ MSHA = Mine Safety and Health Administration \\ NIHL $=$ noise-induced hearing loss \\ NIOSH $=$ National Institute of Occupational Safety and Health \\ OSHA = Occupational Safety and Health Administration \\ PEL = permissible exposure limit \\ P.R = penetration rate \\ $\mathrm{Rd} \quad=$ round \\ RMS $=$ root mean square \\ R.R = rotational rate \\ S.E. = specific energy \\ SLM = sound level meter \\ SPL $=$ sound pressure level \\ T.D. = temperature differences before and after drilling \\ TWA = time weighted average
}




\section{CHAPTER 1 INTRODUCTION}

\subsection{Background}

Noise induced hearing loss is a severe health issue in the United States mining industry. Mine workers are exposed to high noise level through the use of heavy equipment in the confined work environment underground. According to a NIOSH analysis of 1999-2004 data from the National Health and Nutrition Examination Survey (NHANES), the mining industry has the highest prevalence of hazardous workplace noise exposure among all industrial sectors. About $75.8 \%$ of mining workers are reporting exposure to workplace noise (Tak et al., 2009). About $24.3 \%$ of mine workers are reported to have hearing loss, which is second only to the railroad industry (Tak \& Calvert, 2008). About $80 \%$ of the nation's miners are working in an environment where the time weighted average (TWA) noise level exceeds $85 \mathrm{dBA}$ and more than $25 \%$ of the miners are exposed to a TWA noise level that exceeds $90 \mathrm{dBA}$, the permissible exposure limit (PEL) (Matetic, 2006). A NIOSH study of a large sample of audiograms also indicated that about $65 \%$ of coal miners suffered hearing impairment at age 55, compared to only $10 \%$ of the non-occupationally exposed group of the same age (Figure 1.1). Noise-induced hearing loss (NIHL) has been identified by NIOSH as one of the ten leading work-related diseases and injuries (Matetic, 2006). 


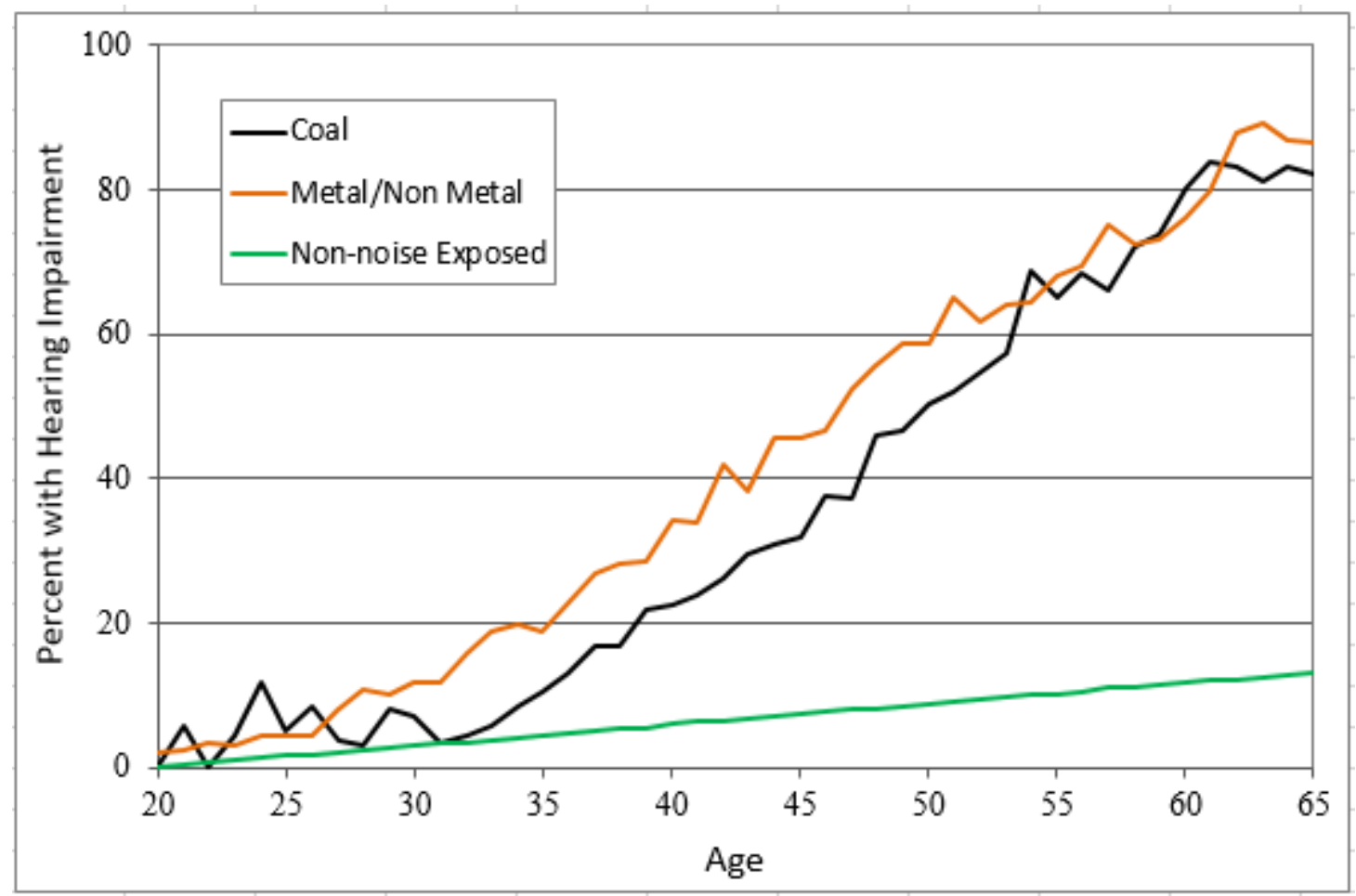

Figure 1.1 Percent with hearing impairment among coal, metal/nonmetal miners and nonnoise exposed group (Matetic, 2006)

The roof bolting operation is one of the noisiest underground mining operations. Analysis of MSHA noise sample data from 2010 to 2014 shows that there are seven equipment that compose $81 \%$ of all the equipment whose operators exceed the MSHA Permissible Exposure Level (PEL) dose of 100\%: auger miner, bulldozers, continuous miners, front end loaders, roof bolters, shuttle cars, and trucks (MSHA, 2015). Among these seven types of equipment, the roof bolter is the second highest only to the continuous miner (Figure 1.2). Analysis also shows that $17 \%$ of miners are exposed to an excessive noise dose of $85 \mathrm{dBA}$, the action level, and $10 \%$ of miners are exposed to an excessive noise dose of $90 \mathrm{dBA}$, the permissible exposure limit (PEL). 18\% of roof bolter 
operators are exposed to an excessive noise dose of the $90 \mathrm{dBA}$, the permissible exposure limit (PEL), which is the second highest among all types of mine operators (Figure 1.3).

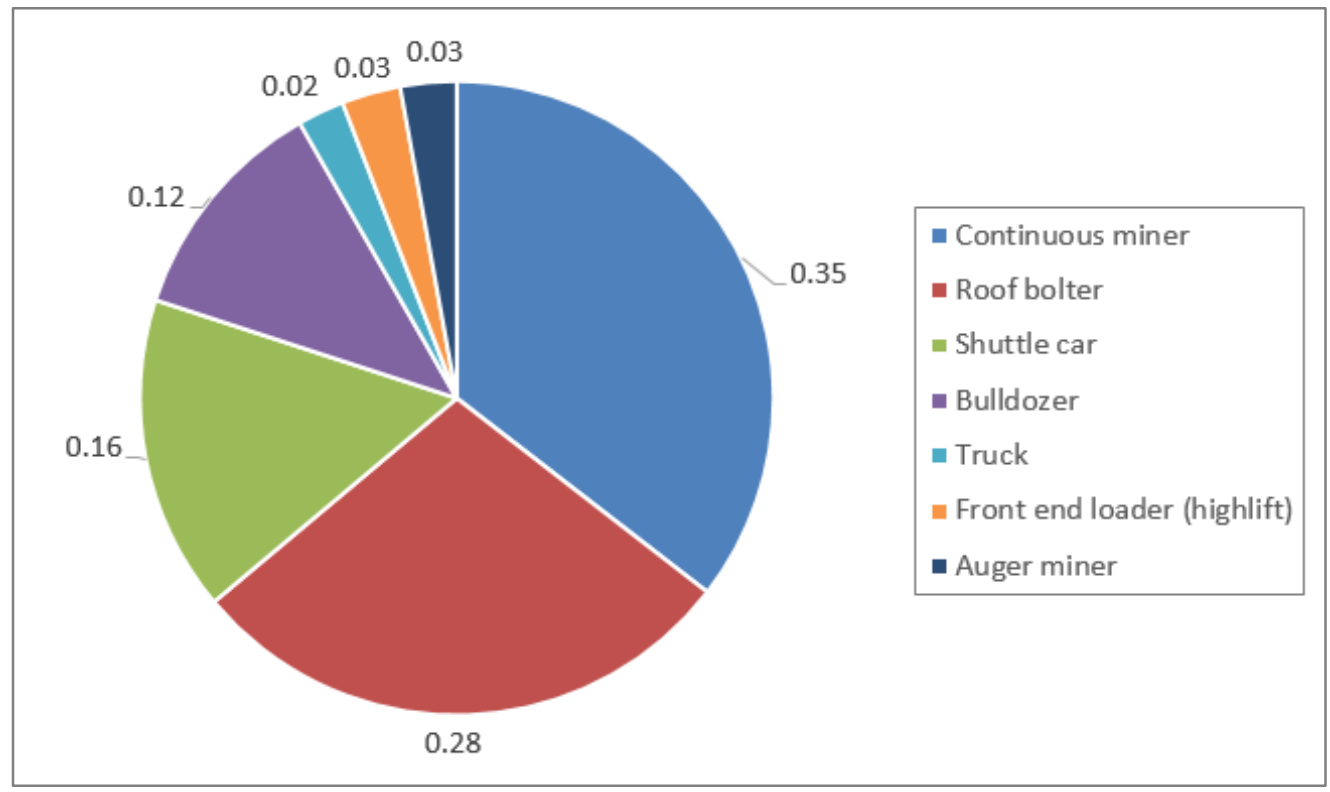

Figure 1.2 Percentage of equipment whose operators exceeded $100 \%$ dose

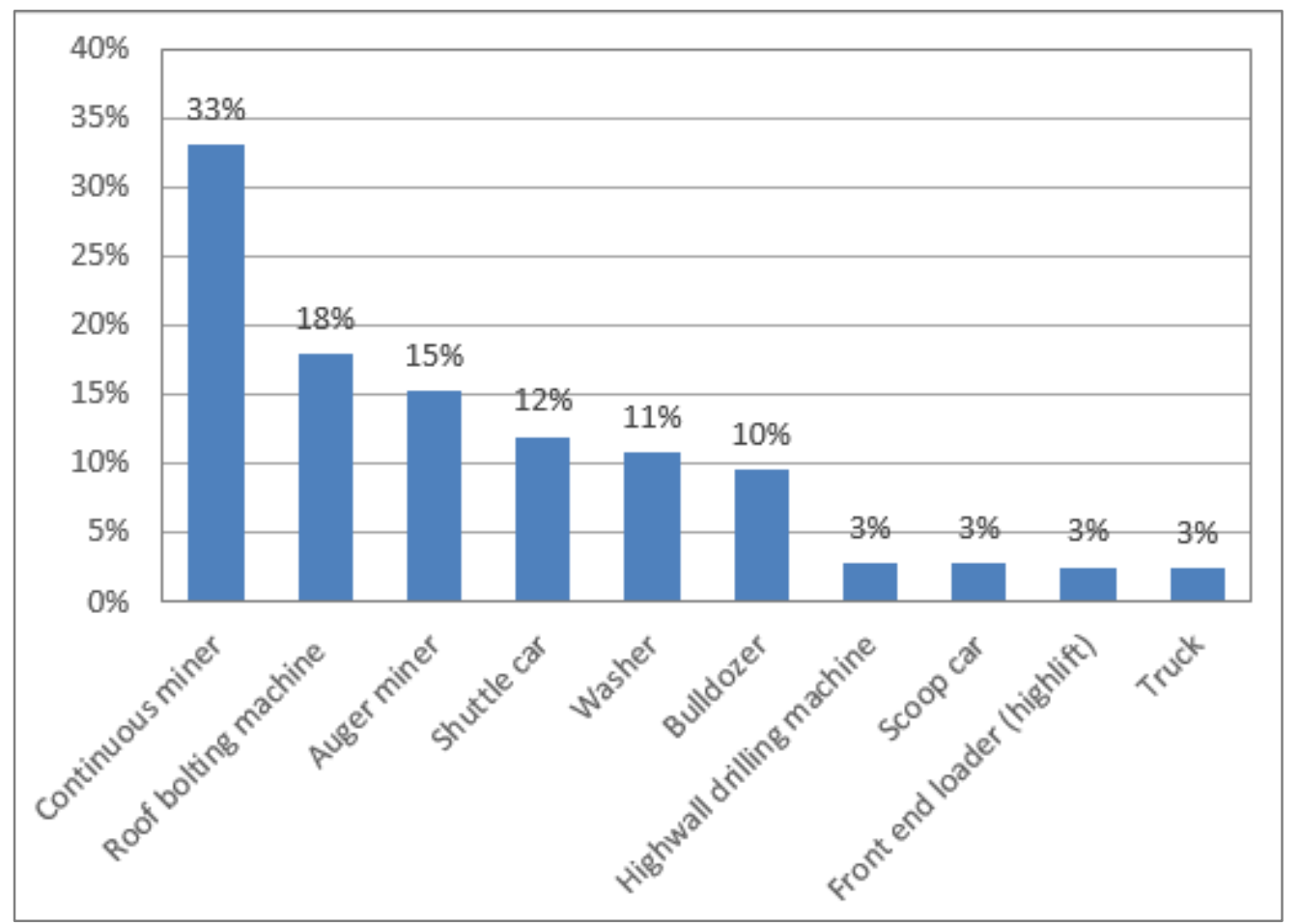

Figure 1.3 Percentage of operators who exceeded $100 \%$ noise dose 
The noise sources of a roof bolting machine that may be considered worthy of examination include the vacuum pump, hydraulic pumps, drill chuck, drill steel, and drill bit. The vacuum pump, hydraulic pump, and drill chuck may vary from different drill manufacturers. Both the vacuum pump and the hydraulic pump contribute some to overall noise emissions. However, early tests at NIOSH's Pittsburgh Research Laboratories (PRL) confirmed that the hydraulic and vacuum pumps are not a major noise source for roof bolters. The main source of noise in the roof bolting operation is produced from the rock breaking process especially when drilling into hard rocks.

There are many variables that can affect both drilling efficiency and noise emission of the roof bolting operation in underground coal mines. Some of these variables, such as the acoustic environment, the geometry and compressive strength of the drilled rocks, are uncontrolled. Other variables, such as drill steel shape, bit type, and size, drilling dynamic parameters (e.g. applied thrust and torque, achieved penetration rate, and rotational rates) can be controlled by the roof bolter operators. The NIOSH study on the roof bolter sound power level shows the sound power level is affected by different size and shape drill steel and drill bits. The sound power level is also affected by the drilling parameters, thrust, and rotation speed (Peterson et al., 2005).

The solutions to reduce or eliminate personnel exposure to hazardous noise include: engineering controls, administrative controls, and personal protective equipment. The engineering controls involve any modification or replacement of equipment, or related physical change at the noise source or along the transmission path to reduce the noise level at the employee's ears. Engineering controls are available and technologically feasible for most noise sources. The administrative controls reduce noise exposure 
through changes in the work schedule or operations which is an effective, simple, and inexpensive method. Personal protective equipment, such as earmuffs and plugs, are considered an acceptable but less desirable option to control noise exposures, and are generally used when the implemented engineering or administrative controls cannot sufficiently reduce the noise exposure level (OSHA, 2014). The use of personal protective equipment relies too much on constant human vigilance. According to Suter (Suter, 1989), personal protective equipment has several drawbacks which influence the effect of the personal protectors and also cause the workers to be unwilling to wear hearing protectors. For instance, the personal protectors have an adverse effect on speech recognition, decrease the ability to detect warning signals, and other useful sounds. In the Mine Safety and Health Administration (MSHA)'s 1999 rule, which focuses on noise exposure in an effort to reduce the occurrence of noise-induced hearing loss, engineering and/or administrative controls to reduce the noise exposures of overexposed miners are required rather than relying only on hearing protection devices (Health Standards for Occupational Noise Exposure: Final Rule, 1999 and Yantek et al., 2007).

\subsection{Research objectives and scope}

The research objective of this dissertation is to develop a drilling control technology for roof bolting machines to reduce the noise exposure of roof bolter operators. This method will not use add-ons or change the mechanical design of the drilling tool. The goal of this technology development is to find a control algorithm for drilling coal-measure rocks with varying strength that can be used for automatic control of the roof bolt drilling operation for the following purposes: (1) reducing the noise dose of roof bolter operators in the roof drilling operation; (2) increasing the energy efficiency 
while maintaining good drilling productivity; and (3) maintaining a safe drilling environment. The drilling control for the roof bolting operation will be implemented through proper penetration rate and rotational rate according to the rock strength, drill steel, and drill bit used.

This research will be conducted both experimentally and theoretically to study the drilling noise in relation to drilling control parameters (penetration rate and rotational rate), rock strength, and drilling tools (i.e., steel and bits). Drilling tests are to be conducted to explore the characteristics of the drilling noise (sound power level and noise dose) by utilizing different drilling controls on drilling medium strength rock. The drilling noise will be correlated with the specific energy consumed and the energy efficiency of drilling each hole. Meanwhile, a previously developed mathematical model for simulating roof bolt drilling is to be improved to include the noise generation. This model will be used to estimate the rock strength as well as required drilling thrust and torque, specific energy, energy efficiency, and noise level for a given rock strength. The safety check of the drilling operation will also be included in this model. An algorithm will be developed for finding the rational drilling control parameters that can minimize the noise level of the bolter operators in drilling in rocks with varying strength without sacrificing safety and productivity. It is desired that the algorithm can be incorporated into the existing drill control unit for potential drilling automation. 


\section{CHAPTER 2 LITERATURE REVIEW}

\subsection{Introduction of sound and noise}

\subsubsection{Physics of sound}

Sound is defined as the auditory sensation evoked by the oscillations in pressure of a medium that has elasticity and viscosity (Ostergaard, 2003). Noise is any undesired sound. In an industrial environment, noise can be either continuous (i.e., a steady sound, such as a running fan) or intermittent (i.e., a broken sound or a sound burst, such as that generated by a drill) (Bise, 2001). Frequency of sound is the rate of oscillation of the sound wave at a fixed position in space or in a solid medium. Frequency is commonly expressed in hertz $(\mathrm{Hz})$, which is the number of complete cycles that occur in 1 second. The hearing range for human is commonly from approximately 20 to $20,000 \mathrm{~Hz}$. To better analyzing a frequency basis source, the frequency range is divided into a set of frequency band. Each band covers a specific range frequencies. The commonly used frequency band is the octave band and one-third octave band. In an octave band, the upper band-edge frequency is twice the lower band-edge frequency and the center frequency is the geometric mean of the lower band-edge frequency and upper band-edge frequency. The individual bandwidths for the full octave bands is shown in Table 2.1 (Bise, 2001). A one-third octave band has a frequency band whose upper band-edge frequency is the lower band-edge frequency times of cube root of two. 
Table 2.1 Full octave band (Bise, 2001)

\begin{tabular}{ccc}
\hline Center frequency & Lower band-edge frequency & Upper band-edge frequency \\
\hline $31.5 \mathrm{~Hz}$ & $22.4 \mathrm{~Hz}$ & $45.0 \mathrm{~Hz}$ \\
$63.0 \mathrm{~Hz}$ & $45.0 \mathrm{~Hz}$ & $90.0 \mathrm{~Hz}$ \\
$125.0 \mathrm{~Hz}$ & $90.0 \mathrm{~Hz}$ & $180.0 \mathrm{~Hz}$ \\
$250.0 \mathrm{~Hz}$ & $180.0 \mathrm{~Hz}$ & $355.0 \mathrm{~Hz}$ \\
$500.0 \mathrm{~Hz}$ & $355.0 \mathrm{~Hz}$ & $710.0 \mathrm{~Hz}$ \\
$1000.0 \mathrm{~Hz}$ & $710.0 \mathrm{~Hz}$ & $1,400.0 \mathrm{~Hz}$ \\
$2000.0 \mathrm{~Hz}$ & $1,400.0 \mathrm{~Hz}$ & $2,800.0 \mathrm{~Hz}$ \\
$4000.0 \mathrm{~Hz}$ & $2,800.0 \mathrm{~Hz}$ & $5,600.0 \mathrm{~Hz}$ \\
$8000.0 \mathrm{~Hz}$ & $5,600.0 \mathrm{~Hz}$ & $11,200.0 \mathrm{~Hz}$ \\
$16,000.0 \mathrm{~Hz}$ & $11,200.0 \mathrm{~Hz}$ & $22,400.0 \mathrm{~Hz}$ \\
\hline
\end{tabular}

Several parameters and measurements are helpful to understand the characteristics of sound and noise. The intensity of a sound wave is defined as the amount of energy that is transported through a unit area of a medium normal to the direction the sound is traveling, which is measured in watts per square meter. The sound power of a source is the total acoustic output that it produces in watts. It is usually expressed in terms of sound power level $\left(L_{w}\right)$ and defined as

$$
L_{W}=10 \log \left(\frac{W}{W_{0}}\right)
$$

Where $L_{w}$ is the sound power level in $\mathrm{dB}$,

$W$ is the sound power of the source in watts,

$W_{0}$ is the reference sound power, the value is $10^{-12}$ watts.

The sound pressure is related to the root-mean-square values of the pressure changes above and below atmospheric pressure. Sound pressure is measured in Pascals $(\mathrm{Pa})$ or Newtons $(\mathrm{N})$ per square meter $\left(\mathrm{N} / \mathrm{m}^{2}\right)$. The range of sound pressure that a normal 
human ear can hear is from $20 \mu \mathrm{Pa}$ to $2000 \mathrm{~Pa}$. In order to deal with the wide range of human hearing, sound pressure level $\left(L_{p}\right)$ is developed as the logarithmic measure of a sound pressure relative to a reference value. It is measured in decibel and can be expressed as

$$
L_{p}=20 \log \left(\frac{P}{P_{0}}\right)
$$

Where $L_{p}$ is the sound pressure level in $\mathrm{dB}$,

$P$ is the root-mean-square sound pressure in $\mathrm{Pa}$, $P_{0}$ is the reference sound pressure, $20 \mu \mathrm{Pa}$.

The human ear is more sensitive to sound in the frequency range $1 \mathrm{kHz}$ to $4 \mathrm{kHz}$ than to sound at lower or higher frequencies. To compensate, a sound level meter are normally has frequency-response weighting network to attenuate sounds of certain frequencies, resulting in a weighted total sound pressure level (Bise, 2001). Commonly used scales are A-weighting, B-weighting and C-weighting. The A scale, which reduces the influence of the lower frequencies (below about $500 \mathrm{~Hz}$ ) is the closest weighting to approximate the ear's response characteristics. A weighting also has the potential to assess hearing damage caused by loud noise (Bise, 2001). A-weighting scale is standard in many sound level meters and has been widely used for noise measurement. A scale is also used by regulatory agencies such as Mine Safety and Health Administration (MSHA) and the Occupational Safety and Health Administration (OSHA) (Bise, 2001). The Aweighted sound level is expressed as dBA. 


\subsubsection{Noise induced hearing loss}

Noise-induced hearing loss (NIHL) is caused by exposure to sound levels or durations that damage the sensitive structures in the inner ear (NIOSH, 1998). Both intense "impulse" sound (i.e., explosion) and continuous loud sounds (i.e., noise generated in a workshop) can cause NIHL. NIHL is permanent and nonreversible. It limits workers' ability to hear high frequency sounds, understand speeches, and seriously impairs their ability to communicate. Also, hearing loss can interfere with the ability to enjoy socializing with friends, playing with their children or grandchildren, or participation in other social activities, and can lead to psychological and social isolation (OSHA, 2014).

\subsubsection{Current noise standards}

MSHA sets the legal limits on noise exposure in metal and nonmetal mines and coal mines (30 CFR PART 62, 2014). The permissible exposure limit (PEL) is $90 \mathrm{dBA}$ for a time weight average noise level over 8 hour per day. $5 \mathrm{dBA}$ exchange rate is used in MSHA standard, which means that when the noise level is increased by $5 \mathrm{dBA}$, the allowable exposure time to maintain the same noise dose is cut in half. In addition, no exposure to sound levels exceeding $115 \mathrm{dBA}$ is permitted at any time. The National Institute for Occupational Safety and Health (NIOSH) recommended the exposure limit for occupational noise exposure of $85 \mathrm{dBA}$ for an 8 -hour time-weight average noise level to reduce the noise induced hearing loss (NIOSH, 1998). A $3 \mathrm{dBA}$ exchange rate is also recommended by NIOSH, which means when the noise level increases by $3 \mathrm{dBA}$, the recommended amount of exposure time will be halved. 
To reduce the noise-induced hearing loss among miners, MSHA requires the miners to be enrolled in a hearing conservation program (HCP) if the noise exposure equals or exceeds the time-weighted average of $85 \mathrm{dBA}$. The HCP must include a monitoring system, the provision and use of hearing protectors, audiometric testing, training, and recordkeeping (30 CFR PART 62, 2014).

\subsection{Roof bolting}

Roof bolting has been the primary roof support system in underground mining since 1950s (Mark et al., 2003). Most of the U.S. underground coal is mined under roofbolted roofs. Peng (1984) summarized the state-of-the-art on roof bolting. The report emphasized the significant results on the most commonly used roof bolts, the mechanical (mainly expansion-shell) bolts and fully grouted resin bolts, which included the installation of roof bolts, theories of roof bolting and factors affecting results of roof bolting. It also addressed the advantages of fully grouted resin bolts. NIOSH conducted a survey in 1999 (Dolinar \& Bhatt, 2000) which interested in the types of roof bolts that were used by U.S. coal industry and how the various parameters could affect the number of roof falls. The trend of the roof bolts used was the large reduction in the relative number of mechanical anchor bolts which was replaced mainly by the resin-grouted rebar system. In the 1999 survey, it was found that about $80 \%$ of roof bolts were fully grouted bolts.

A roof bolting machine is a drilling machine used to install roof support bolts in an underground mine (Matetic et al., 2008). Roof bolting usually consists two major processes: drilling and bolting. In the drilling process, a hole is drilled to the desired length into the mine roof at the required location. In the bolting process, a plastic tube 
with resin is inserted into the drilled hole and then a roof bolt is inserted into the hole and rotated by the roof bolting machine. The plastic tube of resin is teared and mixed to the bolt and the surrounding rock layers, in which way, the roof is supported. In most underground mines, a roof bolt is placed approximately every four feet. The commonly used rebar of rockbolts in mining industry are 5/8-in (\#5) and 3/4-in (\#6) in 1-in hole (Dolinar \& Bhatt, 2000), and 7/8-in (\#7) and 1-in diameter (\#8) in 1-3/8-in hole (ASTM F432-13, 2013 and Chen, 2015).

\subsection{Study of a roof bolting machine noise}

NIOSH has conducted research on the noise of roof bolting machines. The studies were focused on the noise exposure of roof bolting operators, noise characteristics of the roof bolting machine and sound levels prediction for underground roof bolting machines.

A report entitled, "Equipment Noise and Worker Exposure in the Coal Mining Industry, 2006" was published by NIOSH in 2006 (NIOSH, 2006). This report summarized the noise sources and worker noise exposures in the coal mining industry which included the part of noise exposure for roof bolting machines. It shows that the equivalent sound level of a roof bolting machine in and underground coal mine is between 86-112 dBA. For roof bolting machine operators, the percentage of recorded doses that were above the MSHA Permissible Exposure Level (PEL) dose of $100 \%$ and the percent above the citable level of $132 \%$ was $81 \%$ and $69 \%$, respectively.

In recent years, NIOSH carried out more detailed studies on sound power level and noise exposure from roof bolting operations both in coal mines and in the laboratory. Measurements to evaluate noise exposure during a duty cycle of a typical roof bolting machine operation were conducted at two coal mines (Peterson \& Alcorn, 2007). A 
dosimeter time-motion study of an operator's shift was conducted. Each activity for the mines was logged including tramming the machine, drilling holes, installing the roof bolt, etc. The results show that a significant portion of the time in which the operators accumulated greater than $90 \%$ of their noise exposure, is during actual roof drilling and bolting. From the time motion study, it was shown that drilling the hole requires four to nine times more time than the associated installation of the roof bolt during a typical drilling/bolting cycle. The operator is exposed to greater sound pressures during drilling than bolting, and thus dose accumulates at a significantly faster rate when drilling than bolting installation. The roof drilling task was determined to be the most significant contributor to the operators' noise exposure during the roof bolting machine duty cycle.

Matetic (2006) proposed research to assess and evaluate noise controls on roof bolting equipment and predict sound pressure levels in underground coal mining. In his research, the sound power levels radiated by a roof bolting machine during different drilling configurations and utilizing differing types of drilling methods in high compressive strength rock media were measured in the Pittsburgh Research Laboratory (PRL). His research characterized the sound power levels from laboratory testing and provided the mining industry with information on empirical data relative to utilizing differing noise control technologies (drilling configurations and types of drilling methods) in reducing the sound power level produced by a roof bolting machine. A statistic model was developed by Matetic which could be used to determine or predict the sound level for any drilling method or drilling configuration used. In the model, five parameters were utilized as independent variables including bit size, drill steel type, speed, thrust, and drilling method. Further, two different methods for predicting sound pressure levels of a 
roof bolting machine in an underground mine were developed based on the laboratory test results. Also in this research, a method for determining a roof bolting machine operator's noise dosage of a roof bolting machine utilizing predicted, or calculated sound pressure level was provided.

\subsection{Engineering noise control method on roof bolting machine}

A report "Mining Machinery Noise Control Guidelines" published by the former Bureau of Mines in 1983 (Bartholomae \& Parker, 1983) synthesized information on evolving and available noise controls for major pieces of mining equipment to disseminate within the mining industry. Noise control treatments related to roof bolting machines were provided in this report, which included modification to the dust collection blower or changing to quieter model, covering or enclosing the hydraulic pump and sealing the enclosure around the motor and pump-blower drives using existing cover panels. After the application of most of the recommended controls by the manufacturers of roof bolting machine, the noise exposure of the operator still exceeded the regulatory limits when conducting the drilling or bolting installation process (Matetic, 2006).

NIOSH has developed a number of engineering noise control methods to reduce the noise emission of a roof bolting machine. A suite of controls which consists of a bit isolator, chuck isolator, and a collapsible drill steel enclosure has been developed by NIOSH (Lowe et al., 2010). The bit and chuck isolators are developed to reduce the noise sources near the drill bit and chuck. These devices are similar in design, except for having slightly different geometry in the steel components to connect to the chuck, drill steel, and bit. Photographs of the two kinds of control suites are shown as Figure 2.1 (Lowe et al., 2010 and Peterson et al., 2009).The steel members of the devices were 
machined out of 4130/4140 steel and heat treated to $350 \mathrm{BHN}$. They consist of inner and outer parts which are isolated from each other by a layer of 75 durometer Shore A natural rubber. The duromenter was used because the fatigue life of the rubber was a concern. The 75 durometer elastomer is bonded to the inner steel member, precompressed, and assembled in the outer steel part. A post-vulcanization (PV) bond attaches the elastomer's outer surface to the inner surface of the outer steel member (Lowe et al., 2010).

The collapsible drill steel enclosure (CDSE) reduces the noise level by creating a barrier to block noise radiated by the drill steel from reaching the operator's ear (Figure 2.1). The prototype CDSE consists a bellows with a spring to support it, a hinge which allows the CDSE to move out of the way for roof bolt installation, a cap to help the CDSE seal against the roof, and the customized mounting hardware to install the CDSE onto a specific RBM. The results of laboratory tests when drilling into granite conducted by NIOSH shows that each noise control can reduce roof bolting drilling noise. The bit isolator, chuck isolator, and CDSE reduce overall A-weighted sound pressure level (SPL) at the operator's ear location by 4,2 , and $7 \mathrm{dBA}$, respectively. The combination of two or more control shows more effective noise reduction. The combination of bit and chuck isolators, and combination of a bit isolator and CDSE yield a total SPL reduction of 5 $\mathrm{dBA}$ and $12 \mathrm{dBA}$, respectively. The combination of all three controls has the highest SPL reduction of $13 \mathrm{dBA}$. The noise reduction results of the suite of three noise control devices are shown in Table 2.1. Similar information can be found in related papers (Matetic et al., 2008 and Peterson, 2008).

NIOSH redesigned the Collapsible Drill Steel Enclosure (CDSE) to improve its usability and durability features recently (Azman et al., 2014). The new designed CDSE is 
mainly different from the prototype in the material, diameter, and installation. The bellows of the CDSE has changed from aluminum coated fiberglass to a pure elastomer formed flexible hollow tube. The top and bottom sections that slide over the drill steel are constructed of aluminum. The new design CDSE is much slimmer, as shown in Figure 2.2. Laboratory tests by NIOSH shows the CDSE reduced the A-weighted sound level by $2-4 \mathrm{~dB}$ at the operator's ear position.

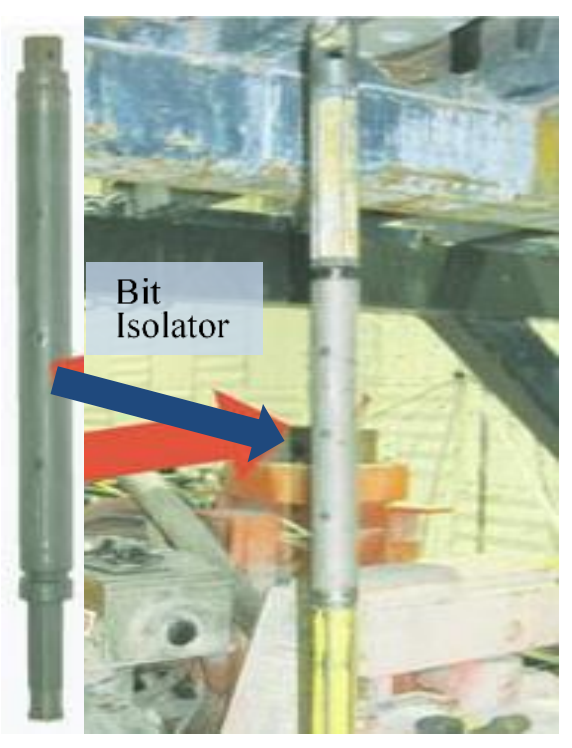

(A)

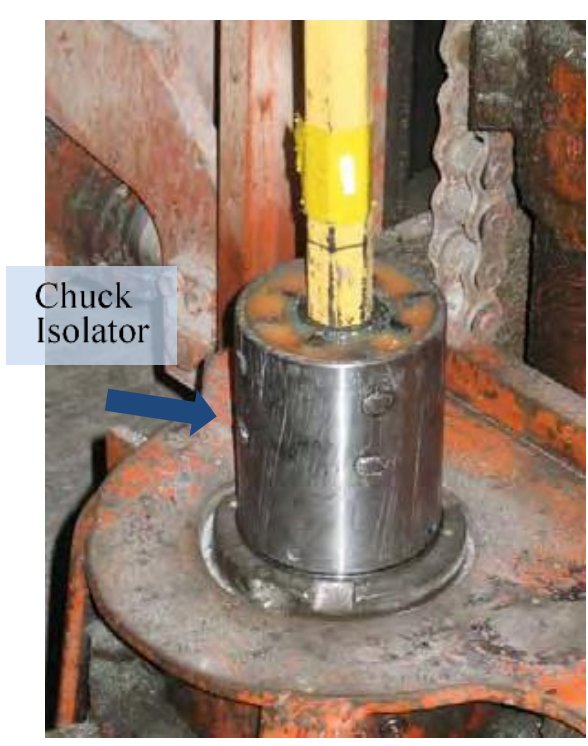

(B)

Figure 2.1 Roof bolting noise control methods ((A) Bit isolator (Coal News, 2013) and (B) Chuck isolator (Peterson et al., 2009) 

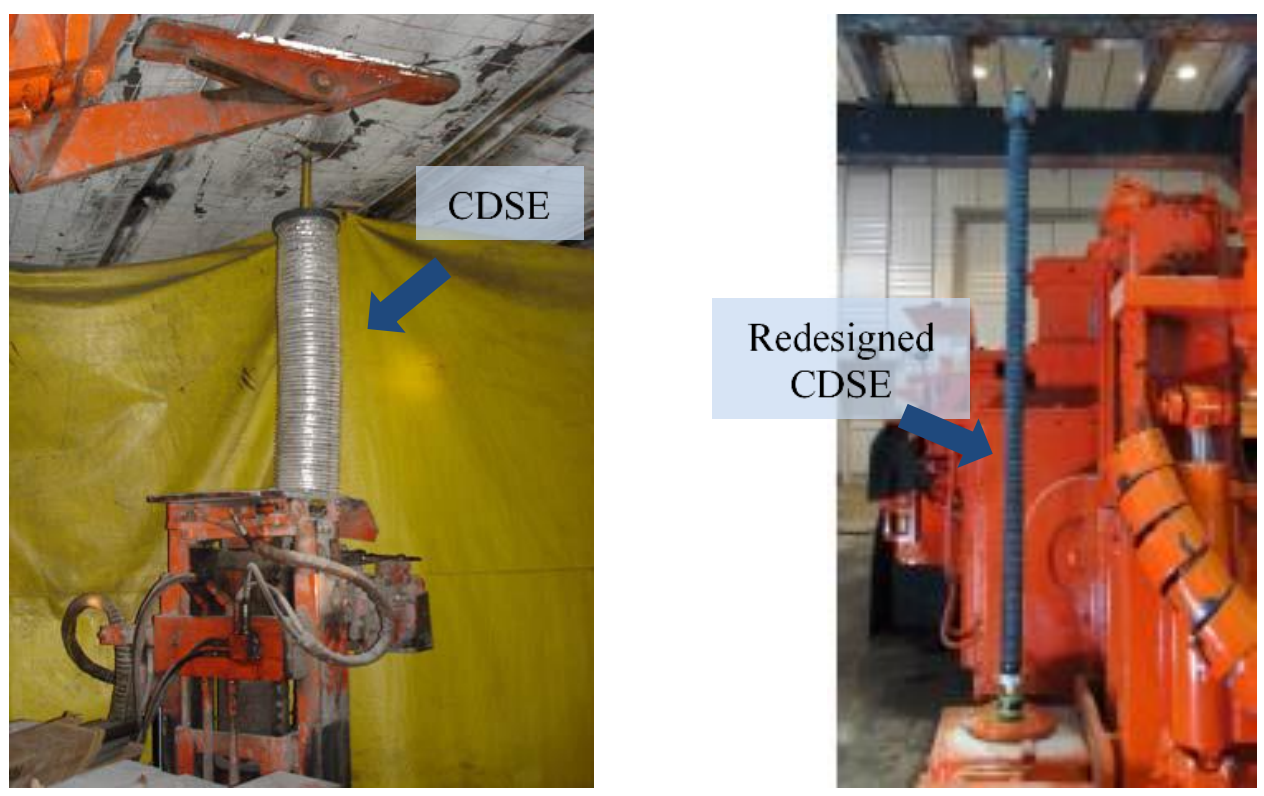

Figure 2.2 Roof bolting noise control methods (CDSE (Matetic et al., 2008) and redesigned CDSE (Azman et al., 2014))

Table 2.2 Comparison of drilling noise control methods (Lowe et al., 2010)

\begin{tabular}{|l|c|c|}
\hline Configuration & Overall SPL, dBA & $\Delta \mathrm{dB}$ from baseline \\
\hline Baseline & 106 & - \\
\hline 75 Durometer Bit Isolator & 102 & 4 \\
\hline 75 Durometer Chuck Isolator & 104 & 2 \\
\hline CDSE & 99 & 7 \\
\hline Bit Isolator and Chuck Isolator & 101 & 5 \\
\hline Bit Isolator and CDSE & 94 & 12 \\
\hline Bit Isolator, Chuck Isolator & 93 & 13 \\
\hline Redesigned CDSE & - & $2-4$ \\
\hline
\end{tabular}

Efforts were also made on developing a damped drill steel to reduce roof bolting machine drilling noise by Peterson and Camargo (2010). A constrained layer damping technique was examined by NIOSH to modify a hexagonal drill steel. The vibration damping material used with a constraining layer to encapsulate a drill steel could reduce 
the drill steel vibration which has shown in their past research to be a common source of noise during drilling operations. The modified drill steel consists of a standard hexagonal drill steel, and a steel casing, which is folded and seam welded to encase the drill steel and function as a constraining layer. A vibration damping elastomer was between the drill steel and casing and the surfaces were bonded with epoxy. The outside diameter of the damped drill steel was increased by applying the constraining layer damping elastomer. A $4.1 \mathrm{~cm}(1.625$-in) vacuum drill bit mounted on a standard hexagonal drill steel and a damped drill steel is shown in Figure 2.3. Their laboratory testing showed a $4.3 \mathrm{~dB}$ reduction of the overall sound level at the operators' location when drilling with the modified hexagonal drill steel compared to a standard hexagonal drill steel. The analysis of one-third-octave bands data in this research shows that one-third-octave bands 1,600 $\mathrm{Hz}$ through $6,300 \mathrm{~Hz}$ is particular important to the operator location sound levels. There is $5 \mathrm{~dB}$ reduction of sound level in this frequency using a damped drill steel.
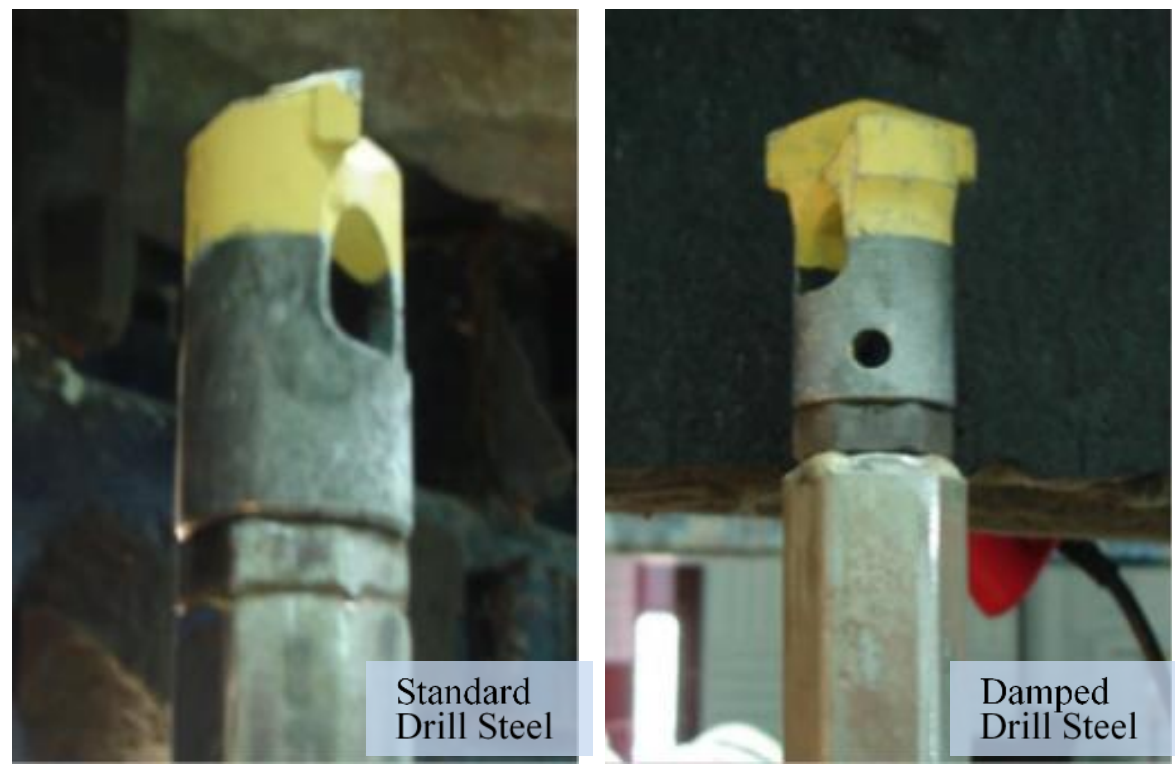

Figure 2.3 Standard and damped hexagonal drill steel and $4.1 \mathrm{~cm}$ [1.625-in] bit (Peterson \& Camargo, 2010) 


\subsection{Rock drilling energy}

The concept of specific energy in rock drilling was proposed by Teale (1965) as the energy required to excavate a unit volume of rock. It is a useful parameter to describe the energy and volume relationships and also an index of the mechanical efficiency of a rock-working process. Rotary drilling can be regarded as two components: indentation and rotation cutting. Indentation pushes the cutting edge of the bit into the rock. Simultaneously, the rotary cutting gives the bit a lateral movement to break out fragments of rock. In rotary non-percussive drilling, the specific energy includes two parts; the work done by the thrust and by the torque. The specific energy can be defined as the following equation.

$$
e=\frac{F}{A}+\frac{2 \pi}{A} \frac{\omega T}{\mathrm{v}} \quad \text { in.lb/in }{ }^{3}
$$

where: $e$ is specific energy, $i n-l b / i n^{3}$

$F$ is the thrust, $l b$

$T$ is the torque, $l b$-in

$A$ is area of the hole or excavation, $i n^{2}$

$v$ is penetration rate, $\mathrm{in} / \mathrm{sec}$ and

$\omega$ is rotation speed, $\mathrm{rev} / \mathrm{min}$ 
Using $e_{F}$ and $e_{T}$ to denote the two components: thrust and rotary.

$$
\begin{gathered}
\mathrm{e}_{F}=\frac{F}{A} \quad \text { in.lb/in } \\
e_{T}=\frac{2 \pi}{A} \frac{\omega T}{\mathrm{v}} \quad \text { in.lb/in }{ }^{3}
\end{gathered}
$$

The thrust component $e_{F}$ is always small compared to $e_{T}$, sometimes negligible. Therefore, the energy consumed by rotation was the part that most interested Teale. For a given hole cross-sectional area and rotation speed, $e_{r}$ is proportional to $(T / v)$. The torque/penetration-rate curves for rotary drilling approximates to straight lines through the origin over a fairly wide working range. Thus $(T / v)$, the slope of the line, is also approximately constant. Further, $e_{T}$ and $e$ itself should not vary a great deal over the referred working range, which is consistent with the suggested constant value of specific energy at large particle sizes. Another approach proposed by Teale is to put $b$ (penetration per revolution) into the equation.

$$
e_{T}=\frac{2 \pi}{A} \frac{T}{b} \quad \text { in.lb/in }{ }^{3}
$$

The rotation speed may not significantly affect $(T / b)$ for a given type of rock, as the amount of energy required to break brittle rock is not much affected by the rate at which it is applied.

For an actual drilling machine, Teale assumes that there is a minimum value of specific energy relating to some parameter of rock strength. The specific energy will be very high at low thrusts. At a thrust below a certain value, the thrust will be inadequate to push the drill bit into the rock, in other words, zero volume will be excavated but a finite 
amount of work still be needed for overcoming friction. Rock breakage into smaller particles increases the specific energy. When considering these facts together, the specific energy will tend to be infinity at zero thrust. But a rapid fall in specific energy will occur as the thrust increases for the reason that the size of breaking the particle will increase and the work lost in friction will constitute less of percentage of the total work done. However, the specific energy will remain constant or actually increase again after it reaches a certain value. The lowest value of specific energy equals the maximum mechanical efficiency when the same rock is drilled using a particular tool in a particular operations condition.

A number of rock drilling experiments have been examined by Teale to support his assumption. The specific energy at different thrusts has been calculated. From the results, the fall to a minimum specific energy for various types of rock always occurs, although the ensuing rise again occurs only in certain types of drilling. The results also shows that in all cases the minimum value appears to be very roughly correlated with the crushing strength of the media drilled into for rotary, percussive-rotary and roller-bit drilling.

\subsection{Drilling parameters utilized to estimate rock strength}

Leung and Scheding (2015) proposed research on automated coal seam detection using a modulated specific energy measure in a monitor-while-drilling context. In their research, a link between derived drill performance and geomechanical properties of sedimentary rock strata (shear and compressive strengths) was established to increase the coal discriminative power of modulated specific energy relative to Teale's specific energy measure. The rotation-to-thrust power ratio was employed as an indicator to 
distinguish coal and non-coal rock layers in rotary drilling. Their results indicated that accurate coal seam detection can be achieved using monitor-while-drilling data without relying on geophysical data, such as bulk density or natural gamma in a monitoringwhile-drilling.

Peng and Luo (Peng et al., 2005a) (Peng et al., 2005b) developed a method for predicting the roof geology based on the drilling parameters obtained during roof bolting operation. In their research, a series of laboratory and underground tests were conducted. It was found from their results that feed pressure was a good indicator for identifying the voids/fractures and estimating the roof rock strength. Their research also described the method for determining quantitatively the location and the size of void/fracture and estimating the roof rock strength from the drilling parameters of roof bolter. A more detailed discussion of their work will be discussed in next chapter.

\subsection{Sound level used to determine rock properties}

Vardhan et al. (2009) and Rajesh et al. (2013) conducted research estimating rock properties using sound levels produced during rock drilling. The sound level during rock drilling was regarded as a useful parameter to determine rock or rock properties as they anticipated that the sound level would be different with drilling into rocks of different physical-mechanical properties for the same type of drill machine. Vardhan conducted experiments to measure the sound pressure level generated by drilling vertical holes in rocks having varying properties. The tests were conducted in a normal cement plastered room using small portable pneumatic drilling equipment. Their study confirmed the correlation between the sound level and rock properties, for example, the sound level will increase as the compressive strength and the abrasivity of rocks decrease. 
In their study, multiple regression models and artificial neural network (ANN) models were developed based on the results of drilling tests on various rock samples. In their mathematical models, the drill bit speed, penetration rate, drill bit diameter, and equivalent sound level produced during drilling are taken as input parameters to determine the uniaxial compressive strength (UCS), Schmidt rebound number (SRN), dry density $(\rho)$, p-wave velocity $\left(\mathrm{V}_{\mathrm{p}}\right)$, tensile strength (TS), modulus of elasticity (E), and porosity of the rock. Further, according to their validation and comparison of these two models, both methods yield similar results and the ANN method was generally more efficient to predict rock properties from sound level during drilling.

\subsection{Other related issues in roof bolting}

\subsubsection{Dust in roof bolting}

The drilling of rock in roof bolting produces dust, usually with a high content of quartz. Most roof bolting machines have the dust collection systems installed to remove dust during drilling. However, roof bolter operators can experience overexposure to dust from the drilling process if the dry dust collector is not properly maintained. Goodman (2002 and 2006) conducted research to assess the effectiveness of methods to control dust exposure for roof bolter operators, including using a canopy air curtain for protecting roof bolters, air tubing, and cleaning the roof bolter dust box. NIOSH published a book entitled Best Practices for Dust Control in Coal Mining in 2010 (Colinet et al., 2010). Several practices are suggested to reduce dust exposure to the roof bolter operator, including maintaining the dust collector system, cleaning the dust box, using dust collector bags, removing, and replacing the canister filter, cleaning the discharge side of 
the collector, installing a sock on precleaners, using "dust hog" bit, positioning to avoid working downwind of the continuous miners and wet/mist drilling.

The new MSHA rule, as of August 1, 2016, requires a lower concentration limit for respirable coal dust from $2.0 \mathrm{mg} / \mathrm{m}^{3}$ to $1.5 \mathrm{mg} / \mathrm{m}^{3}$ in the coal mine atmosphere during a working shift. Analysis of MSHA dust sample data, which includes all operator and inspector dust samples collected from 2010-2014, shows over two times of samples of the mine operators are exposed to excessive respirable coal dust under the new standard than that of the original standard. Among all the 341,788 dust samples, 9,060 samples show the operators exposed to excessive occupational exposure to respirable coal dust of the $2.0 \mathrm{mg} / \mathrm{m}^{3}$, and 18,668 samples show excessive exposure to respirable coal dust of 1.5 $\mathrm{mg} / \mathrm{m}^{3}$. Among all the 23,416 dust samples of roof bolter operators, the sample numbers showing excessive exposure under $2.0 \mathrm{mg} / \mathrm{m}^{3}$ and $1.5 \mathrm{mg} / \mathrm{m}^{3}$ standard are 381 and 983 , respectively.

\subsubsection{Bit wear in roof bolting}

During the rock breakage, part of the total energy will eventually dissipated as heat. The roof bolter drill bit is many times harder than the normal rock that is drilled in underground bolt hole drilling. However, the drill bit could be worn out after several times of drilling. This accelerated bit wear is often attributed to the bit becoming overly hot. The temperature was referred as one of the most important bit-wear parameters. Wingquist and Hanson (1987) studied the bit wear-flat temperatures generated by linear cutting in Berea sandstone as a function of cutting depth and speed. It was concluded that at least for deeper cut (1/2 in), bit temperature, and therefore wear, can be reduced by lowering the cutting speed. Finfinger (2003) studied the bit wear in rock drilling of roof 
bolting in laboratory. The test results showed that there was a linear relationship between the drill bit wear and energy consumed during roof bolting drilling of the test holes. Furthermore, the relationship between energy efficiency and bit wear was studied using a bit-rock interaction model. It was found the energy efficiency decreased considerably when the wear of bit progressed. 


\section{CHAPTER 3 SCIENTIFIC BASES}

\subsection{Drill bit mechanical model}

The approach in this research targets drilling operation so that the percent of the input energy for rock breakage can be increased while that for producing noise and causing bit wear can be decreased. This research is based on a previous study utilizing the acquired drilling parameters to identify the geological structures and to estimate the mechanical properties of the roof strata (Luo et al., 2002, 2003, and 2004). A mechanical model was developed in that research to determine the uniaxial compressive strength and shear strength of the rock being drilled, and the presence of fractures and voids. The required minimum drilling energy to cause shear and compressive failure in drilling a particular rock can also be determined. It was found that the drilling energy efficiency (the ratio of the energy for rock breakage to the total input energy) is strongly related to how the drill is operated. The model shows that a significant amount of drilling energy is wasted in excessive rubbing actions between the drill bits and the rocks. Such rubbing action could limit the drilling energy efficiency to less than $20 \%$. The wasted energy not only causes excessive heat and wear of the drill bits, but also produces noise and fine dust. If drilling is not properly controlled, the noise and bit wear problems become very serious when hard rocks are drilled. An important finding from that research was that the specific energy of drilling decreases as the bite depth increases. The bite depth (b) is defined as the penetration depth per drill rotation and is related to penetration rate $(v)$ and rotational rate $(\omega)$. 


$$
b=60 v / \omega
$$

Where $b$ is bite depth in in/rev

$v$ is penetration rate in in/sec

$\omega$ is rotational rate in rpm

In the drilling process, the input mechanical energy from the drill head is applied by the drill bit to the rock. The interaction between the drill bit and rock plays an important part in studying the drilling process. In rotary drilling, the input mechanical energy is applied in the forms of thrust $(\mathrm{F})$ and torque $(\mathrm{T})$ as shown in Figure 3.1 (Luo et al., 2014). The energy causes rock breakage and allows the drill bit to advance in the rock with a penetration rate $(v)$ and rotational rate $(\omega)$.

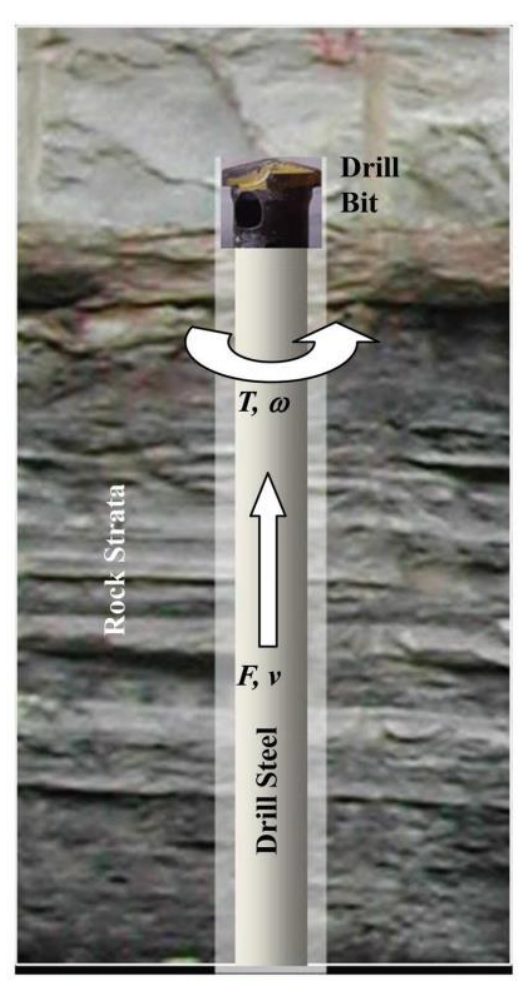

Figure 3.1 Schematic of drilling roof bolt hole (Luo et al., 2014) 


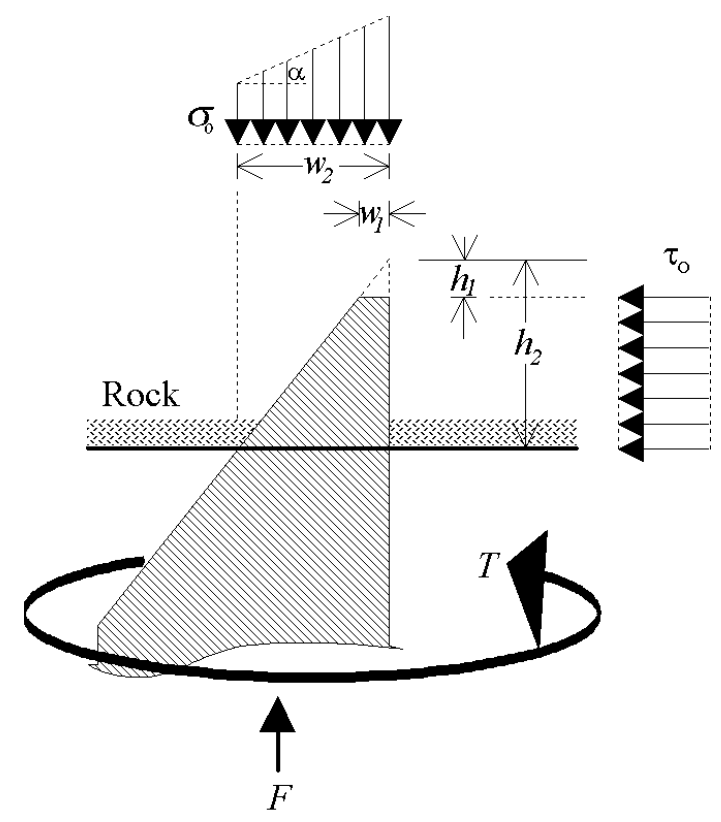

Figure 3.2 Bit-rock interaction model in rotary drilling (Luo et al., 2002) $\alpha$ - Angle of increment of compressive strength, $\sigma_{0}$ - Unconfined compressive strength, $\tau_{0}$ - Shear strength, $h_{1}$ - Height of bit wear, $h_{2}$ - Height of bit inside the rock, $w_{1}$ - Width of bit wear, $w_{2}$ - Normal contact width, $F$ - Thrust, $T$ - Torque.

Based on the interaction model shown in Figure 3.2, it is reasonable to assume that the net thrust $(\mathrm{F})$ causes compressive failure, while the net torque $(\mathrm{T})$ caused the shear failure of the rock in the rotary drilling process. The required net thrust at a particular bite depth should be proportional to the product of the compressive strength of the rock and the normal contact area between the bit and rock. Similarly, the required net torque is the product of the shear strength of the rock and the shear contact area. Both the normal and shear contact areas are the functions of the bit geometry and bite depth. Additional thrust is required to overcome friction as the outer edges of the drill bit touch the wall of the bolt hole when it advances into the rock. Similarly, a considerable amount 
of additional torque is required to overcome friction along the outer edges of the bit and friction along the bit tip as the bit rotates.

Using the interaction model, the unconfined compressive strength $\left(\sigma_{\mathrm{o}}\right)$ and shear strengths $\left(\tau_{\mathrm{o}}\right)$ of the rock can be estimated using the following two equations, respectively.

$$
\begin{gathered}
\sigma_{0}=\frac{F}{D \mathrm{w}_{2}} \frac{1}{1+w_{2} \tan \alpha / 2} \\
\tau_{0}=\frac{4}{b D^{2}}\left[T-\frac{0.85}{4} \sigma_{0} w_{1} D^{2}\left(1+\frac{2 w_{2}-w_{1}}{2} \tan \alpha\right)\right]
\end{gathered}
$$

\subsection{Specific energy and energy efficiency}

An effort was made to link the drilling noise with specific energy of drilling and energy efficiency in the roof bolting operation. The energy applied to a roof bolter head includes the useful drilling energy for breaking the rock in the bolt hole and other forms of energy that are not used directly for rock breakage.

Correctly estimating the rock strengths is the most important task in mapping the roof geology and in applying the developed control technology for drilling noise reduction. The strengths of the rock have been demonstrated to be proportional to the applied drilling energies in forms of total thrust and total torque. Each of the two energy forms consists of the following three parts when the rotary drilling process is at a steady state.

- The non-drilling energy to maintain the linear and rotary movement of the drilling head without actual drilling into the rock. The non-drilling energy is dependent on the drilling system and operating parameters. 
- The net energies of thrust and torque to cause the compressive and shear failures of the rock to be drilled, respectively. This useful portion of energy is responsible for breaking the rock.

- The energy to overcome the frictions between the drill bits and the rock. This portion of energy is wasted in the drilling process to heat and to cause the wear of the drill bit as well as to produce noise and fine dust.

Based on Teale's definition (Teale, 1965) of the specific energy of drilling (e) consists of two parts, the energy consumed by thrust $\left(e_{F}\right)$ and the energy by torque $\left(e_{T}\right)$. It is determined as which is mentioned in the previous part of this chapter, the specific energy was determined as Equation (3.4) (Luo et al., 2002).

$$
e=e_{F}+e_{T}=\frac{F}{A}+\frac{2 \pi \cdot 60 \cdot\left(T_{1}+T_{2}\right)}{A \cdot b}
$$

Since the applied torque is divided into the torque to overcome the shear strength $\left(T_{1}\right)$ and the torque to overcome the frictional resistance $\left(T_{2}\right)$, the specific energy in Equation (3.4) actual contains three parts. The specific energy used to overcome the frictional resistance is wasted in the drilling operation. Therefore, the efficiency $(\eta)$ of the drilling energy can be obtained as Equation (3.5) (Luo et al., 2002).

$$
\eta=1-\frac{2 \pi \cdot 60 \cdot T_{2}}{e \cdot A \cdot b}
$$

In the equation, $\mathrm{A}$ is the cross-sectional area of the bolt hole. Equation (3.5) shows that energy efficiency increases with bite depth. Previous research shows that the maximum energy efficiency is less than $20 \%$, even when a new drill bit is used on a medium hard rock. Therefore, only a small percent of the specific energy is actually 
consumed to cause rock failure during drilling operation, while most of the drilling energy is wasted on overcoming friction at the bit tip. The model also shows that the energy efficiency is higher in drilling soft rocks than hard rocks. This explains why excessive bit wear is induced when very hard rock is drilled. Figure 3.3 shows the relationship between the specific energy and bite depth derived from experimental data while drilling a concrete block (Luo et al., 2014).

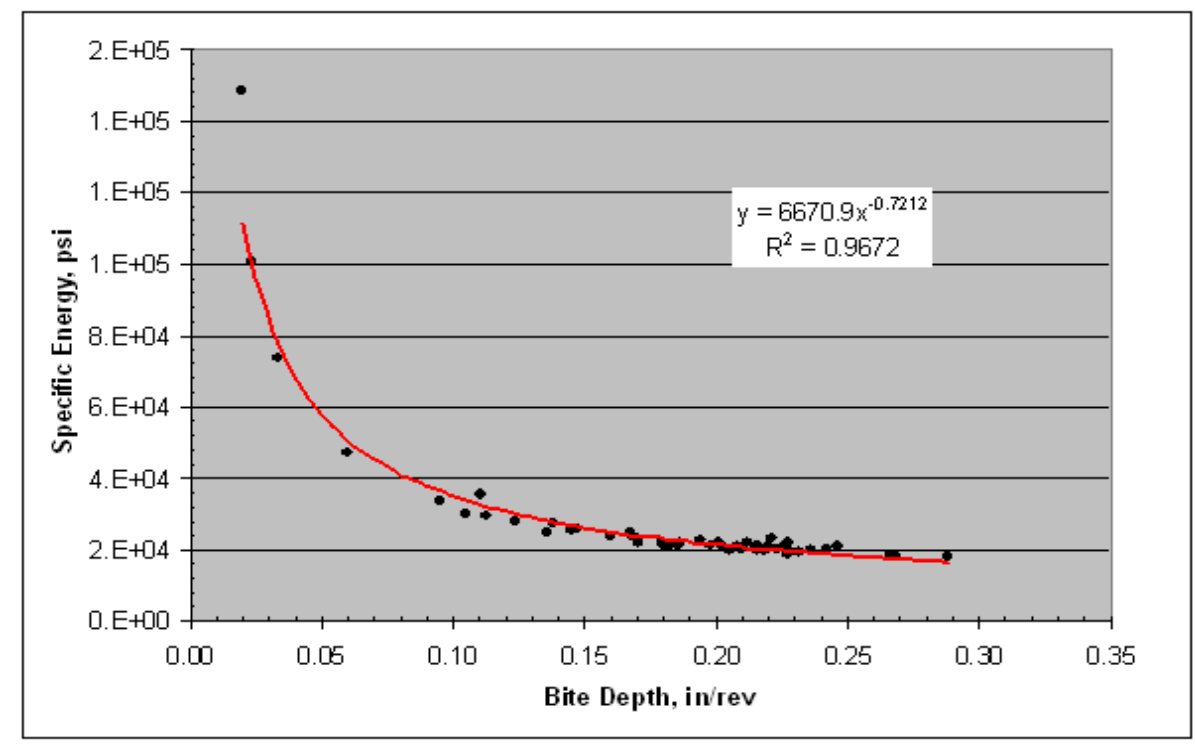

Figure 3.3 Specific energy versus bite depth from drilling data on a concrete block (Luo et al., 2014)

\subsection{Proposed approach in this research}

The rock strengths and other geology properties of the drilled rock were able to be determined using the acquired real-time drilling parameters in roof bolting operation, which was discussed in the previous chapter. The real-time determined roof geology mapping information is essential for proper design and application of roof support. In this research, the real-time rock strength will be further utilized for noise control in the 
drilling operation. After the drilled rock strength is determined, a drilling noise control algorithm for this specific rock type can be utilized to control the drilling by rational parameters for the best noise control. In this research, rational parameters means a range of optimized parameters that can be controlled to reduce drilling noise. At the same time, the safety of the drilling performance will be checked by controlling the drilling below the maximum thrust and torque of the drill steels. Therefore, the drilling will be controlled to achieve the goal of reducing noise while maintaining safe drilling performances. The algorithm can be incorporated into the existing drill control unit for potential drilling automation as shown in Figure 3.4.

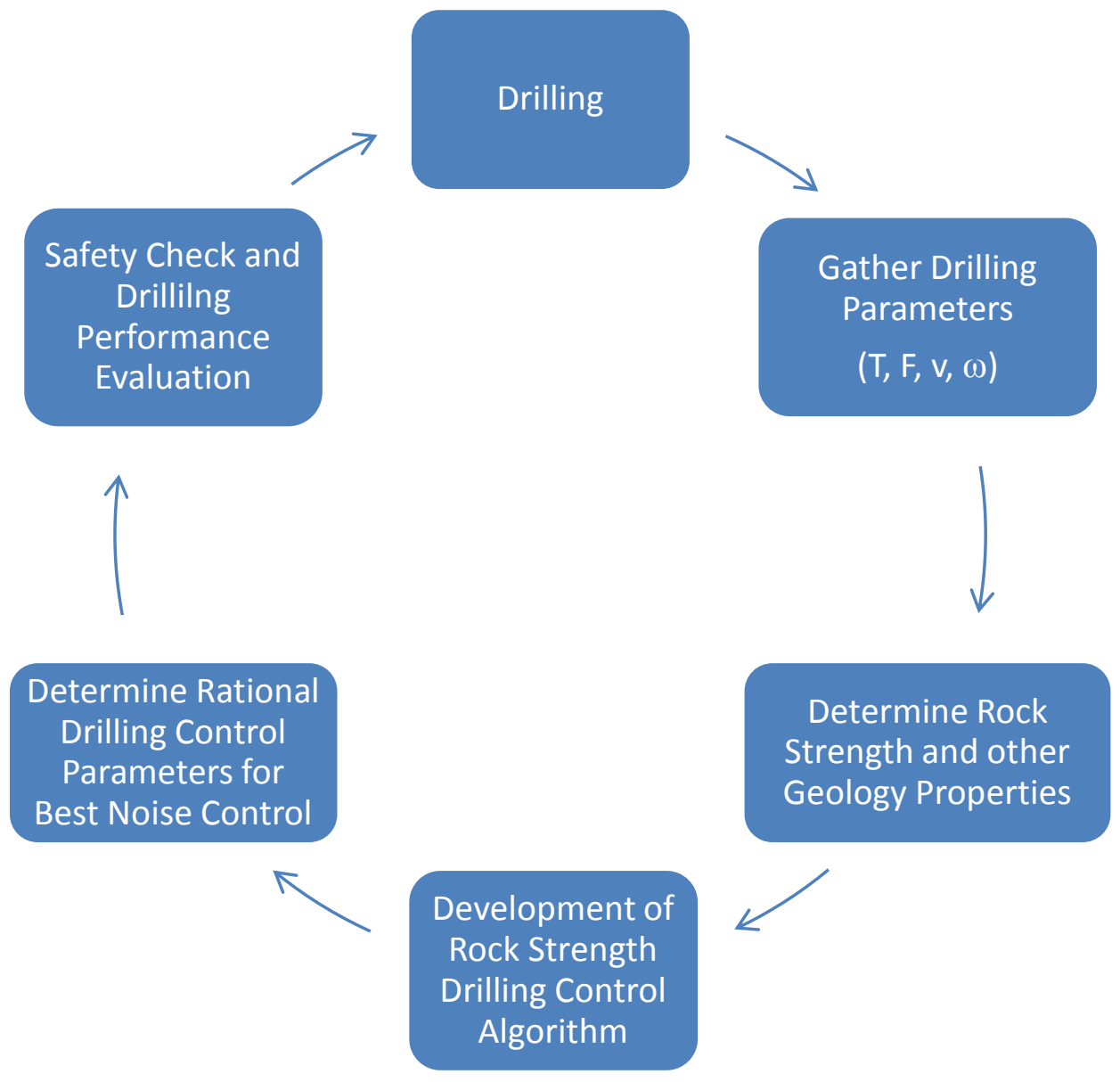

Figure 3.4 Proposed drilling control technology 


\section{CHAPTER 4 SCOPE AND METHOD OF RESEARCH}

In this research, a series of laboratory experiments were conducted to test the feasibility of reducing drilling noise through proper control of the drilling operation. In the drilling tests, drilling parameters (penetration rate and rotational rate) were controlled within the allowable ranges. Different sizes and shapes of drill steels and different sizes of drill bits were used to study the effect of drill steel and bit on reducing drilling noise. The collected laboratory results were then analyzed for the development of drilling control technology.

\subsection{Development of drilling strategy}

Wasted energy not only causes excessive heat and drill bit wear, but also produces noise and fine dust. Noise and bit wear become serious problems when drilling into hard rock. As observed in the field, bolter operators tend to increase the rotational rate and reduce the penetration rate when drilling hard rocks. Such action will result in reduced bite depth (penetration per revolution), thus increasing the wasted energy and making the drilling operation noisier.

Drilling noise is inversely proportional to drilling energy efficiencies. Therefore, it is important to improve the drilling energy efficiency for noise reduction. The following three factors to improve energy efficiency should be considered in developing the drilling strategy:

Proper bit design and selection. Drill bits for roof bolting operations come in different sizes and designs. Using different bits on the same rock can result in different drilling energy efficiency. When the bit body begins to rub the rock, the energy efficiency 
will decrease considerably. To design or select proper drill bits based on the dominant rock types in the roof bolting horizon would be beneficial in maintaining a good drilling efficiency and lowering the drilling noise.

Properly selected drilling bite depth to match the rock layers. Higher bite depth, using lower rotational but higher penetration rates, normally results in a lower drilling specific energy, as shown Figure 3.3, and possibly in a lower drilling noise. Since high drilling noise normally occurs when hard rock is drilled, proper control of the rotational and penetration rates for drilling hard rock could be the best strategy to reduce drilling noise. In determining the proper bite depth, the available input energy, the maximum allowable thrust and drill steel strength should all be considered.

Proper management of bit usage to avoid excessive bit wear. Use of excessively worn drill bits would greatly reduce the efficiency of drilling energy and, thus, increase drilling noise. Changing drill bits at the proper time could also be a means to reduce drilling noise in addition to improving productivity and economics.

\subsection{Design of experimental setup}

The drilling experiments were conducted in the drilling laboratory of $\mathrm{J}$. H. Fletcher \& Company in Huntington, WV (Figure 4.1). The drilling laboratory room is a partially partitioned space in a large workshop. The drilling system developed by J. H. Fletcher consists of a set of sensors (Figure 4.2), a drill control unit and a head for a drill. The drill control unit acquires the drilling parameters including torque, thrust, rotation rate, rotation pressure, feed pressure, and hole depth and stores them to a computer in real-time. The drilling parameters, penetrate rate and rotational rate, can be preset in the drill control unit which then automatically operates the drill to achieve and maintain the 
preset penetration rate and rotational rate. The test block is held and firmly fixed at the top of the test frame with the help of the frame and the four steel chains. The rotary drill is firmly clamped at the bottom on the floor. The tests were conducted on medium compressive strength media (8,000-10,000 psi), cement block of $3 \mathrm{ft}$ width, $3 \mathrm{ft}$ length and $5 \mathrm{ft}$ height.

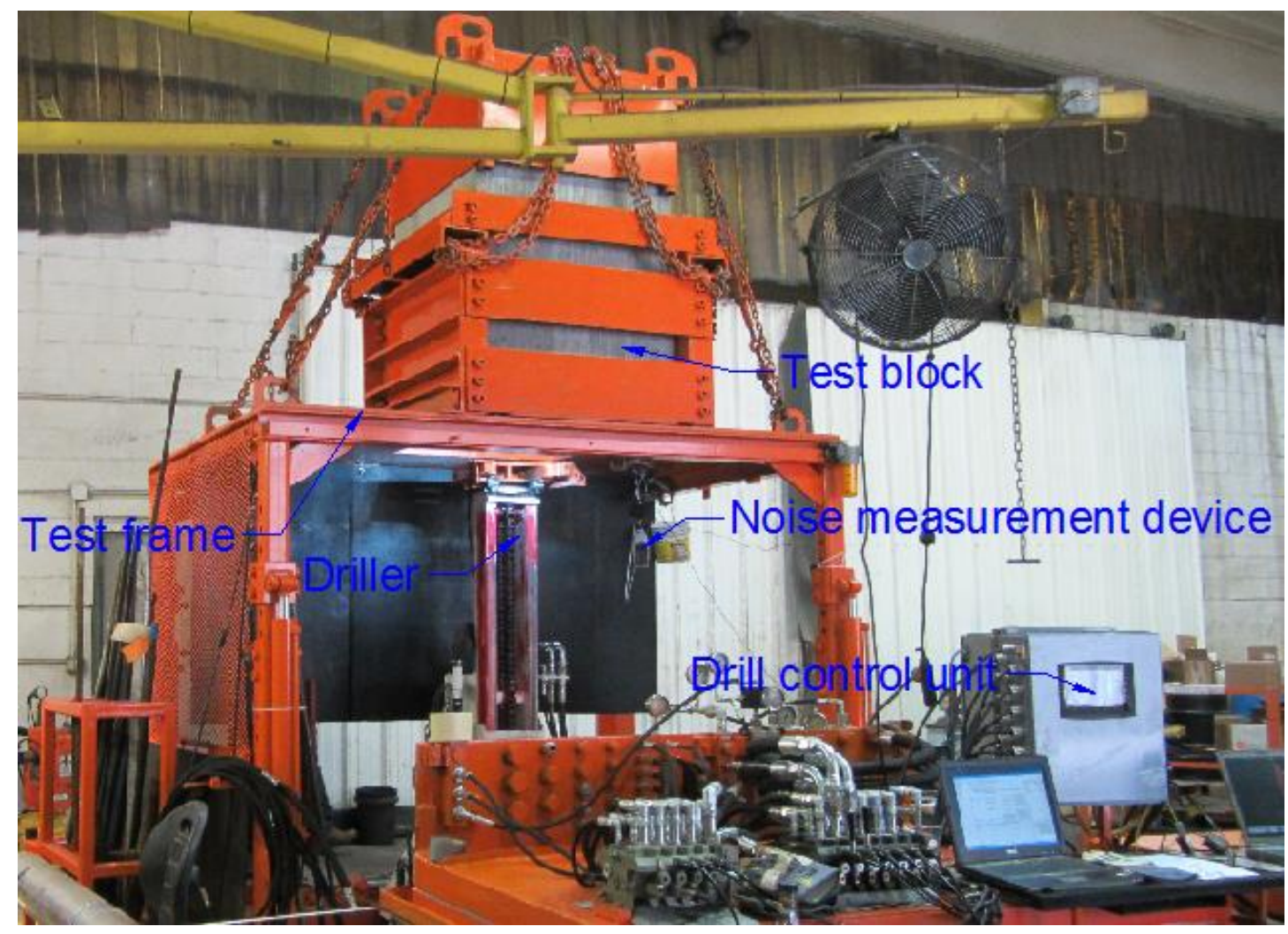

Figure 4.1 Experimental setup of the drilling noise study 


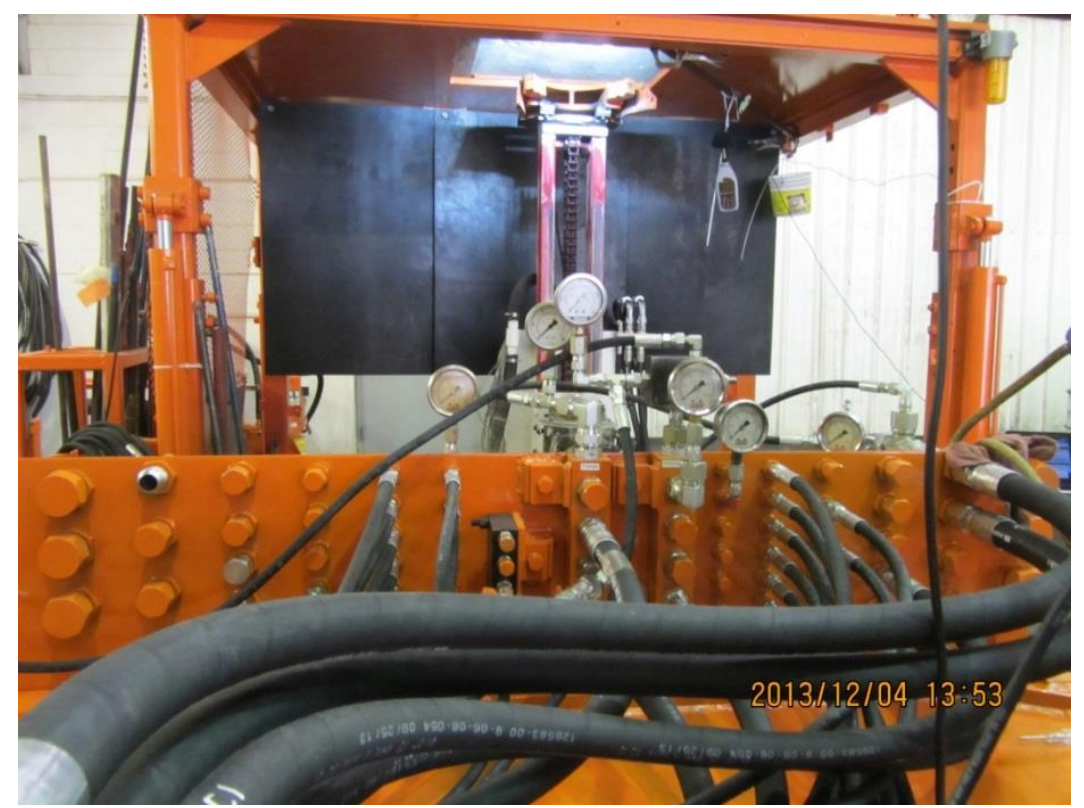

Figure 4.2 Pressure gages of drilling system

\subsection{Methodology}

\subsubsection{Drill steels and drill bits}

A set of drilling tests were conducted on a cement block to study the characteristics of the drilling noise from the roof drilling operation. The drill steels and bits used in the tests were standard roof bolt drill steels and bits designed for underground coal mines. In order to study the factors on drilling noise, three different types of drill steels, 7/8-in round, 7/8-in hexagon, and 1-1/8-in hexagon and two different size drill bit, 7/8-in and 1-3/8-in, were used. The drill bits used in the 7/8-in round and 7/8-in hexagon drill steels were the same, which were 7/8-in diameter drill bits. These two types of drill steel and drill bit combinations produced 1-in diameter holes. The larger bits used in the 1-1/8-in drill steels were 1-3/8-in in diameter bit and produced 1-3/8-in diameter holes (Figure 4.3). The bits are carbide insert drag bits designed primarily for coal-bearing 
sequence rocks (Figure 4.4). The reason to select these sizes and designs was their widespread use in the underground coal mining industry.

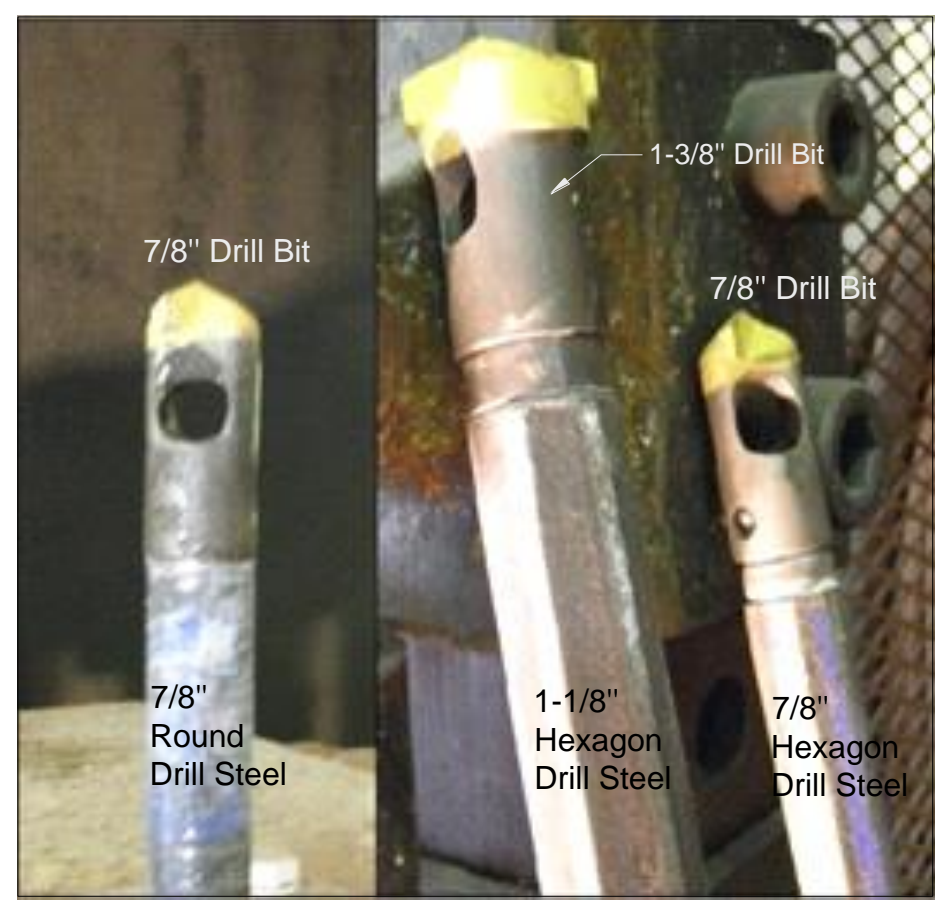

Figure 4.3 Drill steels and drill bits used in the test

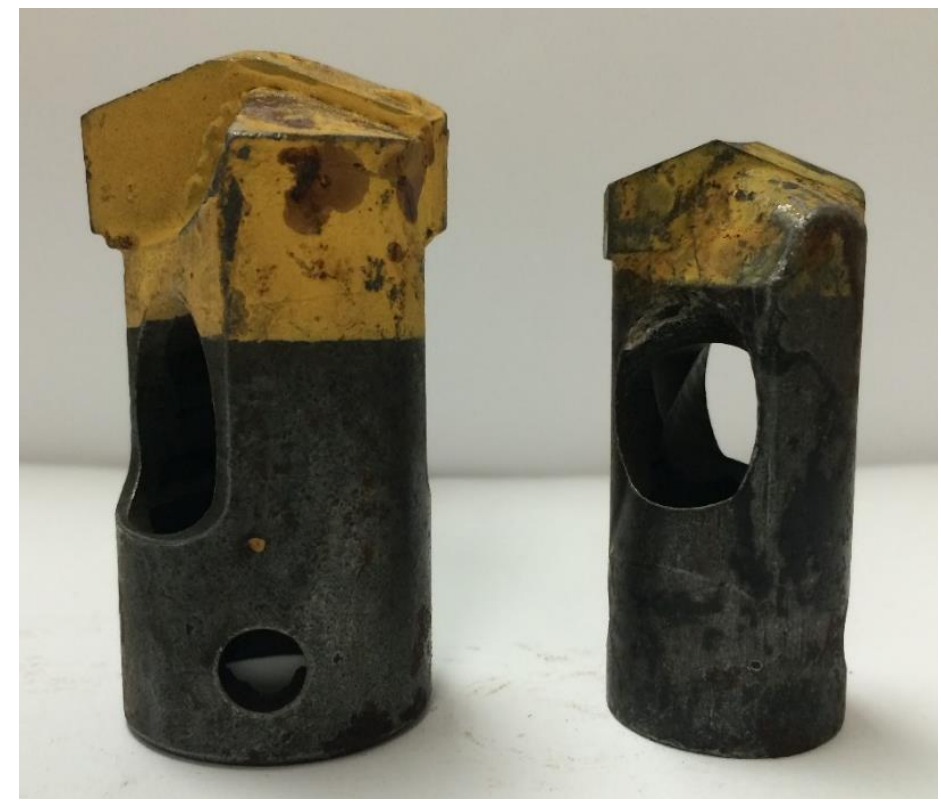

Figure 4.4 Drill bits used in the test (left: 1-3/8-in, right: 7/8-in) 


\subsubsection{Drilling control parameters}

4 sets of drilling tests were conducted in the drilling laboratory. The penetration rate and rotational rate were set at different levels in each test. The drilling penetration rate was set between 0.3 and $2.8 \mathrm{in} / \mathrm{sec}$ and rotational speed ranges from 300 and $600 \mathrm{rpm}$ for each drill steel and bit combination. The penetration rate and rotational rate were selected based on the hydraulic power limit of the drilling control unit. The drilling control parameters display is showing in Figure 4.5.

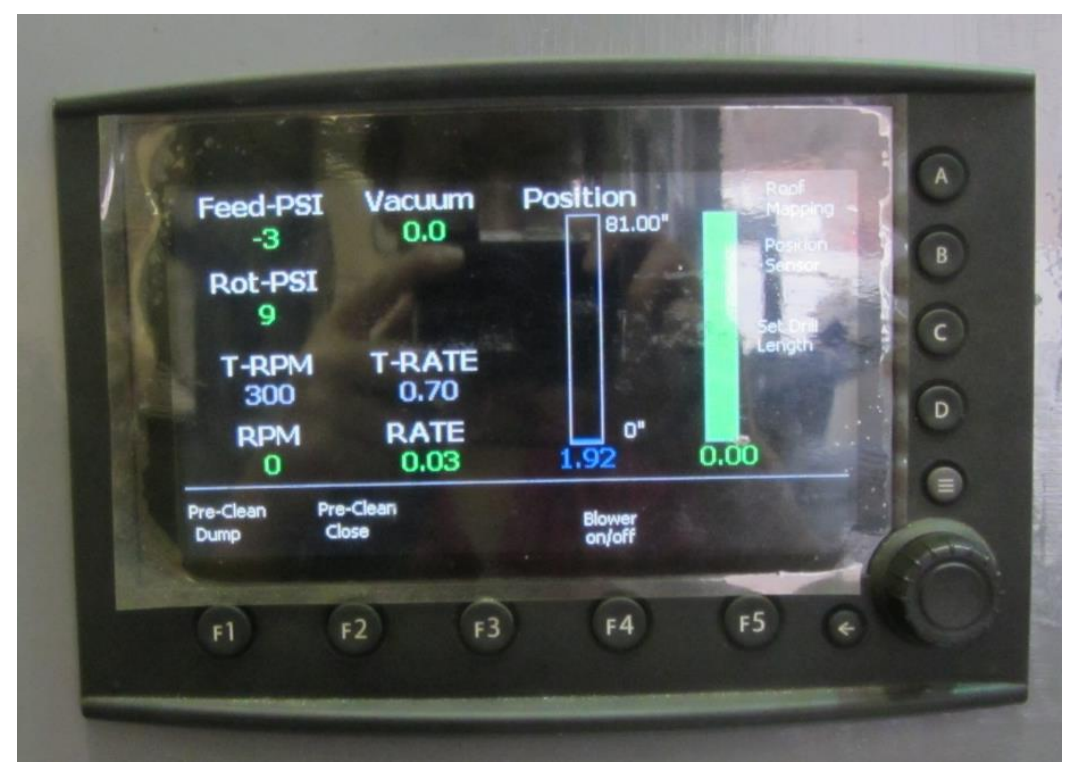

Figure 4.5 Drilling parameters display panel

The first set of experiments was used to test the feasibility of controlling the drilling parameters to reduce drilling noise. In order to find a rational range of drilling parameters, the bite depths were preset into a wide range, which was between 0.03 and $0.56 \mathrm{in} / \mathrm{rev}$. The penetration rate for the first set varied at three levels $0.3,1.3$ and 2.8 $\mathrm{in} / \mathrm{sec}$ and the rotational rate was preset at 300, 400, and $600 \mathrm{rpm}$ for each drill steel and bit combination. A complete batch of tests for a set of steel-bit combinations should 
include nine holes to be drilled as it included three penetration rates and three rotational rates. Therefore, a complete experimental set consists of 27 tests. Due to some failed tests, a total of 31 holes were drilled in the first set of tests.

The bit depth for the second set of tests was still preset at relatively wide range to confirm the results of the first set of tests was correct. The bite depth in the second set of tests was between 0.05 to $0.50 \mathrm{in} / \mathrm{rev}$. The penetration rate was preset at three different levels of $0.5,2.0$, and $2.5 \mathrm{in} / \mathrm{sec}$. The rotational rate was preset the same as that in the first set of test, which was 300, 400, and $600 \mathrm{rpm}$. Due to the limited power of the thrustgenerating motor used in the second set of tests, the machine was unable to drill holes with 1-1/8-in drill steel at the highest penetration rate of $2.5 \mathrm{in} / \mathrm{sec}$. A total of 30 holes were drilled in the second set of tests including 24 effective holes and 6 failed holes.

In the third and fourth tests, the drilling parameters were set to a relatively narrower, but more rational range based on the noise generation and energy efficiency calculation from the first two tests. The details of the test results will be discussed in next chapter. In the third test, the rotational rate was set at 300, 400, 500 and $600 \mathrm{rpm}$ and the penetration rate was preset at $0.7,1.0,1.2$ and $1.6 \mathrm{in} / \mathrm{sec}$. In the fourth test, the rotational rate was preset at 350, 400, 500, and $550 \mathrm{rpm}$, and the penetration rate varied at 0.6, 1.1, 1.4 , and $1.7 \mathrm{in} / \mathrm{sec}$. To ensure the bite depth was more reasonable, the drilling penetration and rotational rate combination of the lowest rotational rate with highest penetration rate and the highest rotational rate with lowest penetration rate were not drilled. The bite depth was set in the range of 0.08 to $0.24 \mathrm{in} / \mathrm{rev}$ for the third set of tests, and 0.09 to 0.20 in/rev for the fourth set of tests. The drilling parameters for the four sets of tests are shown in Table 4.1. 
Each test begins when the drill bit has just drilled into the drill medium and ends when the drill steel reaches the end. The duration of each test varied from 25 seconds to 300 seconds depending on the preset penetration rate of drilling.

Table 4.1 Preset drilling parameters

\begin{tabular}{|c|c|c|c|c|c|}
\hline & \multirow[t]{3}{*}{ Preset RMP } & \multicolumn{4}{|c|}{ Preset Penetration Rate, in/sec } \\
\hline \multirow{5}{*}{ 1st Set } & & 0.3 & 1.3 & 2.8 & \\
\hline & & \multicolumn{3}{|c|}{ Bite Depth } & \\
\hline & 300 & 0.06 & 0.26 & 0.56 & \\
\hline & 400 & 0.05 & 0.20 & 0.42 & \\
\hline & 600 & 0.03 & 0.13 & 0.28 & \\
\hline \multirow{6}{*}{ 2nd Set } & & \multicolumn{4}{|c|}{ Preset Penetration Rate, in/sec } \\
\hline & & 0.5 & 2.0 & 2.5 & \\
\hline & \multicolumn{5}{|c|}{ Bite Depth } \\
\hline & 300 & 0.10 & 0.40 & 0.50 & \\
\hline & 400 & 0.08 & 0.30 & 0.38 & \\
\hline & \multirow[t]{2}{*}{600} & 0.05 & 0.20 & $0.25^{*}$ & \\
\hline \multirow{7}{*}{ 3rd Set } & & \multicolumn{4}{|c|}{ Preset Penetration Rate, in/sec } \\
\hline & & 0.7 & 1.0 & 1.2 & 1.6 \\
\hline & & \multicolumn{4}{|c|}{ Bite Depth } \\
\hline & 300 & 0.14 & 0.20 & 0.24 & - \\
\hline & 400 & 0.11 & 0.15 & 0.18 & 0.24 \\
\hline & 500 & 0.08 & 0.12 & 0.14 & 0.19 \\
\hline & 600 & - & 0.10 & 0.12 & 0.16 \\
\hline & & \multicolumn{4}{|c|}{ Preset Penetration Rate, in/sec } \\
\hline \multirow{6}{*}{ 4th Set } & & 0.6 & 1.1 & 1.4 & 1.7 \\
\hline & & \multicolumn{4}{|c|}{ Bite Depth } \\
\hline & 350 & 0.10 & 0.19 & - & - \\
\hline & 400 & 0.09 & 0.17 & 0.21 & - \\
\hline & 500 & - & 0.13 & 0.17 & 0.20 \\
\hline & 550 & - & 0.12 & 0.15 & 0.19 \\
\hline
\end{tabular}

Note:

* not available on 1-1/8 hexagon drill steel due to hydraulic limitation. 


\subsubsection{Noise measurement}

In the tests, three different sets of noise measuring devices were used: a $3 \mathrm{M}$ SoundPro SP DL-2-1/1 Sound Level Meter (SLM), a Mectronic NoisePro Personal Noise Dosimeter and a PC-microphone sound recording system as shown in Figure 4.6.

The SounPro sound level meter meets the (International Electrotechnical Commission) IEC 61672-1(2002) - Electro Acoustics - Sound Level Meters - part 1: Specifications/ Class 2 . The sound pressure level data can be logged every 1 second. Both the octave band sound level and A-weighted sound level (dBA) can be measured directly from the sound level meter, as shown in Figure 4.7. The A-weighting is chosen because it most closely approaches the way human ears receive and perceive sound pressures.

The noise dosimeter measures the total noise exposure over the testing period of drilling each hole based on the MSHA noise dose standard (90 dBA criterion level, 5-dB exchange rate and an eight-hour working shift). The PC-microphone sound recording system records sound during drilling with a high-fidelity microphone, and the sound segments can thus be analyzed with a sound analyzer program in Matlab. 


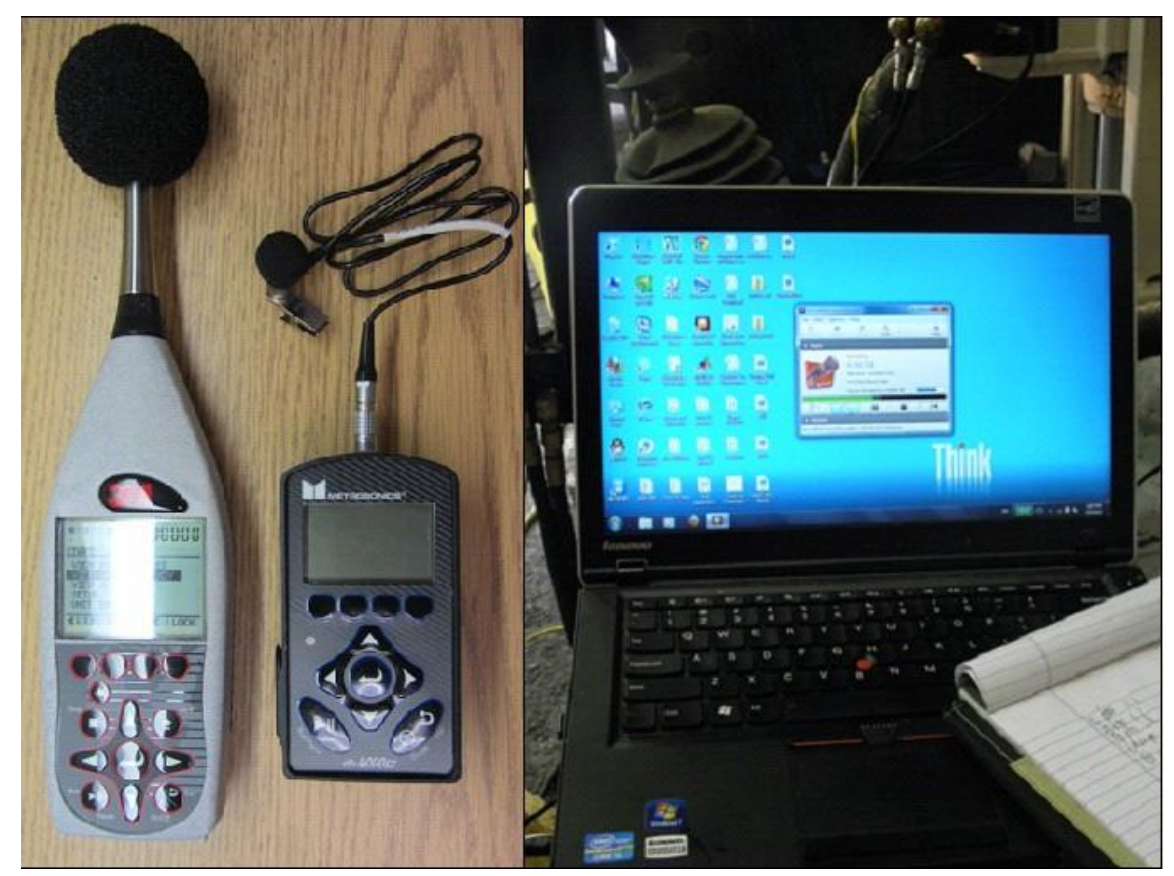

Figure 4.6 Sound Level Meter, Noise Dosimeter, and PC Sound Recording System (left to right) used in noise measurements

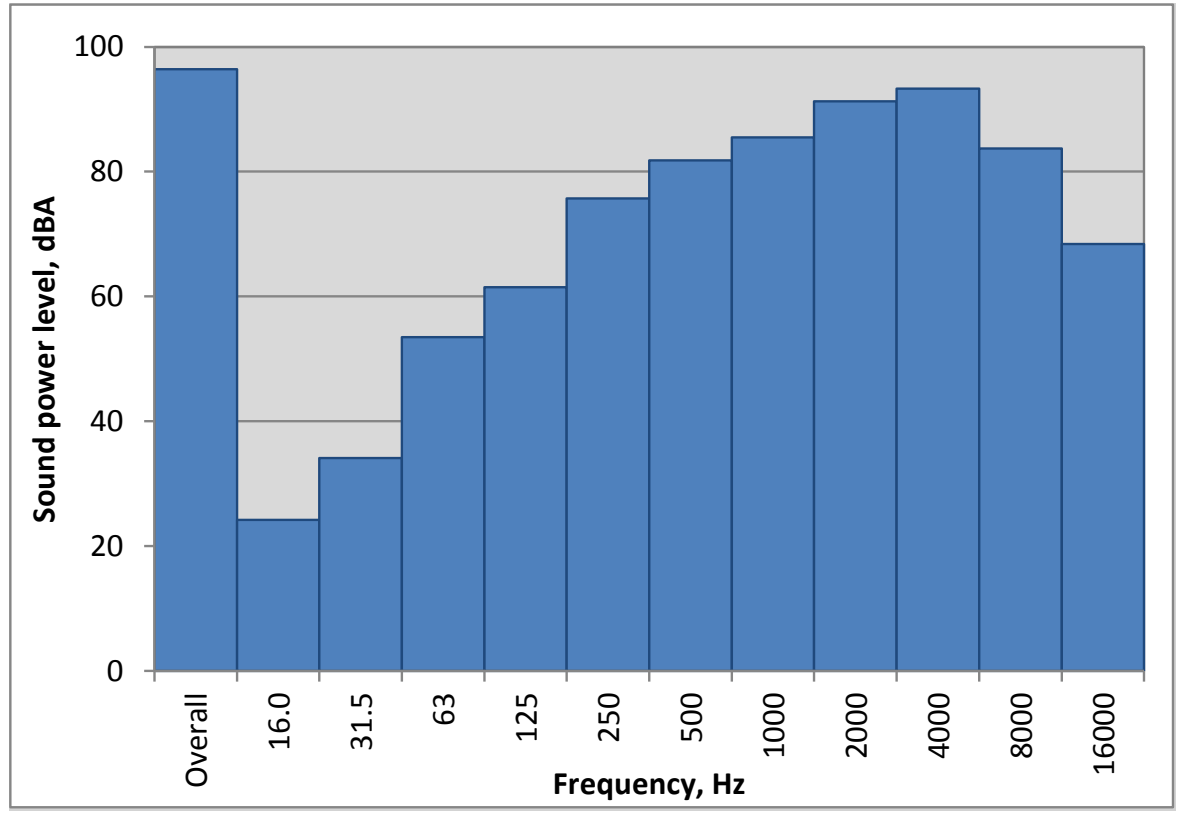

Figure 4.7 Reading from Sound Level Meter 
Since the sound level is a function of distance from its source, the microphones of the three noise measuring devices were hung on the test frame about 5'4" above the floor level and about 1' below the mouth of the drill holes. Laterally, the microphones are about 2' away from the center of the bolt holes. The placement of the microphones corresponds to the approximate ear position of the roof bolting operator when drilling.

\subsubsection{Temperature measurement}

Also, A MSA EVOLUTION® 5600 Thermal Imaging Camera (Figure 4.8) is used to measure the temperatures of the drill bit immediately before and after drilling a bolt hole.

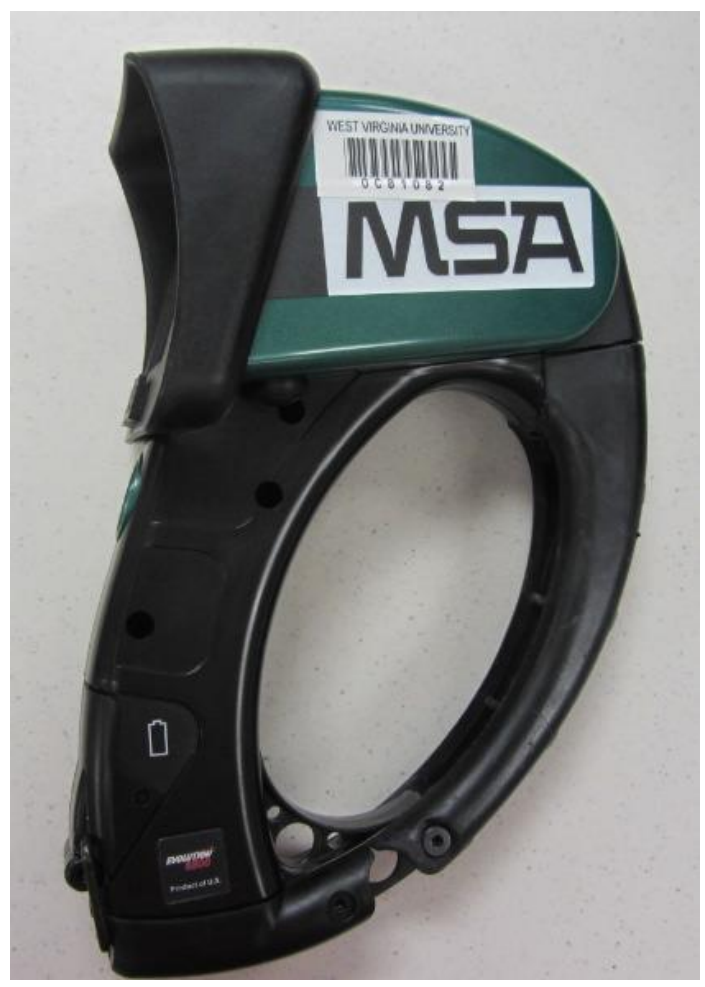

Figure 4.8 Thermal imaging camera used in noise measurement 


\subsubsection{Drill dust collection}

In order to study the effect of drilling control on reducing drill dust, dust samples from the drilled holes were collected in the fourth set of tests. The drilled holes were flushed using the internal vacuum system on the roof bolter and rock cuttings were removed through the inside of the hollow drill rods (Finfinger, 2003). The dust then went into the dust box of the dust collector system in a roof bolting machine. After the dust were dumped from the dust box into a plastic bucket, dust samples were collected. Dust was dumped after drilling several holes. These holes were drilled at close bite depths. The average bite depth in each group is $0.10,0.13,0.16$, and $0.20 \mathrm{in} / \mathrm{rev}$. 


\section{CHAPTER 5 EXPERIMENT RESULTS AND ANALYSIS}

\subsection{Drilling data collection}

The data collected from the drilling control system on the roof bolter were recorded on a computer. The data were collected in terms of sensor outputs then converted to engineering units. The drilling control system was able to collect the data into a spreadsheet for further handling and analysis of the data. An example of the data from the drilling control unit is shown in Table 5.1.

Table 5.1 Raw data collected from the roof bolter control system

\begin{tabular}{|c|c|c|c|c|c|c|c|c|}
\hline $\begin{array}{c}\text { Time } \\
{[\mathrm{ms}]}\end{array}$ & $\begin{array}{c}\text { Feed } \\
\text { PSI } \\
{[\text { PSI }]}\end{array}$ & $\begin{array}{c}\text { Velocity } \\
\text { Butterworth } \\
\text { Filter 2 } \\
{[\mathrm{in} / \mathrm{sec}]}\end{array}$ & $\begin{array}{c}\text { RPM } \\
\text { Sensor } \\
{[\text { RPM] }]}\end{array}$ & $\begin{array}{c}\text { Rotation } \\
\text { PSI [\%] }]\end{array}$ & $\begin{array}{c}\text { Vacuum } \\
\text { Sensor } \\
{[\%]}\end{array}$ & $\begin{array}{c}\text { Drill Position } \\
\text { Sensor Output } \\
{[\mathrm{mV}]}\end{array}$ & $\begin{array}{c}\text { Bite } \\
\text { Rate }\end{array}$ & Time \\
\hline 17450 & 559.03 & 0.30 & 297.01 & 427.08 & 5.26 & 11.99 & 0.06 & 13.54 \\
\hline 17500 & 566.53 & 0.29 & 297.01 & 434.56 & 5.29 & 11.99 & 0.06 & 13.54 \\
\hline 17550 & 560.53 & 0.29 & 295.62 & 468.21 & 5.26 & 12.01 & 0.06 & 13.54 \\
\hline 17600 & 580.79 & 0.28 & 295.62 & 456.99 & 5.30 & 12.01 & 0.06 & 13.54 \\
\hline 17650 & 546.27 & 0.27 & 297.01 & 419.60 & 5.35 & 12.01 & 0.05 & 13.54 \\
\hline 17700 & 571.79 & 0.27 & 295.62 & 451.76 & 5.32 & 12.02 & 0.05 & 13.54 \\
\hline 17750 & 588.29 & 0.27 & 297.01 & 424.08 & 5.39 & 12.02 & 0.05 & 13.54 \\
\hline 17800 & 592.05 & 0.27 & 295.62 & 473.45 & 5.40 & 12.02 & 0.06 & 13.54 \\
\hline 17850 & 613.06 & 0.28 & 294.22 & 469.71 & 5.38 & 12.02 & 0.06 & 13.54 \\
\hline 17900 & 621.31 & 0.29 & 295.62 & 406.13 & 5.45 & 12.03 & 0.06 & 13.54 \\
\hline 17950 & 647.57 & 0.29 & 295.62 & 403.14 & 5.45 & 12.03 & 0.06 & 13.54 \\
\hline 18000 & 645.32 & 0.30 & 295.62 & 459.24 & 5.45 & 12.03 & 0.06 & 13.54 \\
\hline 18050 & 598.05 & 0.31 & 295.62 & 434.56 & 5.51 & 12.03 & 0.06 & 13.54 \\
\hline 18100 & 580.79 & 0.31 & 295.62 & 461.48 & 5.51 & 12.05 & 0.06 & 13.54 \\
\hline 18150 & 581.54 & 0.32 & 294.22 & 456.99 & 5.51 & 12.05 & 0.06 & 13.54 \\
\hline 18200 & 590.55 & 0.32 & 294.22 & 442.78 & 5.53 & 12.07 & 0.07 & 13.54 \\
\hline 18250 & 579.29 & 0.32 & 294.22 & 461.48 & 5.62 & 12.07 & 0.07 & 13.54 \\
\hline 18300 & 580.04 & 0.32 & 294.22 & 436.05 & 5.57 & 12.07 & 0.07 & 13.54 \\
\hline 18350 & 581.54 & 0.33 & 294.22 & 452.51 & 5.65 & 12.07 & 0.07 & 13.54 \\
\hline
\end{tabular}


The above table presents approximately 1 second of drilling at a penetration rate of about $0.3 \mathrm{in} / \mathrm{sec}$ and rotational rate of about $300 \mathrm{rpm}$. From the above data set, the drilling parameters of thrust, torque, and hole depth were calculated based on the appropriate conversion factors. The specific energy consumed during drilling were calculated based on Teale's (1965) specific energy definition. The calculated drilling parameters and derived specific energy is shown as Table 5.2.

Table 5.2 Measured and calculated drilling parameters based on the raw data

\begin{tabular}{|c|c|c|c|c|c|c|c|c|}
\hline \multirow{2}{*}{ Time } & \multirow{2}{*}{$\begin{array}{c}\text { Drill } \\
\text { position }\end{array}$} & $\begin{array}{c}\text { Penetration } \\
\text { rate }\end{array}$ & \multirow{2}{*}{$\begin{array}{c}\text { Rotational } \\
\text { rate }\end{array}$} & Thrust & Torque & $\begin{array}{c}\text { By } \\
\text { thrust }\end{array}$ & $\begin{array}{c}\text { By } \\
\text { torque }\end{array}$ & Total \\
\hline ms & in & in/sec & rpm & lbs & in-lbs & lb/in & lb/in & lb/in $^{2}$ \\
\hline 8400 & 1.08 & 0.750 & 604 & 3,647 & 1,296 & 3,081 & 91,842 & 94,923 \\
\hline 8450 & 1.14 & 0.783 & 603 & 3,607 & 1,302 & 2,585 & 74,053 & 76,638 \\
\hline 8500 & 1.21 & 0.815 & 603 & 3,573 & 1,306 & 2,524 & 69,850 & 72,374 \\
\hline 8550 & 1.29 & 0.847 & 603 & 3,564 & 1,308 & 3,051 & 79,810 & 82,861 \\
\hline 8600 & 1.38 & 0.881 & 603 & 3,600 & 1,310 & 3,366 & 84,223 & 87,589 \\
\hline 8700 & 1.46 & 0.916 & 603 & 3,681 & 1,313 & 3,564 & 85,210 & 88,774 \\
\hline 8750 & 1.54 & 0.952 & 603 & 3,794 & 1,318 & 3,584 & 81,155 & 84,739 \\
\hline 8800 & 1.61 & 0.989 & 603 & 3,915 & 1,325 & 3,282 & 68,827 & 72,109 \\
\hline 8850 & 1.69 & 1.025 & 603 & 4,029 & 1,333 & 3,429 & 67,926 & 71,355 \\
\hline 8900 & 1.77 & 1.064 & 603 & 4,131 & 1,344 & 4,259 & 78,956 & 83,215 \\
\hline 8950 & 1.86 & 1.103 & 603 & 4,228 & 1,354 & 4,625 & 82,187 & 86,812 \\
\hline 9050 & 1.95 & 1.143 & 604 & 4,318 & 1,363 & 4,698 & 80,559 & 85,257 \\
\hline 9100 & 2.04 & 1.182 & 604 & 4,398 & 1,369 & 4,516 & 74,723 & 79,239 \\
\hline 9150 & 2.12 & 1.217 & 604 & 4,452 & 1,372 & 3,991 & 63,284 & 67,275 \\
\hline 9200 & 2.21 & 1.249 & 604 & 4,468 & 1,375 & 4,132 & 64,086 & 68,218 \\
\hline 9250 & 2.30 & 1.280 & 603 & 4,445 & 1,380 & 4,186 & 64,008 & 68,194 \\
\hline 9300 & 2.38 & 1.309 & 603 & 4,400 & 1,388 & 4,165 & 62,856 & 67,022 \\
\hline 9350 & 2.47 & 1.338 & 603 & 4,365 & 1,393 & 4,117 & 60,923 & 65,040 \\
\hline 9400 & 2.57 & 1.366 & 603 & 4,371 & 1,393 & 4,090 & 58,697 & 62,788 \\
\hline 9450 & 2.66 & 1.396 & 602 & 4,427 & 1,388 & 4,115 & 56,657 & 60,772 \\
\hline 9500 & 2.76 & 1.427 & 602 & 4,526 & 1,384 & 4,200 & 55,138 & 59,339 \\
\hline 9550 & 2.87 & 1.461 & 601 & 4,651 & 1,383 & 4,328 & 54,074 & 58,402 \\
\hline
\end{tabular}




\subsection{Background noise analysis}

The drilling laboratory is located in a partially partitioned large workshop. Normal machine building production was conducted in this workshop except for the lunch hour. Also a busy railroad is located within a short distance from the laboratory. Trains passed the site a number of times during the tests. Although the sound level was measured very close to the drill system, the background noise in the workshop due to machine construction and the passing trains affect the testing results to some degree. The background noise during non-drilling times was also measured or recorded occasionally. In order to eliminate the background noise effects, the measured background noise sources were analyzed. All measured noise data are corrected to a condition with background noise similar to the lunch hour. The measured sound power at a given time should consist of the sound powers produced by the machine and by the background noise. The corrected sound power $\left(W^{\prime}\right)$ and corrected sound power level $\left(L_{w}{ }^{\prime}\right)$ to the condition with lunch hour background noise can be determined using the following two equations.

$$
\begin{gathered}
W^{\prime}=W-\left(W_{B G}-W_{B 0}\right) \\
L_{W}{ }^{\prime}=10 \log _{10}\left(\frac{W^{\prime}}{W_{0}}\right)
\end{gathered}
$$

Where $\mathrm{W}$ is the measured sound power at a given time

$\mathrm{W}^{\prime}$ is the corrected sound power at a given time

$\mathrm{W}_{\mathrm{BG}}$ is the average sound power of a noisy background

$\mathrm{W}_{\mathrm{B} 0}$ is the average background sound power during the lunch hour

$\mathrm{L}_{\mathrm{w}}{ }^{\prime}$ is the corrected sound power level and $\mathrm{W}_{0}$ is $10^{-12}$ watts. 
Figure 5.1 shows the adjusted noise level data when drilling into three typical holes in the first set of tests. In these three tests, the drill steel used was $7 / 8$-in round. The preset rotational rate for these three tests was $400 \mathrm{rpm}$, while the preset penetration rates were $0.3,1.3,2.8 \mathrm{in} / \mathrm{sec}$, respectively. The corresponding bite depths are $0.045,0.195$, $0.420 \mathrm{in} / \mathrm{rev}$. It should be noted that the penetration rate of $2.8 \mathrm{in} / \mathrm{sec}$ was set too high, and it created a condition for the bit body to rub the rock. For all three tests, a high level of sound pressure level, which is higher than $100 \mathrm{dBA}$, was generated within the first two second of drilling. It was followed by a period of low noise at about $86 \mathrm{~dB}$ in each of the tests. Then, the sound pressure level increased to a relatively high level and remained at that level while drilling the remaining length of the hole. Occasional spikes of high sound power level above $100 \mathrm{dBA}$ occurred. The time-weighted average sound levels for the three tests were $90.8,91$, and $93.4 \mathrm{dBA}$. The time to complete drilling the three 39 inch long holes were 271, 40, and 25 second, respectively.

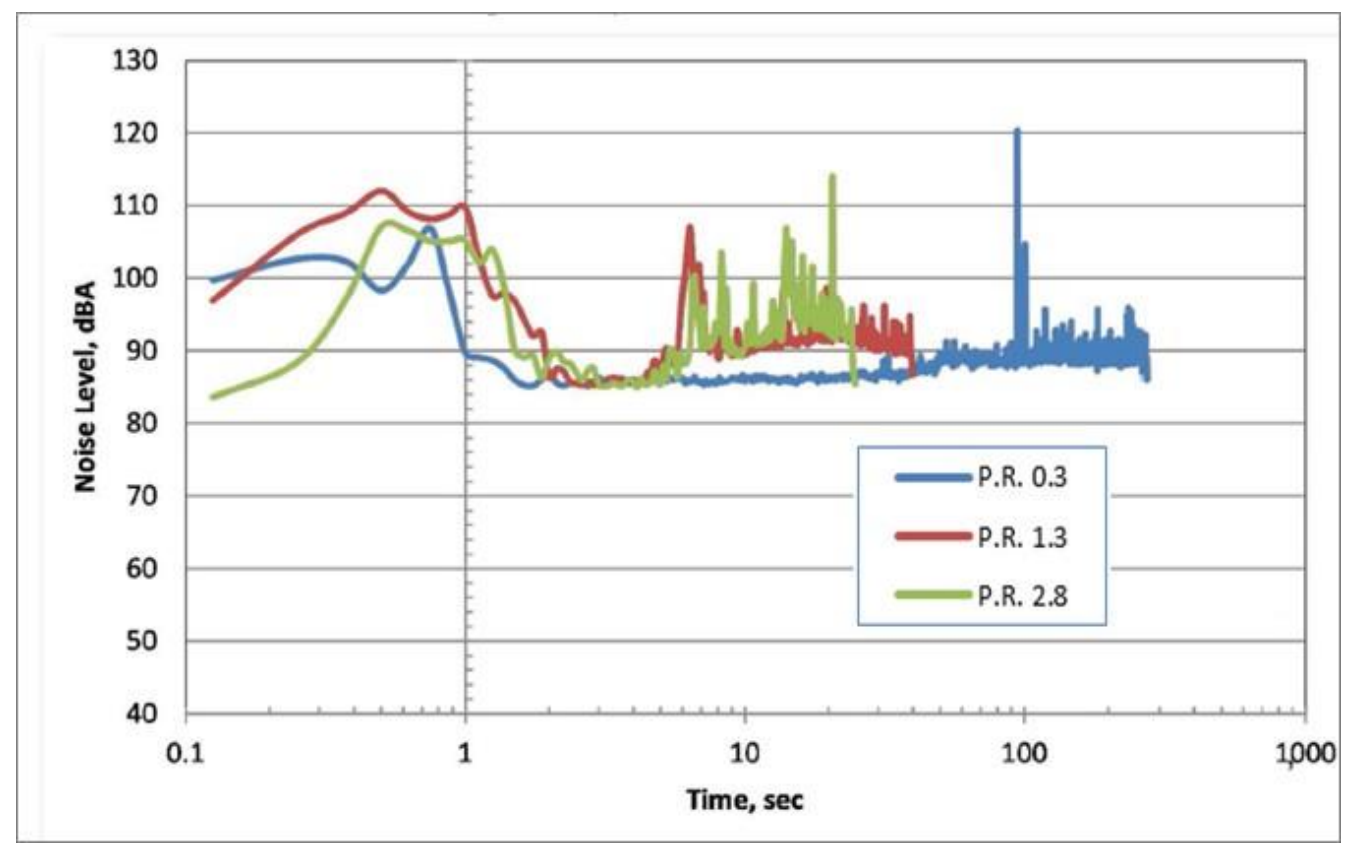

Figure 5.1 Typical measured sound pressure level 


\section{- Sound pressure level at difference location}

The location of the microphone of the noise measurement devices was placed to simulate the location of the operator's ear when drilling. In each set of tests, the distance between two adjacent holes was between 3 to 4 inches. As sound pressure level is a function of distance from the source, the different locations of the drilled holes on the testing block affected the test resulting to some degree. In order to eliminate the effects of holes locations, the sound pressure level was corrected to the same distance, which is about 2' from the microphone.

$$
L_{p 1}=L_{p 1}+20 \log \left(\frac{r_{2}}{r_{1}}\right)
$$

Where $L_{p 1}$ is the sound pressure level at location $1, \mathrm{dBA}$

$L_{p 2}$ is the sound pressure level at location $2, \mathrm{dBA}$

$r_{1}$ is the distance from the source at location $1, \mathrm{ft}$

$r_{2}$ is the distance from the source at location $2, \mathrm{ft}$

\section{- Noise dose}

The noise dose that considers both the sound level and the exposure time is an alternate, and even a better way to assess the effects of drilling noise on the bolter operator. The noise dose for drilling a bolt hole (D) is determined using Equation (5.4). It is derived based on the U.S Mine Safety and Health Administration (MSHA) noise dose standard which defines $90 \mathrm{dBA}$ as the criterion level, 5-dB exchange rate and an eighthour working shift. It should be noted that time $(\mathrm{t})$ and the drilling duration $(\mathrm{T})$ are 
measured in seconds (not hours). The resulting D is the calculated percent of the MSHA standard noise dose.

$$
D=100 \cdot \int_{0}^{\mathrm{t}_{10 l}} \frac{2^{\frac{L^{\prime}(t)}{5}}}{28,800} d t \%
$$

Where $\mathrm{D}$ is the noise dose for drilling a bolt hole, \%

$t_{\text {tol }}$ is the total duration time, second

$\mathrm{t}$ is time, second

$\mathrm{L}(\mathrm{t})$ is the sound pressure level at time $\mathrm{t}, \mathrm{dB}$

Figure 5.1 shows the average sound pressure level (SPL) for one set of three tests using 7/8-in round drill steel. The average sound power level for these three tests is 90.8 , 91.0, and 93.4 dBA, respectively. The calculated noise doses for drilling these holes were $1.129 \%, 0.322 \%$, and $0.215 \%$, respectively. The noise dose can be used to manage the noise compliance for the roof bolter operators. If a 50\% MSHA allowable noise dose is allocated for drilling the bolt holes, the previously determined doses indicate that 44,155 , and 232 holes can be drilled per eight-hour shift using the prescribed three drilling, respectively. The results are summarized in Table 5.3.

Table 5.3 A typical sample of noise dose

\begin{tabular}{c|c|c|c|c}
\hline $\begin{array}{c}\text { Test } \\
\text { No }\end{array}$ & $\begin{array}{c}\text { Avg. SPL } \\
(\mathrm{dBA})\end{array}$ & Time(s) & Dose & $\begin{array}{c}\text { Max. } \\
\text { holes/shift }\end{array}$ \\
\hline 1 & 90.8 & 271 & $1.13 \%$ & 44 \\
\hline 2 & 91 & 40 & $0.32 \%$ & 155 \\
\hline 3 & 93.4 & 25 & $0.22 \%$ & 232 \\
\hline
\end{tabular}




\subsection{Test results analysis}

As discussed before, the drilling control would be implemented by controlling the penetration rate and rotational rate. The optimization of drilling parameter would be the key for controlling drilling noise. To choose rational penetration rate and rotational rate, the following aspects were considered in the following section: the feasibility of the drilling system, the drilling sound level, noise dose, specific energy, and temperature differences of drill bits before and after drilling each hole.

\subsubsection{Feasibility to achieve preset controls}

As discussed previously, it is desirable to achieve a high drilling bite depth for the purpose of reducing drilling noise. However, whether it is feasible for the machine to achieve the preset bite depth depends on the rock strengths, available hydraulic powers and the stiffness of the drill steel. For understanding the feasibility, the achieved bite depths were compared with the preset bite depths for drilling these holes. Figure 5.2 shows a plot of the preset versus the actual bite depths with a $45^{\circ}$ line for the first two sets of drilling tests. The data on the $45^{\circ}$ line means the preset bite depth can be achieved while the data below the $45^{\circ}$ line indicates that the actual average bite depth is smaller than the preset bite depth in this test. It shows that the preset bite depth can be easily achieved when it is smaller than about $0.18 \mathrm{in} / \mathrm{rev}$. When the preset bite depth is higher than about $0.18 \mathrm{in} / \mathrm{rev}$, the actual achieved bite depth is smaller than the preset value, the higher the preset bite depth, the larger the differences between the achieved bite depth and preset bite depth. 
This maximum bite depth also correlates with the height of the tungsten carbide insert above the steel body of new drill bits. Drilling at a bite depth higher than the maximum bite depth could result in excessive rubbing actions between the bit body and the rock, along with low energy efficiency and high noise.

For the third and fourth sets of drilling tests, the bite depths are preset to a narrower and more achievable range between 0.08 and $0.24 \mathrm{in} / \mathrm{rev}$ based on the results from the first two sets of tests. The results show that the preset bite depth can be achieved easily in most of the third and fourth sets of tests (Figure 5.3). In the tests, when the bite depth is higher than $0.18 \mathrm{in} / \mathrm{rev}$, the achieved bite depth is slightly lower than the preset value.

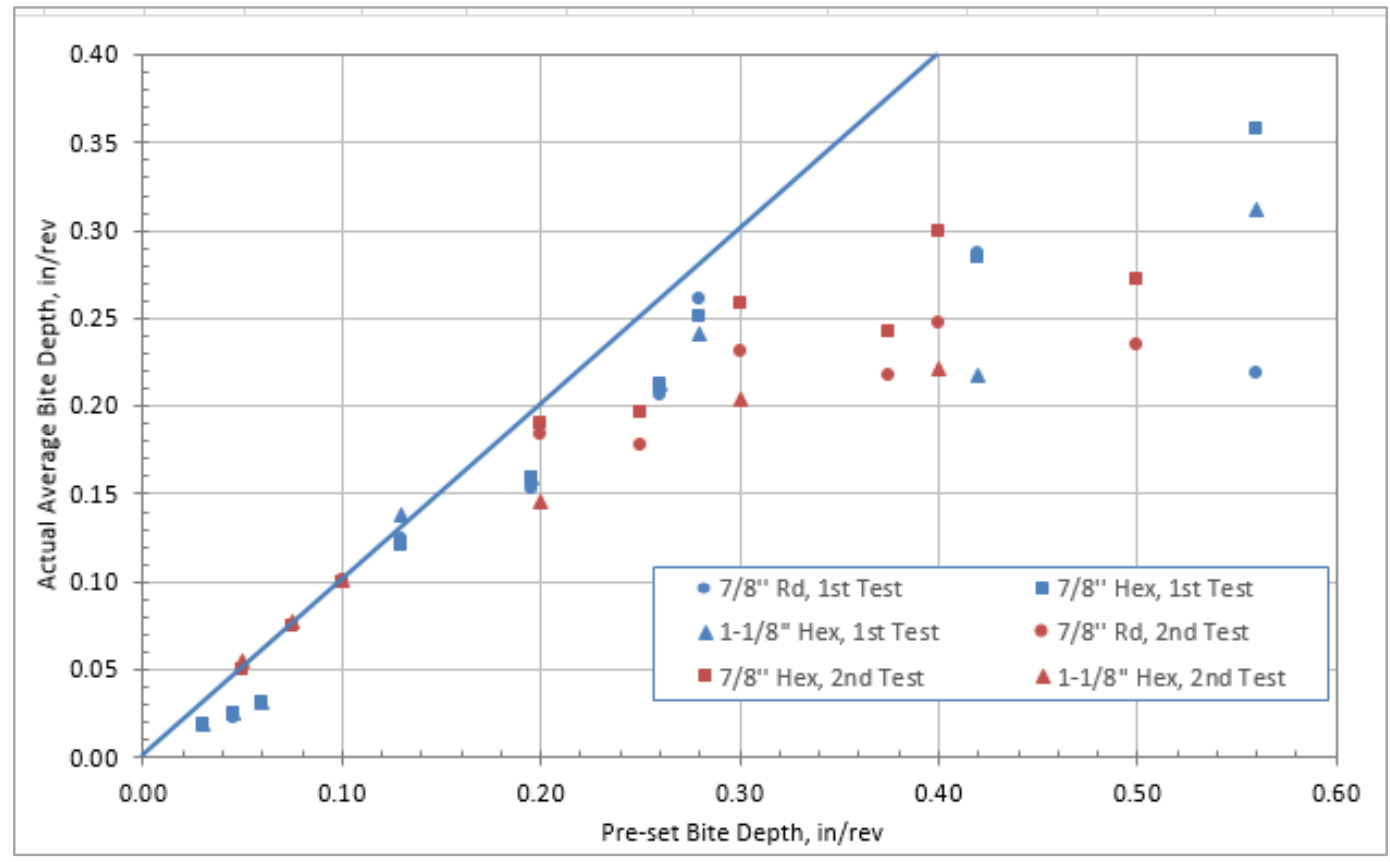

Figure 5.2 Preset versus achieved bite depth in the 1st and 2nd sets of drilling tests 


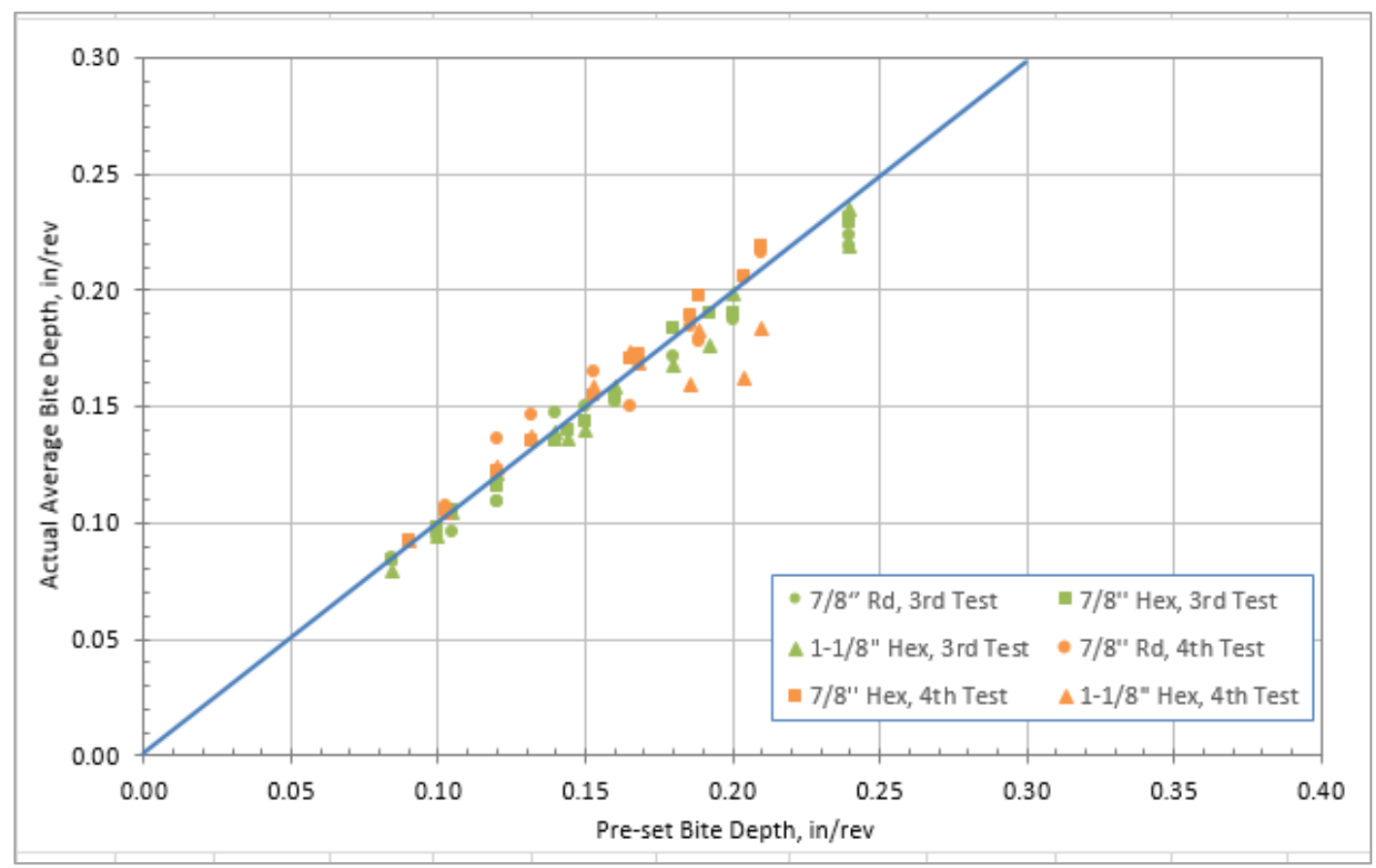

Figure 5.3 Preset versus achieved bite depth in the 3rd and 4th sets of drilling tests

\subsubsection{Average specific energy}

The calculated average specific energy are shown in Figure 5.4-5.7. The Figures show the testing results in these three batches using the different drill bit and steel combinations (e.g., 7/8' $\mathrm{Rd}$ means test using 7/8-in round drill steel). In each batch, the rotational rate was preset at a different value. In each group using the same rotational rate, the penetration rate was preset at different levels.

In the first set of tests, for each of the groups, the average specific energy shows considerable reductions as the penetration rate increases from 0.3 to $1.3 \mathrm{in} / \mathrm{sec}$. For example, in the tests utilizing 7/8 inch round drill steel drilling at rotational rate $400 \mathrm{rpm}$, the average specific energy with $0.3 \mathrm{in} / \mathrm{sec}$ penetration rate is about 5 times of that with $1.3 \mathrm{in} / \mathrm{sec}$. Some minor decreases are induced as the penetration rate further increases from 1.3 to $2.8 \mathrm{in} / \mathrm{sec}$. 
In the second set of tests, for each of the groups, the average specific energy shows some degree of reductions as the penetration rate increases from 0.5 to $2.0 \mathrm{in} / \mathrm{sec}$. No decreases in the specific energy are induced as the penetration rate increases from 2.0 to $2.5 \mathrm{in} / \mathrm{sec}$. For the third and fourth sets of tests, the penetration rates are preset at values between 0.6 and $1.7 \mathrm{in} / \mathrm{sec}$. In each of the groups using same rotational rate, the average specific energy shows some degree of decrease as the penetration increases.

For tests with the large bit-steel combination, the average specific energies are apparently lower than the tests with smaller bit-steel combinations. Among the tests using small drill bits but with different steel, the 7/8 inch bit on round steel and on hexagon steel produced similar specific energy. 


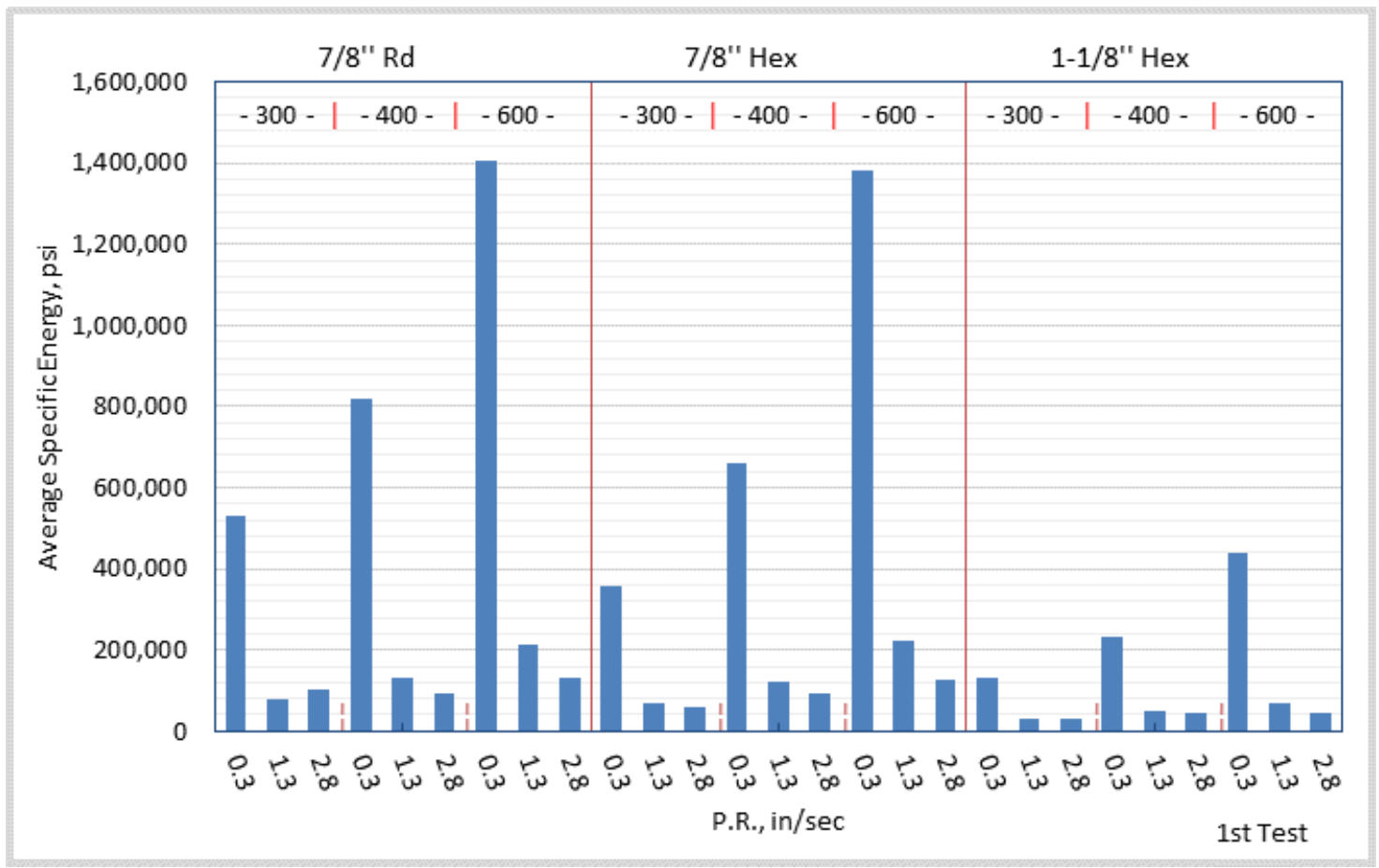

Figure 5.4 Average specific energy from the first set of drilling tests

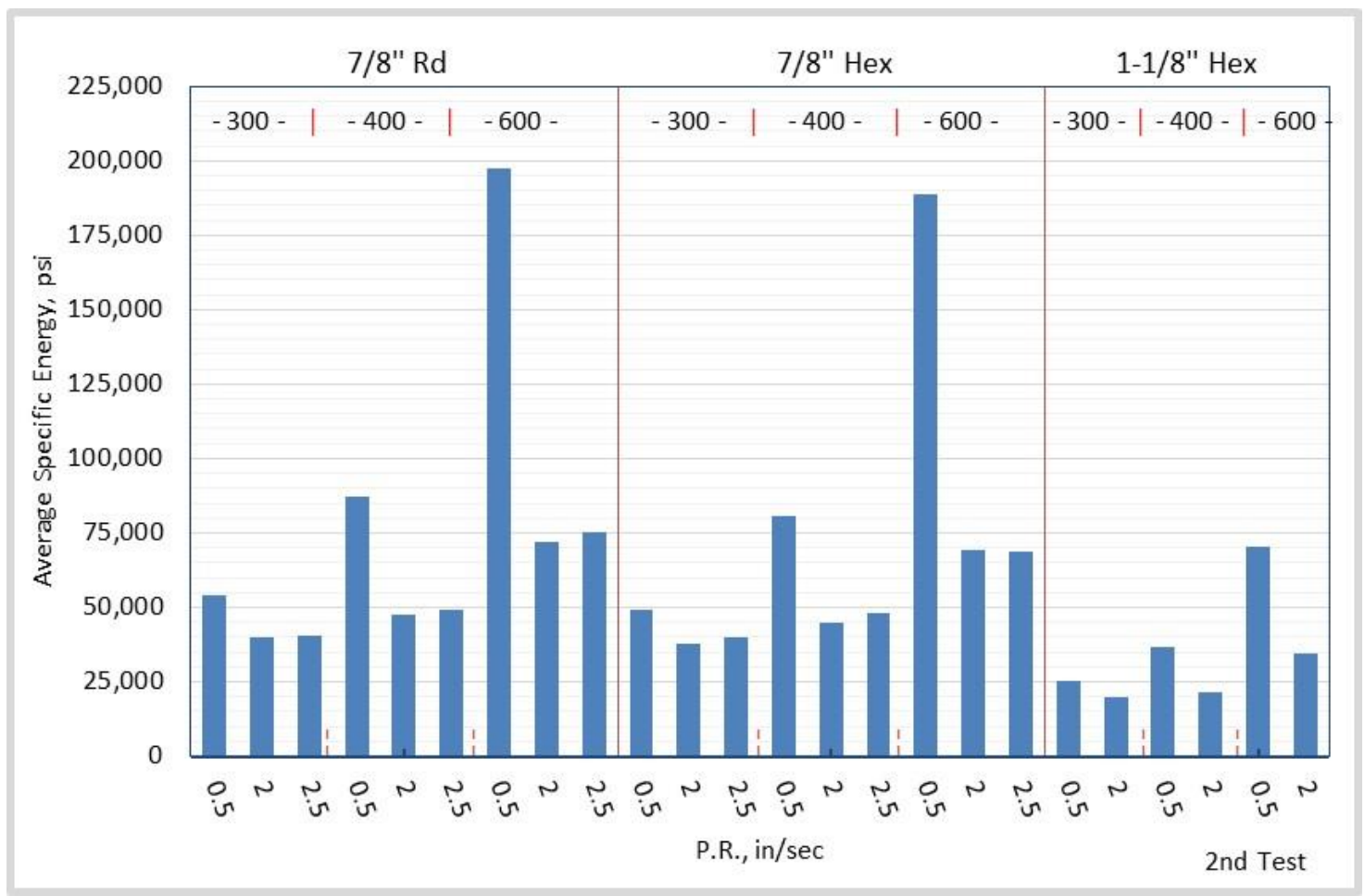

Figure 5.5 Average specific energy from the second set of drilling tests 


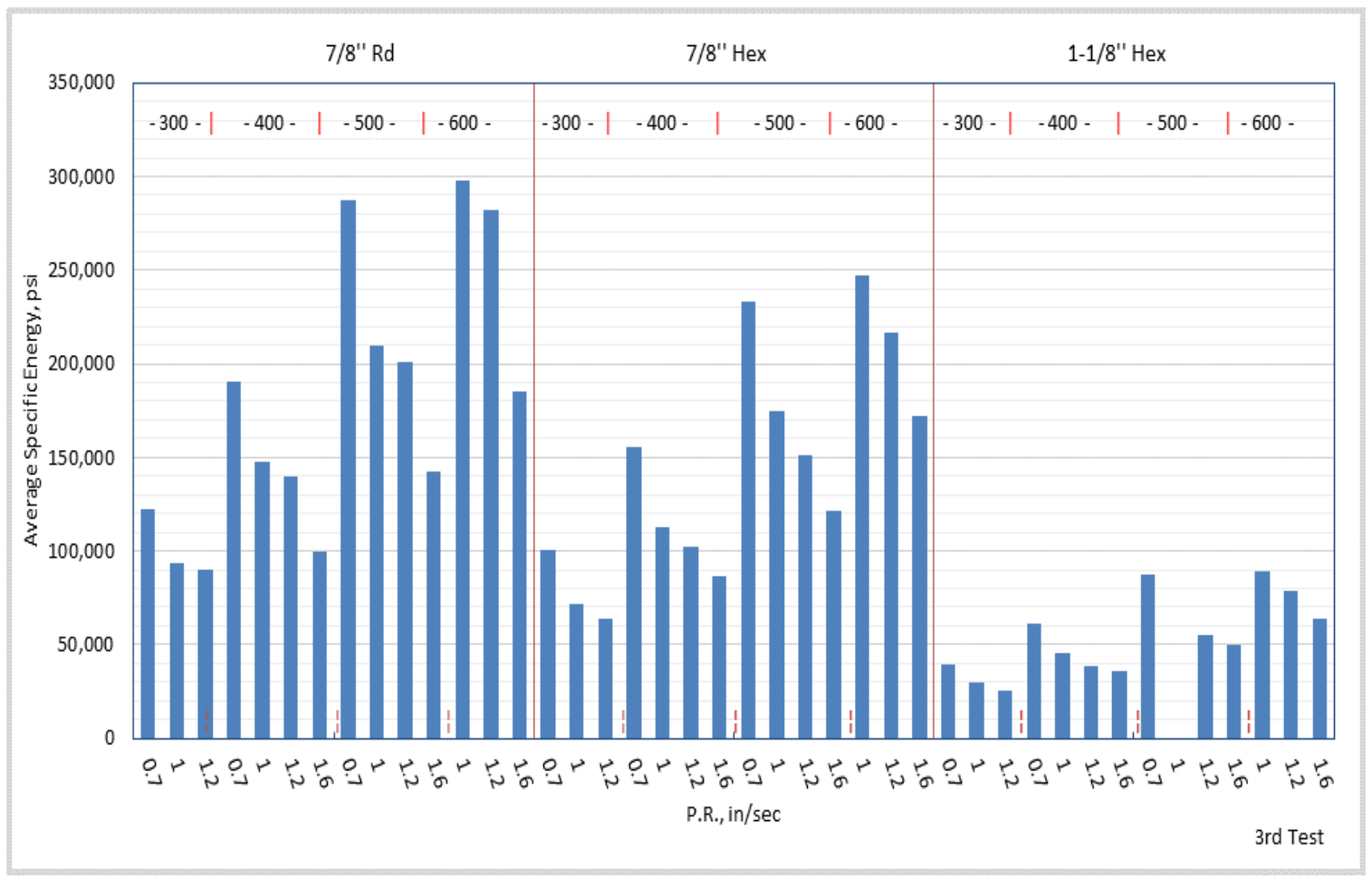

Figure 5.6 Average specific energy from the third set of drilling tests

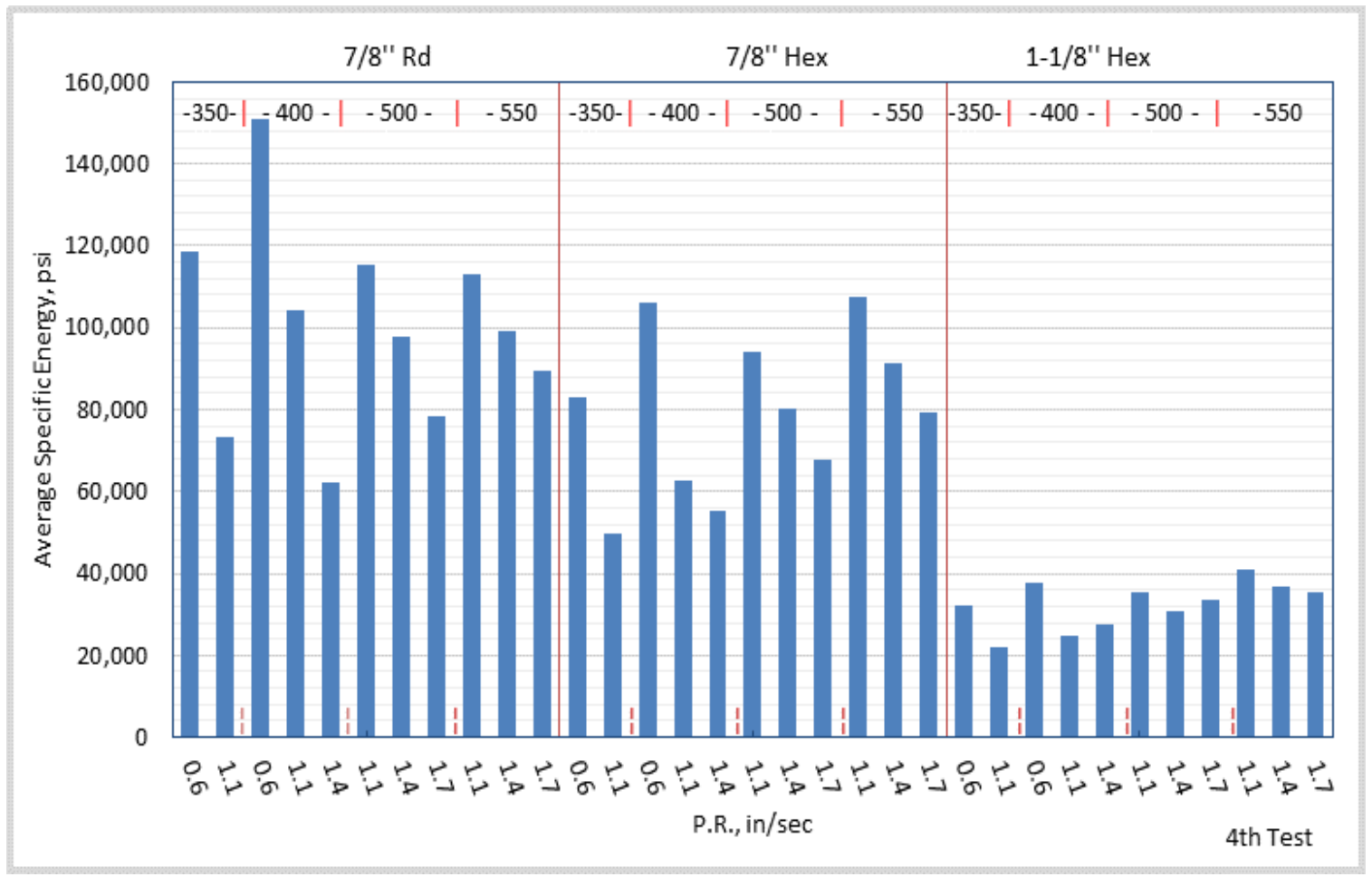

Figure 5.7 Average specific energy from the fourth set of drilling tests 


\subsubsection{Noise dose}

The noise dose shows a very similar trend as the average specific energy in each of the drilling tests as shown in Figures 5.8-5.11. In the first set of tests, for each of the groups, the noise dose shows considerable reductions as the penetration rate increases from 0.3 to $1.3 \mathrm{in} / \mathrm{sec}$. For example, in the tests utilizing $7 / 8$ inch round drill steel drilling at rotational rate $400 \mathrm{rpm}$, the noise dose for the $0.3 \mathrm{in} / \mathrm{sec}$ penetration rate is about $1.2 \%$. When penetration rate increased to $1.3 \mathrm{in} / \mathrm{sec}$, the noise dose reduced to $0.35 \%$. Some minor decreases in noise dose are induced when the penetration rate increased from 1.3 to $2.8 \mathrm{in} / \mathrm{sec}$.

However for tests using varying bit-steel combinations, the large bit-steel combination produced the higher noise dose than tests using smaller bit-steel combinations. Among the tests using small drill bits but with different steel, the 7/8 inch bit on round steel produced less noise dose than that produced by 7/8 inch bit on round drill steel. 


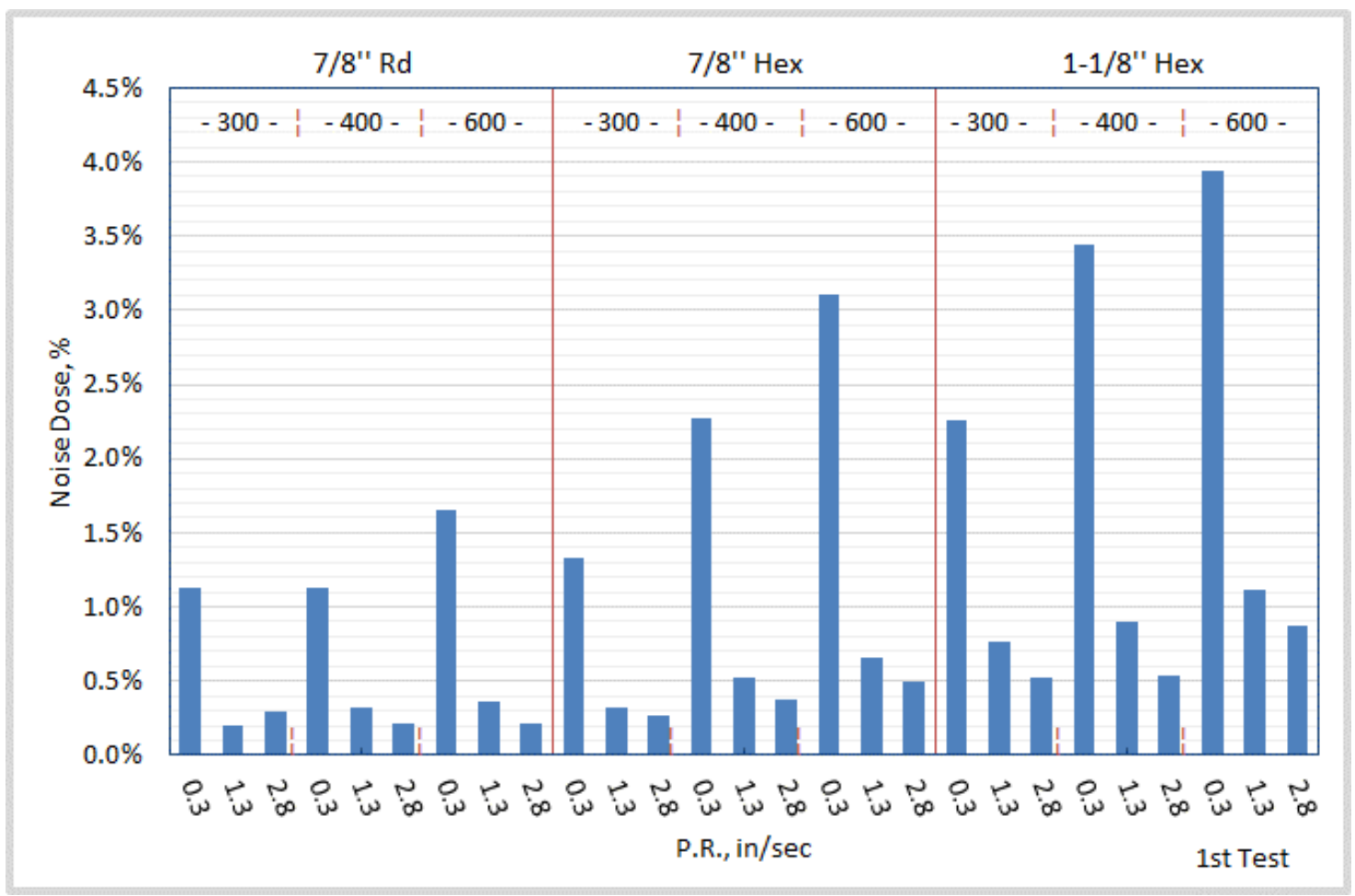

Figure 5.8 Noise dose from the first set of drilling tests

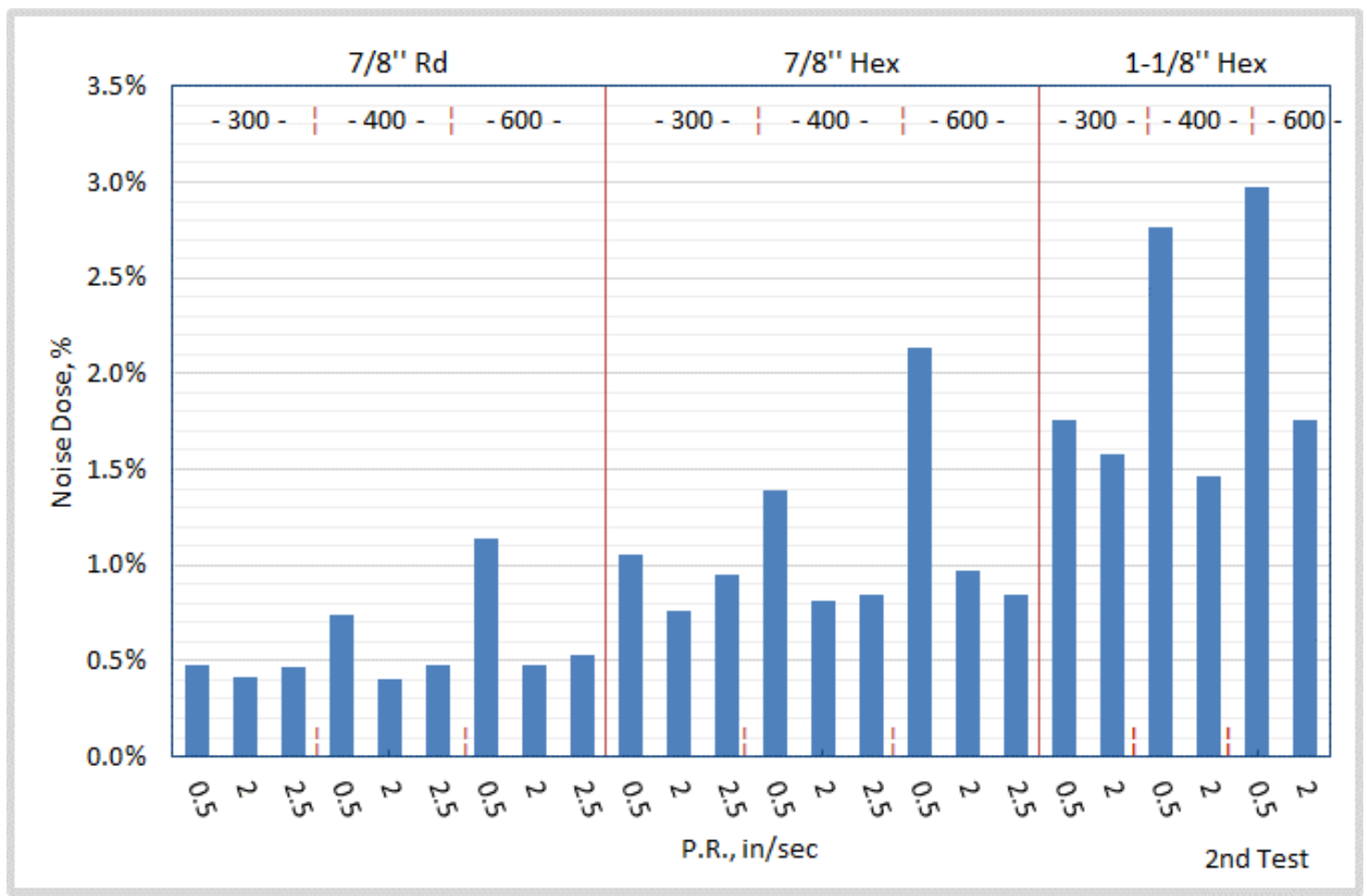

Figure 5.9 Noise dose from the second set of drilling tests 


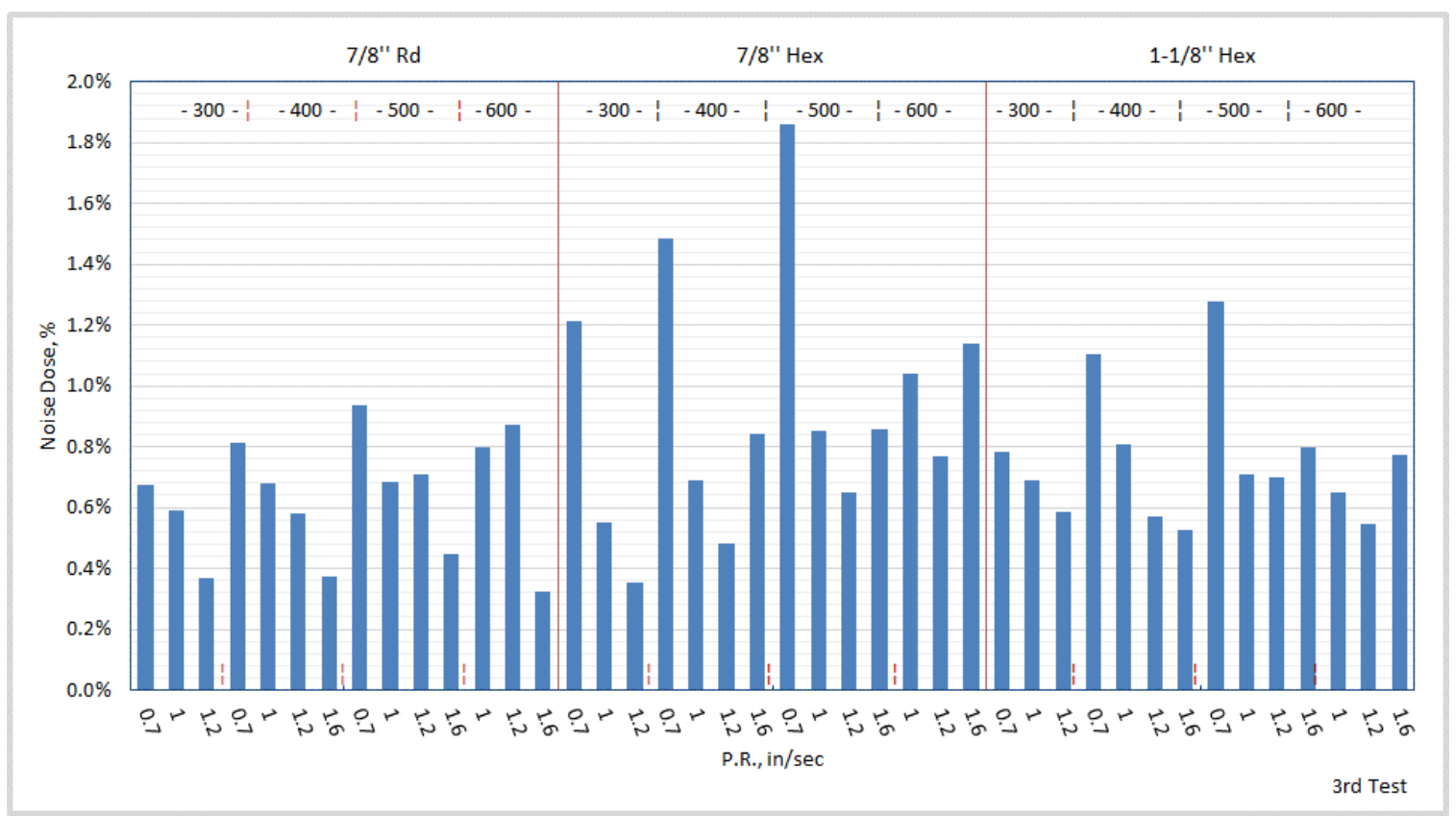

Figure 5.10 Noise dose from the third set of drilling tests

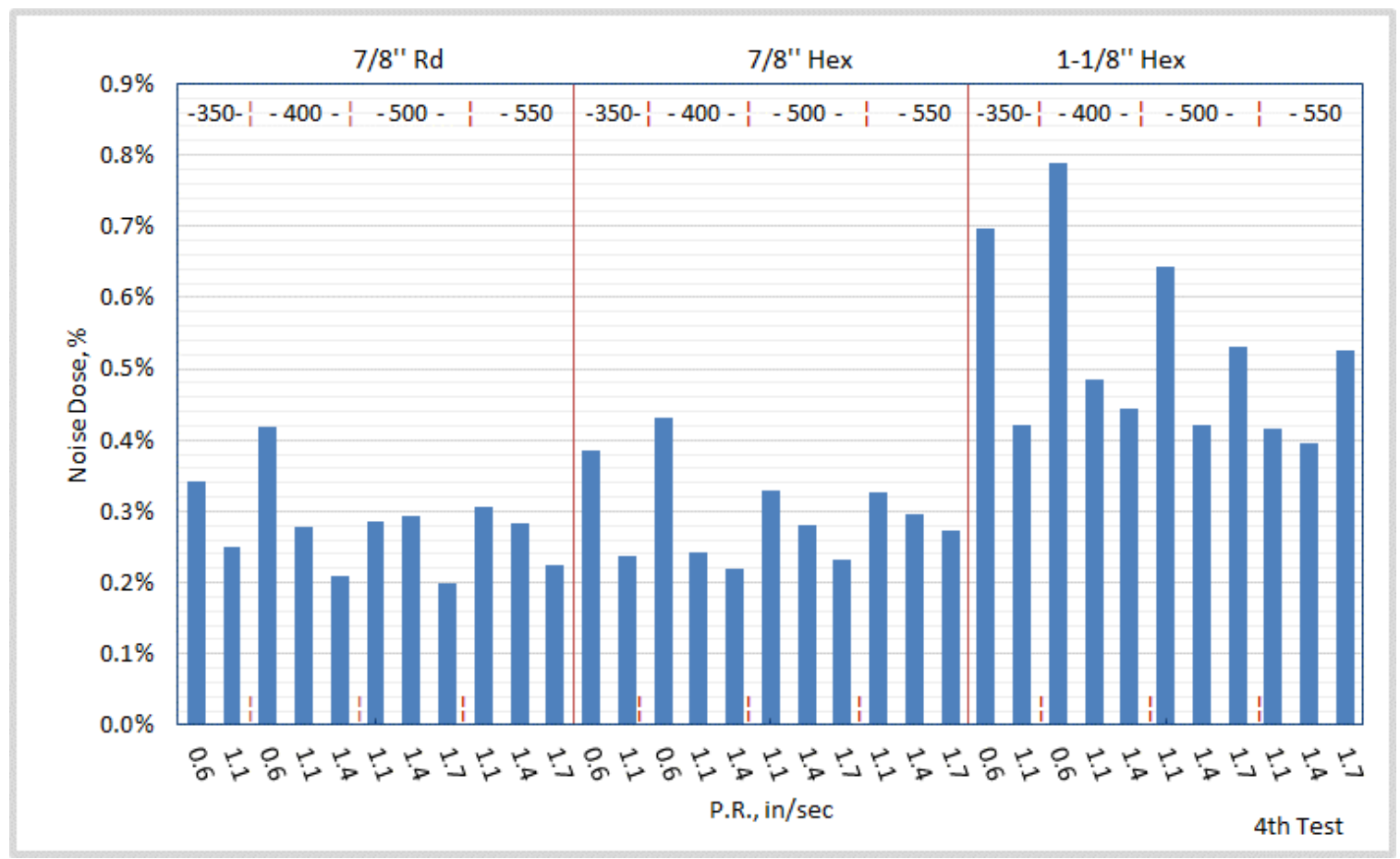

Figure 5.11 Noise dose from the fourth set of drilling tests 


\subsubsection{Average sound level}

The average sound pressure levels of the four sets of drilling tests are showing in Figure 5.12-5.15. The correlations between sound pressure level and drilling parameters or sound pressure level and different drill bit are not as obvious as that for the specific energy and noise dose, which was discussed before. However, there are some roughly trends. The sound pressure increases with the rotational rate. The sound pressure level for the 1-1/8-in hexagon drill steel is higher than that for the 7/8-in hexagon and round drill steel. When using the 7/8-in drill steels with different shape, the sound pressure level produced by the hexagon drill steel is higher than that for the round drill steel.

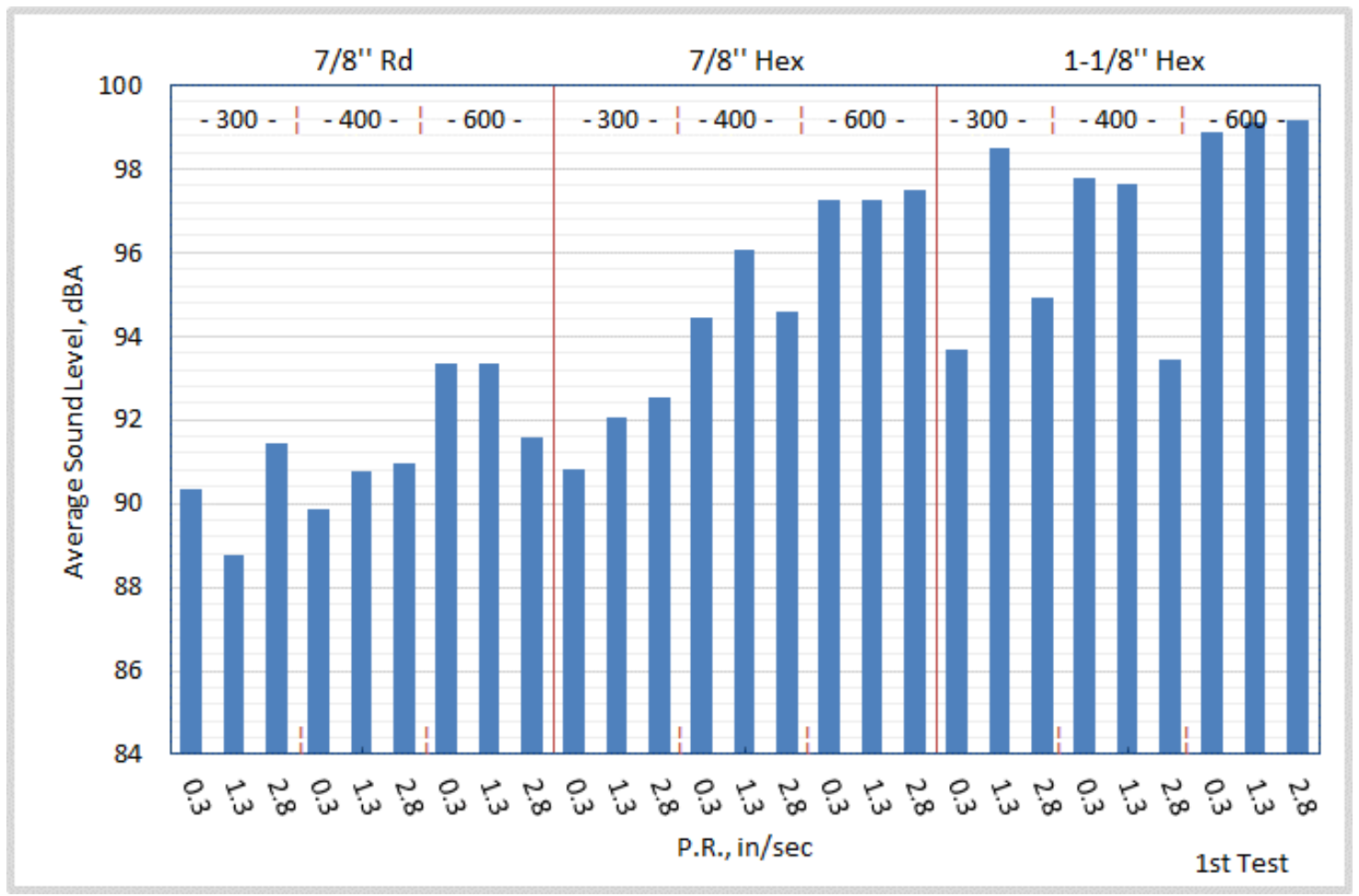

Figure 5.12 Average sound level from the first set of drilling tests 


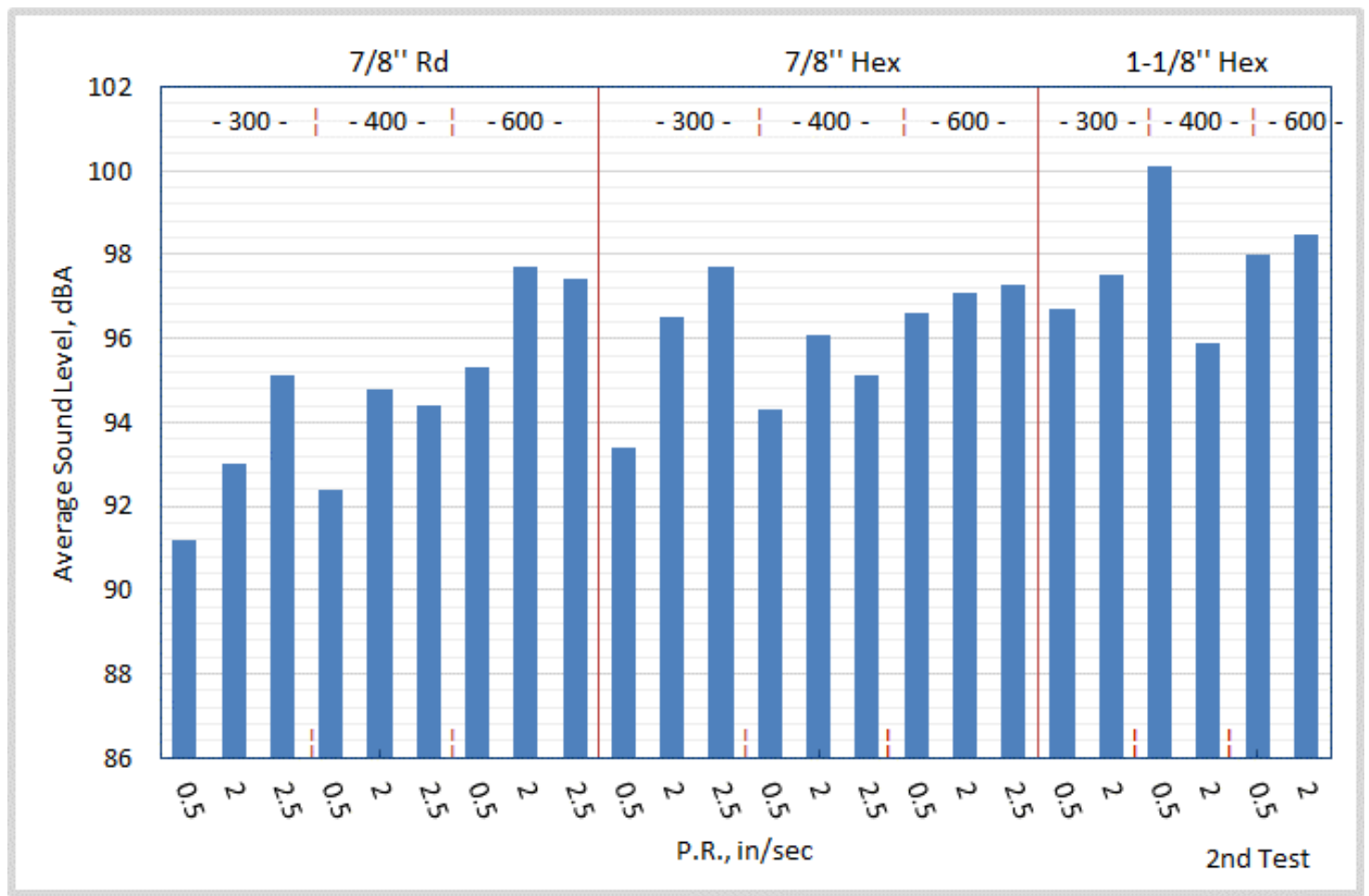

Figure 5.13 Average sound level from the second set of drilling tests

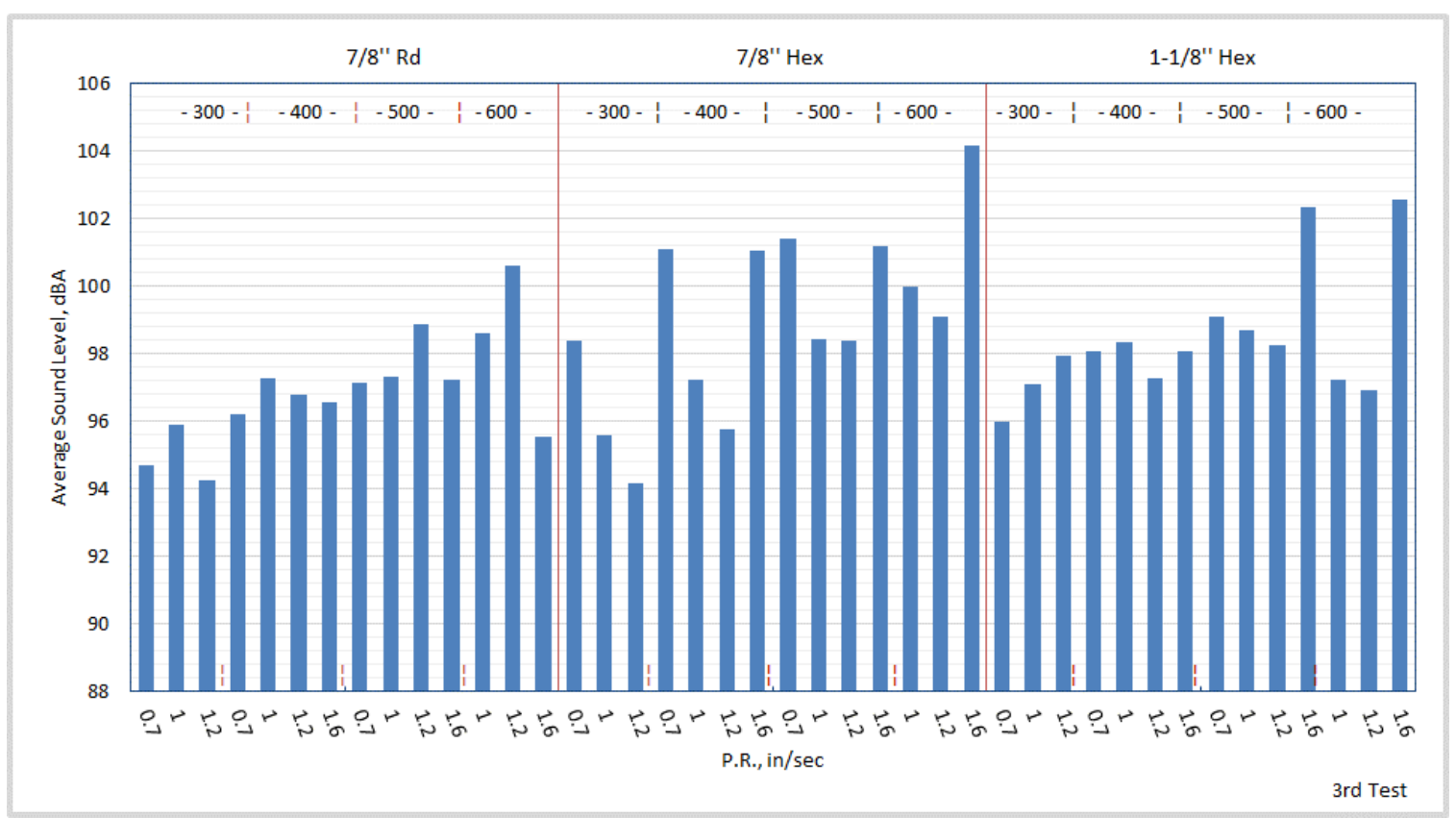

Figure 5.14 Average sound level from the third set of drilling tests 


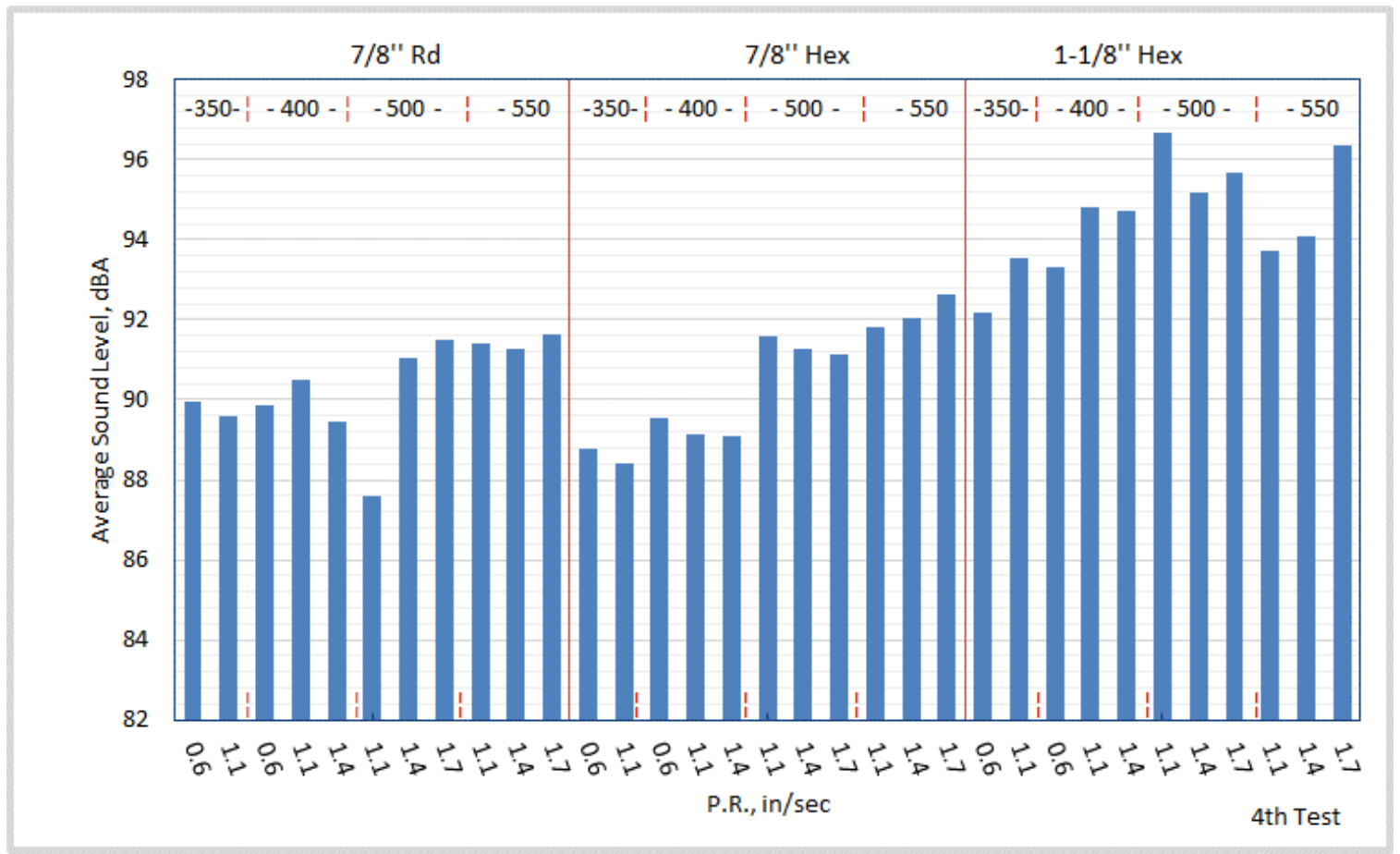

Figure 5.15 Average sound level from the fourth set of drilling tests

Figure 5.16 shows the octave band sound level of drilling tests using the 7/8-in hexagon bit-steel combination drilling at different rotational rates. The background sound level is also plotted in this figure. The increase of the sound level for the drilling tests relative to background noise is from nominal octave band $31.5 \mathrm{~Hz}$ to $16 \mathrm{~K} \mathrm{~Hz}$. The most significant increase of sound level during drilling is at 4000 and $8000 \mathrm{~Hz}$, which is about 28 and $31 \mathrm{~dB}$, respectively. In these four tests, the penetration rates are preset at the same level, $1.2 \mathrm{in} / \mathrm{sec}$, while the rotational rates are preset at different levels of $300,400,500$, and $600 \mathrm{rpm}$. The overall sound level increases as the rotational rate increases. It is obvious that during roof bolting drilling, the most significant sound pressure level is produced at $4000 \mathrm{~Hz}$. When rotational rate increases, the sound pressure level for the four tests remains almost the same at the frequency less than $500 \mathrm{~Hz}$, while the sound 
pressure level in the octave band higher than $1 \mathrm{kHz}$ increases. The increase is about $2 \mathrm{~dB}$ when rotational rate increases from $300 \mathrm{rpm}$ to $600 \mathrm{rpm}$.

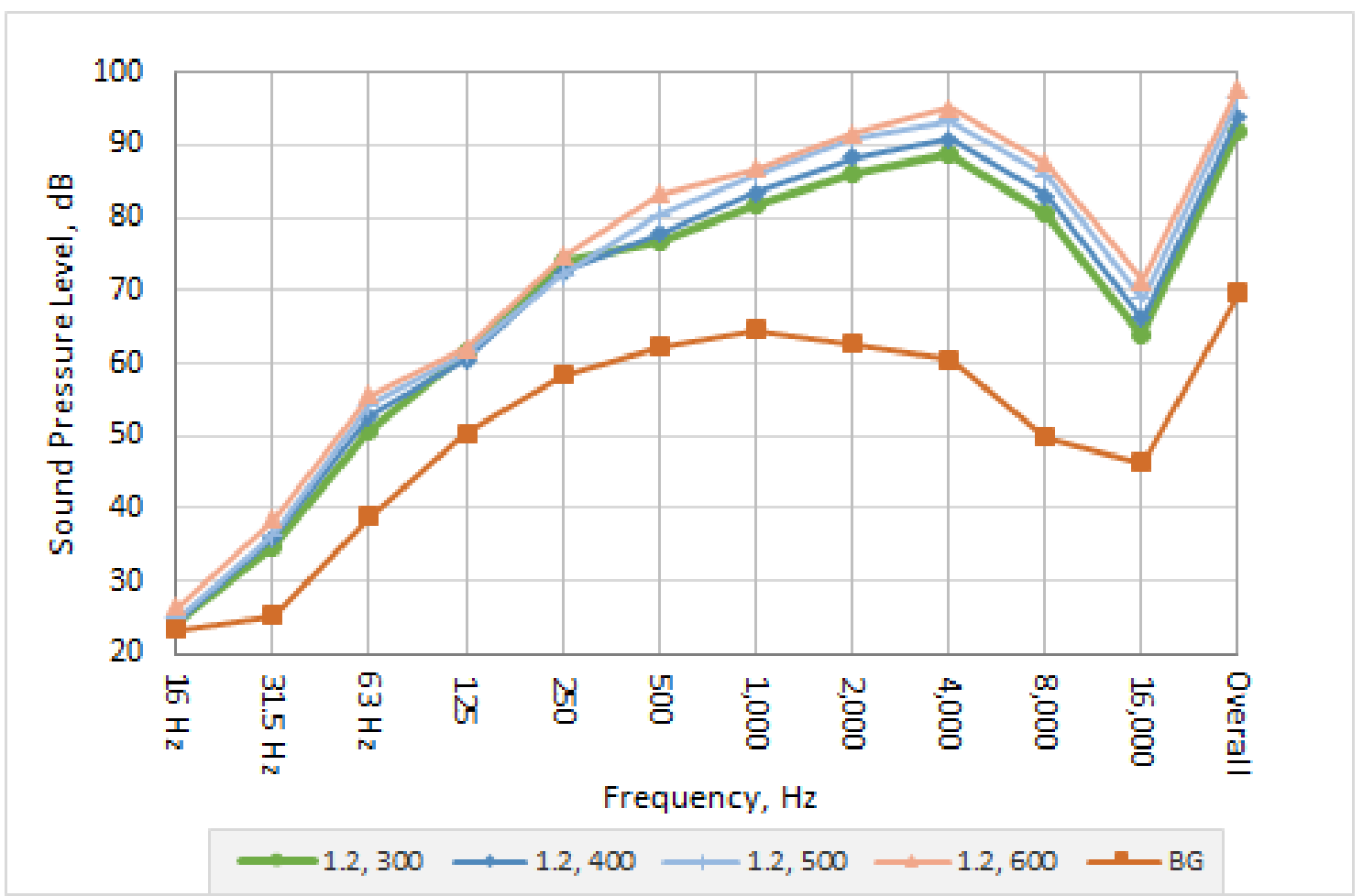

Figure 5.16 Octave band sound level of drilling tests at varying rotational rate

A similar analysis is conducted on the octave band sound level when drilling at a different penetration rate as well. Figure 5.17 shows the octave band sound level of drilling tests using $7 / 8$ hexagon bit-steel combination drilling at different penetration rates. In these four tests, the rotational rates are preset at the same level of $400 \mathrm{rpm}$, while the penetration rates are preset at different levels $0.7,1.0,1.2$, and $1.6 \mathrm{in} / \mathrm{sec}$. The sound level is lowest when drilling at the medium level penetration rate of $1.2 \mathrm{in} / \mathrm{sec}$. When drilling at a too low $(0.7 \mathrm{in} / \mathrm{sec})$ or too high $(1.6 \mathrm{in} / \mathrm{sec})$ penetration rate, the sound pressure level is about $3 \mathrm{~dB}$ higher than drilling at $1.0 \mathrm{in} / \mathrm{sec}$. Comparing the different 
penetration rates, the increase of sound level were generated at a frequency higher than 1 $\mathrm{kHz}$.

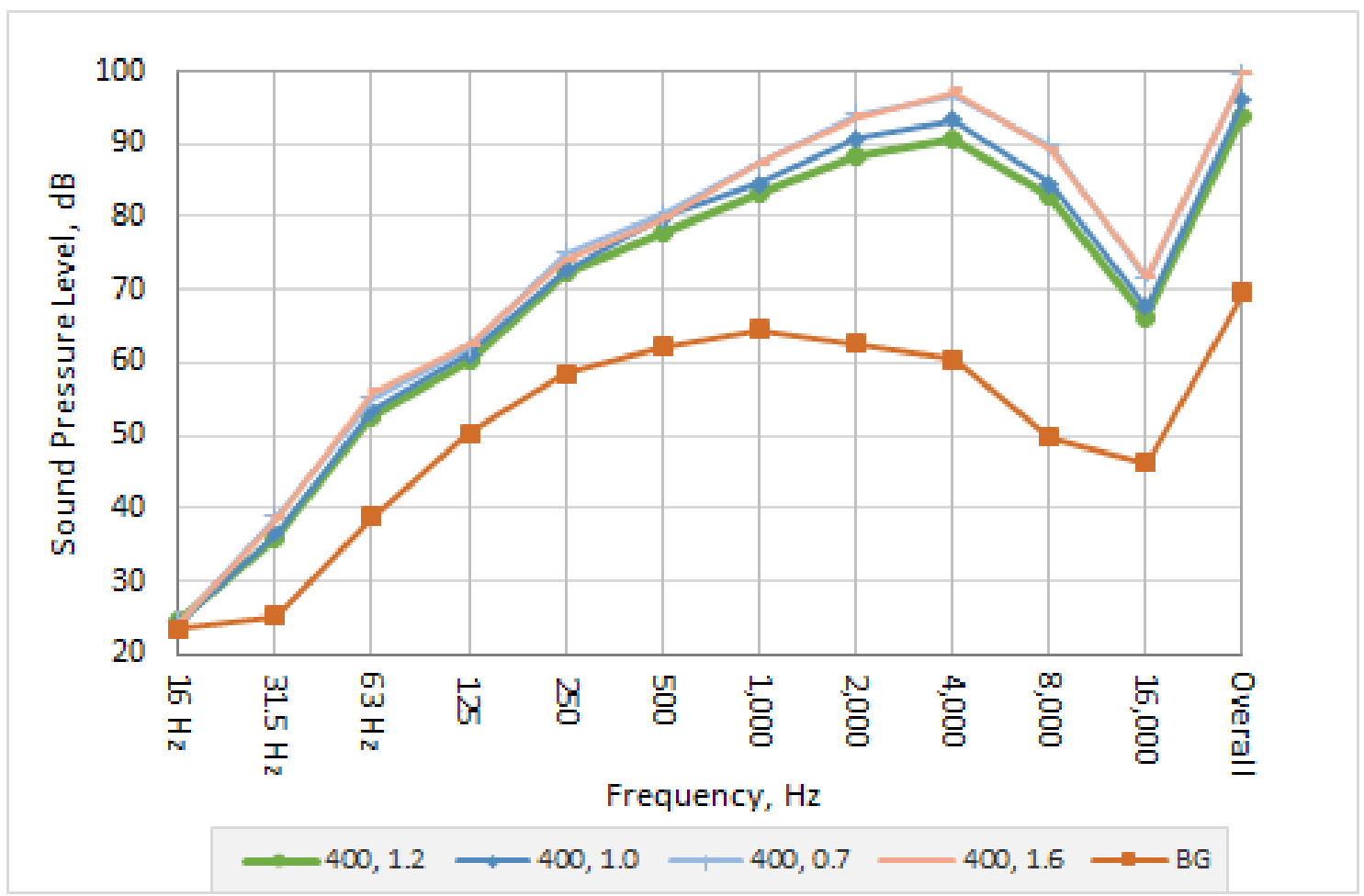

Figure 5.17 Octave band sound level of drilling tests at varying penetration rate

The effect of drilling utilizing different drill bit-steel combination on octave band sound level is shown in Figure 5.18. The drilling parameters are all preset at $300 \mathrm{rpm}$ rotational rate and $1.2 \mathrm{in} / \mathrm{sec}$ penetration rate. The sound level at all frequency ranges is lowest when drilling using $7 / 8$ round drill steel. When comparing the 7/8 hexagon and 11/8-in hexagon drill steel, the sound levels are almost the same when the frequency is lower than $250 \mathrm{~Hz}$. However, when the frequency is higher than $500 \mathrm{~Hz}$, the sound level produced by the 1-1/8-in hexagon drill steel is higher than that of the 7/8-in hexagon drill steel. 


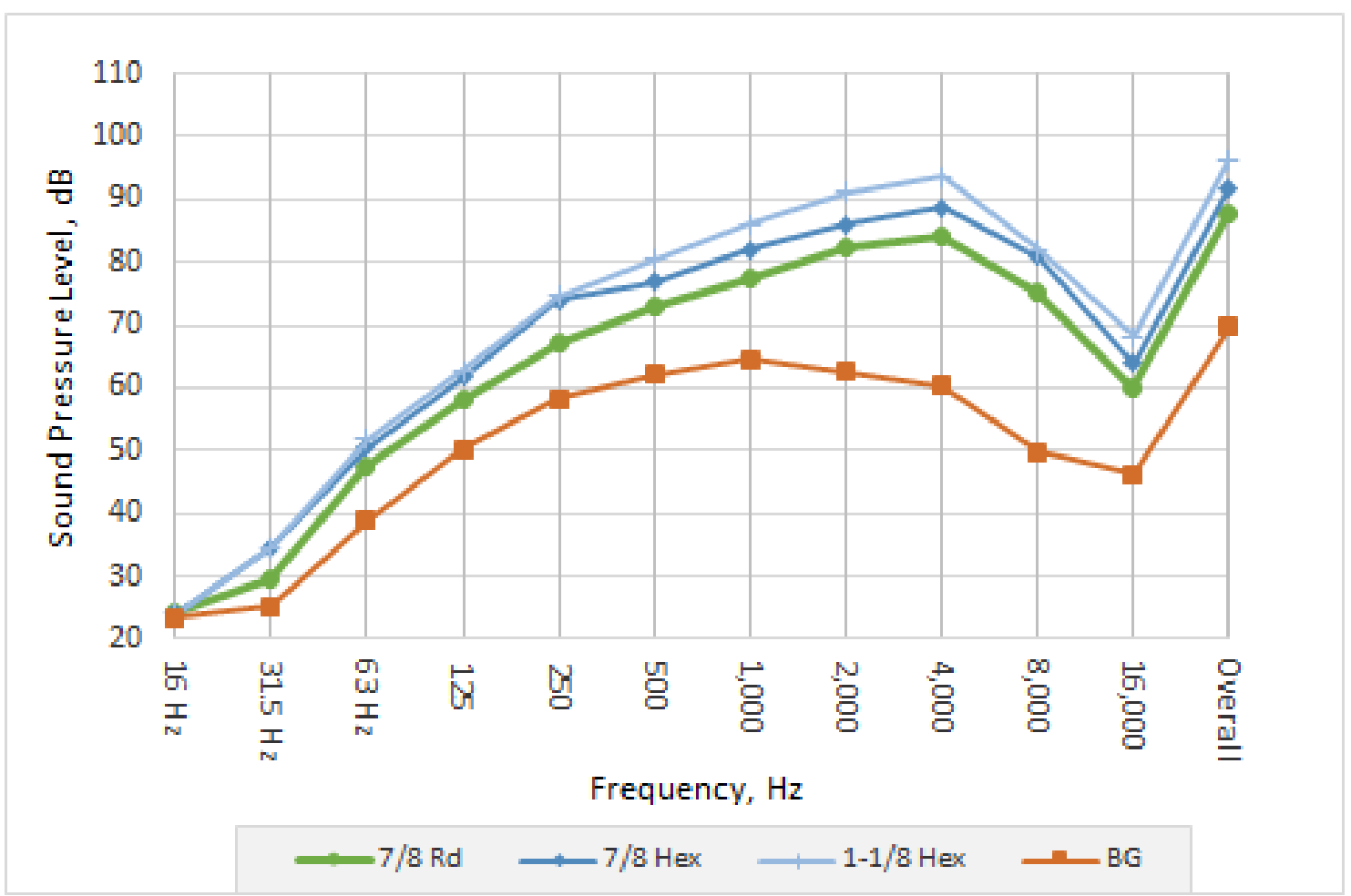

Figure 5.18 Octave band sound level of drilling tests using varying drill steels

\subsubsection{Temperature increases of drill bit}

The temperature differences of the drill bit before and after each drilling test are showing in Figure 5.19-5.22. However, it is hard to see constantly obvious patterns in the temperature increases of drill bit. The temperature increase rate was analyzed, which calculated by dividing the temperature increase for drilling each hole by the total drilling time (Figure 5.23-5.26). It was found that the temperature increase rate increases with the penetration rate and rotational rate. 


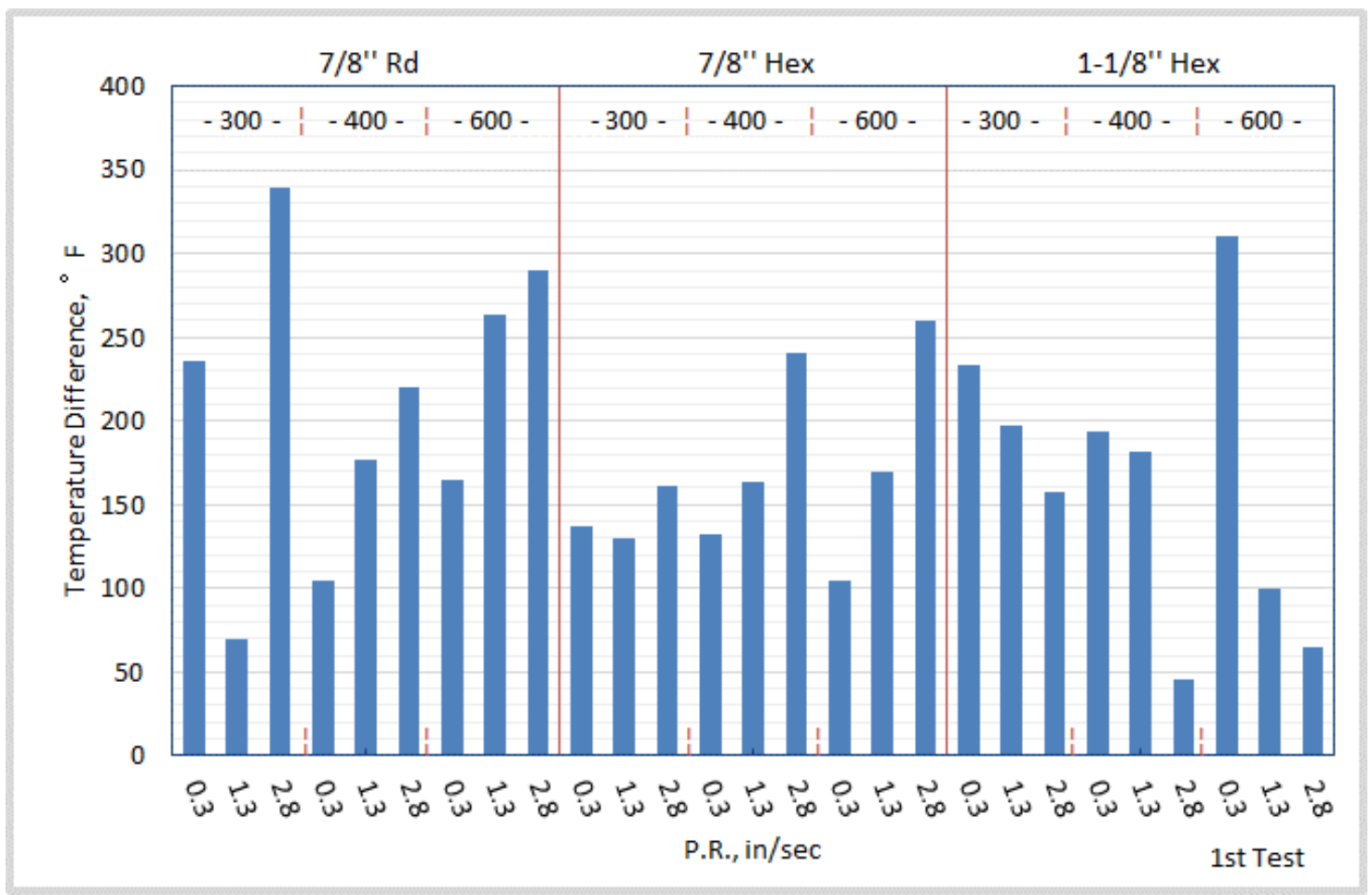

Figure 5.19 Temperature increases of drill bit from the first set of drilling tests

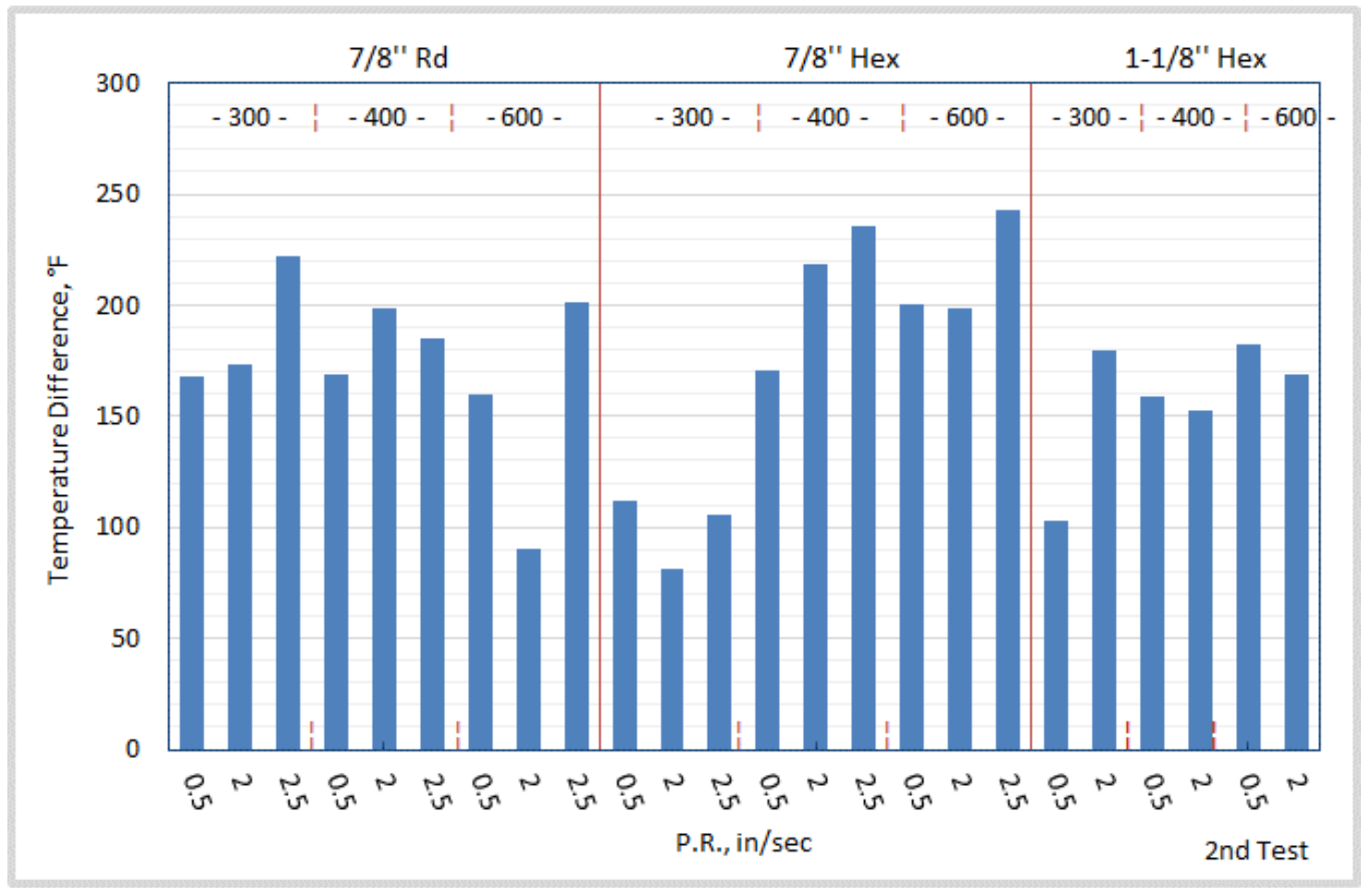

Figure 5.20 Temperature increases of drill bit from the second set of drilling tests 


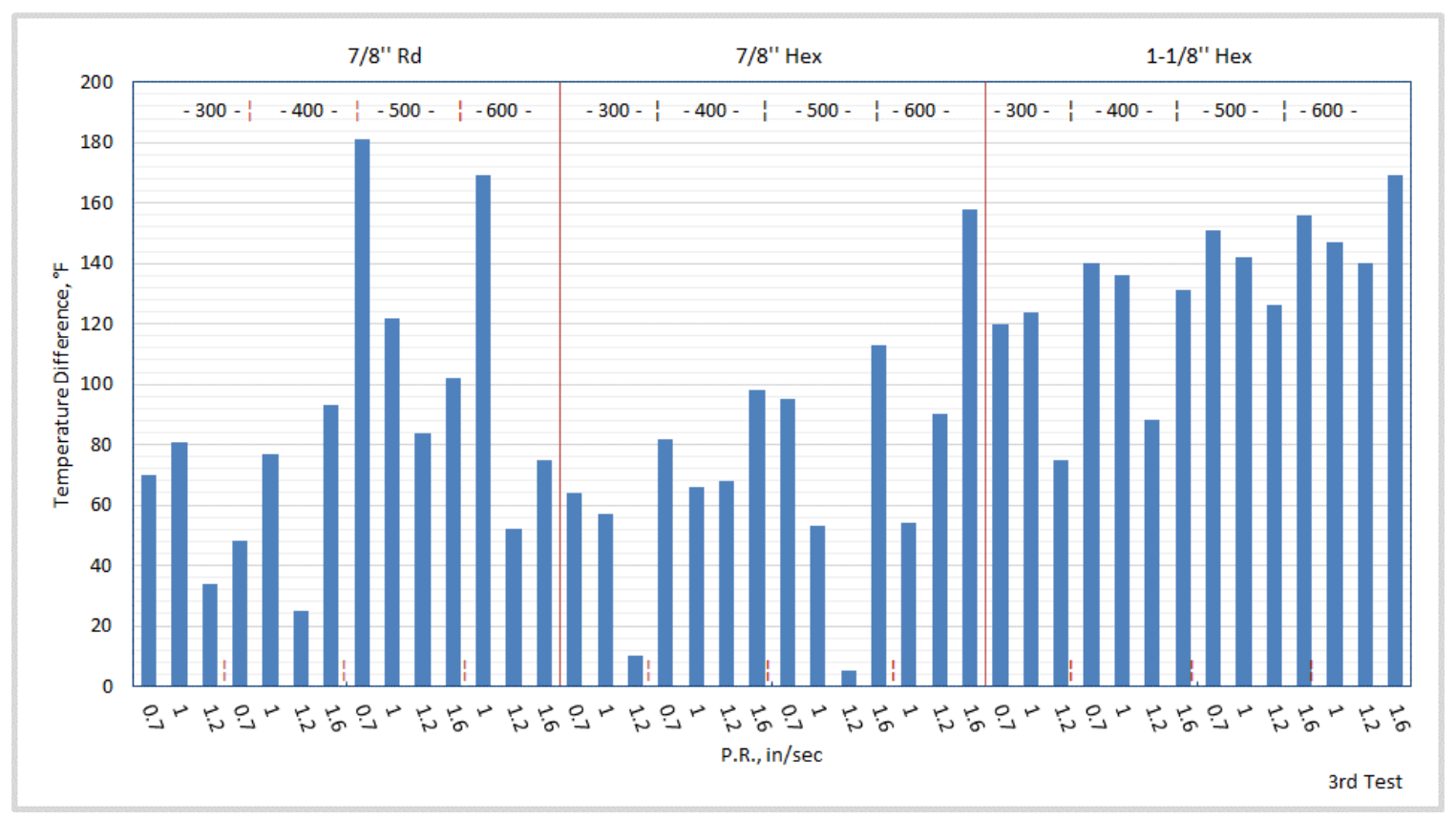

Figure 5.21 Temperature increases of drill bit from the third set of drilling tests

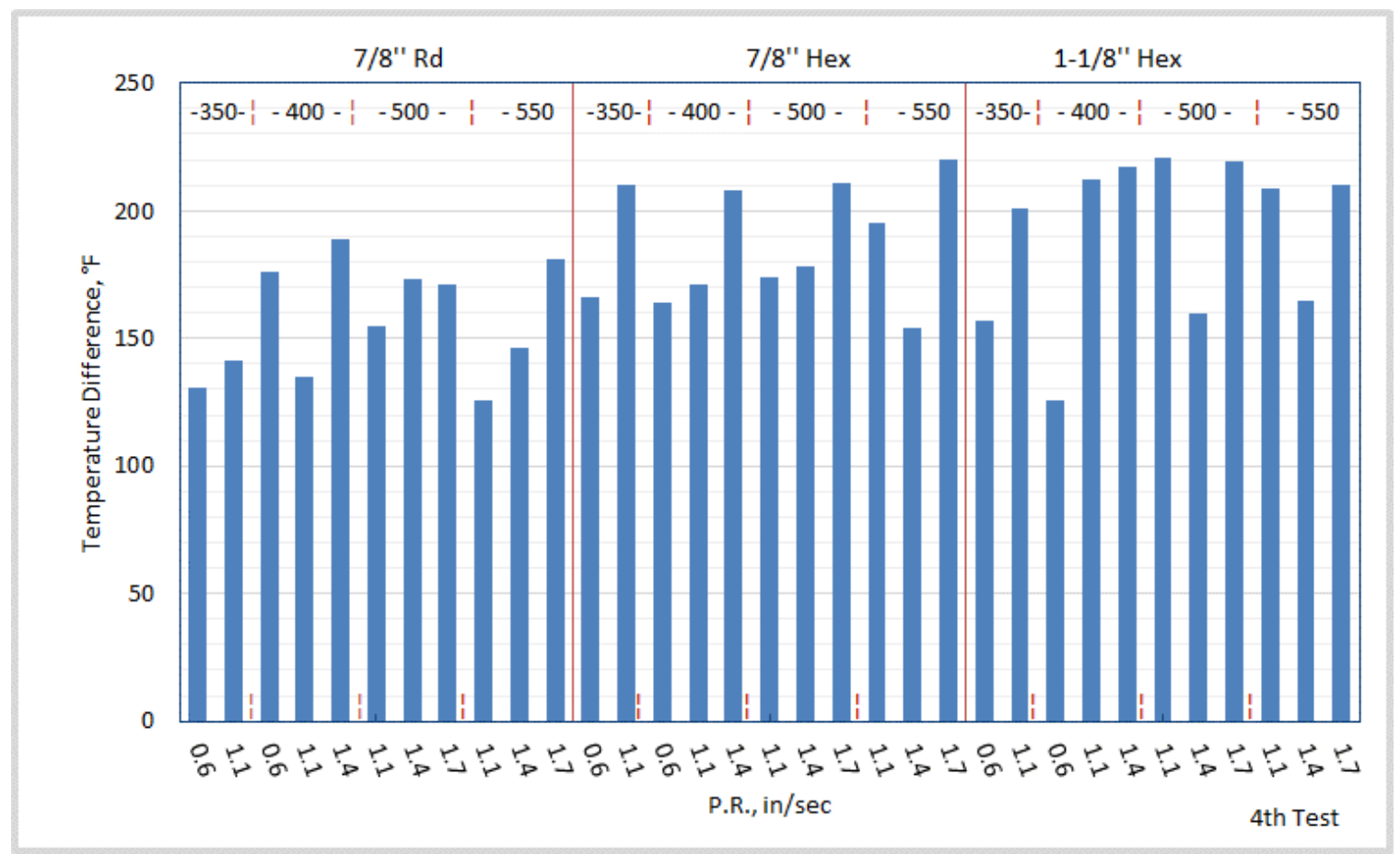

Figure 5.22 Temperature increases of drill bit from the fourth set of drilling tests 


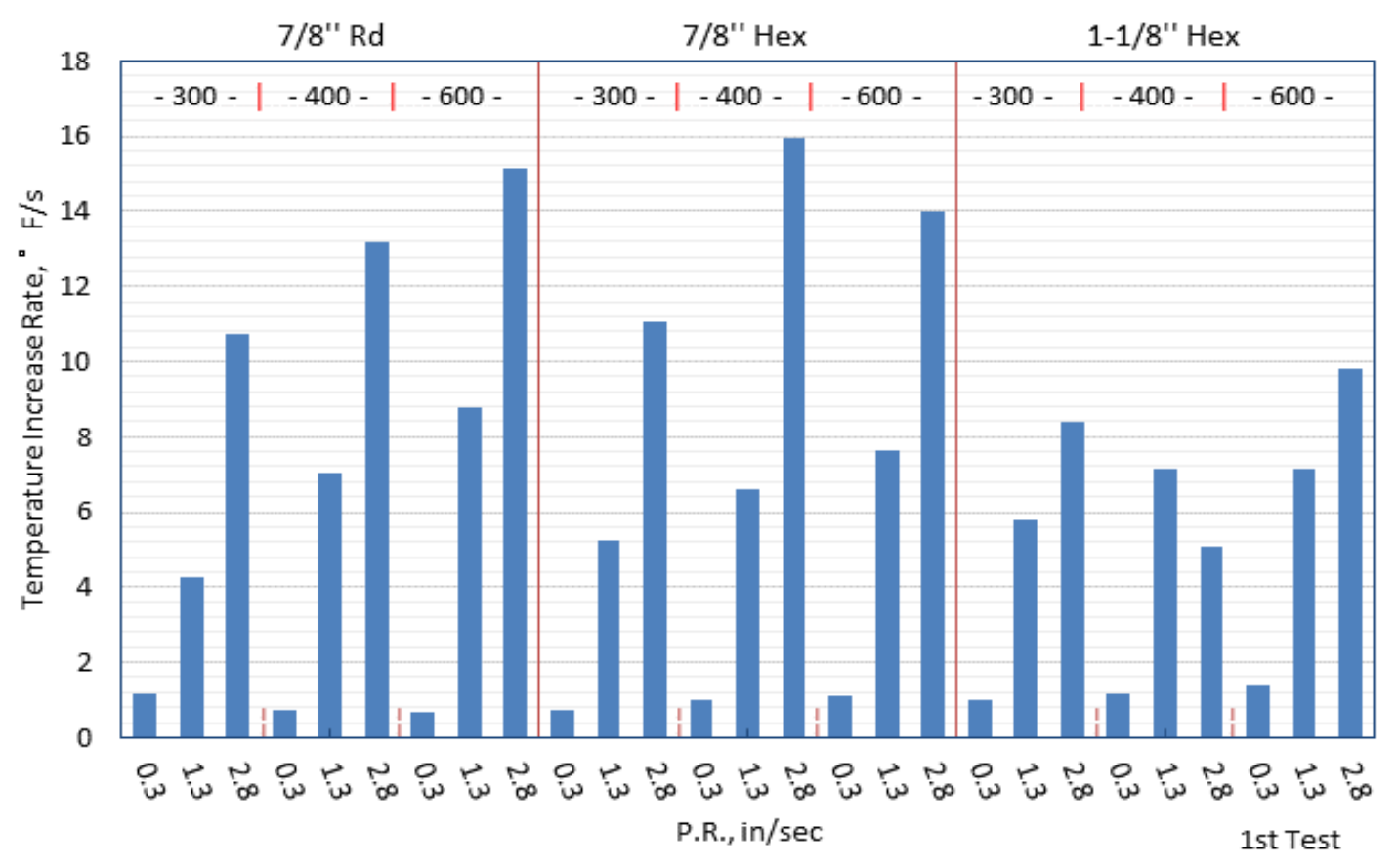

Figure 5.23 Temperature increase rate of drill bit from the 1st set of drilling tests

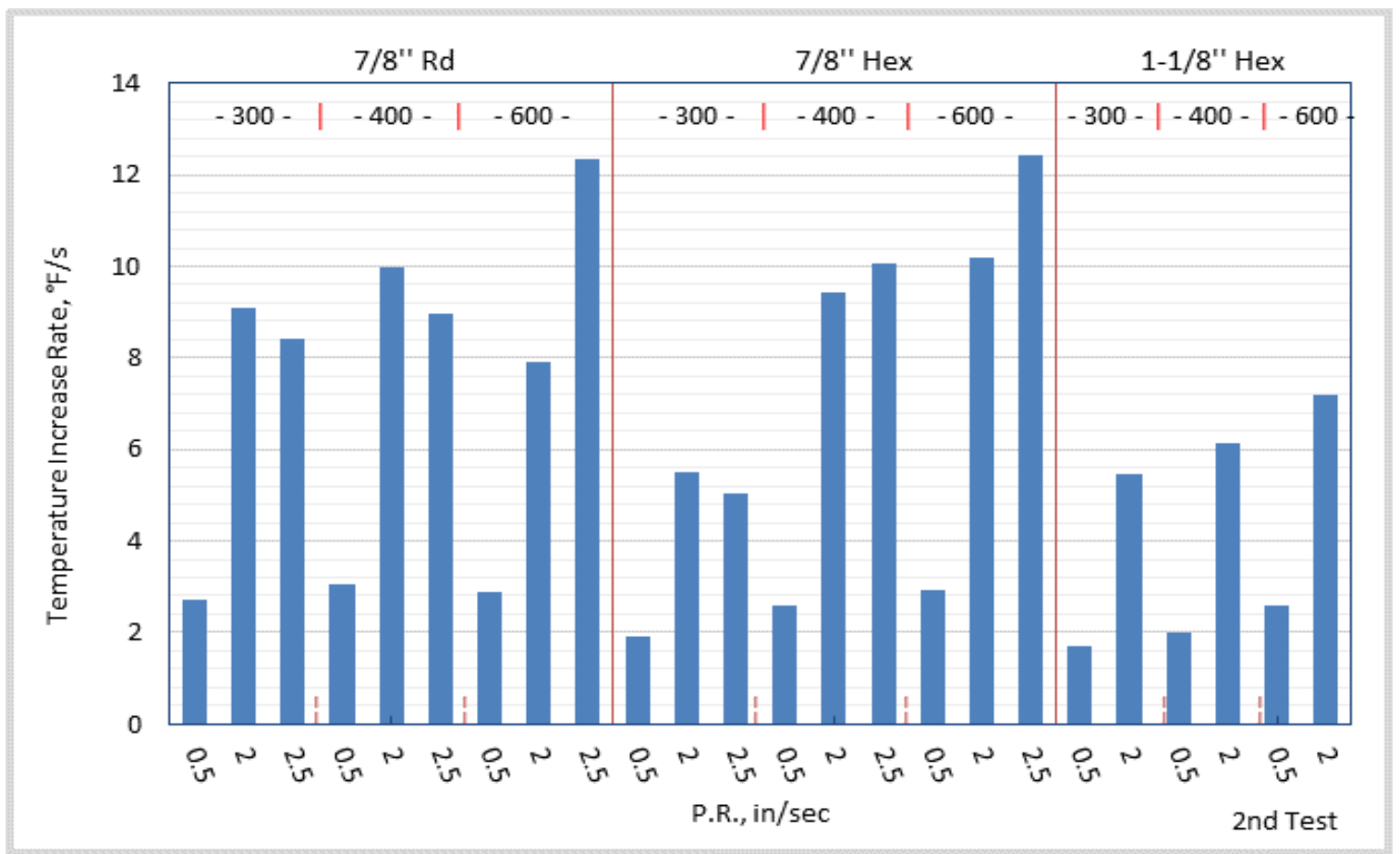

Figure 5.24 Temperature increase rate of drill bit from the 2 nd set of drilling tests 


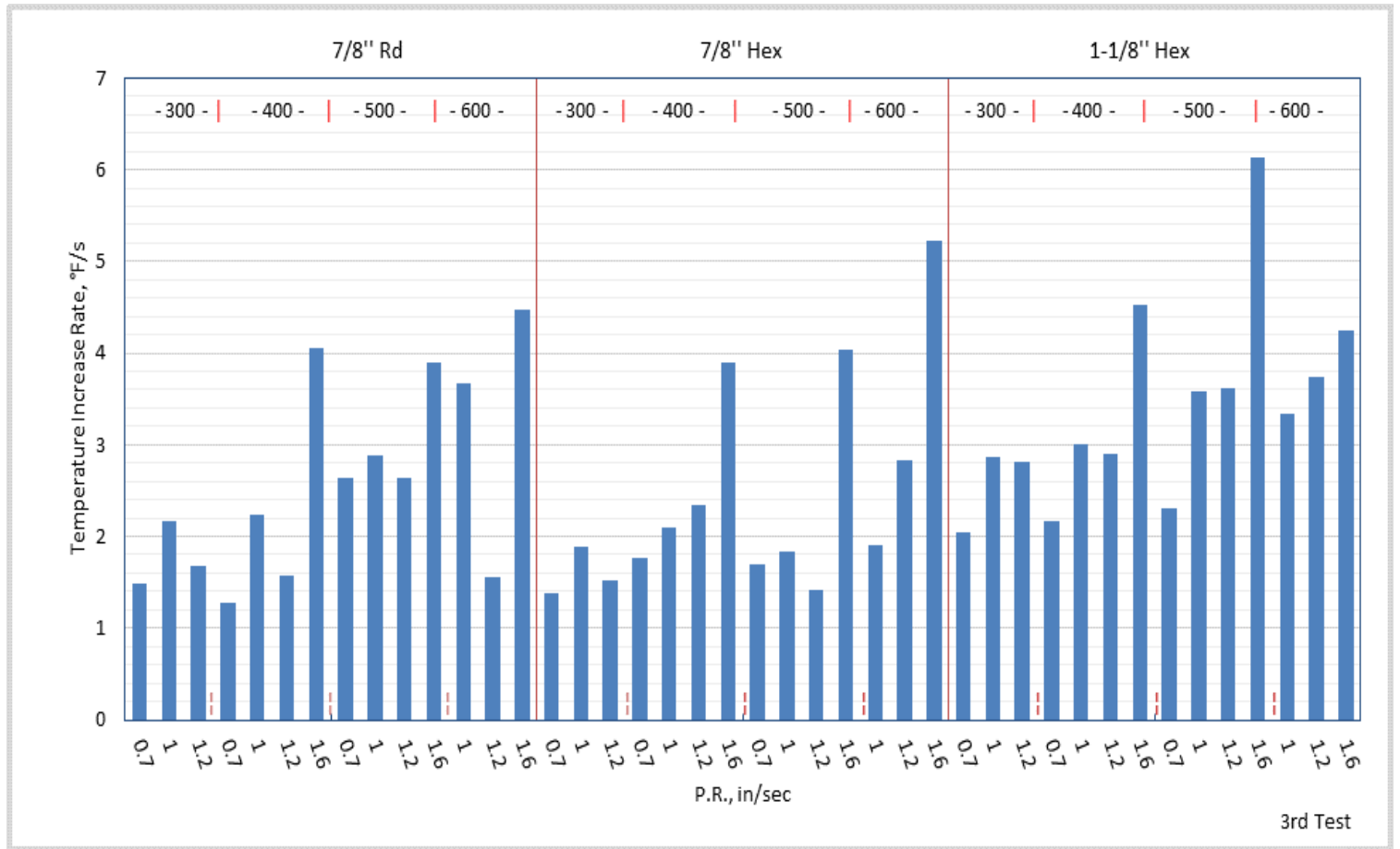

Figure 5.25 Temperature increase rate of drill bit from the 3rd set of drilling tests

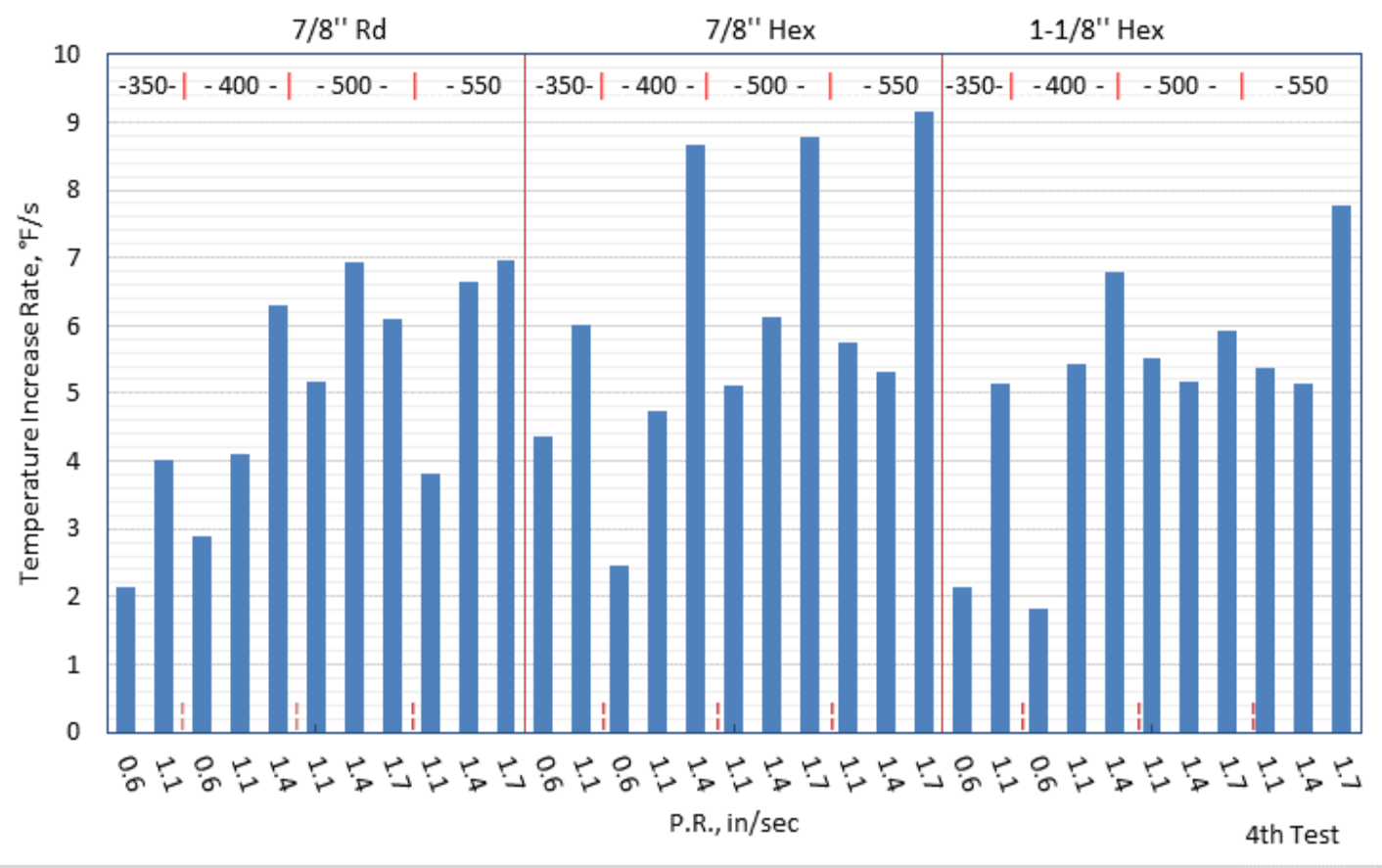

Figure 5.26 Temperature increase rate of drill bit from the 4th set of drilling tests 


\subsection{Selection of proper bite depth}

To study the correlation between the average specific energy, noise dose and bite depth, the derived average specific energy and noise dose from the measurements of the first set of tests are plotted against the achieved bite depth in Figure 5.27 and Figure 5.28, respectively. Though their magnitudes are different for different steel-bit combinations, the general trends are similar. Initially, both the noise dose and specific energy decrease significantly as the bite depth increases. After the bite depth reaches the value of about $0.16 \mathrm{in} / \mathrm{rev}$, they reach their respective stable state near the minimum levels. For example, when the bite depth is small at $0.07 \mathrm{in} / \mathrm{rev}$, the noise dose is twice of that at $0.16 \mathrm{in} / \mathrm{rev}$. Such low bite depth is resulted from drilling slow penetration rate and fast rotational rate. When drilling is conducted this way, the drill bit consumes more energy to overcome the friction force between the rock and the drill bit both at its front tip and side edges and produces high-frequency noise resulting in lower energy efficiency for rock breakage. Also it takes a longer time at low bite depth to drill a complete bolt hole resulting in a higher noise dose to the bolter operators. As the bite depth increases within a rational range, less drilling energy is consumed for over breakage of rock and rubbing actions, and less time is taken to drill a hole. The specific energy and noise dose would decrease too. However, when the bite depth increase to certain value depending on the bit design and worn condition, the benefit gained in energy saving and noise reduction from not over breaking the rock would begin to be cancelled out by the additional rubbing action between the bit body and rock. For the bits used in the experiments, the height of the tungsten carbide insert above the bit body is between 0.16 to 0.18 inches. It explains the phenomena that both specific energy and noise dose level off at that bite depth. In 
addition, bite depth increase beyond this value would require much high thrust and torque which are limited by the power supply of the machine and the strength of the drill steel.

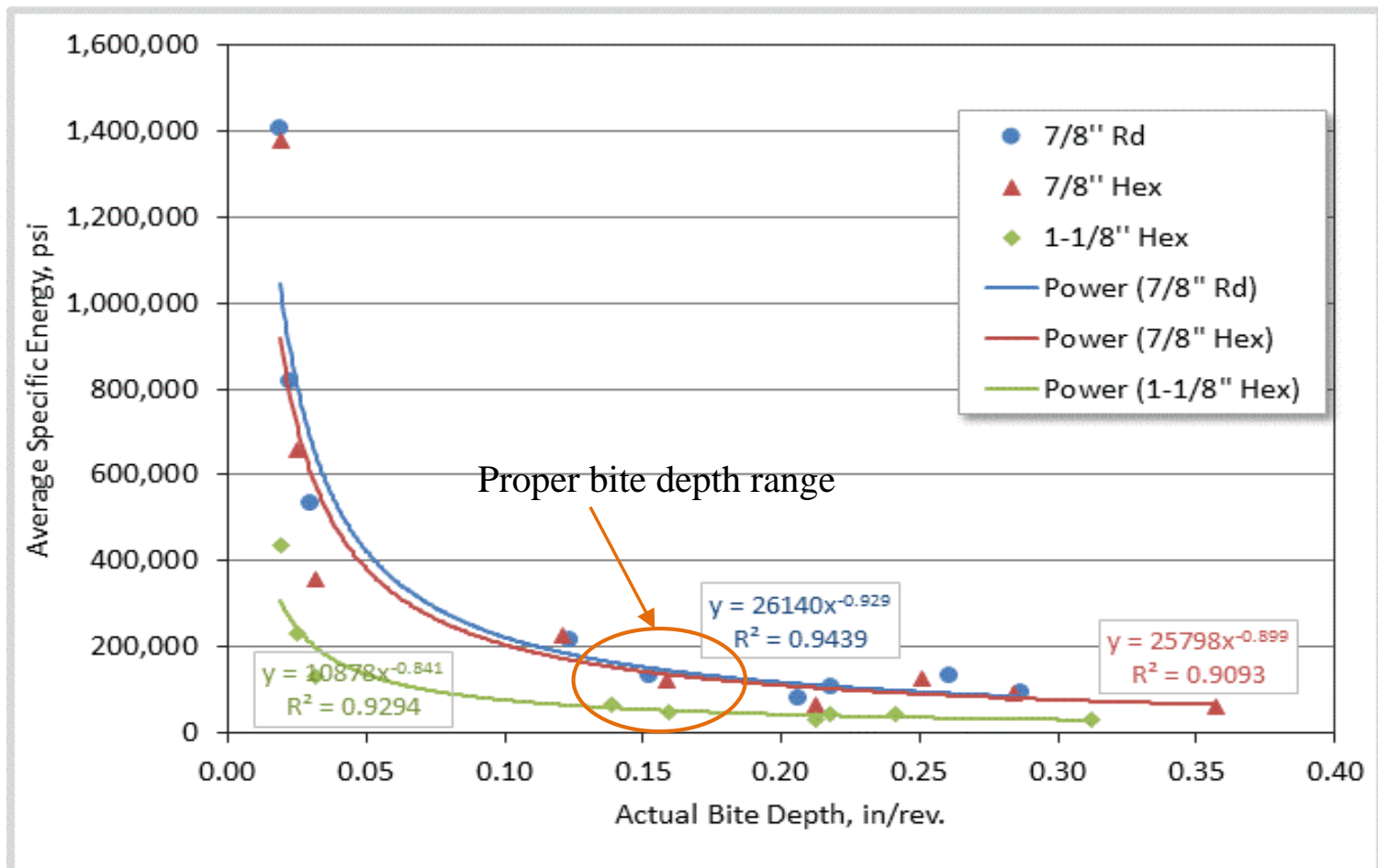

Figure 5.27 Average specific energy vs. bite depth for drilling tests using different bit-steel combinations in the 1 st test 


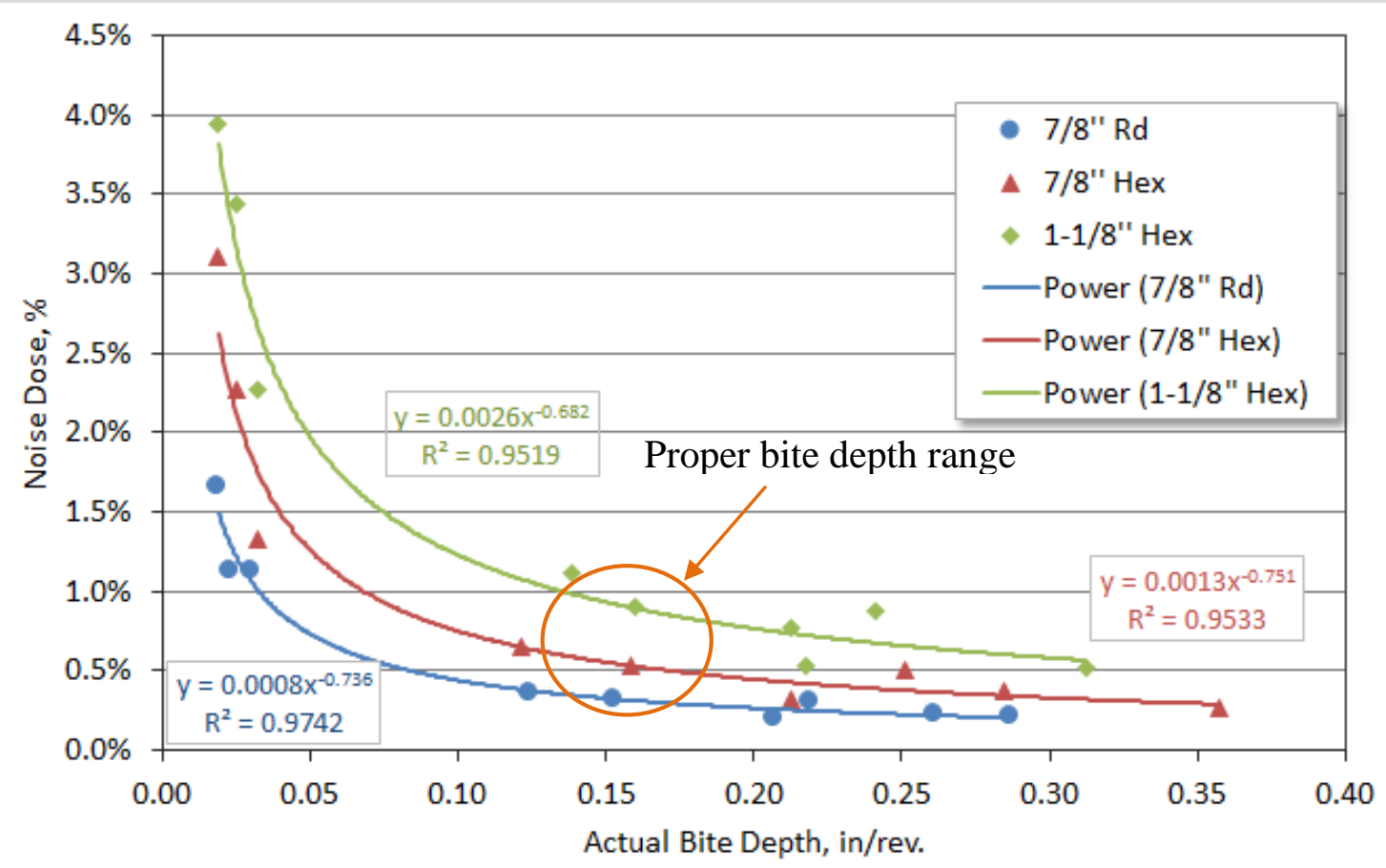

Figure 5.28 Noise dose vs. bite depth for drilling tests using different bit-steel combinations in the 1 st test

The relations between specific energy and bite depth, and the noise dose and bite depth for the other three sets of tests is shown in Appendix B. In the four sets of tests, the 1-1/8-in Hexagon drill steel produces the lowest specific energy while the 7/8-in round drills steel produces the highest specific energy. The specific energy for the 7/8-in round and hexagon drill steel are very close to each other. That may be because the hole diameter produced by the 1-1/8-in Hexagon drill steel is larger, and the hole diameter produced by 7/8-in round and hexagon drill steel are the same. Therefor the hole area created by the 1-1/8-in hexagon drill steel is larger than that created by the $7 / 8$-in drill steels. When the penetration rate and rotational rate were the same, the total energy consumption was almost the same when drilling one hole of same length using different 
drill steels. As the specific energy is defined as the energy consumed to drill a unit of rock, the specific energy for the drill steel which created larger hole.

For the noise dose, the 1-1/8-in hexagon drill steel produces the highest noise dose except for the third set of tests. The 7/8-in round drill steel produces the lowest noise dose in the four sets of tests for the first three sets of test. For the fourth set of test, the noise dose produced by the 7/8-in round drill steel and 7/8-in hexagon drill steel are very similar. The order of the noise dose produced by each drill steel is roughly in the same order as the cross section area of each drill steel, which is very obvious in the first two sets of test. This can be explained as the larger contact area between the drill steel and drill rock causes more friction which results in higher noise dose.

Figure 5.29 shows the relationships between the average specific energy and noise dose in the firsts set of drilling tests. For each of the drill bit-steel combinations, the average specific energy relates with the noise dose well with an exponential function. For the different bit and steel combinations, when the same specific energy was consumed, the 7/8-in round drill steel produces the lowest noise dose, while the 1-1/8-in hexagon drill steel produces the highest noise dose. 


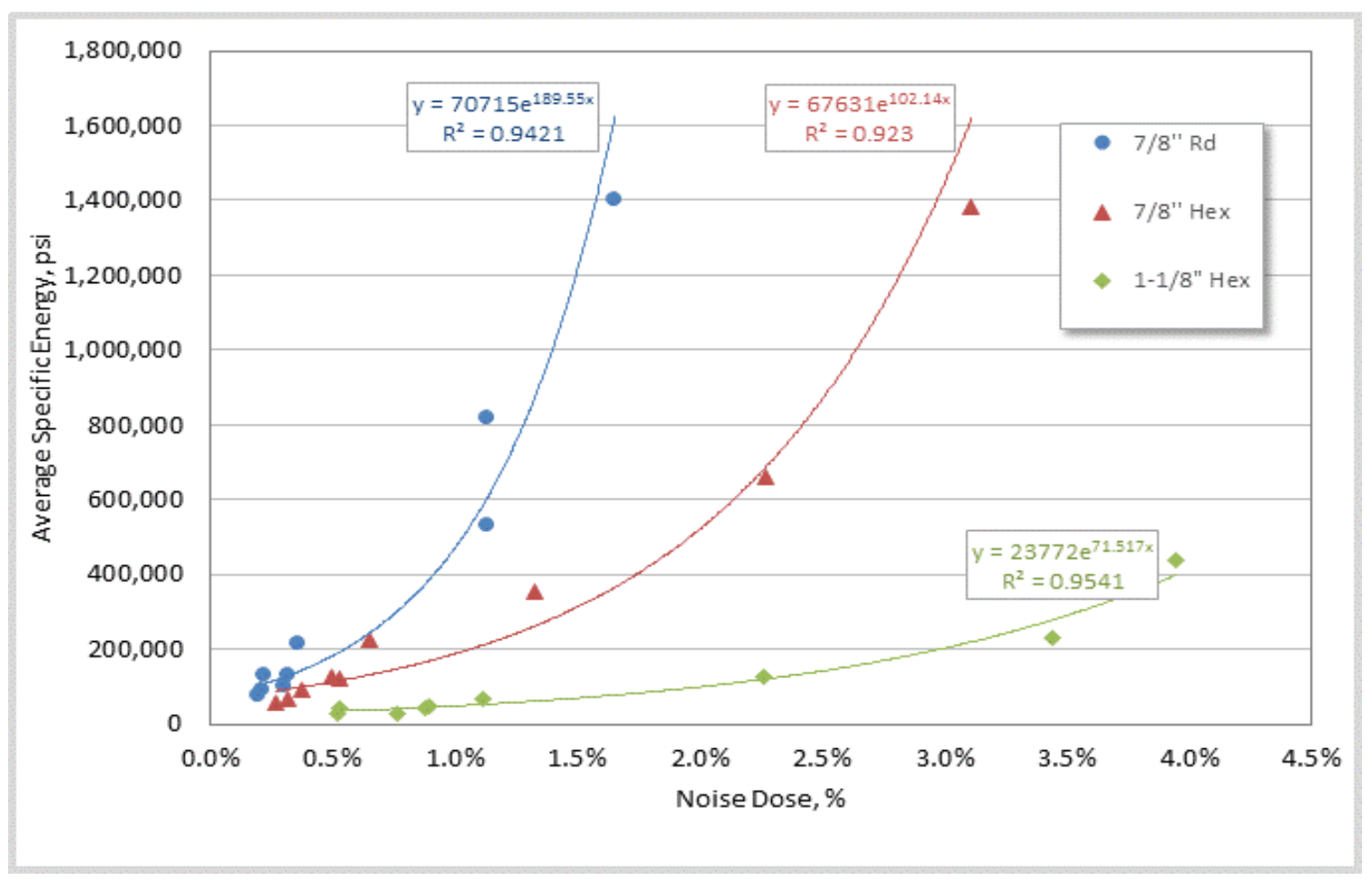

Figure 5.29 Specific energy vs. noise dose for the 1st set of drilling tests

As the specific energy and noise dose correlate with bite depth very well, they can be used for the selection of proper bite depth. The bite depth between $0.13 \mathrm{in} / \mathrm{rev}$ and $0.18 \mathrm{in} / \mathrm{rev}$ is the recommended operation range using the bit design in the tests drilling similar strength rock. Drilling at bite depth in this range, both the specific energy and noise dose are close to their minimum values. The bite depth higher than 0.18 should be avoided when using this type of bit design because the specific energy and noise dose will not be reduced as further increase bite depth to higher than 0.18 . The too high bite depth could also cause the safety issues as the limitation of the thrust that the drill steel can endure. 


\subsection{Proposed drilling control strategy}

Both the equivalent noise dose and average specific energy of drilling decreases as the average bite depth increases. Therefore, control of drilling parameters (i.e., penetration rate and rotational rate) in a specific rational range for a type of rock to be drilled can reduce both the noise exposure to the bolter operators and the specific energy used for drilling. Within this knowledge, the drilling parameters, penetration rate and rotational rate could be optimized for the purpose of noise reduction. In Figure 5.30, the dependent variables (average specific energy, noise dose, equivalent sound level and temperature increase) for the tests using 7/8-in bit and round steel combinations are plotted against the achieved penetration rates and rotational rates in contour form.
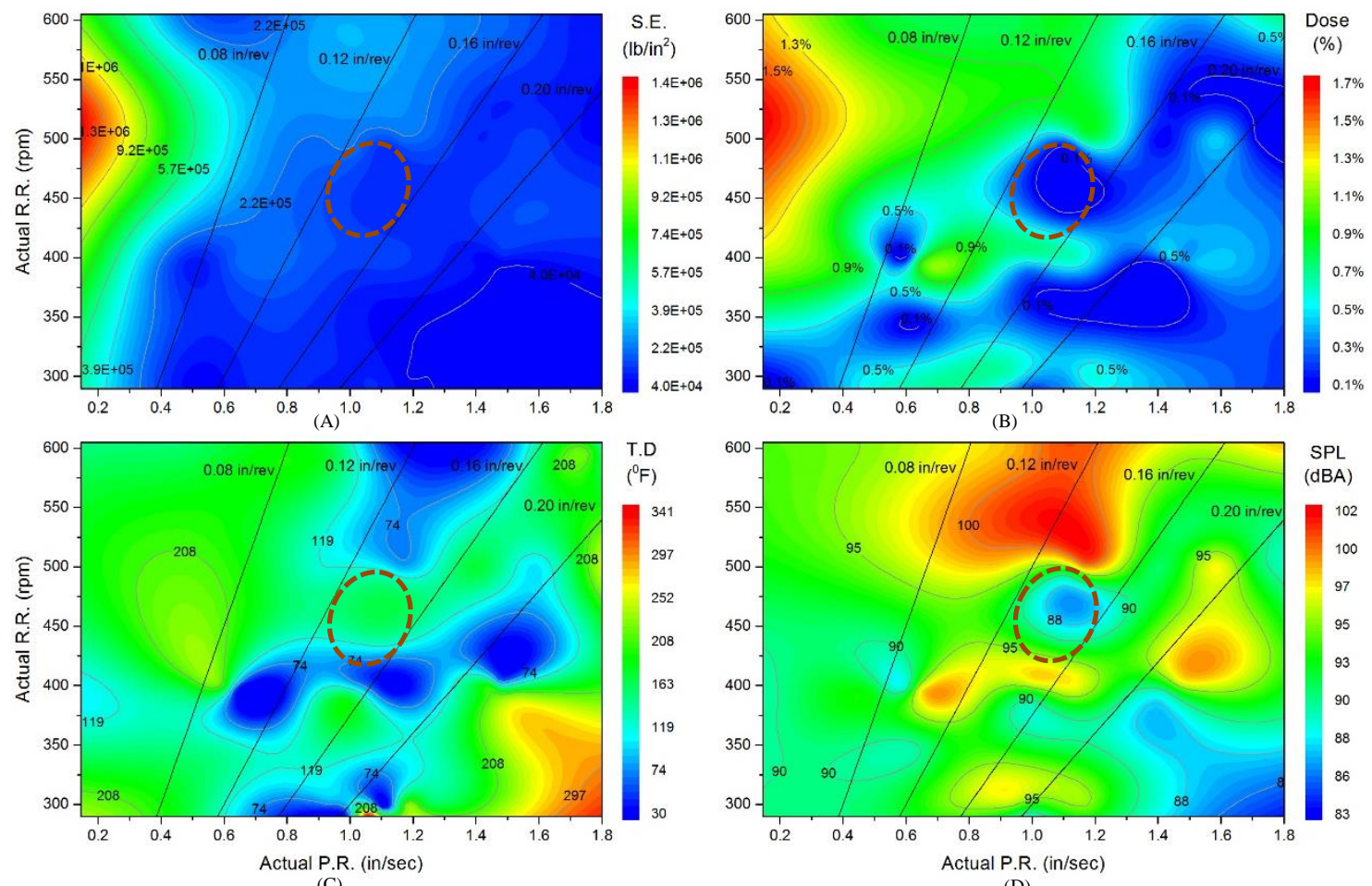

Figure 5.30 Distributions of average specific energy (A), noise dose (B), bit temperature increase (C), and equivalent sound level (D) for the drill operating range of 7/8-in round drill steel 
On the dose and specific energy plots, the low values are located on the right lower part of the domain. Based on designs of the drill bits used in the tests, a maximum allowable bite depth of $1.6 \mathrm{in} / \mathrm{rev}$ should be imposed as a straight line plotted in these figures to avoid the contact between the bit base and rock at the front side. This maximum allowable bite-depth also coincides with the height of the tungsten carbide insert above the steel body of new drill bits. The comparison of the actually achieved and preset bite depths in the drilling tests shows that a preset bite depth smaller than 1.6 in/rev can be easily achieved for the testing block. The other bite depths are also plotted in the figures. When an operating point is located on the right side of the $1.6 \mathrm{in} / \mathrm{rev}$ bite depth line, the drill is not operated properly. After considering the noise dose, average specific energy, equivalent sound level and bit temperature increase (indicating the bit wear), a rational zone in the lower central part of the figures between the $1.2 \mathrm{in} / \mathrm{rev}$ and the $1.6 \mathrm{in} / \mathrm{rev}$ bite depth line can be considered as the rational drilling control zone.

For the goal of controlling the noise dosage generated by drilling the rock with similar strengths of the testing block, the recommended operation range for the penetration rate is about $0.9-1.2 \mathrm{in} / \mathrm{sec}$, and the recommended operation range for the rotational rate is about $420-500 \mathrm{rpm}$.

The tests for other bit-steel combinations generally show similar pattern as that for $7 / 8$ inch round bit-steel combinations. The recommended rational operation range for the $7 / 8$ inch hexagon drill steel located in the same range as the round drill steel as shown in Figure 5.31. For the 1-1/8 inch hexagon drill steel, the rational operation range is a little different as the smaller drill steel as shown in Figure 5.32. The recommended 
operation range for the penetration rate is about $1.0-1.3 \mathrm{in} / \mathrm{sec}$, and for the rotational rate is about $480-560 \mathrm{rpm}$.
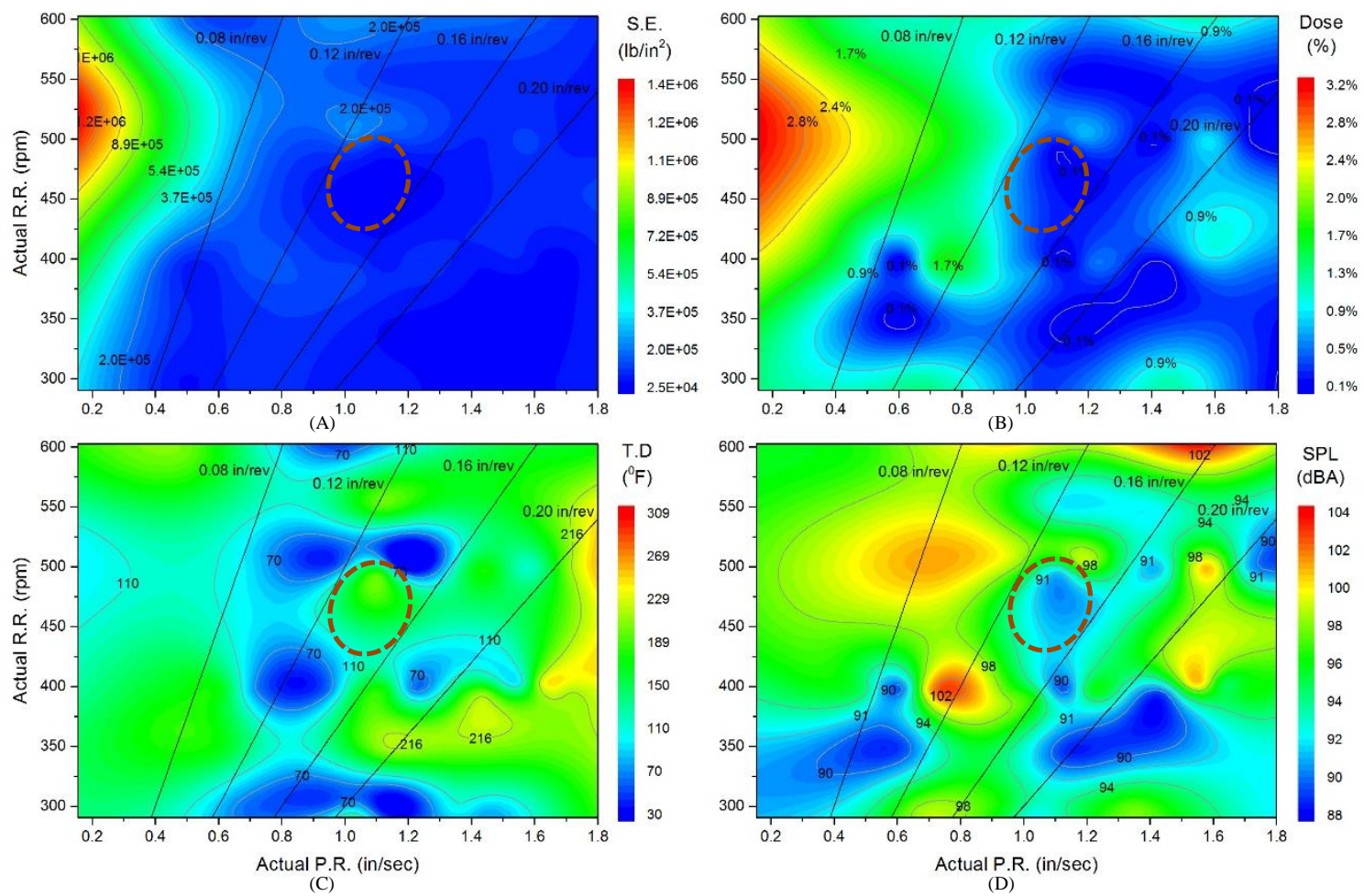

Figure 5.31 Distributions of average specific energy (A), noise dose (B), bit temperature increase (C), and equivalent sound level (D) for the drill operating range of 7/8-in hexagon drill steel 

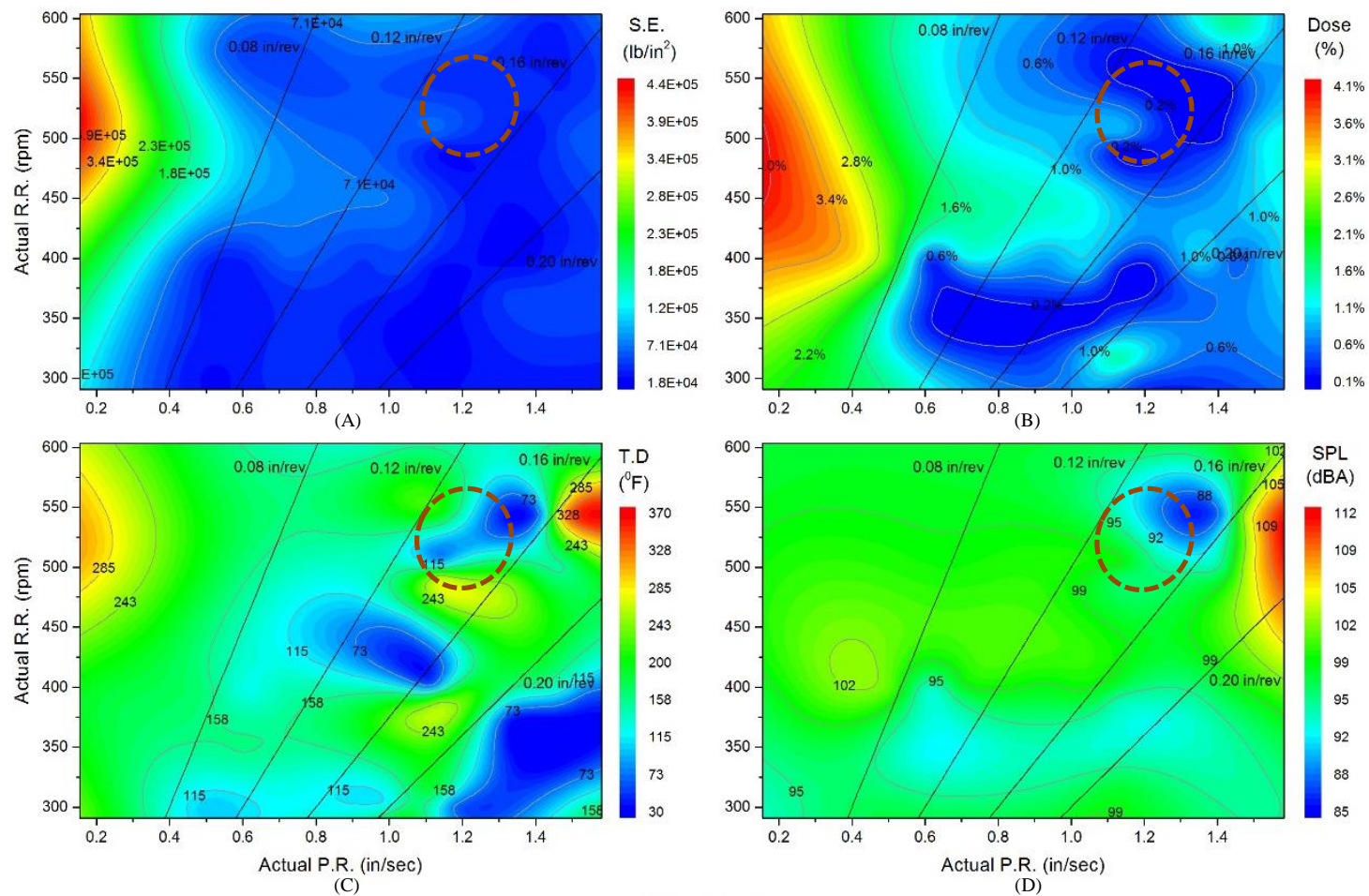

Figure 5.32 Distributions of average specific energy (A), noise dose (B), bit temperature increase (C), and equivalent sound level (D) for the drill operating range of 1-1//8-in hexagon drill steel

\subsection{Drill dust size analysis}

When the roof bolting machine is drilling a hole, rock is broken into small pieces before it is moved out of the drilling hole. The compression and cutting applied by the drill bit break the rock into assorted sizes. When drilling at a very low penetration rate and high rotational rate, robbing occurs, which produces fine dusts. Laboratory observation indicates that the fine dust size during drilling is different when controlling the drilling in different ways.

Dust samples in the drilling holes were collected after drilling several holes grouped by close bite depth. The average bite depth in each group is $0.10,0.13,0.16$, and 
$0.20 \mathrm{in} / \mathrm{rev}$, respectively. The samples collection from the drilling holes were summarized in Table 5.4.

Table 5.4 Dust sample collection in the fourth set of drilling tests

\begin{tabular}{|c|c|c|c|c|c|c|}
\hline Drill steel & $\begin{array}{c}\text { Dust } \\
\text { sample }\end{array}$ & $\begin{array}{c}\text { Average bite } \\
\text { depth } \\
\text { (in/rev) }\end{array}$ & $\begin{array}{c}\text { Sample } \\
\text { weight }(\mathrm{g})\end{array}$ & $\begin{array}{l}\text { Bite depth } \\
\text { (in/rev) }\end{array}$ & $\begin{array}{l}\text { Penetration } \\
\text { rate (in/sec) }\end{array}$ & $\begin{array}{l}\text { Rotational } \\
\text { rate (rpm) }\end{array}$ \\
\hline \multirow{11}{*}{ 7/8 Rd } & \multirow{2}{*}{ Sample 1} & \multirow{2}{*}{0.10} & \multirow{2}{*}{494.94} & 0.10 & 0.6 & 350 \\
\hline & & & & 0.09 & 0.6 & 400 \\
\hline & \multirow{2}{*}{ Sample 2} & \multirow{2}{*}{0.13} & \multirow{2}{*}{219.76} & 0.13 & 1.1 & 500 \\
\hline & & & & 0.12 & 1.1 & 550 \\
\hline & \multirow{3}{*}{ Sample 3} & \multirow{3}{*}{0.16} & \multirow{3}{*}{261.81} & 0.17 & 1.1 & 400 \\
\hline & & & & 0.17 & 1.4 & 500 \\
\hline & & & & 0.15 & 1.4 & 550 \\
\hline & \multirow{4}{*}{ Sample 4} & \multirow{4}{*}{0.20} & \multirow{4}{*}{356.80} & 0.19 & 1.1 & 350 \\
\hline & & & & 0.21 & 1.4 & 400 \\
\hline & & & & 0.20 & 1.7 & 500 \\
\hline & & & & 0.19 & 1.7 & 550 \\
\hline \multirow{11}{*}{ 7/8 Hex } & \multirow{2}{*}{ Sample 5} & \multirow{2}{*}{0.10} & \multirow{2}{*}{307.44} & 0.10 & 0.6 & 350 \\
\hline & & & & 0.09 & 0.6 & 400 \\
\hline & \multirow{2}{*}{ Sample 6} & \multirow{2}{*}{0.13} & \multirow{2}{*}{293.71} & 0.13 & 1.1 & 500 \\
\hline & & & & 0.12 & 1.1 & 550 \\
\hline & \multirow{3}{*}{ Sample 7} & \multirow{3}{*}{0.16} & \multirow{3}{*}{325.00} & 0.17 & 1.1 & 400 \\
\hline & & & & 0.17 & 1.4 & 500 \\
\hline & & & & 0.15 & 1.4 & 550 \\
\hline & \multirow{4}{*}{ Sample 8} & \multirow{4}{*}{0.20} & \multirow{4}{*}{383.97} & 0.19 & 1.1 & 350 \\
\hline & & & & 0.21 & 1.4 & 400 \\
\hline & & & & 0.20 & 1.7 & 500 \\
\hline & & & & 0.19 & 1.7 & 550 \\
\hline \multirow{11}{*}{$\begin{array}{l}1-1 / 8 \\
\text { Hex }\end{array}$} & \multirow{2}{*}{ Sample 9} & \multirow{2}{*}{0.10} & 32858 & 0.10 & 0.6 & 350 \\
\hline & & & & 0.09 & 0.6 & 400 \\
\hline & Sample 10 & 013 & 28720 & 0.13 & 1.1 & 500 \\
\hline & & 0.15 & & 0.12 & 1.1 & 550 \\
\hline & & & & 0.17 & 1.1 & 400 \\
\hline & Sample 11 & 0.16 & 286.25 & 0.17 & 1.4 & 500 \\
\hline & & & & 0.15 & 1.4 & 550 \\
\hline & & & & 0.19 & 1.1 & 350 \\
\hline & & 0.20 & 327.55 & 0.21 & 1.4 & 400 \\
\hline & Sample 12 & 0.20 & 321.55 & 0.20 & 1.7 & 500 \\
\hline & & & & 0.19 & 1.7 & 550 \\
\hline
\end{tabular}


The rock dust samples were separated using Sieves and Ra-tap machine. The nest of sieves used is as follows: bottom pan, 74 um (200 mesh Tyler), 149 um (100 mesh Tyler), 250 um (60 mesh), 595 um (28 mesh), 1190 um (14 mesh), and lid. The weight of the following size ranges were measured: $<0.074 \mathrm{~mm}, 0.074-0.149 \mathrm{~mm}, 0.149-0.25 \mathrm{~mm}$, 0.25-0.595 $\mathrm{mm}, 0.595-1.19 \mathrm{~mm}$, and $>1.19 \mathrm{~mm}$. The photo of the separated dust sample in each size range is shown in Figure 5.33.

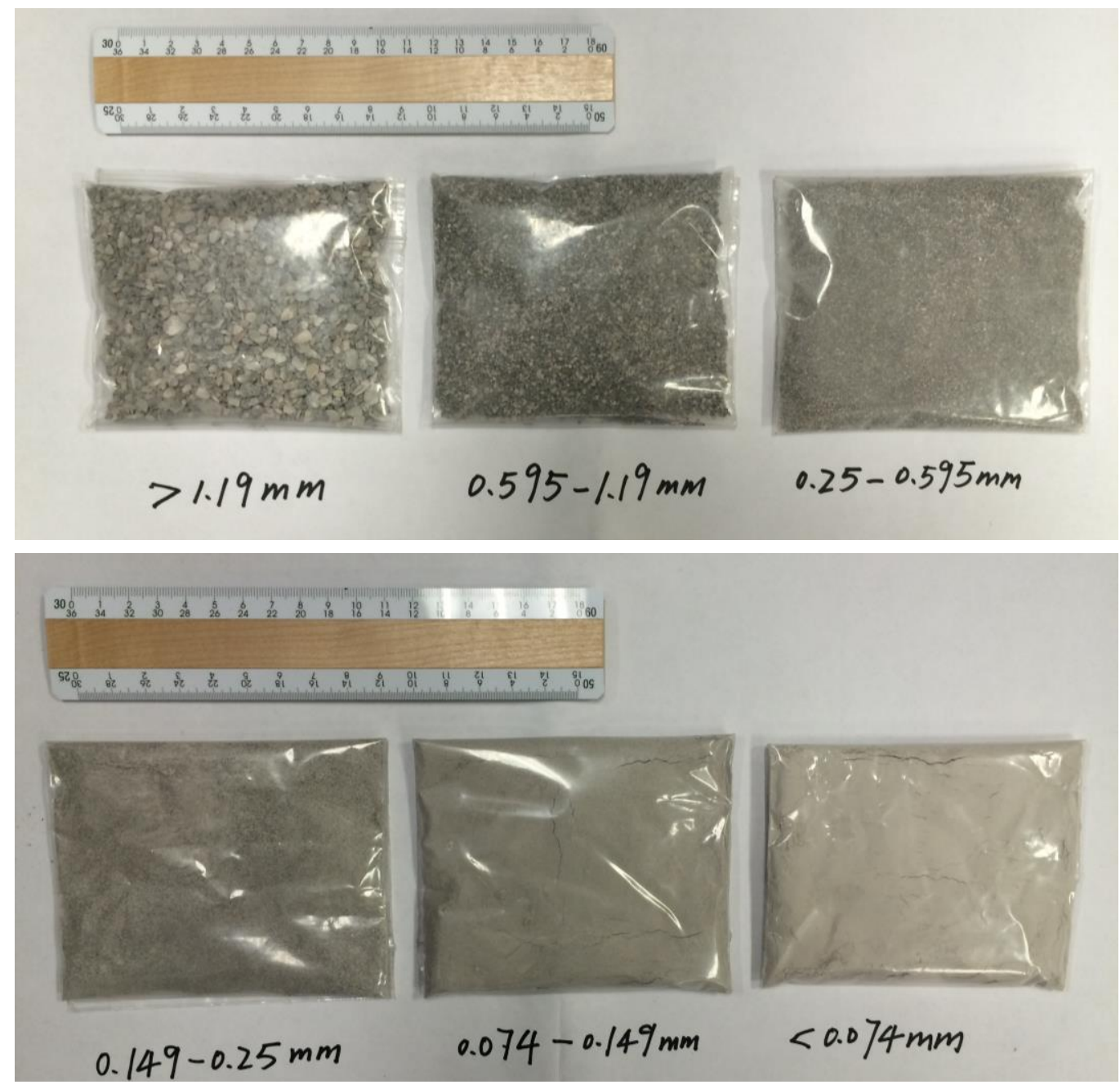

Figure 5.33 Rock dust sample separated at varying particle sizes 
The weight percentages of rock dust of varying particle sizes are computed. Figure 5.34 shows the weight percentages of the rock dust for the 7/8-in round drill bitsteel combination. It shows that drilling at $0.10 \mathrm{in} / \mathrm{rev}$ produces the highest percentage of fine rock dust whose diameter is less than $0.1 \mathrm{~mm}$, while drilling at $0.16 \mathrm{in} / \mathrm{rev}$ and 0.20 in/rev produce the lowest percentages of fine dust with diameter less than $0.1 \mathrm{~mm}$. The size distributions of dust when drilling at $0.16 \mathrm{in} / \mathrm{rev}$ and $0.20 \mathrm{in} / \mathrm{rev}$ are almost the same. Those results indicate that the higher the bite depth, the lower of the percentages of fine dust diameter less than $0.1 \mathrm{~mm}$ is produced when drilling utilizing 7/8-in round bit-steel combination.

The average particle size are also analyzed using the weight percentages at the varying size ranges as shown in Table 5.5. According to the observation of the particles, the diameters of the particles diameter smaller than $0.074 \mathrm{~mm}$ and larger than $1.19 \mathrm{~mm}$ are estimated to be $0.037 \mathrm{~mm}$ and $2.38 \mathrm{~mm}$, respectively. For the $7 / 8$ round drill steel, the average particle size diameter is in order of the bite depth, which means drilling at a higher bite depth produce larger average particles.

The correlations of the dust size distribution and the bite depth for the $7 / 8$-in hexagon (Figure 5.35) and 1-1/8-in hexagon (Figure 5.36) have the same trend but different from that of the 7/8-in round bit-steel combination. Drilling at $0.13 \mathrm{in} / \mathrm{rev}$ produces the lowest percentage of fine dust with diameter less than $0.1 \mathrm{~mm}$ while drilling at highest bite depth, $0.2 \mathrm{in} / \mathrm{rev}$ produced the highest percentage of fine dust with diameter less than $0.1 \mathrm{~mm}$. For drilling utilizing 7/8-in hexagon and 1-1/8 hexagon bitsteel combination, the average dust diameter is the largest when drilling at $0.13 \mathrm{in} / \mathrm{rev}$ while that is highest when drilling at $0.20 \mathrm{in} / \mathrm{rev}$. 


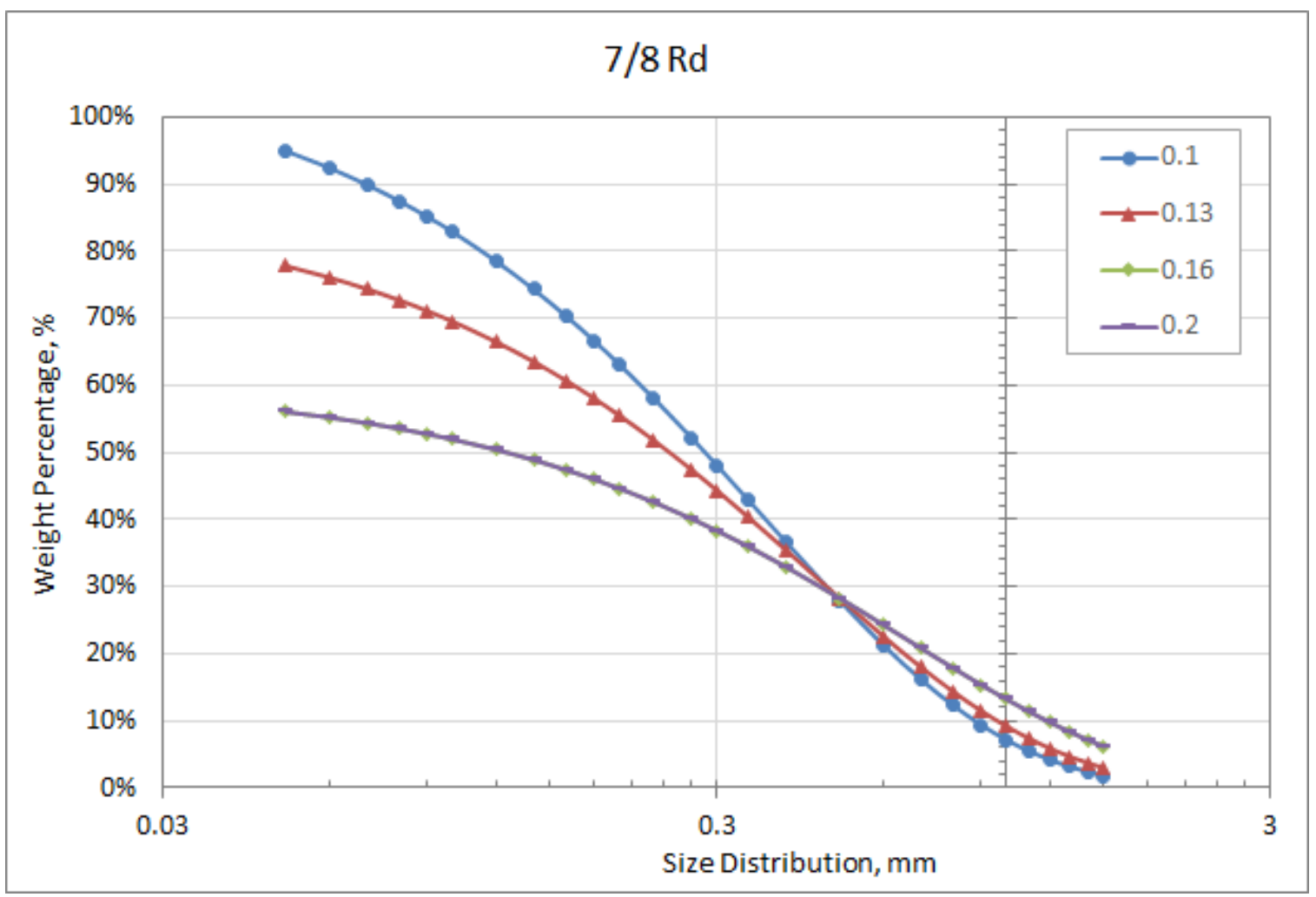

Figure 5.34 Particle size distribution of dust in drilling tests using 7/8-in round drill steel

Table 5.5 Average particle size for drilling tests at different bite depth

\begin{tabular}{|c|c|c|c|c|c|}
\hline Average bite depth (in/rev) & & 0.1 & 0.13 & 0.16 & 0.2 \\
\hline \multirow{4}{*}{ Average particle size (mm) } & $7 / 8 \mathrm{Rd}$ & 0.51 & 0.67 & 0.85 & 0.90 \\
\cline { 2 - 6 } & $7 / 8 \mathrm{Hex}$ & 0.98 & 1.10 & 0.96 & 0.58 \\
\cline { 2 - 6 } & $1-1 / 8 \mathrm{Hex}$ & 0.90 & 1.08 & 1.02 & 0.62 \\
\hline
\end{tabular}




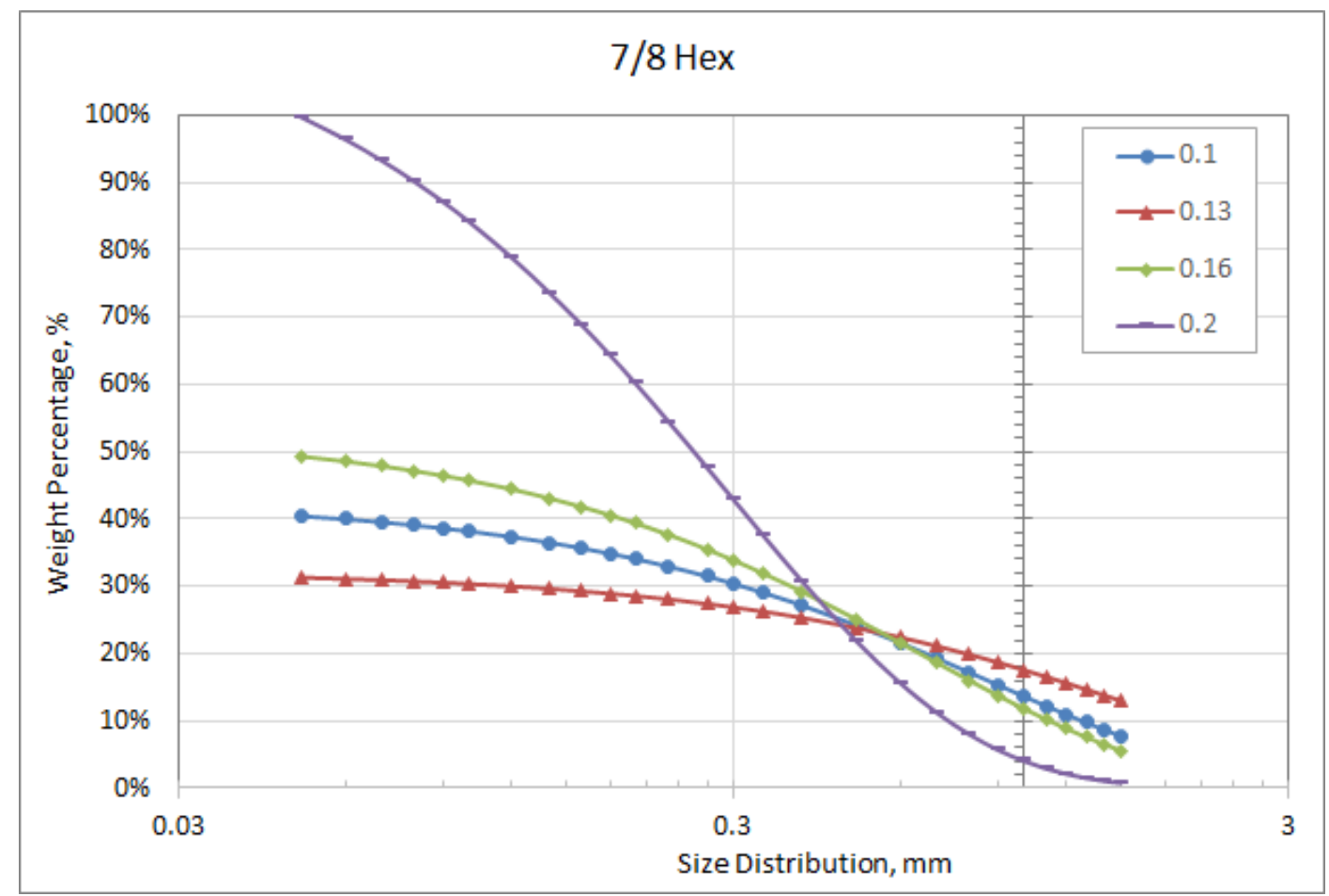

Figure 5.35 Particle size distribution of dust in drilling tests using 7/8-in hexagon drill steel

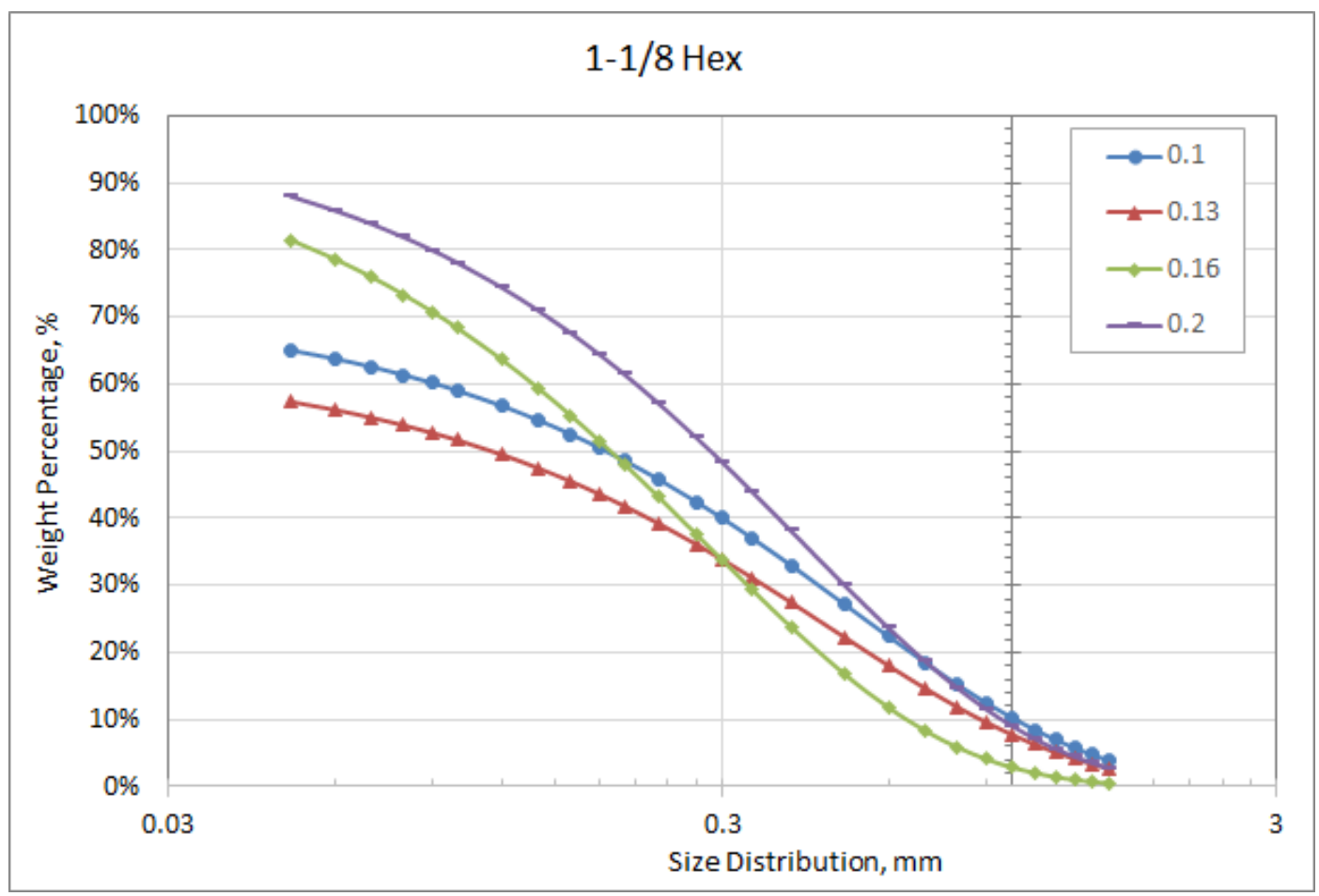

Figure 5.36 Particle size distribution of dust in drilling tests using 1-1/8-in hexagon drill steel 
As the fine dust is more important to human respirable system than the coarse dust, the dust samples smaller than $74 \mu \mathrm{m}$ were further analyzed. The Cilas 1190 Particle Size Analyzer was used for the analysis. This equipment was able to analyze the size and volume distribution of particle samples from 0.04 to $2,500 \mu \mathrm{m}$. The size distribution of thoracic aerosol $(<25 \mu \mathrm{m})$ and respirable dust $(<5 \mu \mathrm{m})$ are also analyzed.

The cumulative volume percentage of particles less than $74 \mu \mathrm{m}$ for the $7 / 8$ hexagon drill steel is plotted as an example (Figure 5.37). In each drill steel, the size distributions of samples of four different average bite depths show a similar trend. For the different drilling bite depths, the size composition of each individual sample deviates from each other to some small degree.

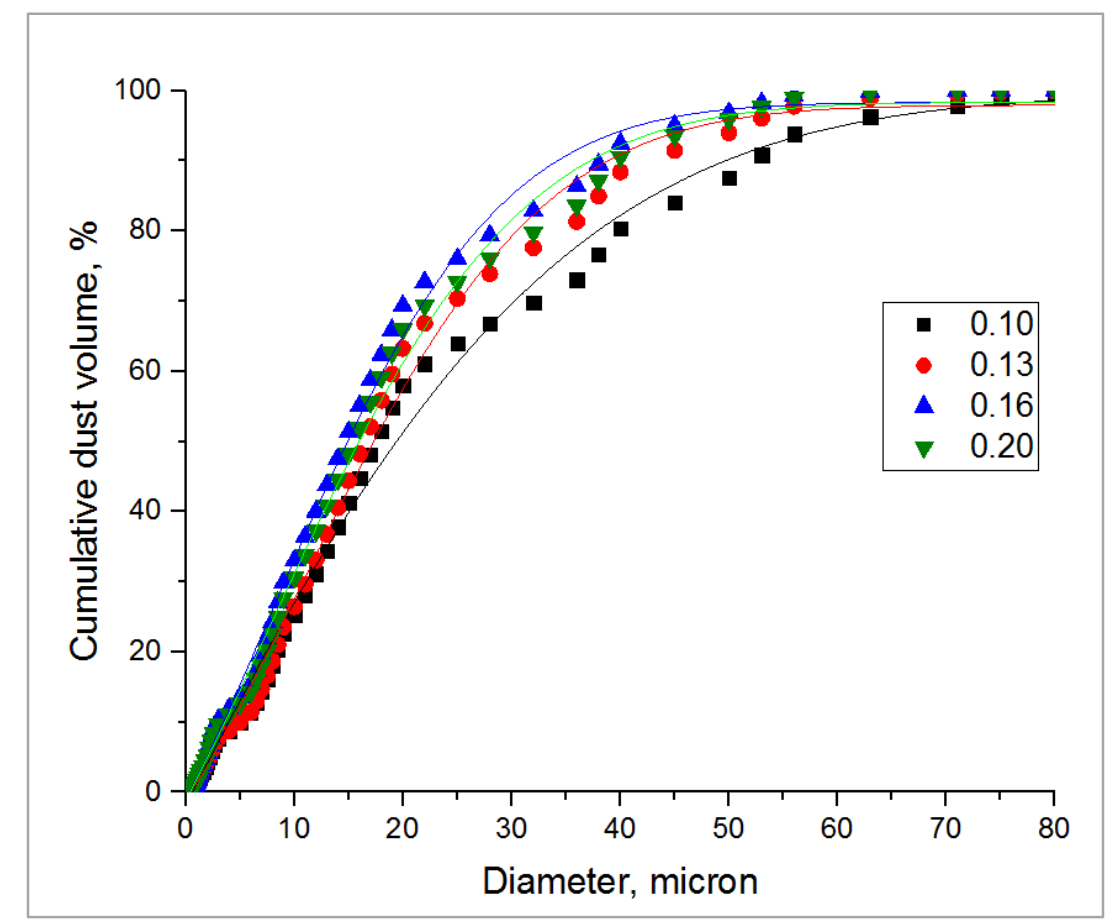

Figure 5.37 Cumulative volume percent of dust smaller than $74 \mu \mathrm{m}$ for $7 / 8$ hex drill steel 
The size distribution of particles less than $25 \mu \mathrm{m}$ and $5 \mu \mathrm{m}$ are shown in Figure 5.38 and 5.39, respectively. From Figure 5.38, the order of volume percentage for the four different bite depths from lowest to highest is: $0.13,0.10,0.20$, and 0.16 for the particles smaller than $10 \mu \mathrm{m}$. Reversed order of volume percentage occurs for the particles larger than $10 \mu \mathrm{m}$. For the particles smaller than $5 \mu \mathrm{m}$, the distribution is very similar when drilling at different bite depths. The highest percentages of particles are at particle diameter of about $2.2 \mu \mathrm{m}$. There is about $2 \%$ lower value of bite depth $0.13 \mathrm{in} / \mathrm{rev}$ than other bite depths. The small differences of particle size distribution may be because the differences between the four bite depths are small. The Figures show that size distribution of particles, when drilling at different bite depths, could be different. The particle size distribution for bite depths in a wider range need to be analyzed in future work (e.g. bite depth from 0.3 to $2.8 \mathrm{in} / \mathrm{rev}$ ). 


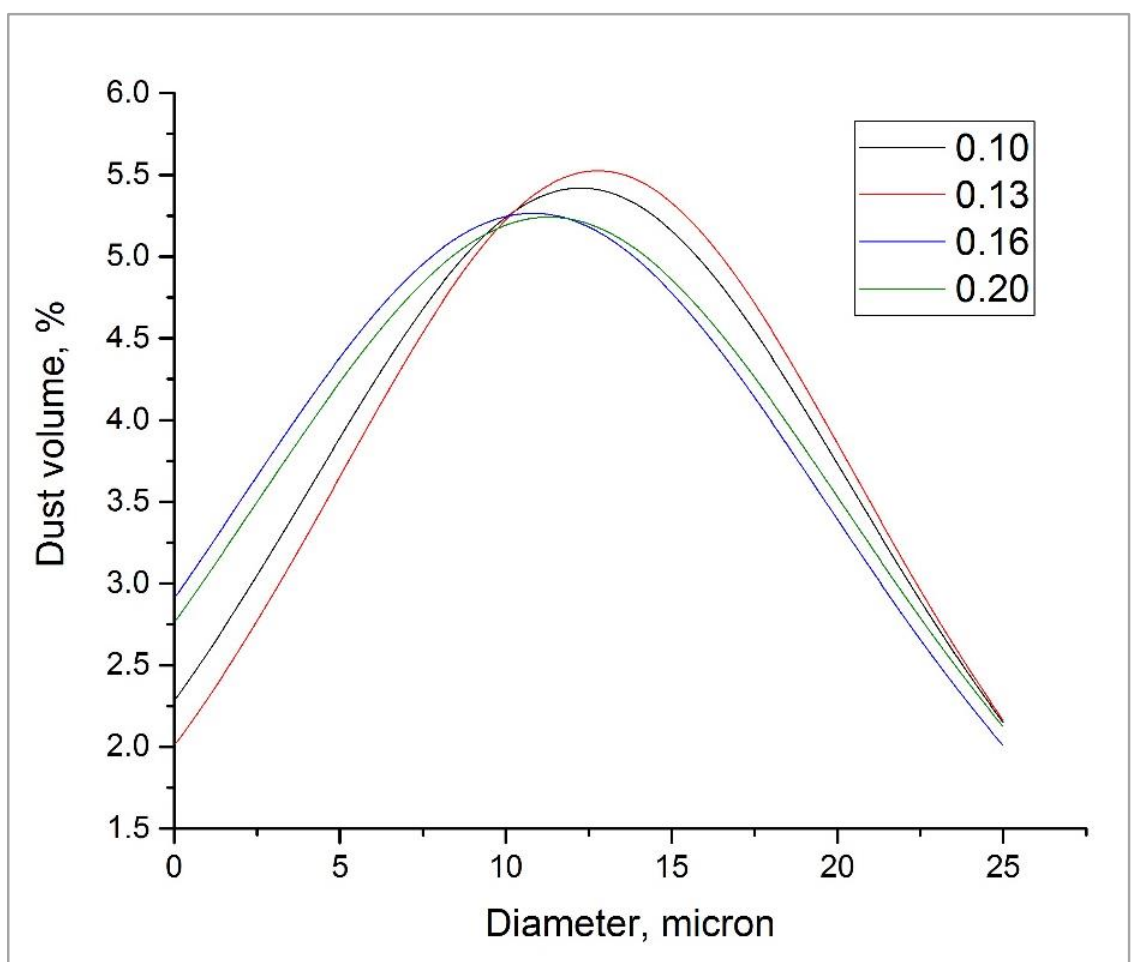

Figure 5.38 Size distribution of dust smaller than $25 \mu \mathrm{m}$ for $7 / 8$ hex drill steel

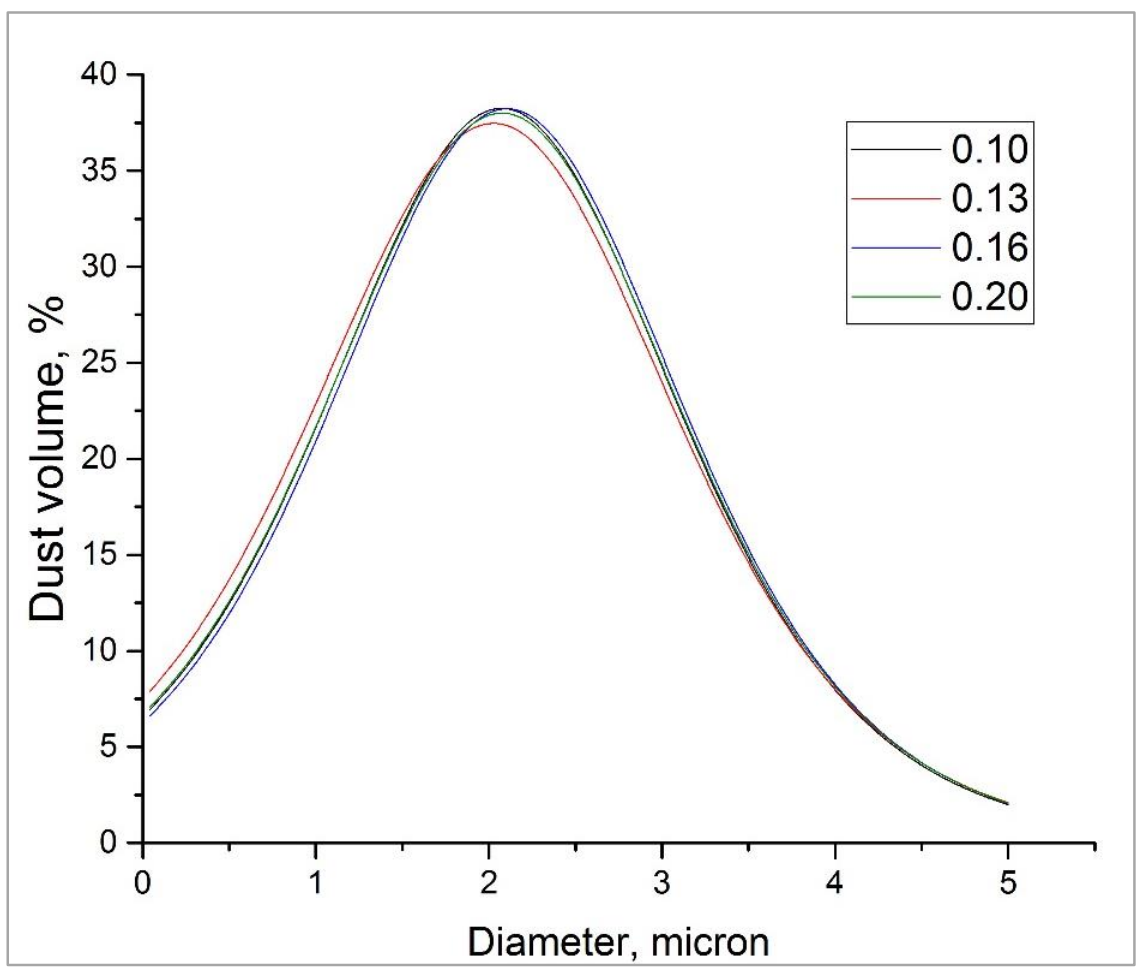

Figure 5.39 Size distribution of dust smaller than $5 \mu \mathrm{m}$ for $7 / 8$ hex drill steel 


\subsection{Summary of test results}

The feasibility of controlling noise through proper drilling control has been proven through laboratory experiments. Drilling tests are conducted on medium hard cement using different drill bit-steel combinations and varying drilling parameters (penetration rate and rotational rate). From the test results, lower specific energy and higher energy efficiency can be achieved at a properly selected high bite depth as a function of the design of the drill bit and compressive strength of the rock. The optimal operation parameters for drilling similar compressive strength rock are recommended for each type of drill bit-steel combination.

By reducing wasted energy and improving the energy efficiency, the heat, noise, fine dust, and bit wear are expected to be reduced. Through proper control of the drilling parameters according to rock type, the noise exposure doses to the roof bolter operators can be significantly reduced, while the bolting productivity is not affected or is even improved. 


\section{CHAPTER 6 DEVELOPMENT OF DRILLING CONTROL TECHNOLOGY}

\subsection{Drill control algorithm}

The laboratory testing results prove that drilling can be controlled by rational drilling parameters to achieve higher energy efficiency and lower noise dose. At the same time, the bit wear and fine dust can also be reduced while the productivity will not to be affected or may even be improved. In order to achieve the set objectives, the envisioned drill control process for a bolt hole is shown in Figure 6.1. At a given position of drilling a bolt hole, the drilling parameters (i.e., thrust, torque, penetration rate, and rotational rate) are obtained. Instantaneous parameters are used for the determination of the rock strength. Meanwhile the noise level, specific energy required to drill this type of rock, and the energy efficiency can be estimated. Then the drilling control algorithms will be used to adjust the drilling operation for achieving different goals (reduced sound power levels, increased drilling efficiency, and drilling safety, etc).

If the rock is determined to be soft (e.g., claystone and soft shale) based on the drilling parameters feedback information, drilling noise is not a main concern in the drilling operation. However, clogging of the drill bit and steel by oversized or plasticized rock debris can considerably increase the idle time. As an additional goal, a drilling control algorithm to avoid producing oversized or plasticized cuttings is to be developed that determines the appropriate thrust and rotational speed based on the determined rock strengths and the drill bit. 


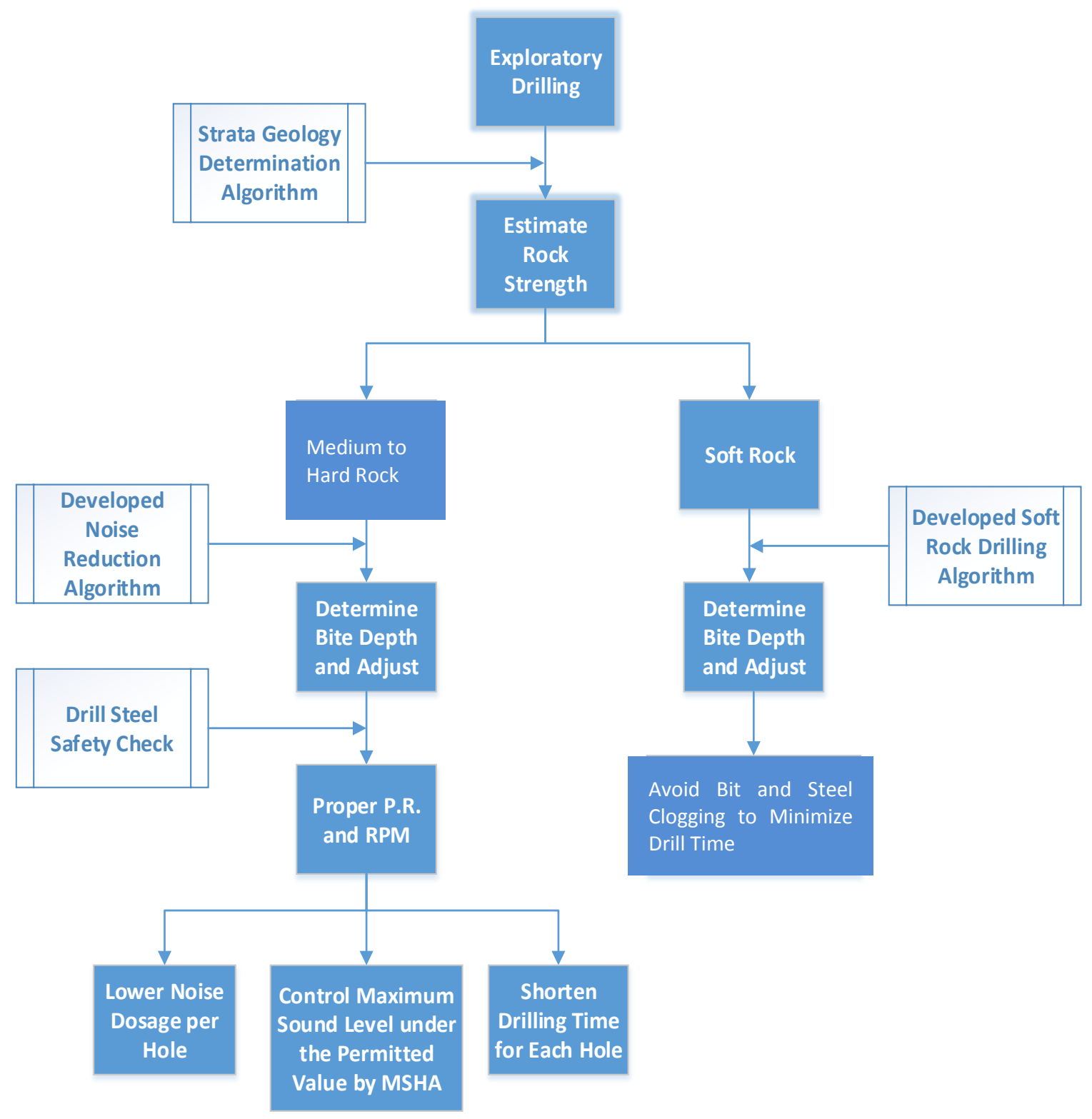

Figure 6.1 Drill control algorithm 


\subsection{Minimum specific energy of drilling}

From the drilling test results, the specific energy shows a good correlation with noise dose, as discussed in 5.4. It is reasonable to assume that by controlling the drilling parameters to achieve less specific energy, the noise dose of roof bolter operators can be significantly reduced.

The minimum specific energy of rock drilling was found to be correlated to the compressive strength of the drilled rock. Teale (1965) studied drilling data from a number of sources and found the minimum specific energy appears to be very roughly correlated with the crushing strength of the medium drilled in for rotary, percussive rotary and rollbit drilling. Simon (1963) reported that the values of the energy required to break out a unit volume of rock under favorable circumstances are substantially in agreement for rotary drilling, percussion drilling and drop testing at atmospheric pressure. The energy per unit volume is a quantity of the order of magnitude of roughly twice the compressive strength of the rock as measured by a uniaxial loading test. The energy per unit volume may range from roughly the same up to several times the compressive strength. In the previous study of the mechanical model for estimating rock strength, the specific energy was found to increase with compressive strength of the rock as shown in Figure 6.2 (Luo et al., 2002). The minimum specific energy of drilling a type of rock of specific rock strength usually can be achieved when the bite depth reaches a relatively high value. 


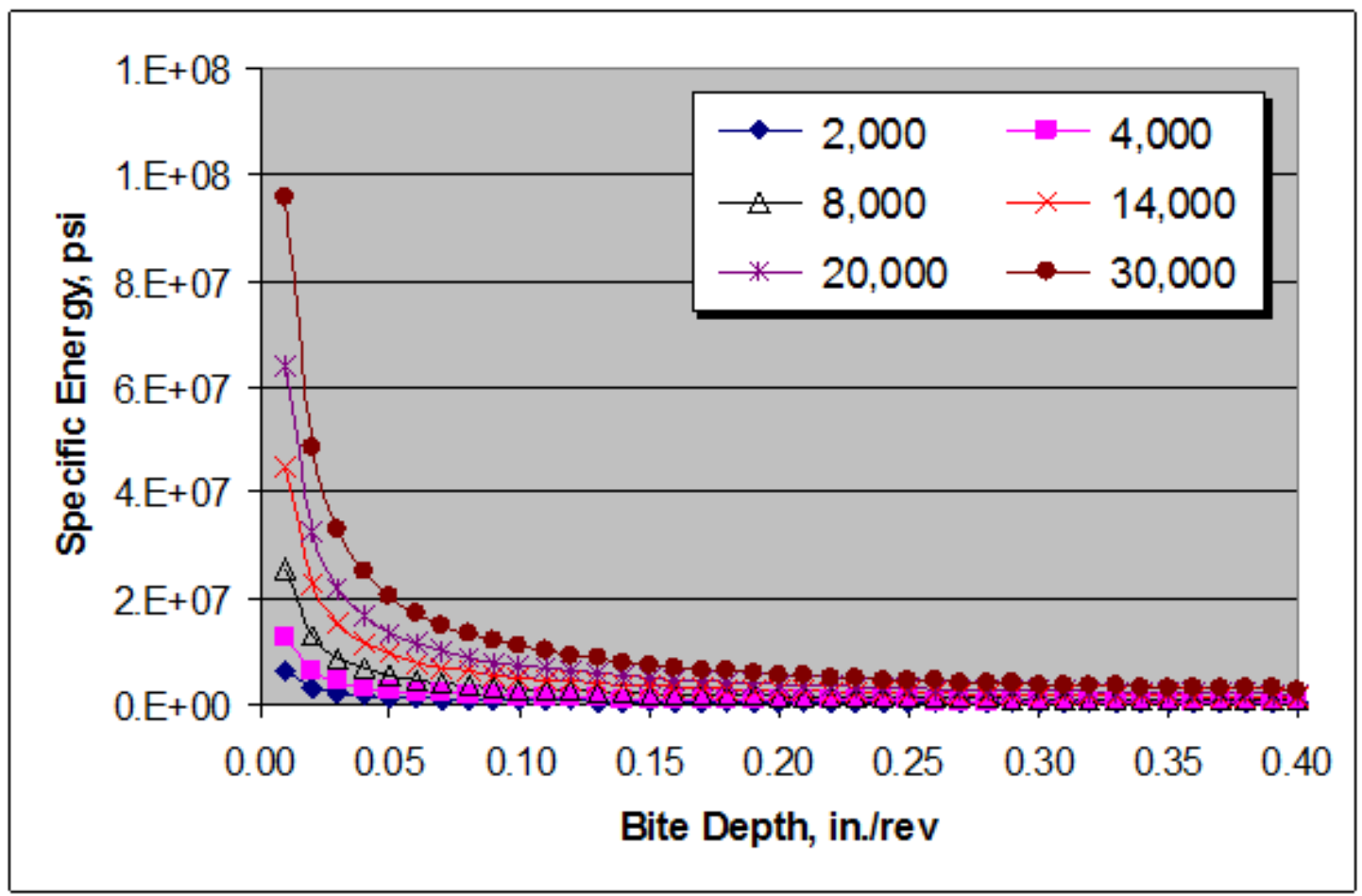

Figure 6.2 Required specific energy for various unconfined compressive strength of rock (Luo et al., 2002)

\subsection{Drilling thrust and torque}

From both the mechanical model and the drilling tests result, the drilling bite depth is correlated with the drilling thrust and torque. The relationship between the drilling thrust and bite depth is shown in Figure 6.3. The thrust correlates with the bite depth as a second order polynomial function. The increased bite depth would result in the increase of thrust. The capability of the drill machine to achieve the desired bite depth is limited by the thrust capability of the drilling system. 


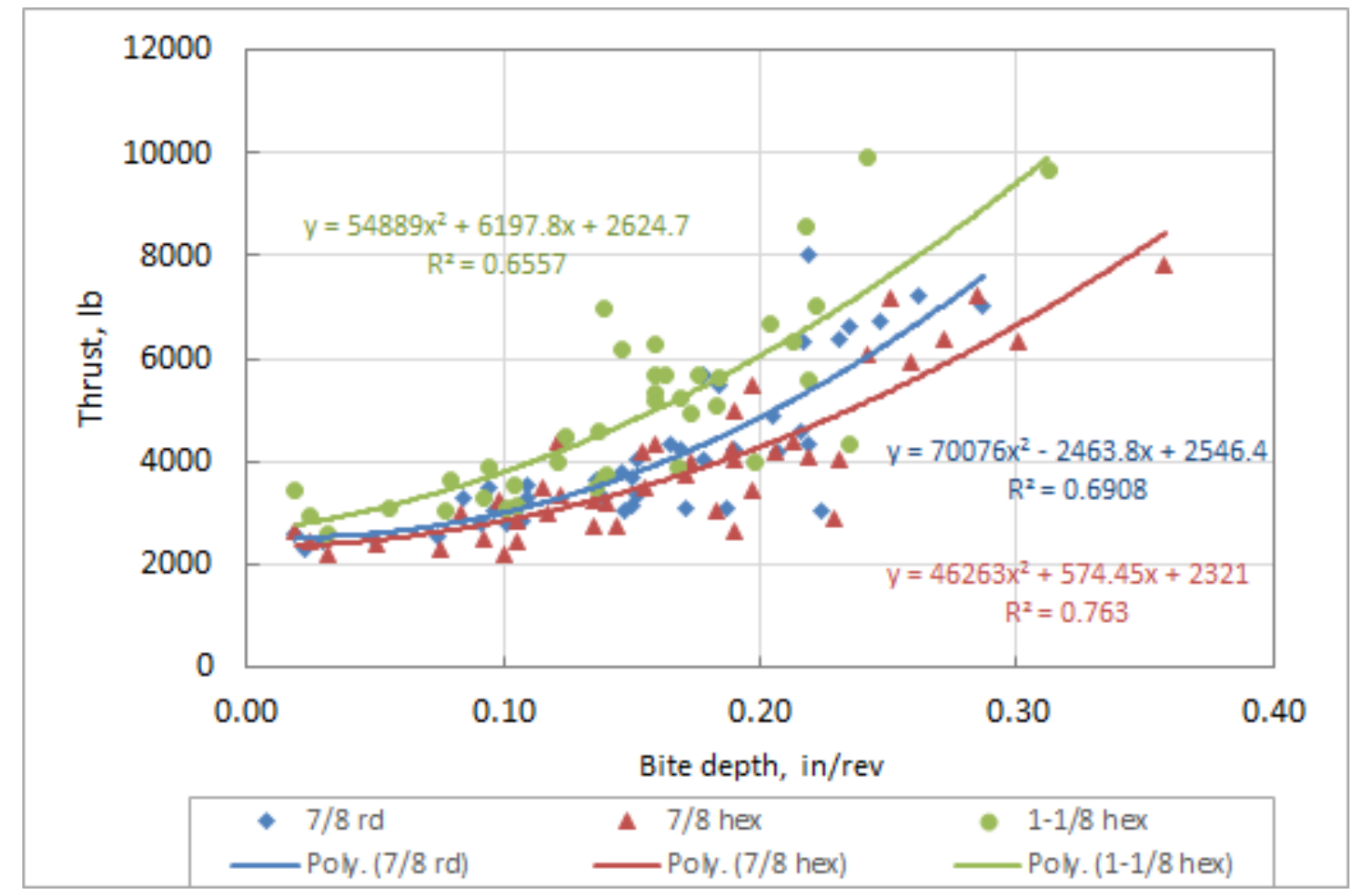

Figure 6.3 Correlations between thrust and bite depth in the drilling tests

From the drilling tests, torque increases as both the penetration rate and rotational rate increase. As the values of the penetration rate and rotational rate are not in the same level, the influence of the penetration rate and rotational rate to the torque are not the same. A scaled drilling parameter is computed to relate the penetration rate and rotational rate to the torque using the following equation:

$$
T=k v^{B} \omega^{C}
$$

Where $v$ is penetration rate,

$\omega$ is rotation rate,

and $k, B, C$ are constant factors 
The computed relationship between the torque and the scaled drilling parameter in the drilling tests are shown in Figure 6.4. The values of the three constants are 10.56, 0.074 , and 0.9198, separately.
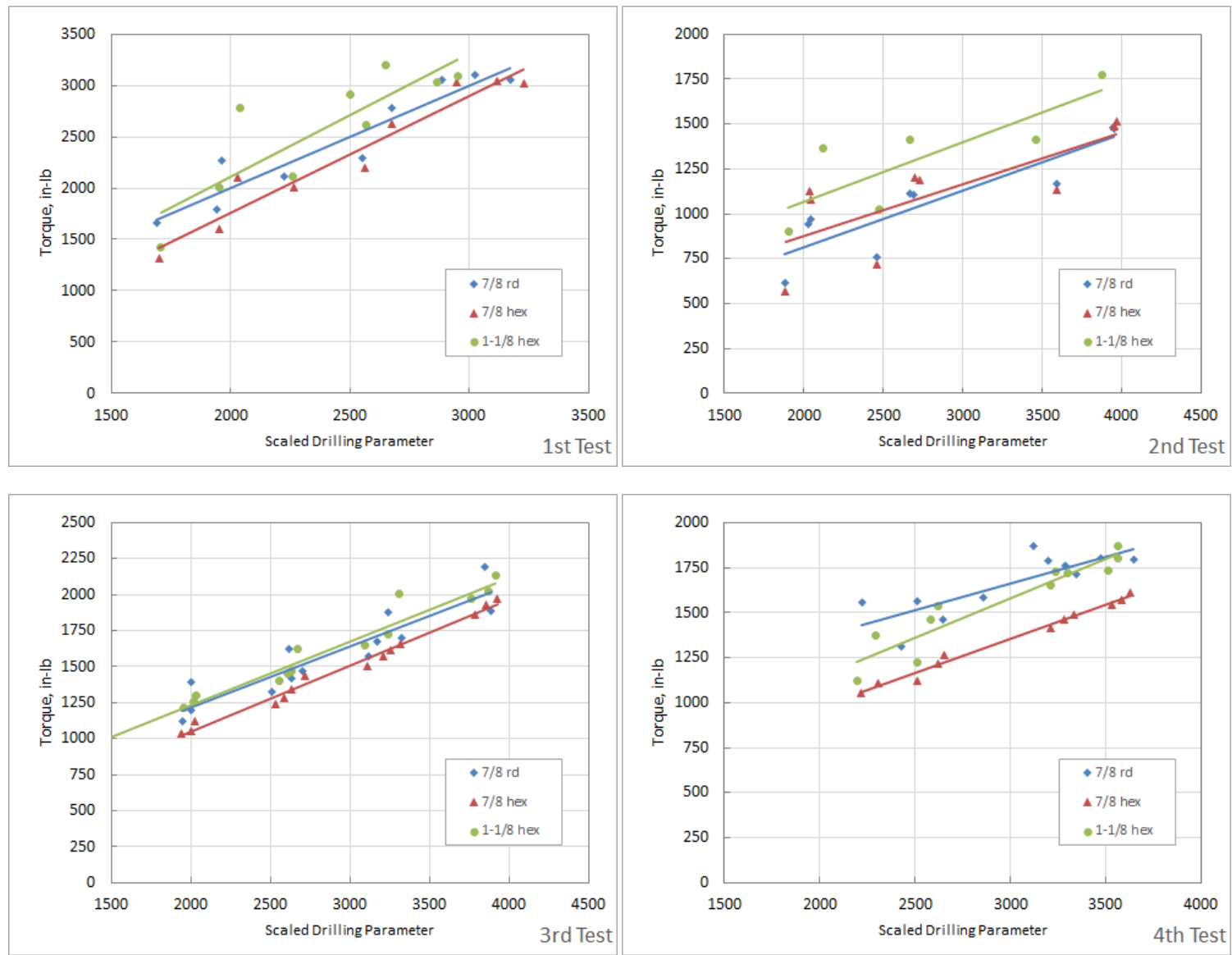

Figure 6.4 Correlations between torque and scaled drilling parameters in the drilling tests

\subsection{Safety checks of drill steels}

As shown previously, a reasonably high drilling bite depth is desirable for the purpose of reducing drilling noise. The previous studies (Luo et al., 2002) have shown that the required thrust and torque increases linearly with bite depth and strengths of the rock. Multiple factors, such as rock strengths, available hydraulic power, and the strength and stiffness of the drill steel, may limit the capability of the drilling machine to achieve 
the preset bite depth. As a technology to improve miners' health, the safety issues have to be adequately addressed first. For roof bolting operation, mechanical failure of the drill steel is one of the first safety concerns. To avoid the failure of drill steel, the maximum thrust and torque permitted by the drill steel should be determined.

\subsubsection{Maximum drilling thrust}

The drilling energy for thrust is used to advance the drill bit. A high thrust is required to achieve a high bite depth in drilling hard rock. It should be noted however that excessive thrust may cause buckling of the drill steel if it is laterally deformed, creating a safety hazard. Buckling is characterized by a sudden failure of a column-type structural member subjected to high axial compressive stress even though the actual compressive stress at the point of failure maybe much less than the ultimate compressive stresses. The maximum or critical thrust $\left(F_{\max }\right)$ that would cause the drill steel to buckle when a slight lateral force is introduced can be determined as the following equation.

$$
F_{\text {max }}=\frac{\pi^{2} E I}{(K L)^{2}}
$$

Where: $F_{\max }$ is the maximum or critical thrust

$E$ is the Young's modulus of the drill steel material

$I$ is the area moment of inertia

$L$ is the unsupported length of the drill steel

$K$ is the column effective length factor 
The drill steel is considered as fixed at the bottom while pinned at the top at the beginning of drilling a bolt hole and $K=0.699$. Once the drill bit is completely located inside the bolt hole, both ends can be considered as fixed and $K=0.5$.

The two types of drill steel used in the tests are round and hexagonal hollow bars. The area moments of inertia for these two types of drill steels $\left(I_{R d}\right.$ and $\left.I_{H e x}\right)$ depend on the inner and outer diameters of the steels $\left(D_{I}\right.$ and $\left.D_{O}\right)$ and can be determined by the following two equations.

$$
\begin{gathered}
I_{R d}=\frac{\pi}{64}\left(D_{O}^{4}-D_{I}^{4}\right) \\
I_{H e x}=\frac{5 \sqrt{3}}{256} D_{O}^{4}-\frac{\pi}{64} D_{I}^{4}
\end{gathered}
$$

Where: $I_{R d}$ is the area moment of inertia of round drill steel

$I_{H e x}$ is the area moment of inertia of round drill steel

$D_{O}$ is outer diameter of drill steel and $D_{I}$ is inner diameter of drill steel

\subsubsection{Maximum drilling torque}

Torque provided to the drill head causes the rotation of the drill string. Torque induces shear stress in the drill steel and the maximum shear stress occurs at the outer surface of the cross-sectional area. The shear stress is related to the torque, diameter of the outer surface $(D o)$ and the polar second moment of area $(J)$. The maximum allowable torque $\left(T_{\max }\right)$ to prevent shear failure is determined by the following equation (Marghitu, 2001). 


$$
T_{\max }=\frac{\tau_{\mathrm{all}} J}{D_{o}}
$$

In this equation, $\tau_{\text {all }}$ is the maximum allowable distortion stress. According to the distortion energy theory, the maximum allowable distortion stress for steels is a fraction of its ultimate tensile strength $\left(\mathbf{S}_{u t}\right)$ as shown in the following equation (Marghitu, 2001).

$$
0.35 S_{\mathrm{ut}} \leq \tau_{\text {all }} \leq 0.52 S_{u t}
$$

The polar second moments of area for the round and hexagonal drill steels can be determined using the following two equations, respectively. Their magnitudes are essentially twice of the area moments of inertia in Equation (5.5) and (5.6) respectively.

$$
\begin{gathered}
J_{R d}=\frac{\pi}{32}\left(D_{O}^{4}-D_{I}^{4}\right) \\
J_{H e x}=\frac{5 \sqrt{3}}{128} D_{O}^{4}-\frac{\pi}{32} D_{I}^{4}
\end{gathered}
$$

Using Equation (6.2), (6.5), (6.7), and (6.8), the maximum allowable thrust and torque for the drill steel for safety can be determined, and the results are plotted in Figure 6.5 and Figure 6.6, respectively. In determining the maximum torque, the ultimate strength of 100,000 psi (690 Mpa) is used for the drill steel. When drilling with long steel in hard rock, the maximum allowable thrust could become a critical limiting factor for achieving the desirable bite depth. The figures also show that the $7 / 8$-in round drill steel used in the experiments is stronger than the 7/8', (22 mm) and 1-1/8', (28.6 mm) hexagonal drill steels in terms of withstanding higher drilling thrust and torque. 


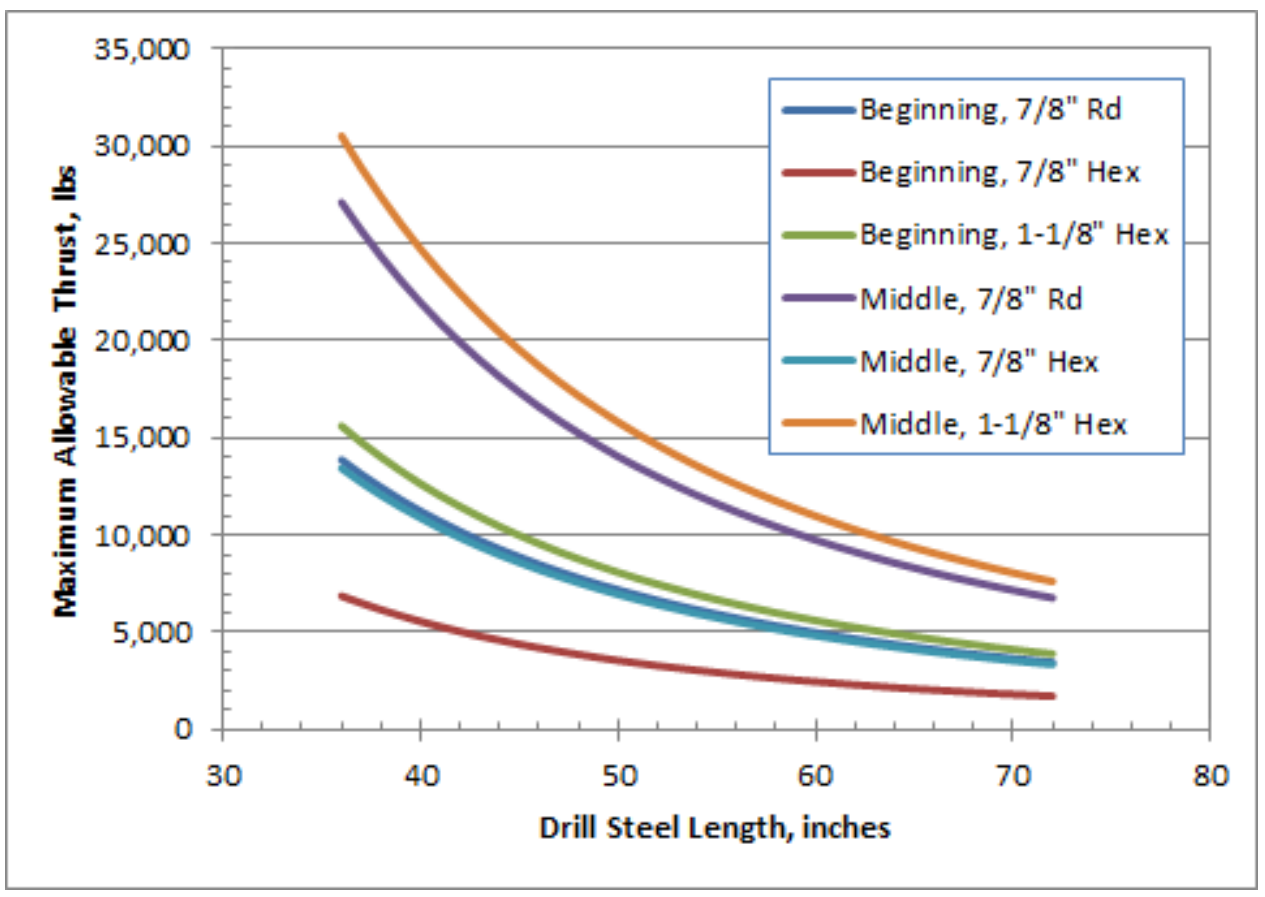

Figure 6.5 Maximum allowable thrusts for the three types of drill steel in the beginning and middle drilling stages

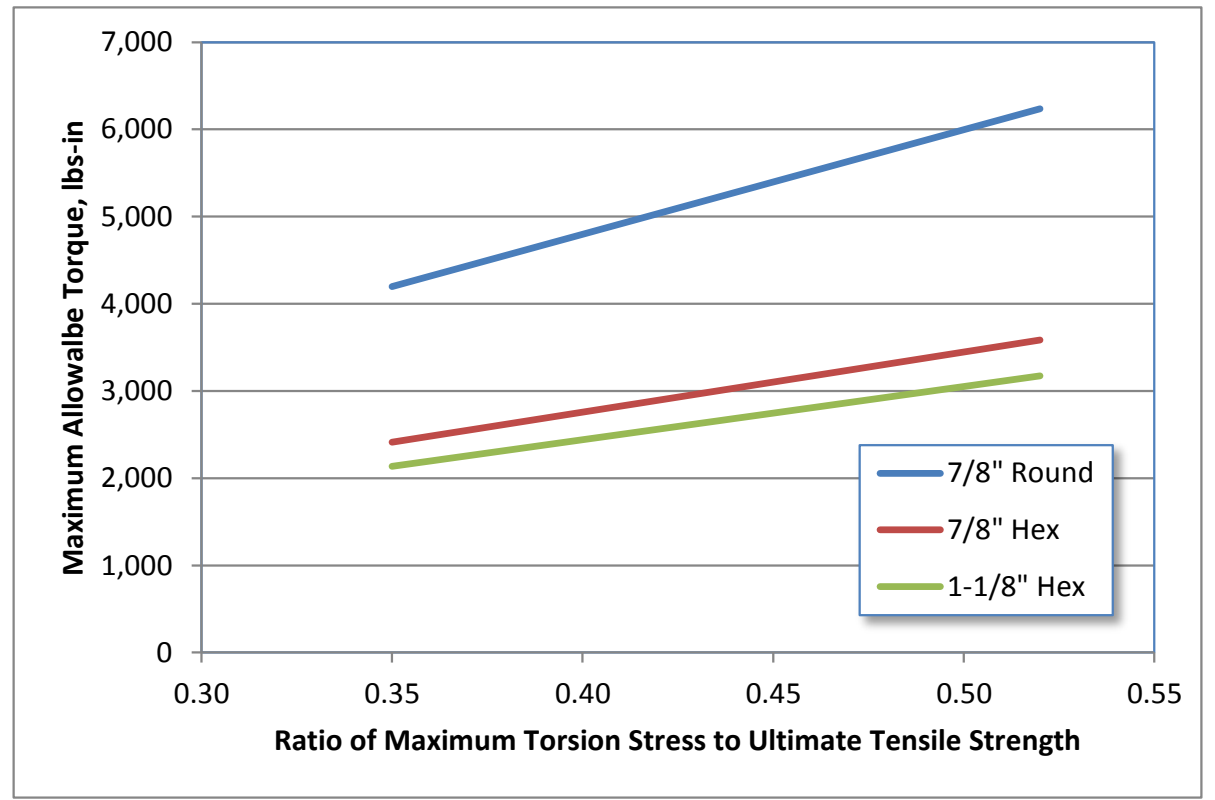

Figure 6.6 Maximum allowable torque of the three types of drill steels 


\subsection{Summary}

A drilling control algorithm is developed to control the drilling to achieve the lower specific energy. The lower specific energy means higher energy efficiency and less energy is wasted to produce noise, heat, and fine dust. By controlling the drilling to achieve lower specific energy, the goal of reducing noise dose, reducing bit wear and fine dust can be achieved. A relatively high bite depth for drilling is desired to achieve the minimum specific energy. However, the capability of the drilling to achieve the desired bite depth is limited by the drilling thrust and torque of the drill system. The maximum drilling thrust and torque for the drill steel are computed. The drilling should be controlled below the maximum allowable drilling thrust and torque of the drill steels to ensure safe drilling operation. 


\section{CHAPTER 7 CONCLUSIONS AND RECOMMENDATIONS}

\subsection{Conclusions}

The objective of this research is to develop a drilling control technology to reduce the noise exposure of roof bolter operators. This technology is an active engineering control method for noise control. It reduces the noise exposure of roof bolter operators by reducing the noise generation from its source. One big advantage of utilizing this noise control technology is that it does not change the design of the existing drilling tools or add any additional parts to the drilling machine.

This research is based on a previous research which showed that the specific energy consumed in drilling bolt holes is inversely proportional to the bite depth (penetration per drill revolution). Less specific energy at a reasonably high bite depth

means less energy is wasted in the drilling process for producing heat, bit wear, and noise. Therefore, proper control of the drilling operation to achieve a reasonably higher bite depth can reduce the drilling noise from its sources.

Laboratory drilling tests have been conducted to investigate and prove the feasibility of this noise control method. Drilling control in the drilling tests was implemented drilling with different penetration rates and rotational rates utilizing different drill bit-steel combinations by drilling medium hard rock. The results show that significant reduction in noise dose can be achieved by drilling at a reasonably high bite depth, about $0.16 \mathrm{in} / \mathrm{rev}$. The noise dose and specific energy correlate with each other well with an exponential relationship. To the different drill bit-steel combinations, the larger size (1-1/8-in hexagon) drill bit-steel combination produced the lowest specific 
energy but highest noise dose. The 7/8-in round drill bit-steel combination produced the lowest noise dose.

The four variables of interest including the derived specific energy, noise dose, sound pressure level, and temperature increases of drill bit before and after drilling were employed to optimize the drilling parameters by plotting them in contour forms. For the 7/8-in round and hexagon drill bit-steel combination, the recommended operation range for the penetration rate is about $0.9-1.2 \mathrm{in} / \mathrm{sec}$, and for the rotational rate is about $420-500$ rpm for drilling the rock with similar strengths of the testing block. For the 1-1/8-in hexagon drill bit-steel combination, the recommended operation range for the penetration rate is about $1.0-1.3 \mathrm{in} / \mathrm{sec}$, and for the rotational rate is about $480-560 \mathrm{rpm}$ for drilling the rock with similar strengths of the testing block.

Efforts were also focused on controlling the drilling to reduce fine dust. The size distributions of rock dust when drilling at four bite depths were analyzed. The correlations between the weight percentages of fine dust (in this study, refers to dust of diameter less than $0.1 \mathrm{~mm}$ ) generated during drilling tests and the bite depth were studied. For the 7/8-in round drill steel, drilling at a higher bite depth $(0.16 \mathrm{in} / \mathrm{rev}$ or $0.20 \mathrm{in} / \mathrm{rev})$ produced the lowest percentages of fine dust, while drilling at the lowest bite depth produced the highest percentages of fine dust among the analyzed samples. But for the 7/8-in hexagon and 1-1/8-in hexagon drill bit-steel combinations, drilling at $0.13 \mathrm{in} / \mathrm{rev}$ produced the lowest percentages of fine dust, while drilling at $0.20 \mathrm{in} / \mathrm{rev}$ produced the highest percentages of fine dust.

A theoretical drilling control algorithm for roof bolting operations was provided in this research for finding the rational drilling control parameters that can minimize 
specific energy of drilling and the noise dose of the roof bolter operators according to the immediate rock strength and the drill steel used. A safety evaluation of the drill steels is also included in this algorithm. Utilizing this control technology, the noise dose of roof bolter operators can be significantly reduced while the safety performance and drilling productivity will not be sacrificed. The algorithm can be incorporated into the existing drill control unit for potential drilling automation.

\subsection{Research Significance}

The significance of this research is that by controlling the drilling process in the roof bolting operation several goals can be achieved: 1) reduce the noise dose of roof bolter operators, 2) increase the energy efficiency and productivity of drilling operation, 3) reduce bit wear and fine dust, and 4) maintain safe performances.

\subsection{Recommendations for future research}

This research has provided the mining industry with the information that proves through proper control of drilling, the noise exposure of roof bolter operators can be significantly reduced. The rational operation ranges for the penetration rate and rotational rate by drilling this type of medium strength cement block were recommended. The control method in this research is proposed to control drilling according to rock strength and drill steel used. The control method can be utilized for reducing noise dose when drilling into different compressive strength of rocks by controlling drilling to achieve minimum specific energy. Additional research efforts are still needed to study the specific energy consumed and noise dose produced when drilling into different compressive strength of rocks including hard rock (e.g. sandstone) and soft rock (e.g., 
claystone and soft shale). Similar drilling tests should be performed comparable to the tests conducted on drilling the medium strength testing block in this study.

Secondly, further research relative to reducing the fine dust generated during roof bolting should be conducted through controlling the drilling operation. Dust samples should be collected from drilling at a wide range of bite depth to study the correlation of dust size distribution and bite depth.

Additionally, further study should be conducted to develop hardware and software for the drilling control automation system in order to apply the findings in this research. In the drilling control system, the drilling parameters should be automatically set and adjusted to achieve the best noise control while maintaining good productivity and safe performance according to the encountered roof strata immediately. The noise dose of drilling each hole should also be estimated. The total noise dose of a roof bolter operator during his/her operation time should be computed while considering the noise dose percentage of drilling in the whole roof bolting operation. The function of recording and tracking the noise dose of the roof bolter should also included in this system. This control system should be applied in the underground mines. 


\section{REFERENCES}

ASTM F432-13 (2013). Standard Specification for Roof and Rock Bolts and Accessories. West Conshohocken, PA.

Azman, A., Camargo, H. and Alcorn, L. (2014). Laboratory evaluations of a redesigned collapsible drill steel enclosure to reduce noise from roof bolting machines. NOISE-CON, Ft. Lauderdale, Florida, September 8-10.

Bauer, E.R., Babich, D.R., and Vipperman, J.R. (2006). Equipment Noise and Worker Exposure in the Coal Mining Industry. NIOSH, IC 9492, Information Circular, $77 \mathrm{pp}$.

Bartholomae, R.C. and Parker, R.P. (1983). Mining Machinery Noise Control Guidelines. United States Department of the Interior, Bureau of Mines, 87pp.

Berger et al., (2003). The Noise Manual (Revised Fifth Edition). (L. R., Ed.) Fairfax, VA: American Industrial Hygiene Association.

Bise, Christopher J., 2001. Noise. In Mine health and Safety Management. Edited by Michael Karmis. Littleton, CO: Society of Mining, Metallurgy, and Exploration.

Coal News (2013), Tools for Effective Noise Control and Hearing Loss Prevention. Retrieved from: http://www.coalnews.net/papers/January2013/HTML/files/assets/seo/page16.html.

Code of Federal Regulations, 2014. Title 30-Mineral Resources. Parts 30 CFR Part 62.

Colinet, J. F., James P. R., Jeffrey M. L., John A. O. and Anita L. W.(2010). Best Practices for Dust Control in Coal Mining. NIOSH. 
Dolinar, D.R. and S.K. Bhatt (2000). Trends in Roof Bolt Application. Proceeding of the New Technology for Coal Mine Roof Support, NIOSH Publication No. 2000-151, IC 9453.

Department of Labor, Mine Safety and Health Administration, (1999). "Health Standards for Occupational Noise Exposure: Final Rule,” 30 CFR Part 62. Federal Register.

Finfinger, Gerald L (2003). Methodology for determining the character of mine roof rocks. Ph.D. Thesis, West Virginia University, 2003, 214 pp.

Goodman, G.V.R., T.W. Beck, D.E. Pollock, J.F. Colinet, and J.A. Organiscak (2006). Emerging technologies control respirable dust exposures for continuous mining and roof bolting personnel. Proceedings of the 11th U.S./North American Mine Ventilation Symposium. University Park, PA, June 5-7, 2006: 211-216.

Goodman GVR, Organiscak JA [2002]. An evaluation of methods for controlling silica dust exposures on roof bolters. SME preprint 02-163. Littleton, CO: Society for Mining, Metallurgy, and Exploration, Inc.

Hanjie Chen (2015). Personal Communication. Keystone Mining Services. Pittsburgh, PA.

Leung, R., \& Scheding, S. (2015). Automated coal seam detection using a modulated specific energy measure in a monitor-while-drilling context, 75, 196-209.

Lowe, M.J., Peterson, J.S., Alcorn, L.A., Yantek, D.S. and Michael, R.J. (2010). A Control Suite to Reduce Roof Bolting Machine Drilling Noise. Proceedings of the 2010 National Conference on Noise Control Engineering and 159th Meeting of the Acoustical Society of America, Baltimore, Maryland, April 19-21. 
Luo, Y., Peng, S.S., and Wilson, G.(2004). Identification of lithologic changes using drilling parameters. SME Transactions 2003, 314, 5-10.

Luo, Y., Peng, S.S., Finfinger, G. and Wilson, G. (2004). A mechanical approach to estimate roof strata strength from bolting drilling parameters. Paper presented at 2004 SME Annual Meeting, Feb. 23-25, 2004, Denver, CO, Preprint No. 04-190.

Luo, Y., Peng, S., Mirabile, B., Finfinger, G., and Wilson, G. (2002). Estimating Rock Strengths Using Drilling Parameters During Roof Bolting Operations - Progress Report. Proceeding of 21st Conference on Ground Control in Mining, S.S. Peng, ed., West Virginia University, Morgantown, 288-294.

Luo, Y., Collins, C., Qiu, B., and Li, M.(2014). Experimental Studies on Controlling Drilling Parameters to Reduce Roof Bolt-hole Drilling Noise. Mining Engineering, 66 (5), 54-61.

Mark, C., C.S. Compton, D.R. Dolinar, D.C. Oyler (2003). Field Performance Testing of Fully Grouted Roof Bolts. 2003 SME Annual Meeting, Feb 24-26, Cincinnati, Ohio, preprint 03-138. Littleton, CO: Society for Mining, Metallurgy, and Exploration, Inc., 2003 Feb, 1-8.

MSHA noise samples data, 2015. Available on MSHA Open Government Data Sets.

MSHA dust samples data, 2015. Available on MSHA Open Government Data Sets.

Marghitu. D. B.(2001). Mechanical Engineer's Handbook. Edited by. Academic Press. London, UK.

Matetic, R.J. (2006). Assessment and Evaluation of Noise Controls on Roof Bolting Equipment and a Method for Predicting Sound Pressure Levels in Underground Coal Mining. Ph.D. Thesis, West Virginia University, 2006, 193 pp. 
Matetic, R.J., Kovalchik P.G., Perterson, J.S. and Alcorn, L.A. (2008). A Noise Control for a Roof Bolting Machine: Collapsible Drill Steel Enclosure. Proceedings of the 2008 National Conference on Noise Control Engineering, Dearborn, Michigan, July 28-31, 2008.

NIOSH (1998). Criteria for a Recommended Standard: Occupational Noise Exposure, Revised Criteria 1998. Publication No. 98-126. Cincinnati: NIOSH.

NIOSH (2006). Equipment Noise and Worker Exposure in the Coal Mining Industry.

Occupational Noise Exposure. Occupational Safety \& Health Administration, [viewed 5 April 2014]. Available from: https://www.osha.gov/SLTC/noisehearingconservation/

Ostergaard, Paul B. (2003). Physics of Sound and Vibration. In The Noise Manual (Revised Fifth Edition). Edited by E.H.Berger. Fairfax, VA: American Industrial Hygiene Association.

Wingquist, C. F. and Hanson, B. D.. Bit Wear-Flat Temperature as a Function of Depth of Cut and Speed, Bureau of Mines Report of Investigations, 1987.

What can be done to reduce the hazard from noise? Occupational safety and health administration, [viewed 5 April 2014]. Available from: https://www.osha.gov/SLTC/noisehearingconservation/\#hazards.

Peng, S.S., and D.H.Y. Tang (1984). Roof bolting in underground mining: a state-of-theart review. International Journal of Mining Engineering, 2 (1), 1-42. 
Peng, S.S., Tang, D., Sasaoka, T., Luo, Y., Finfinger, G. and Wilson, G. (2005a). A Method for Quantitative Void / Fracture Detection and Estimation of Rock Strength for Underground Mine Roof. $24^{\text {th }}$ International Conference on Ground Control in Mining: Proceedings, August 2-4, WV, USA. pp. 187-195.

Peng, S.S., Sasaoka, T., Tang, D., Luo, Y., and Wilson, G. (2005b). Mine Roof Geology Information System - A method for Quantitative Void/Fracture Detection and Estimation of Rock Strength for Underground Mine. Coal Age, May, pp. 44-49.

Peterson, J.S., Kovalchik, P.G. and R.J. Matetic (2005). A Sound Power Level Study of a Roof Bolter, SME Preprint No. 05-72, 2005 SME Conference, Salt Lake City, Utah, 2005, 8 pp.

Peterson, J. S., Kovalchik, P. G. and Yantek, D. (2009). Development of Roof-bolting penMachine Bit and Chuck Isolators for Drilling Noise Reductions. NIOSH.

Peterson J.S. (2008). Collapsible Drill Steel Enclosure for Reducing Roof Bolting Machine Drilling Noise. NIOSH Technology News No. 532.

Peterson, J.S., and Alcorn, L.A.(2007). Results of Noise Measurements from Underground Testing of a Roof Bolting Machine Duty Cycle. Noise Conference.

Peterson, J.S., Camargo, H. (2010). The Development of a Damped Drill Steel to Reduce Roof Bolting Machine Drilling Noise. Proceedings of the 2010 National Conference on Noise Control Engineering and 159th Meeting of the Acoustical Society of America, Baltimore, Maryland, April 19-21, 2010.

Poletto, F. (2005). Energy balance of a drill-bit seismic source, part 1: Rotary energy and radiation properties. Geophysics, 70, T13-T28. 
Rajesh, K.B., Vardhan,H., Govindaraj, M., and Vijay, G. (2013). Regression analysis and ANN models to predict rock properties from sound levels produced during drilling.International Journal of Rock Mechanics and Mining Sciences, 58, 61-72.

Simon, R. (1963). Energy balance in rock driling. SPE Paper No. 499, 298-306.

Suter, A.H. (1989). The Effects of Hearing Protectors on Speech Communication and the Perception of Warning Signals. Technical Memorandum. 2-89, U.S. Army Human Engineering Lab., Aberdeen Proving Ground, MD.

Tak, S., Davis, R.R., and Calvert, G.M. (2009). Exposure to Hazardous Workplace Noise and Use of Hearing Protection Devices among US Workers-NHANES, 19992004. American Journal of Industrial Medicine, 52, 358-371.

Tak, S., and Calvert, G.M. (2008). Hearing Difficulty Attributable to Employment by Industry and Occupation: An Analysis of the National Health Interview SurveyUnited States, 1997 to 2003. Journal of Occupational and Environmental Medicine, 50, 46-56.

Teale, R. (1965). The Concept of Specific Energy in Rock Drilling, International Journal of Rock Mechanics, Mining Science and Geomechanics, 2, 57-73.

Vardhan, H., Adhikari, G.R., and Govindaraj, M. (2009). Estimating rock properties using sound levels produced during drilling. International Journal of Rock Mechanics and Mining Sciences, 46, 604-612.

Wingquist, C. F. and Hanson, B. D. (1987). Bit Wear-Flat Temperature as a Function of Depth of Cut and Speed, Bureau of Mines Report of Investigations.

Yantek, D.S., Peterson, J.S. and Smith, A.K. (2007). Application of a Microphone Phased Array to Identify Noise Sources on a Roof Bolting Machine. Noise Conference. 


\section{APPENDIX A}

The tables within the appendix contains the actual penetration rate and rotational rate, bite depth, temperature differences of drill bit before and after drilling, average sound pressure level, noise dose and specific energy.

\begin{tabular}{|c|c|c|c|c|c|c|c|c|c|c|c|}
\hline $\begin{array}{l}\text { Test } \\
\text { Set }\end{array}$ & $\begin{array}{l}\text { Test } \\
\text { Hole }\end{array}$ & Drill Steel & $\begin{array}{c}\text { Drill } \\
\text { Bit }\end{array}$ & $\begin{array}{c}\text { Hole } \\
\text { Length }\end{array}$ & $\begin{array}{c}\text { Actual } \\
\text { P.R. }\end{array}$ & $\begin{array}{c}\text { Actual } \\
\text { RPM }\end{array}$ & $\begin{array}{l}\text { Actual } \\
\text { B.D. }\end{array}$ & $\begin{array}{c}\text { Temp. } \\
\text { Diff }\end{array}$ & $\begin{array}{l}\text { Avg. } \\
\text { SPL }\end{array}$ & Dose & $\begin{array}{c}\text { Avg. Spec. } \\
\text { Energy }\end{array}$ \\
\hline & & & & inch & in/sec & rpm & in/rev. & ${ }^{\circ} \mathbf{F}$ & dBA & $\%$ & $\mathrm{lb} / \mathbf{i n}^{2}$ \\
\hline 1 st & 1 & 7/8" Rd & $7 / 8 "$ & 32.85 & 0.15 & 291 & 0.03 & 236 & 90.4 & $1.13 \%$ & 531067 \\
\hline $1 \mathrm{st}$ & 2 & 7/8" Rd & $7 / 8 "$ & 33.78 & 0.15 & 392 & 0.02 & 104 & 89.9 & $1.13 \%$ & 817764 \\
\hline 1 st & 3 & 7/8" Rd & 7/8" & 33.67 & 0.16 & 516 & 0.02 & 165 & 93.4 & $1.65 \%$ & 1404654 \\
\hline $1 \mathrm{st}$ & 4 & $7 / 8 " \mathrm{Rd}$ & $7 / 8 "$ & 33.96 & 1.00 & 290 & 0.21 & 70 & 88.8 & $0.20 \%$ & 76246 \\
\hline $1 \mathrm{st}$ & 5 & 7/8" Rd & $7 / 8 "$ & 33.47 & 0.99 & 390 & 0.15 & 177 & 90.8 & $0.32 \%$ & 129234 \\
\hline $1 \mathrm{st}$ & 6 & 7/8" Rd & $7 / 8 "$ & 34.48 & 1.01 & 493 & 0.12 & 264 & 93.3 & $0.36 \%$ & 214954 \\
\hline $1 \mathrm{st}$ & 7 & 7/8" Rd & $7 / 8 "$ & 33.65 & 1.06 & 292 & 0.22 & 340 & 91.4 & $0.30 \%$ & 102487 \\
\hline $1 \mathrm{st}$ & 8 & $7 / 8 " \mathrm{Rd}$ & $7 / 8 "$ & 34.21 & 1.87 & 390 & 0.29 & 220 & 91.0 & $0.21 \%$ & 90332 \\
\hline $1 \mathrm{st}$ & 9 & 7/8" Rd & $7 / 8 "$ & 34.32 & 1.86 & 446 & 0.26 & 290 & 91.6 & $0.22 \%$ & 131195 \\
\hline $1 \mathrm{st}$ & 10 & 7/8" Hex & $7 / 8 "$ & 38.47 & 0.15 & 292 & 0.03 & 137 & 90.8 & $1.33 \%$ & 355774 \\
\hline $1 \mathrm{st}$ & 11 & 7/8" Hex & $7 / 8^{\prime \prime}$ & 38.05 & 0.17 & 396 & 0.03 & 132 & 94.4 & $2.27 \%$ & 659688 \\
\hline $1 \mathrm{st}$ & 12 & 7/8" Hex & $7 / 8 "$ & 38.15 & 0.17 & 527 & 0.02 & 104 & 97.3 & $3.11 \%$ & 1380636 \\
\hline $1 \mathrm{st}$ & 13 & 7/8" Hex & $7 / 8 "$ & 38.46 & 1.03 & 290 & 0.21 & 130 & 92.1 & $0.32 \%$ & 66767 \\
\hline $1 \mathrm{st}$ & 14 & 7/8" Hex & $7 / 8 "$ & 38.46 & 1.03 & 391 & 0.16 & 163 & 96.1 & $0.53 \%$ & 121204 \\
\hline $1 \mathrm{st}$ & 15 & 7/8" Hex & $7 / 8 "$ & 38.36 & 1.01 & 503 & 0.12 & 170 & 97.3 & $0.65 \%$ & 224925 \\
\hline $1 \mathrm{st}$ & 16 & 7/8" Hex & $7 / 8 "$ & 38.55 & 1.73 & 291 & 0.36 & 161 & 92.6 & $0.27 \%$ & 59466 \\
\hline $1 \mathrm{st}$ & 17 & 7/8" Hex & $7 / 8 "$ & 38.70 & 1.85 & 390 & 0.28 & 241 & 94.6 & $0.37 \%$ & 93050 \\
\hline $1 \mathrm{st}$ & 18 & 7/8" Hex & $7 / 8 "$ & 38.86 & 1.87 & 461 & 0.25 & 260 & 97.5 & $0.50 \%$ & 128074 \\
\hline $1 \mathrm{st}$ & 19 & 1-1/8" Hex & $1-3 / 8^{\prime \prime}$ & 46.63 & 0.15 & 293 & 0.03 & 234 & 93.7 & $2.26 \%$ & 128995 \\
\hline $1 \mathrm{st}$ & 20 & 1-1/8" Hex & $1-3 / 8$ & 46.58 & 0.17 & 395 & 0.03 & 194 & 97.8 & $3.44 \%$ & 232910 \\
\hline $1 \mathrm{st}$ & 21 & 1-1/8" Hex & $1-3 / 8 "$ & 46.61 & 0.16 & 512 & 0.02 & 310 & 98.9 & $3.94 \%$ & 437831 \\
\hline $1 \mathrm{st}$ & 22 & 1-1/8" Hex & $1-3 / 8 "$ & 46.95 & 1.03 & 291 & 0.21 & 197 & 98.5 & $0.76 \%$ & 28602 \\
\hline $1 \mathrm{st}$ & 23 & 1-1/8" Hex & $1-3 / 8^{\prime \prime}$ & 46.94 & 1.04 & 391 & 0.16 & 182 & 97.7 & $0.90 \%$ & 48148 \\
\hline $1 \mathrm{st}$ & 24 & 1-1/8" Hex & $1-3 / 8 "$ & 46.68 & 1.05 & 455 & 0.14 & 100 & 99.1 & $1.12 \%$ & 66376 \\
\hline $1 \mathrm{st}$ & 25 & 1-1/8" Hex & $1-3 / 8 "$ & 47.07 & 1.54 & 295 & 0.31 & 158 & 94.9 & $0.52 \%$ & 28853 \\
\hline $1 \mathrm{st}$ & 26 & 1-1/8" Hex & $1-3 / 8^{\prime \prime}$ & 19.15 & 1.33 & 373 & 0.22 & 45 & 93.4 & $0.53 \%$ & 45041 \\
\hline $1 \mathrm{st}$ & 27 & 1-1/8" Hex & $1-3 / 8 "$ & 47.15 & 1.54 & 392 & 0.24 & 65 & 99.2 & $0.88 \%$ & 44549 \\
\hline
\end{tabular}




\begin{tabular}{|c|c|c|c|c|c|c|c|c|c|c|c|}
\hline $\begin{array}{l}\text { Test } \\
\text { Set }\end{array}$ & $\begin{array}{l}\text { Test } \\
\text { Hole }\end{array}$ & Drill Steel & $\begin{array}{c}\text { Drill } \\
\text { Bit }\end{array}$ & $\begin{array}{c}\text { Hole } \\
\text { Length }\end{array}$ & $\begin{array}{l}\text { Actual } \\
\text { P.R. }\end{array}$ & $\begin{array}{c}\text { Actual } \\
\text { RPM }\end{array}$ & $\begin{array}{l}\text { Actual } \\
\text { B.D. }\end{array}$ & $\begin{array}{c}\text { Temp. } \\
\text { Diff }\end{array}$ & $\begin{array}{l}\text { Avg. } \\
\text { SPL }\end{array}$ & Dose & $\begin{array}{c}\text { Avg. } \\
\text { Spec. } \\
\text { Energy }\end{array}$ \\
\hline & & & & inch & in/sec & rpm & in/rev. & ${ }^{\circ} \mathbf{F}$ & dBA & $\%$ & $\mathbf{l b} / \mathbf{i n}^{2}$ \\
\hline 2nd & 1 & $7 / 8 " \mathrm{Rd}$ & 7/8" & 39.40 & 0.50 & 296 & 0.10 & 168 & 91.2 & $0.48 \%$ & 53780 \\
\hline $2 \mathrm{nd}$ & 2 & $7 / 8 " \mathrm{Rd}$ & $7 / 8 "$ & 39.30 & 0.49 & 396 & 0.07 & 169 & 92.4 & $0.74 \%$ & 87262 \\
\hline $2 \mathrm{nd}$ & 3 & $7 / 8 " \mathrm{Rd}$ & $7 / 8 "$ & 39.35 & 0.50 & 598 & 0.05 & 160 & 95.3 & $1.14 \%$ & 197317 \\
\hline $2 \mathrm{nd}$ & 4 & $7 / 8 " \mathrm{Rd}$ & $7 / 8 "$ & 39.70 & 1.24 & 301 & 0.25 & 173 & 93.0 & $0.42 \%$ & 39969 \\
\hline 2 nd & 5 & $7 / 8 " \mathrm{Rd}$ & $7 / 8^{\prime \prime}$ & 39.55 & 1.52 & 395 & 0.23 & 199 & 94.8 & $0.40 \%$ & 47774 \\
\hline $2 \mathrm{nd}$ & 6 & 7/8" Rd & $7 / 8 "$ & 39.84 & 1.83 & 597 & 0.18 & 90 & 97.7 & $0.48 \%$ & 72049 \\
\hline 2 nd & 7 & $7 / 8 " \mathrm{Rd}$ & $7 / 8^{\prime \prime}$ & 39.70 & 1.18 & 300 & 0.24 & 222 & 95.1 & $0.46 \%$ & 40611 \\
\hline $2 \mathrm{nd}$ & 8 & $7 / 8 " \mathrm{Rd}$ & $7 / 8 "$ & 39.60 & 1.45 & 401 & 0.22 & 185 & 94.4 & $0.48 \%$ & 49270 \\
\hline 2 nd & 9 & $7 / 8 " \mathrm{Rd}$ & 7/8" & 39.65 & 1.77 & 597 & 0.18 & 201 & 97.4 & $0.54 \%$ & 75195 \\
\hline $2 \mathrm{nd}$ & 10 & 7/8" Hex & $7 / 8 "$ & 44.26 & 0.49 & 296 & 0.10 & 112 & 93.4 & $1.05 \%$ & 49081 \\
\hline $2 \mathrm{nd}$ & 11 & 7/8" Hex & 7/8" & 43.97 & 0.50 & 396 & 0.08 & 171 & 94.3 & $1.39 \%$ & 80730 \\
\hline 2 nd & 12 & 7/8" Hex & $7 / 8 "$ & 44.12 & 0.50 & 597 & 0.05 & 200 & 96.6 & $2.13 \%$ & 188807 \\
\hline $2 \mathrm{nd}$ & 13 & 7/8" Hex & $7 / 8^{\prime \prime}$ & 44.31 & 1.45 & 296 & 0.30 & 81 & 96.5 & $0.76 \%$ & 37590 \\
\hline $2 \mathrm{nd}$ & 14 & 7/8" Hex & $7 / 8 "$ & 44.26 & 1.71 & 396 & 0.26 & 218 & 96.1 & $0.81 \%$ & 45024 \\
\hline 2 nd & 15 & 7/8" Hex & $7 / 8 "$ & 44.46 & & 596 & & 199 & 97.1 & $0.97 \%$ & 69370 \\
\hline $2 \mathrm{nd}$ & 16 & 7/8" Hex & $7 / 8 "$ & 44.56 & 1.36 & 299 & 0.27 & 106 & 97.7 & $0.95 \%$ & 40034 \\
\hline 2nd & 17 & 7/8" Hex & $7 / 8 "$ & 44.36 & 1.63 & 403 & 0.24 & 236 & 95.1 & $0.85 \%$ & 47843 \\
\hline $2 \mathrm{nd}$ & 18 & 7/8" Hex & $7 / 8^{\prime \prime}$ & 44.51 & 1.96 & 596 & 0.20 & 243 & 97.3 & $0.84 \%$ & 68944 \\
\hline $2 \mathrm{nd}$ & 19 & 1-1/8" Hex & $1-3 / 8^{\prime \prime}$ & 48.15 & 0.50 & 300 & 0.10 & 103 & 96.7 & $1.76 \%$ & 25218 \\
\hline $2 \mathrm{nd}$ & 20 & 1-1/8" Hex & $1-3 / 8^{\prime \prime}$ & 47.80 & 0.52 & 397 & 0.08 & 159 & 100.1 & $2.76 \%$ & 36464 \\
\hline $2 \mathrm{nd}$ & 21 & 1-1/8" Hex & $1-3 / 8^{\prime \prime}$ & 48.20 & 0.53 & 572 & 0.06 & 182 & 98.0 & $2.97 \%$ & 70244 \\
\hline 2nd & 22 & 1-1/8" Hex & $1-3 / 8^{\prime \prime}$ & 48.34 & 1.13 & 315 & 0.22 & 180 & 97.5 & $1.58 \%$ & 19772 \\
\hline $2 \mathrm{nd}$ & 23 & 1-1/8" Hex & $1-3 / 8^{\prime \prime}$ & 48.82 & 1.36 & 399 & 0.20 & 153 & 95.9 & $1.46 \%$ & 21372 \\
\hline 2 nd & 24 & 1-1/8" Hex & $1-3 / 8^{\prime \prime}$ & 48.39 & 1.45 & 595 & 0.15 & 169 & 98.5 & $1.76 \%$ & 34554 \\
\hline
\end{tabular}

\begin{tabular}{|c|c|c|c|c|c|c|c|c|c|c|c|}
\hline $\begin{array}{l}\text { Test } \\
\text { Set }\end{array}$ & $\begin{array}{l}\text { Test } \\
\text { Hole }\end{array}$ & $\begin{array}{l}\text { Drill } \\
\text { Steel }\end{array}$ & $\begin{array}{c}\text { Drill } \\
\text { Bit }\end{array}$ & $\begin{array}{c}\text { Hole } \\
\text { Length }\end{array}$ & $\begin{array}{c}\text { Actual } \\
\text { P.R. }\end{array}$ & $\begin{array}{c}\text { Actual } \\
\text { RPM }\end{array}$ & $\begin{array}{c}\text { Actual } \\
\text { B.D. }\end{array}$ & $\begin{array}{c}\text { Temp. } \\
\text { Diff }\end{array}$ & $\begin{array}{l}\text { Avg. } \\
\text { SPL }\end{array}$ & Dose & $\begin{array}{c}\text { Avg. Spec. } \\
\text { Energy }\end{array}$ \\
\hline & & & & inch & in/sec & rpm & in/rev. & ${ }^{\circ} \mathbf{F}$ & dBA & $\%$ & $\mathbf{l b} / \mathbf{i n}^{2}$ \\
\hline $3 \mathrm{rd}$ & 1 & $7 / 8 " \mathrm{Rd}$ & 7/8" & 35.68 & 0.73 & 298 & 0.15 & 70 & 94.68 & $0.68 \%$ & 130537 \\
\hline 3 rd & 2 & 7/8" Rd & 7/8" & 34.41 & 0.64 & 397 & 0.10 & 48 & 96.19 & $0.81 \%$ & 202291 \\
\hline $3 \mathrm{rd}$ & 3 & 7/8" Rd & 7/8" & 34.41 & 0.70 & 498 & 0.08 & 181 & 97.12 & $0.93 \%$ & 304375 \\
\hline 3rd & 4 & 7/8" Rd & 7/8" & 36.21 & 0.94 & 301 & 0.19 & 81 & 95.90 & $0.59 \%$ & 100291 \\
\hline 3rd & 5 & 7/8" Rd & 7/8" & 35.94 & 1.01 & 403 & 0.15 & 77 & 97.28 & $0.68 \%$ & 157519 \\
\hline 3rd & 6 & 7/8" Rd & 7/8" & 35.41 & 0.90 & 497 & 0.11 & 122 & 97.33 & $0.69 \%$ & 222243 \\
\hline $3 \mathrm{rd}$ & 7 & $7 / 8 " \mathrm{Rd}$ & 7/8" & 34.14 & 0.94 & 598 & 0.09 & 169 & 98.59 & $0.80 \%$ & 316155 \\
\hline $3 \mathrm{rd}$ & 8 & 7/8" Rd & 7/8" & 35.94 & 1.11 & 297 & 0.22 & 34 & 94.24 & $0.37 \%$ & 96467 \\
\hline
\end{tabular}




\begin{tabular}{|c|c|c|c|c|c|c|c|c|c|c|c|}
\hline $\begin{array}{c}\text { Test } \\
\text { Set }\end{array}$ & $\begin{array}{l}\text { Test } \\
\text { Hole }\end{array}$ & Drill Steel & $\begin{array}{c}\text { Drill } \\
\text { Bit }\end{array}$ & $\begin{array}{c}\text { Hole } \\
\text { Length }\end{array}$ & $\begin{array}{l}\text { Actual } \\
\text { P.R. }\end{array}$ & $\begin{array}{c}\text { Actual } \\
\text { RPM }\end{array}$ & $\begin{array}{l}\text { Actual } \\
\text { B.D. }\end{array}$ & $\begin{array}{c}\text { Temp. } \\
\text { Diff }\end{array}$ & $\begin{array}{l}\text { Avg. } \\
\text { SPL }\end{array}$ & Dose & $\begin{array}{c}\text { Avg. } \\
\text { Spec. } \\
\text { Energy }\end{array}$ \\
\hline & & & & inch & in/sec & rpm & in/rev. & ${ }^{\circ} \mathbf{F}$ & dBA & $\%$ & $\mathrm{lb} / \mathrm{in}^{2}$ \\
\hline $3 \mathrm{rd}$ & 9 & 7/8" Rd & 7/8" & 37.00 & 1.13 & 396 & 0.17 & 25 & 96.77 & $0.58 \%$ & 148684 \\
\hline $3 \mathrm{rd}$ & 10 & 7/8" Rd & 7/8" & 36.21 & 1.16 & 500 & 0.14 & 84 & 98.87 & $0.71 \%$ & 213870 \\
\hline $3 \mathrm{rd}$ & 11 & $7 / 8 " \mathrm{Rd}$ & 7/8" & 34.15 & 1.10 & 605 & 0.11 & 52 & 100.60 & $0.87 \%$ & 298993 \\
\hline $3 \mathrm{rd}$ & 12 & 7/8" Rd & $7 / 8 "$ & 35.68 & 1.47 & 402 & 0.22 & 93 & 96.55 & $0.38 \%$ & 107701 \\
\hline $3 \mathrm{rd}$ & 13 & $7 / 8 " \mathrm{Rd}$ & $7 / 8 "$ & 34.89 & 1.59 & 501 & 0.19 & 102 & 97.23 & $0.45 \%$ & 152437 \\
\hline $3 \mathrm{rd}$ & 14 & $7 / 8 " \mathrm{Rd}$ & $7 / 8 "$ & 35.42 & 1.51 & 596 & 0.15 & 75 & 95.55 & $0.33 \%$ & 185288 \\
\hline $3 \mathrm{rd}$ & 15 & 7/8" Hex & $7 / 8 "$ & 42.15 & 0.67 & 299 & 0.14 & 64 & 98.40 & $1.21 \%$ & 105090 \\
\hline $3 \mathrm{rd}$ & 16 & 7/8" Hex & $7 / 8 "$ & 42.70 & 0.70 & 397 & 0.11 & 82 & 101.09 & $1.49 \%$ & 160664 \\
\hline $3 \mathrm{rd}$ & 17 & 7/8" Hex & 7/8" & 42.43 & 0.69 & 497 & 0.08 & 95 & 101.41 & $1.86 \%$ & 242548 \\
\hline $3 \mathrm{rd}$ & 18 & 7/8" Hex & $7 / 8^{\prime \prime}$ & 41.87 & 0.95 & 300 & 0.19 & 57 & 95.58 & $0.55 \%$ & 75432 \\
\hline $3 \mathrm{rd}$ & 19 & 7/8" Hex & $7 / 8 "$ & 41.05 & 0.95 & 397 & 0.14 & 66 & 97.21 & $0.69 \%$ & 117247 \\
\hline $3 \mathrm{rd}$ & 20 & 7/8" Hex & $7 / 8 "$ & 42.43 & 0.98 & 502 & 0.12 & 53 & 98.43 & $0.85 \%$ & 181479 \\
\hline $3 \mathrm{rd}$ & 21 & 7/8" Hex & $7 / 8 "$ & 40.28 & 0.98 & 599 & 0.10 & 54 & 99.98 & $1.04 \%$ & 256680 \\
\hline $3 \mathrm{rd}$ & 22 & 7/8" Hex & $7 / 8 "$ & 42.98 & 1.15 & 300 & 0.23 & 10 & 94.16 & $0.35 \%$ & 67466 \\
\hline $3 \mathrm{rd}$ & 23 & 7/8" Hex & $7 / 8 "$ & 42.43 & 1.21 & 397 & 0.18 & 68 & 95.75 & $0.48 \%$ & 107202 \\
\hline $3 \mathrm{rd}$ & 24 & 7/8" Hex & $7 / 8 "$ & 43.47 & 1.17 & 502 & 0.14 & 5 & 98.40 & $0.65 \%$ & 157503 \\
\hline $3 \mathrm{rd}$ & 25 & 7/8" Hex & $7 / 8 "$ & 40.56 & 1.16 & 603 & 0.12 & 90 & 99.10 & $0.77 \%$ & 225801 \\
\hline $3 \mathrm{rd}$ & 26 & 7/8" Hex & $7 / 8 "$ & 41.32 & 1.55 & 403 & 0.23 & 98 & 101.07 & $0.84 \%$ & 90993 \\
\hline $3 \mathrm{rd}$ & 27 & 7/8" Hex & $7 / 8 "$ & 43.47 & 1.58 & 499 & 0.19 & 113 & 101.17 & $0.86 \%$ & 127235 \\
\hline $3 \mathrm{rd}$ & 28 & 7/8" Hex & 7/8" & 43.47 & 1.55 & 602 & 0.15 & 158 & 104.16 & $1.14 \%$ & 179334 \\
\hline $3 \mathrm{rd}$ & 29 & 1-1/8" Hex & $1-1 / 8^{\prime \prime}$ & 38.41 & 0.70 & 300 & 0.14 & 120 & 95.98 & $0.79 \%$ & 42373 \\
\hline $3 \mathrm{rd}$ & 30 & 1-1/8" Hex & $1-1 / 8^{\prime \prime}$ & 37.37 & 0.70 & 401 & 0.10 & 140 & 98.06 & $1.10 \%$ & 64951 \\
\hline $3 \mathrm{rd}$ & 31 & 1-1/8" Hex & $1-1 / 8^{\prime \prime}$ & 40.04 & & 498 & & 151 & 99.08 & $1.28 \%$ & 92721 \\
\hline $3 \mathrm{rd}$ & 32 & 1-1/8" Hex & $1-1 / 8^{\prime \prime}$ & 38.41 & 1.00 & 302 & 0.20 & 124 & 97.11 & $0.69 \%$ & 32451 \\
\hline $3 \mathrm{rd}$ & 33 & 1-1/8" Hex & $1-1 / 8^{\prime \prime}$ & 38.41 & 0.94 & 401 & 0.14 & 136 & 98.34 & $0.81 \%$ & 48128 \\
\hline $3 \mathrm{rd}$ & 34 & 1-1/8" Hex & $1-1 / 8^{\prime \prime}$ & - & - & - & - & 142 & 98.68 & $0.71 \%$ & - \\
\hline $3 \mathrm{rd}$ & 35 & 1-1/8" Hex & $1-1 / 8 "$ & 38.95 & 0.94 & 598 & 0.09 & 147 & 97.21 & $0.65 \%$ & 94658 \\
\hline $3 \mathrm{rd}$ & 36 & 1-1/8" Hex & $1-1 / 8^{\prime \prime}$ & 37.10 & 1.17 & 301 & 0.23 & 75 & 97.92 & $0.59 \%$ & 27744 \\
\hline $3 \mathrm{rd}$ & 37 & 1-1/8" Hex & $1-1 / 8 "$ & 38.46 & 1.12 & 400 & 0.17 & 88 & 97.27 & $0.57 \%$ & 40856 \\
\hline $3 \mathrm{rd}$ & 38 & 1-1/8" Hex & $1-1 / 8^{\prime \prime}$ & 37.91 & 1.14 & 501 & 0.14 & 126 & 98.27 & $0.70 \%$ & 58446 \\
\hline $3 \mathrm{rd}$ & 39 & 1-1/8" Hex & $1-1 / 8^{\prime \prime}$ & 38.68 & 1.22 & 604 & 0.12 & 140 & 96.91 & $0.55 \%$ & 83398 \\
\hline $3 \mathrm{rd}$ & 40 & 1-1/8" Hex & $1-1 / 8 "$ & 36.27 & 1.45 & 397 & 0.22 & 131 & 98.07 & $0.52 \%$ & 38245 \\
\hline $3 \mathrm{rd}$ & 41 & 1-1/8" Hex & $1-1 / 8 "$ & 37.91 & 1.47 & 502 & 0.18 & 156 & 102.36 & $0.80 \%$ & 53358 \\
\hline $3 \mathrm{rd}$ & 42 & 1-1/8" Hex & $1-1 / 8^{\prime \prime}$ & 37.64 & 1.58 & 598 & 0.16 & 169 & 102.56 & $0.77 \%$ & 68088 \\
\hline
\end{tabular}




\begin{tabular}{|c|c|c|c|c|c|c|c|c|c|c|c|}
\hline $\begin{array}{l}\text { Test } \\
\text { Set }\end{array}$ & $\begin{array}{l}\text { Test } \\
\text { Hole }\end{array}$ & Drill Steel & $\begin{array}{c}\text { Drill } \\
\text { Bit }\end{array}$ & $\begin{array}{c}\text { Hole } \\
\text { Length }\end{array}$ & $\begin{array}{c}\text { Actual } \\
\text { P.R. }\end{array}$ & $\begin{array}{c}\text { Actual } \\
\text { RPM }\end{array}$ & $\begin{array}{c}\text { Actual } \\
\text { B.D. }\end{array}$ & $\begin{array}{l}\text { Temp. } \\
\text { Diff }\end{array}$ & $\begin{array}{l}\text { Avg. } \\
\text { SPL }\end{array}$ & Dose & $\begin{array}{c}\text { Avg. } \\
\text { Spec. } \\
\text { Energy }\end{array}$ \\
\hline & & & & inch & in/sec & rpm & in/rev. & ${ }^{\circ} \mathbf{F}$ & dBA & $\%$ & $\mathbf{l b} / \mathbf{i n}^{2}$ \\
\hline 4 th & 1 & 7/8" Rd & $7 / 8 "$ & 31.95 & 0.62 & 348 & 0.11 & 131 & 90.0 & $0.08 \%$ & 118608 \\
\hline 4th & 2 & $7 / 8 " \mathrm{Rd}$ & $7 / 8 "$ & 36.09 & 1.09 & 367 & 0.18 & 141 & 89.6 & $0.04 \%$ & 73419 \\
\hline 4th & 3 & 7/8" Rd & $7 / 8 "$ & 35.84 & 0.61 & 399 & 0.09 & 176 & 89.8 & $0.18 \%$ & 150890 \\
\hline 4th & 4 & $7 / 8 " \mathrm{Rd}$ & $7 / 8 "$ & 36.59 & 1.10 & 438 & 0.15 & 135 & 90.5 & $0.11 \%$ & 104251 \\
\hline 4th & 5 & $7 / 8 " \mathrm{Rd}$ & $7 / 8 "$ & 36.79 & 1.42 & 394 & 0.22 & 189 & 89.5 & $0.07 \%$ & 62079 \\
\hline 4th & 6 & $7 / 8 " \mathrm{Rd}$ & $7 / 8 "$ & 36.09 & 1.17 & 479 & 0.15 & 155 & 87.6 & $0.14 \%$ & 115371 \\
\hline 4th & 7 & $7 / 8 " \mathrm{Rd}$ & $7 / 8 "$ & 36.09 & 1.41 & 499 & 0.17 & 173 & 91.0 & $0.11 \%$ & 97887 \\
\hline 4th & 8 & $7 / 8 " \mathrm{Rd}$ & $7 / 8 "$ & 36.09 & 1.71 & 501 & 0.21 & 171 & 91.5 & $0.09 \%$ & 78329 \\
\hline 4th & 9 & $7 / 8 " \mathrm{Rd}$ & $7 / 8 "$ & 36.59 & 1.12 & 494 & 0.14 & 126 & 91.4 & $0.15 \%$ & 112967 \\
\hline 4th & 10 & $7 / 8 " \mathrm{Rd}$ & $7 / 8 "$ & 36.34 & 1.45 & 529 & 0.16 & 146 & 91.3 & $0.11 \%$ & 98993 \\
\hline 4th & 11 & $7 / 8 " \mathrm{Rd}$ & $7 / 8 "$ & 35.84 & 1.70 & 550 & 0.19 & 181 & 91.6 & $0.10 \%$ & 89336 \\
\hline 4th & 12 & 7/8" Hex & $7 / 8 "$ & 41.68 & 0.61 & 348 & 0.11 & 166 & 88.8 & $0.03 \%$ & 82876 \\
\hline 4th & 13 & 7/8" Hex & $7 / 8 "$ & 41.93 & 1.14 & 346 & 0.20 & 210 & 88.4 & $0.02 \%$ & 49885 \\
\hline 4th & 14 & 7/8" Hex & $7 / 8 "$ & 41.68 & 0.62 & 398 & 0.09 & 164 & 89.6 & $0.07 \%$ & 106021 \\
\hline 4th & 15 & 7/8" Hex & $7 / 8 "$ & 41.93 & 1.13 & 397 & 0.17 & 171 & 89.2 & $0.04 \%$ & 62579 \\
\hline 4th & 16 & $7 / 8 " \mathrm{Hex}$ & $7 / 8^{\prime \prime}$ & 41.68 & 1.44 & 394 & 0.22 & 208 & 89.1 & $0.04 \%$ & 55264 \\
\hline 4 th & 17 & 7/8" Hex & $7 / 8 "$ & 41.43 & 1.12 & 496 & 0.14 & 174 & 91.6 & $0.17 \%$ & 94087 \\
\hline 4 th & 18 & 7/8" Hex & $7 / 8^{\prime \prime}$ & 41.68 & 1.44 & 498 & 0.17 & 178 & 91.2 & $0.12 \%$ & 80122 \\
\hline 4th & 19 & 7/8" Hex & $7 / 8 "$ & 40.68 & 1.71 & 499 & 0.21 & 211 & 91.2 & $0.11 \%$ & 67666 \\
\hline 4th & 20 & 7/8" Hex & $7 / 8 "$ & 41.68 & 1.12 & 550 & 0.12 & 195 & 91.8 & $0.17 \%$ & 107377 \\
\hline 4th & 21 & 7/8" Hex & $7 / 8 "$ & 41.68 & 1.42 & 548 & 0.16 & 154 & 92.0 & $0.14 \%$ & 91109 \\
\hline 4th & 22 & 7/8" Hex & $7 / 8 "$ & 41.18 & 1.73 & 547 & 0.19 & 220 & 92.6 & $0.13 \%$ & 79402 \\
\hline 4 th & 23 & 1-1/8" Hex & $1-3 / 8^{\prime \prime}$ & 34.59 & 0.60 & 345 & 0.10 & 157 & 92.19 & $0.28 \%$ & 32109 \\
\hline 4th & 24 & 1-1/8" Hex & $1-3 / 8^{\prime \prime}$ & 33.89 & 1.05 & 345 & 0.18 & 201 & 93.54 & $0.20 \%$ & 22193 \\
\hline 4th & 25 & 1-1/8" Hex & $1-3 / 8^{\prime \prime}$ & 34.39 & 0.62 & 398 & 0.09 & 126 & 93.30 & $0.33 \%$ & 37635 \\
\hline 4th & 26 & 1-1/8" Hex & $1-3 / 8^{\prime \prime}$ & 33.64 & 1.13 & 391 & 0.17 & 212 & 94.81 & $0.23 \%$ & 24664 \\
\hline 4th & 27 & 1-1/8" Hex & $1-3 / 8^{\prime \prime}$ & 33.64 & 1.21 & 395 & 0.18 & 217 & 94.71 & $0.21 \%$ & 27359 \\
\hline 4th & 28 & 1-1/8" Hex & $1-3 / 8^{\prime \prime}$ & 33.89 & 1.14 & 495 & 0.14 & 221 & 96.67 & $0.30 \%$ & 35521 \\
\hline 4th & 29 & 1-1/8" Hex & $1-3 / 8^{\prime \prime}$ & 34.14 & 1.41 & 501 & 0.17 & 160 & 95.17 & $0.21 \%$ & 30739 \\
\hline 4th & 30 & 1-1/8" Hex & $1-3 / 8 "$ & 33.64 & 1.34 & 493 & 0.16 & 219 & 95.66 & $0.24 \%$ & 33502 \\
\hline 4th & 31 & 1-1/8" Hex & $1-3 / 8^{\prime \prime}$ & 33.64 & 1.13 & 547 & 0.12 & 209 & 93.73 & $0.20 \%$ & 41129 \\
\hline 4 th & 32 & 1-1/8" Hex & $1-3 / 8^{\prime \prime}$ & 33.89 & 1.44 & 544 & 0.16 & 165 & 94.08 & $0.18 \%$ & 36654 \\
\hline 4 th & 33 & 1-1/8" Hex & $1-3 / 8^{\prime \prime}$ & 33.89 & 1.44 & 543 & 0.16 & 210 & 96.35 & $0.25 \%$ & 35352 \\
\hline
\end{tabular}




\section{APPENDIX B}

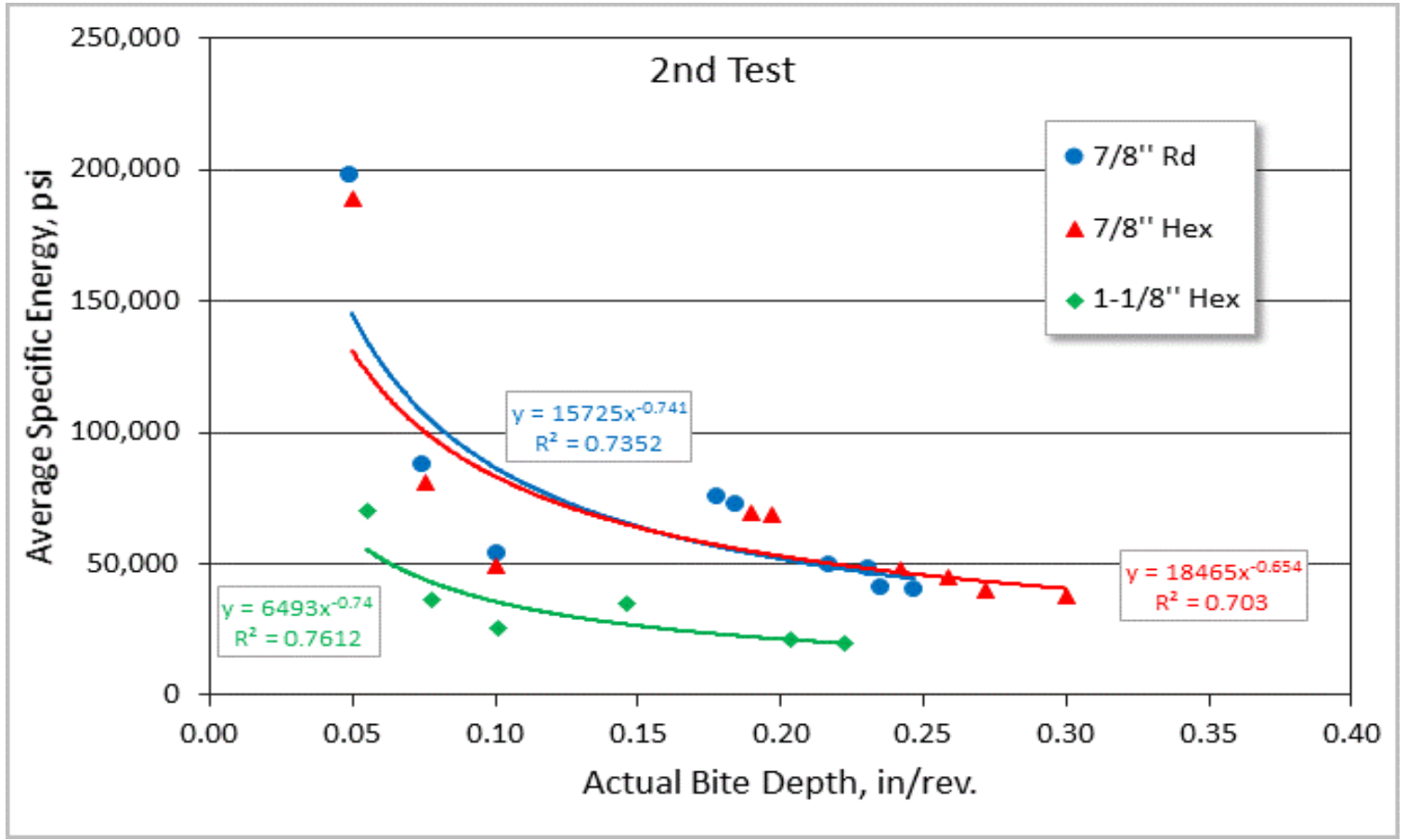

Appendix-1 Average specific energy vs. bite depth for drilling tests using different bitsteel combinations in the 2 nd test 


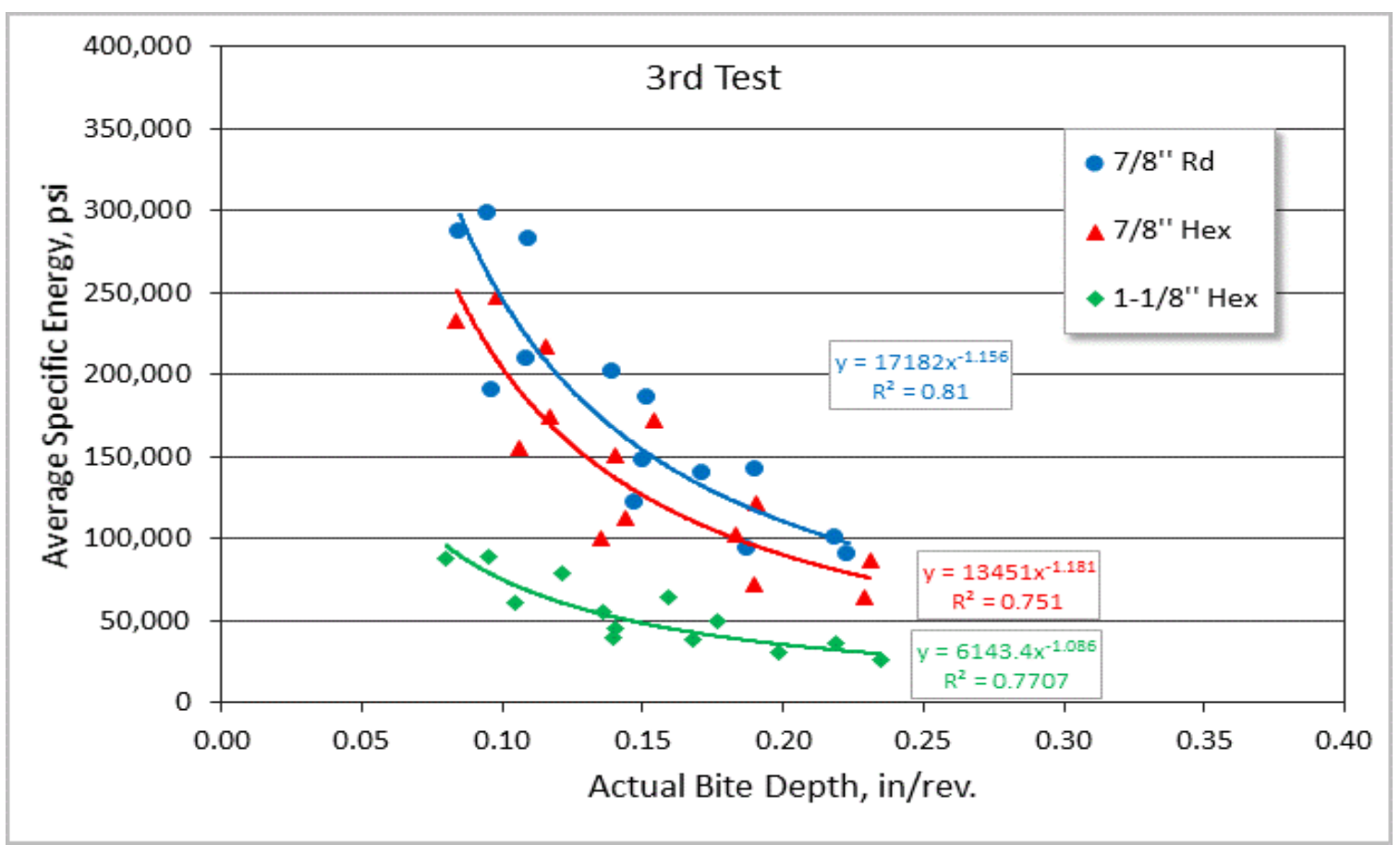

Appendix-2 Average specific energy vs. bite depth for drilling tests using different bitsteel combinations in the 3 rd test

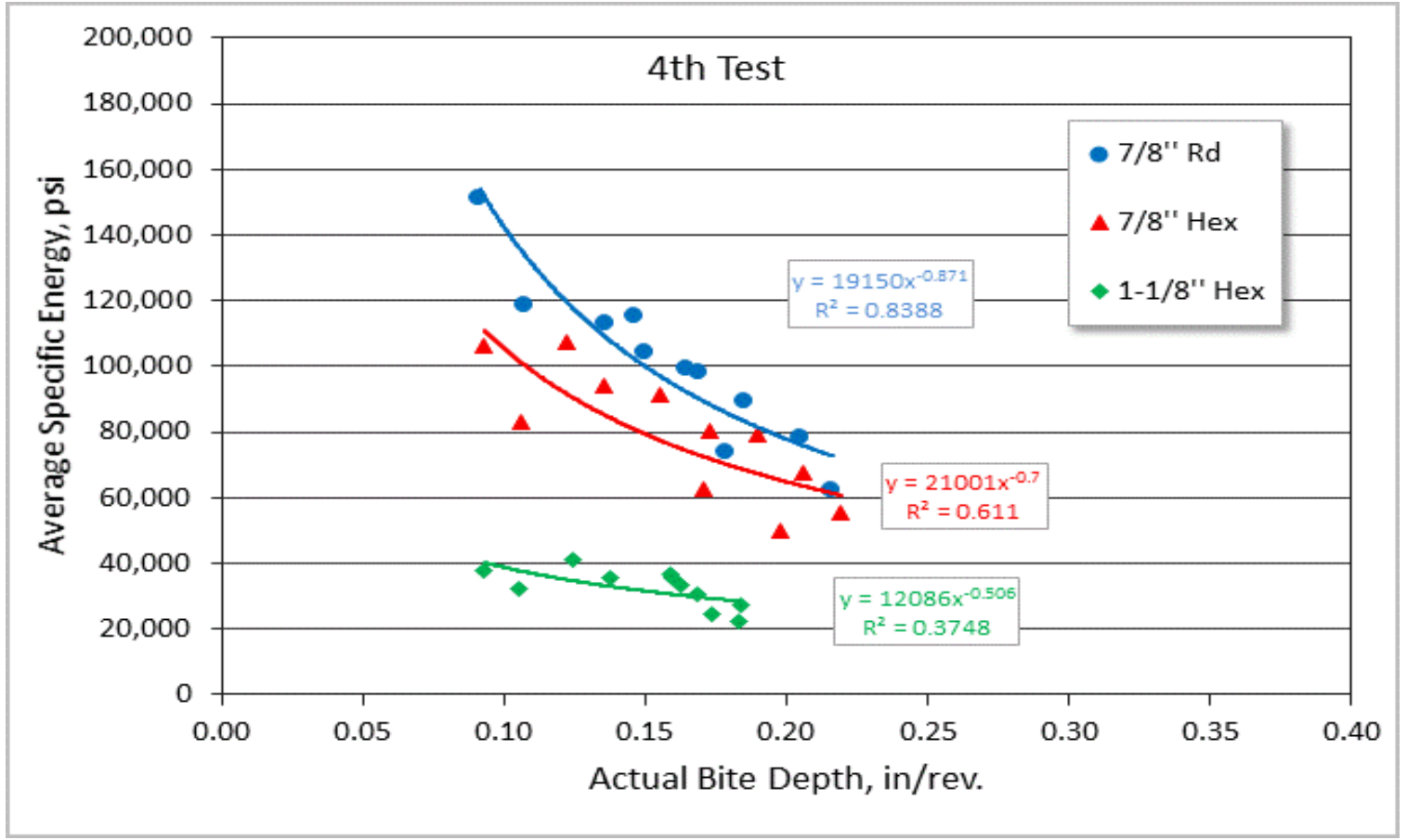

Appendix-3 Average specific energy vs. bite depth for drilling tests using different bitsteel combinations in the 4th test 


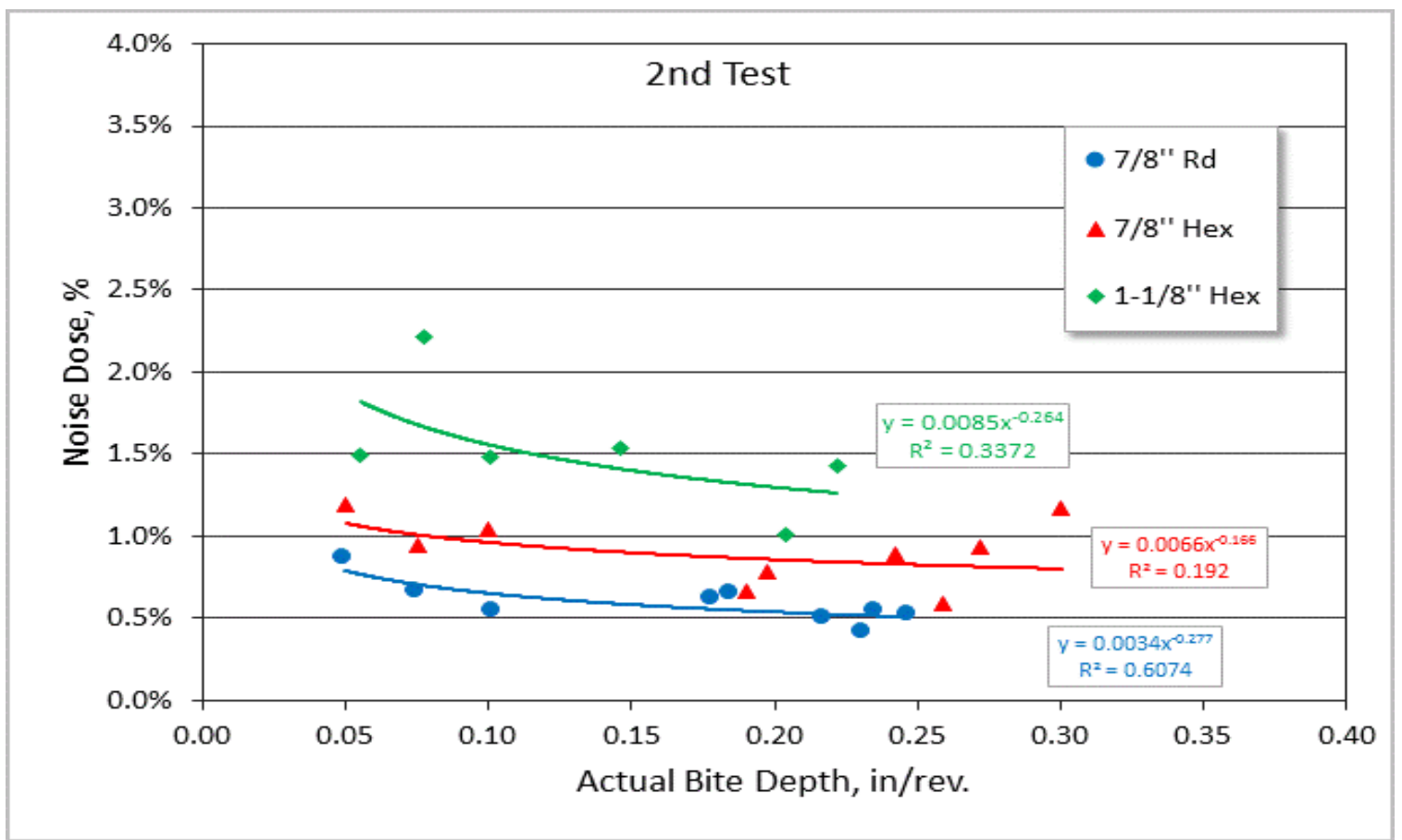

Appendix-4 Noise dose vs. bite depth for drilling tests using different bit-steel combinations in the 2 nd test

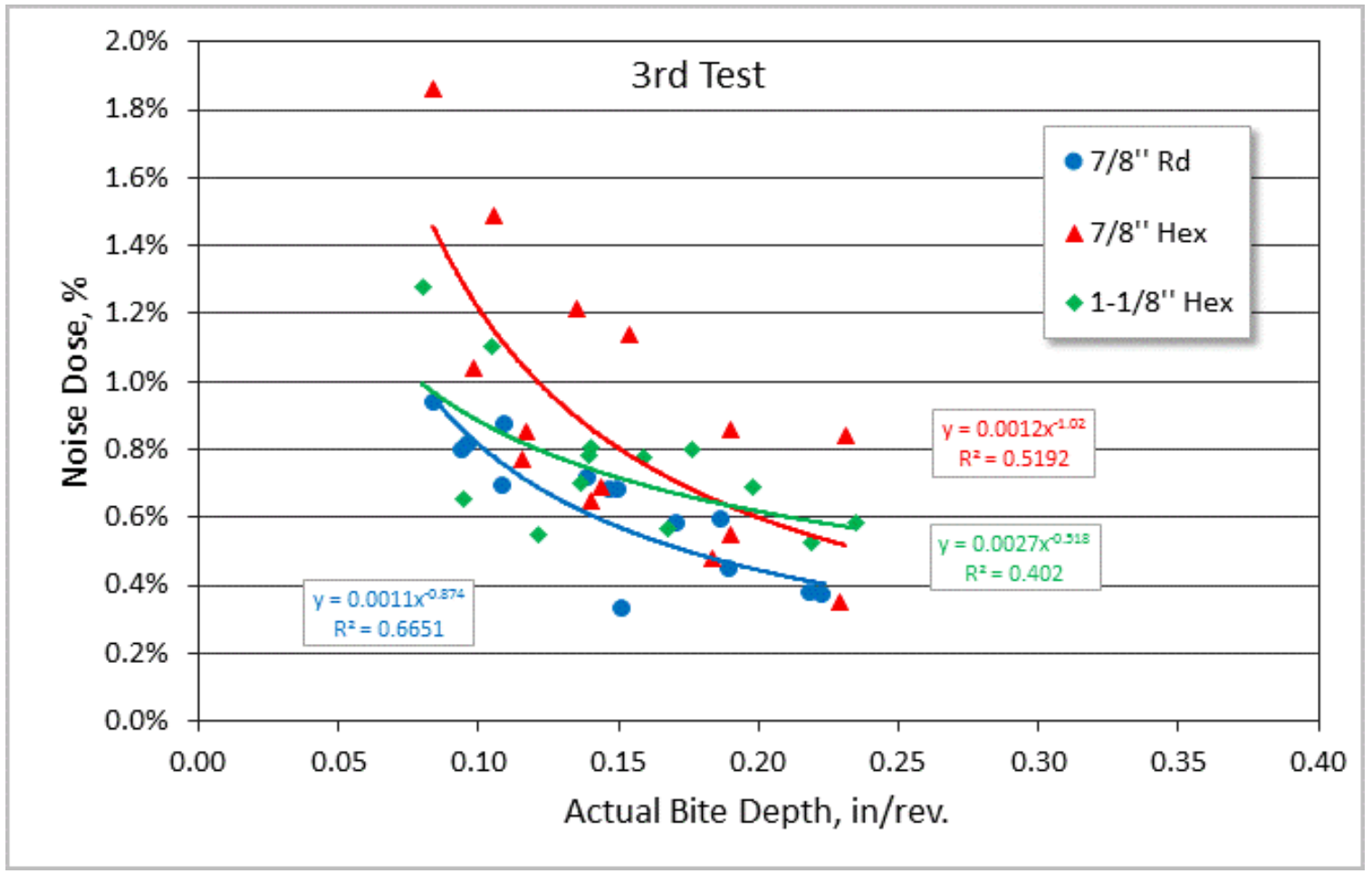

Appendix-5 Noise dose vs. bite depth for drilling tests using different bit-steel combinations in the 3 rd test 


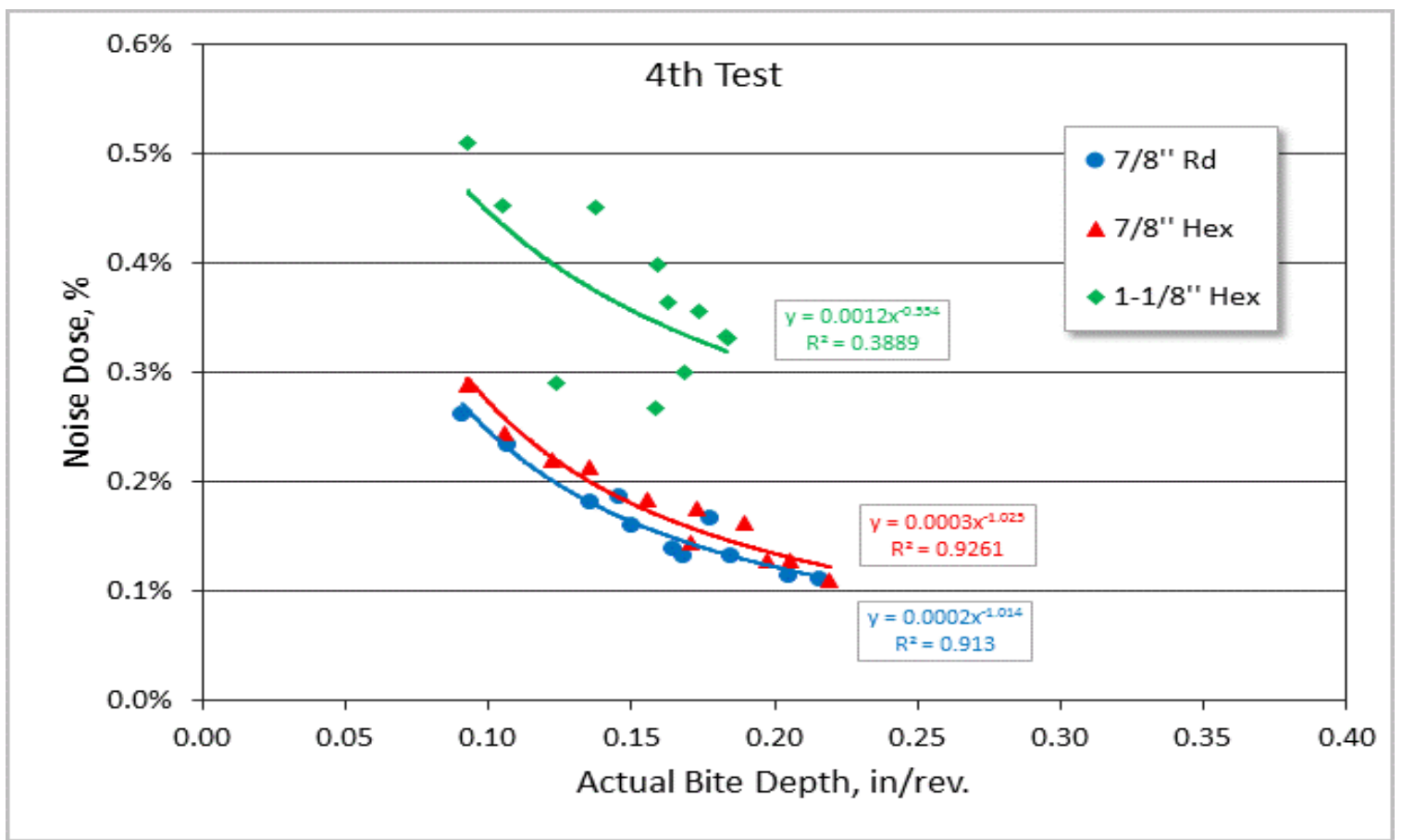

Appendix-6 Noise dose vs. bite depth for drilling tests using different bit-steel combinations in the 4th test

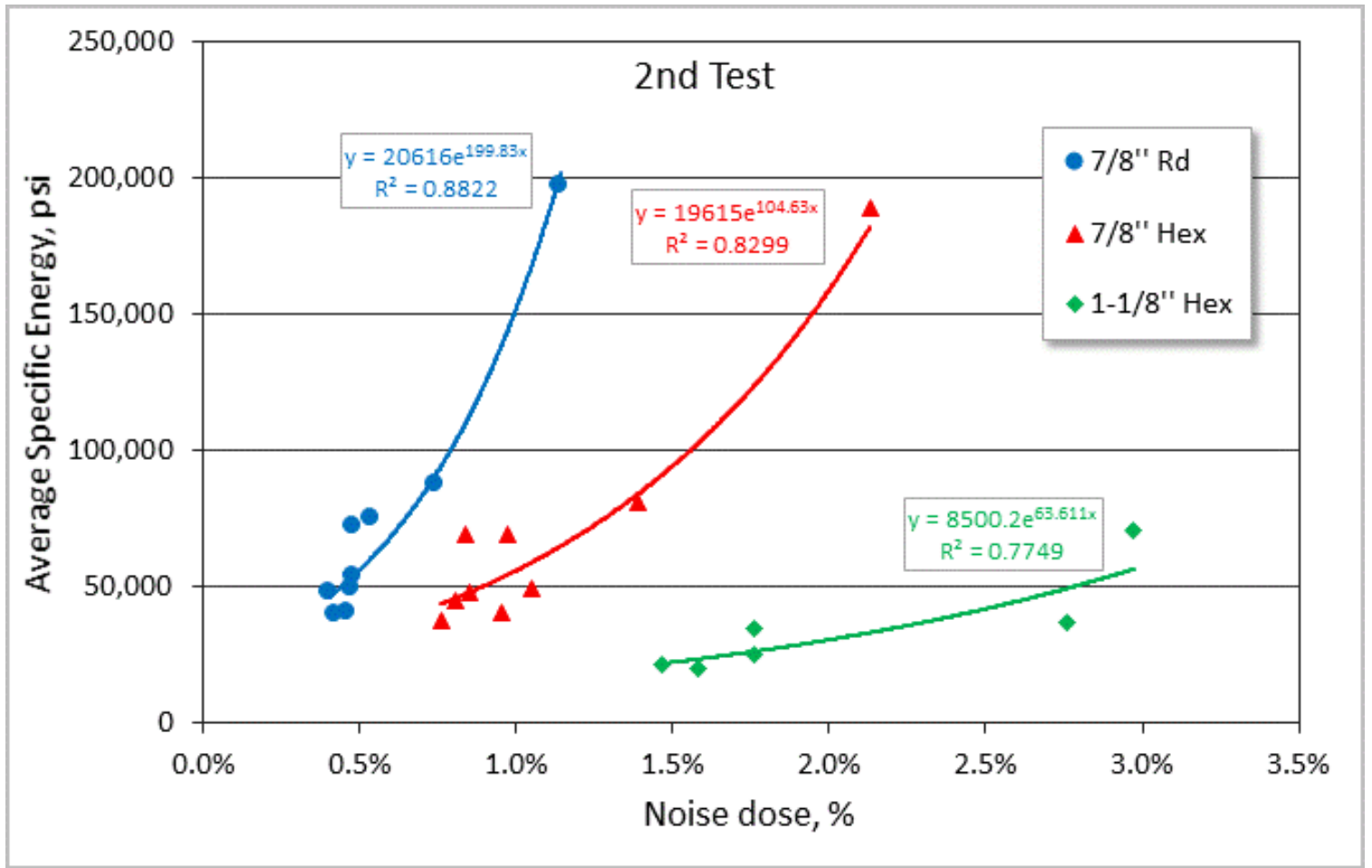

Appendix-7 Specific energy vs. noise dose for the 2nd set of drilling tests 


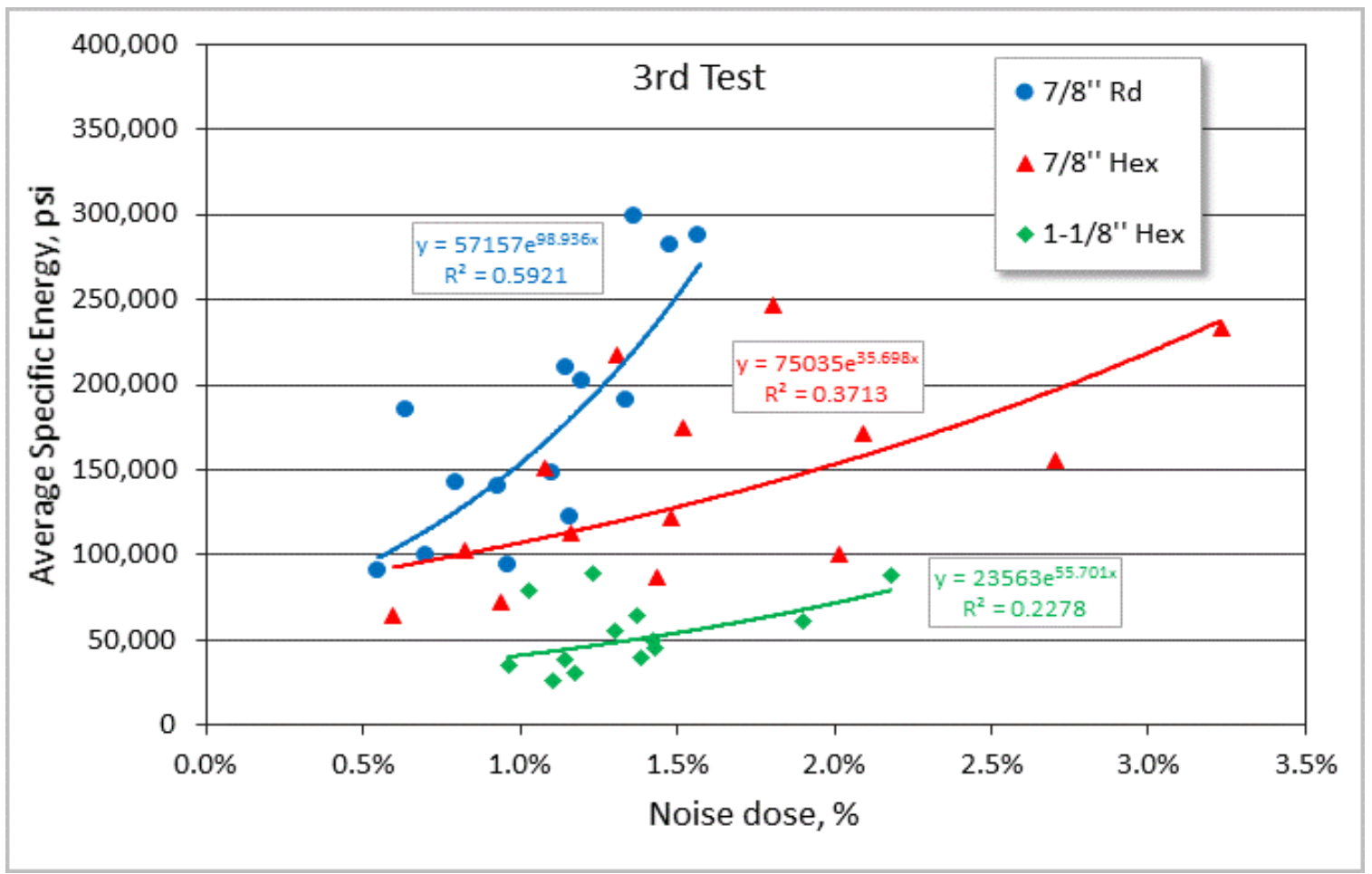

Appendix-8 Specific energy vs. noise dose for the 3rd set of drilling tests

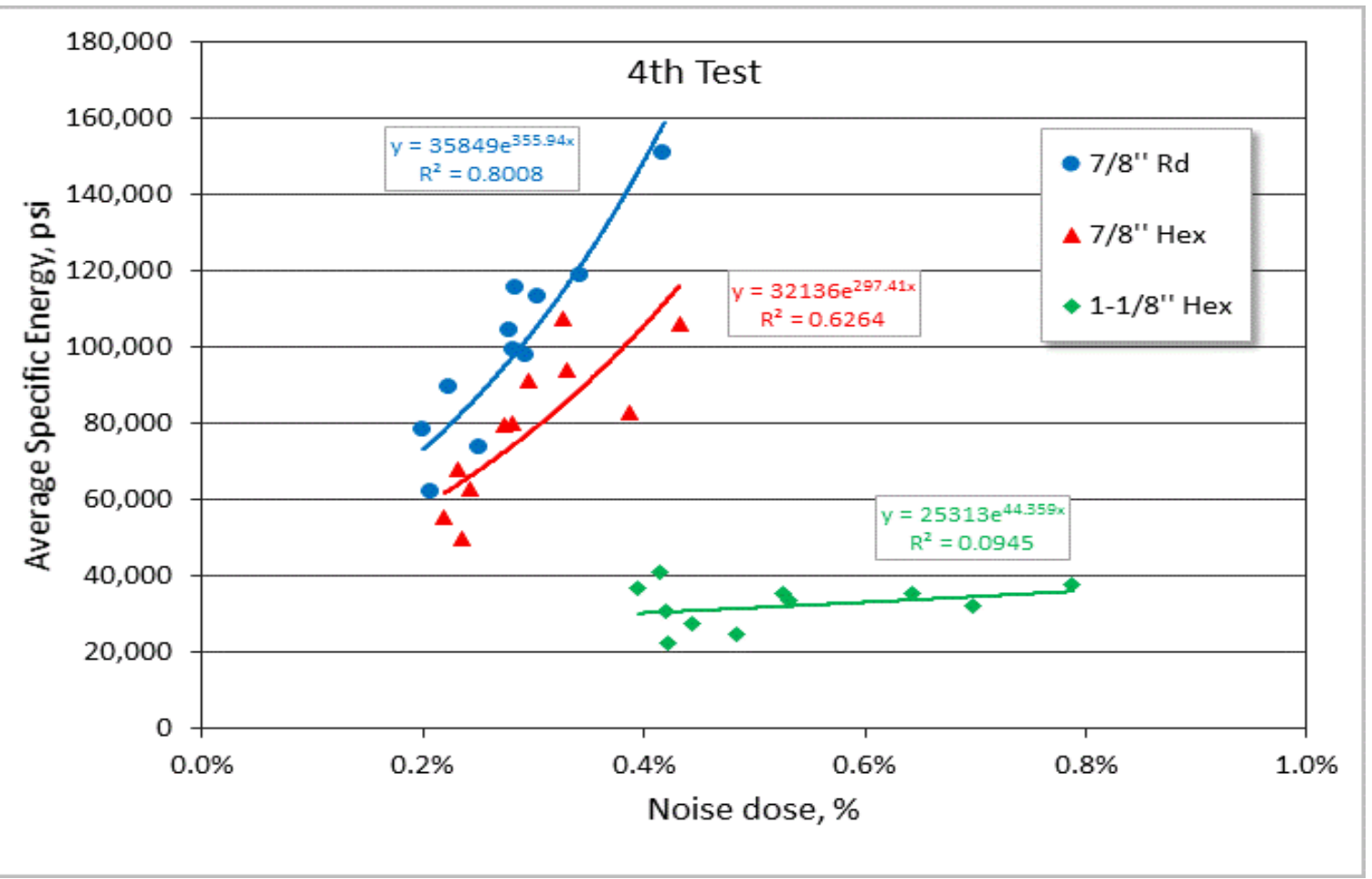

Appendix-9 Specific energy vs. noise dose for the 3rd set of drilling tests 


\section{VITA}

\section{Education}

Xi'an University of Science \& Technology, B.S., 2006

Xi'an University of Science \& Technology, M.S., 2009

West Virginia University, 2011 - present

\section{Professional Experience}

Xi'an University of Science \& Technology, 2009-2011

\section{Author's Publication List during Ph.D. Study:}

Li, M. and Y. Luo, 2015, Mechanical Model for Estimate Energy Requirement and Noise Generation in Roof Bolt Drilling Operation, Paper presented to 2015 SME annual meeting.

Luo, Y., B. Christopher and M. Li, 2014, The Role of Mine Atmospheric Monitoring Systems for Coal Mine Safety, Paper submitted to 2014 SME annual meeting.

Luo, Y., C. Collins, B. Qiu, and M. Li, 2014, Experimental Studies on Controlling Drilling Parameters to Reduce Roof Bolt-hole Drilling Noise. Mining Engineering, Vol. 66, No. 5, pp. 54-61.

Luo, Y. and M. Li, 2014, Rationalizing roof bolting operation to reduce drilling noise, 10th International Mine Ventilation Congress 2014 Proceedings, pp. 615-622.

Luo, Y., B. Qiu, and M. Li, 2013, Reducing Drilling Noise in Roof Bolting Operation through Rationalized Drilling, 23rd World Mining Congress 2013 Proceedings, ISBN: 978-1-926872-15-5. 
Luo, Y., L. Xiao, J. Cheng and M. Li, 2012, Locating and Determining the Status of a Thermal Event in Longwall Panel Using Mine Atmosphere Monitoring Data. 2012 Transactions of the Society for Mining, Metallurgy and Exploration, Vol. 332, pp. 485-493.

\section{Author's Technical Report List during Ph.D. Study:}

Luo, Y., M. Li and H. Jiang, 2015, Subsidence Prediction, Influence Assessment and Mitigation Recommendation for the Harr Barn (1st Phase Study), report submitted to Leer Mine, $33 \mathrm{pp}$.

Luo, Y. and M. Li, 2014, Subsidence Prediction, Influence Assessment and Mitigation Recommendation for the Structures in Boyd Property, a report submitted to Alpha Natural Resources, Inc., 42 pp.

Luo, Y. and M. Li, 2014, Subsidence Prediction, Influence Assessment and Mitigation Recommendation for an Historic Structure - McGary Barn, a report submitted to Murray Energy Corporation, 28 pp.

Luo, Y., M. Li and M. Fan, 2014, Subsidence Prediction and Influence Assessment for the Crown Network Communication Tower near Waynesburg, PA, a report submitted to Alpha Natural Resources, Inc., 19 pp.

Luo, Y., M. Li and M. Fan, 2014, Characteristics of Final and Dynamic Surface Movements and Deformations at a Selected Location over the First Two Longwall Panel, Leer Mine, a report submitted to Leer Mine, 13 pp.

Luo, Y. and M. Li, 2013, Analysis the Status of a Thermal Event and Determining Mine Atmosphere Explosibility for Reopening the Sealed Portion of Elk Creek Mine, a report submitted to Oxbow Mining, LLC, 70 pp. 
Luo, Y. and M. Li, 2013, Subsidence Prediction, Influence Assessment and Recommended Mitigation Measures for Canadian National Railroad near Galatia, IL, a report submitted to Murray Energy, $42 \mathrm{pp}$.

Luo, Y., M. Li and B. Qiu, 2013, Subsidence Prediction, Influence Assessment and Recommended Mitigation Measures for Waynesburg Allegheny Wesleyan Methodist Church, a report submitted to Alpha Natural Resources, Inc., 22 pp.

Luo, Y., B. Qiu and M. Li, 2013, Subsidence Prediction, Influence Assessment and Support Area Design for Structures in Warne Property, a report submitted to Consol Energy, Inc., 33 pp.

Luo, Y. and M. Li, 2013, Subsidence Prediction, Influence Assessment and Recommended Mitigation Measures for Charles Bailey's Property, a report submitted to Alpha Natural Resources, Inc., 22 pp.

Luo, Y. and M. Li, 2013, Subsidence Prediction, Influence Assessment and Recommended Mitigation Measures for Michael Bailey's Property, a report submitted to Alpha Natural Resources, Inc., 22 pp.

Luo, Y. and M. Li, 2013, Subsidence Prediction, Influence Assessment and Recommended Mitigation Measures for David Bailey's Property, a report submitted to Alpha Natural Resources, Inc., 22 pp.

Luo, Y., B. Qiu and M. Li, 2012, Development of Drilling Control Technology to Reduce Roof Bolter Noise, Interim report submitted to WV Coal and Energy Research Bureau, $46 \mathrm{pp}$. 